\author{
Universidade de São Paulo \\ Escola de Engenharia de São Carlos
}

Marcelo Almir Lopes

Avaliação de diferentes coagulantes para remoção de sólidos por flotação e sedimentação de água residuária de uma indústria metal-mecânica

São Carlos 

Marcelo Almir Lopes

\section{Avaliação de diferentes coagulantes para remoção de sólidos por flotação e sedimentação de água residuária de uma indústria metal-mecânica}

Dissertação apresentada à Escola de Engenharia de São Carlos, Universidade de São Paulo, como parte dos requisitos para obtenção do título de mestre em Ciências.

Área de concentração: Engenharia Hidráulica e Saneamento.

Orientador: Prof. Dr. Eduardo Cleto Pires

Versão corrigida

São Carlos 



\section{AUTORIZO A REPRODUÇÃO E DIVULGAÇÃO TOTAL OU PARCIAL DESTE TRABALHO, POR QUALQUER MEIO CONVENCIONAL OU ELETRÔNICO, PARA FINS DE ESTUDO E PESQUISA, DESDE QUE CITADA A FONTE.}

Ficha catalográfica preparada pela Seção de Tratamento da

Informação do Serviço de Biblioteca - EESC/USP

Lopes, Marcelo Almir.
L864a Avaliação de diferentes coagulantes para remoção de sólidos por flotação e sedimentação de água residuária de uma indústria metal-mecânica. / Marcelo Almir Lopes ; orientador Eduardo Cleto Pires. São Carlos, 2011.

Dissertação (Mestrado - Programa de Pós-Graduação e Área de Concentração em Hidráulica e Saneamento)-- Escola de Engenharia de São Carlos da Universidade de São Paulo, 2011 .

1. Esgoto industrial. 2. Água residuária industrial. 3. Coagulação. 4. Precipitação. 5. Sedimentação. 6 . Flotação. 7. Aluminato de sódio. 8. Cloreto férrico. 9. Policloreto de alumínio. I. Título. 



\section{FOLHA DE JULGAMENTO}

Candidato: Engenheiro MARCELO ALMIR LOPES

Título da dissertação: "Avaliação de diferentes coagulantes para remoção de sólidos por flotação e sedimentação de água residuária de uma indústria metal-mecânica".

Data da defesa: 09/12/2011:

Comissão Julgadora:

Resultado:

Prof. Titular Eduardo Cleto Pires (Orientador)

(Escola de Engenharia de São Carlos/EESC)

Prof. Dr. Marco Antonio Penalva Reali

(Escola de Engenharia de São Carlos/EESC)
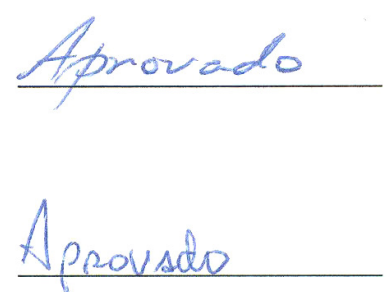

Prof. Dr. Erich Kellner

APROVADO

(Universidade Federal de São Carlos/UFSCar)

Coordenador do Programa de Pós-Graduação em Engenharia Hidráulica e Saneamento:

Prof. Titular Edson Cezar Wendland

Presidente da Comissão de Pós-Graduação:

Prof. Associado Paulo Cesar Lima Segantine 

A meus pais, Milton e Clélia, por toda a dedicação para a minha formação e a minha esposa Alessandra pelo apoio e compreensão nos momentos de ausência. 



\section{AGRADECIMENTOS}

Agradeço primeiramente ao professor Eduardo Cleto Pires, pela orientação, compreensão, incentivo e confiança durante esse trabalho.

A empresa Tecumseh do Brasil Ltda., pelo programa de incentivo ao desenvolvimento profissional de seus funcionários em especial ao gerente da Engenharia Industrial Avançada, Sr. Ivan Dias, pela oportunidade e compreensão na realização desse trabalho e ao gerente da Unidade de Serviços, Sr. Maurício T. S. Silva, por possibilitar o acesso a ETE da empresa e a realização desse estudo.

Ao professor Marco Antonio Penalva Reali, por toda colaboração e paciência durante toda a pós-graduação e pela autorização para acesso ao LATAR e utilização dos equipamentos e materiais envolvidos nesse trabalho.

Ao Daniel e os seus funcionários, Jair e Edes, pelas informações fornecidas da ETE, colaboração nas etapas iniciais desse trabalho e na coleta de amostras.

À Maria Teresa, técnica do LATAR, pelo auxílio na realização de todos os ensaios desse trabalho e pela paciência em relação aos meus horários.

Aos professores Marco Antonio Penalva Reali e Marcelo Zaiat pelas valiosas sugestões no exame de qualificação.

Ao Alcino, funcionário da USP, pelo apoio na manutenção de alguns equipamentos.

A empresa Procytek Indústria e Comércio Ltda. pela colaboração técnica e fornecimento de amostras.

As funcionárias do Departamento de Hidráulica e Saneamento, Sá, Pavi e Rose.

A todos meus familiares e amigos pela amizade e apoio. 

“O insucesso é apenas uma oportunidade para recomeçar de novo com mais inteligência.”

Henry Ford 



\section{RESUMO}

LOPES, M. A. Avaliação de diferentes coagulantes para remoção de sólidos por flotação e sedimentação de água residuária de uma indústria metal-mecânica. 2011. p. Dissertação (Mestrado). Departamento de Hidráulica e Saneamento. Escola de Engenharia de São Carlos. Universidade de São Paulo. 192p. São Carlos, SP.

Uma das abordagens para minimizar o volume de captação de água potável e o descarte de efluentes é o reuso da água dentro da unidade industrial através de técnicas avançadas de tratamento como o sistema de osmose reversa, porém esse sistema exige um afluente com uma baixa quantidade de sólidos, além de outros requisitos. A água residuária utilizada nesse estudo é proveniente de uma empresa do ramo metal-mecânico que utiliza processos de coagulação-floculação-sedimentação como forma de remover os sólidos antes de um sistema de osmose reversa. A proposta deste trabalho foi avaliar três diferentes coagulantes (aluminato de sódio, cloreto férrico e uma mistura de dois coagulantes comerciais, Procytrat 100A e Procytrat 300) em processos de coagulação-floculação e separação de sólidos da fase líquida por sedimentação e flotação por ar dissolvido e também comparar os custos aproximados dos processos envolvidos. Foram realizados ensaios em testes de jarros e flotateste e com os dados obtidos construíram-se diagramas de coagulação-floculação e escolhidas as regiões de maior remoção de sólidos. Através das regiões escolhidas, foram feitas as comparações de eficiência de remoção e custos para cada coagulante estudado. Verificou-se que os diagramas de coagulação-floculação-sedimentação foram os que apresentaram as regiões de maior área com turbidez remanescente menor que $2 \%$, principalmente para os coagulantes cloreto férrico e a mistura Procytrat 100A + Procytrat 300, chegando a alcançar valores próximos a $0,5 \%$. A opção mais econômica foi alcançada com custo de cloreto férrico, na dosagem de $200 \mathrm{mg} / 1$, pH igual a 8,3 e turbidez remanescente igual a $0,6 \%$, de $\mathrm{R} \$ 0,47 / \mathrm{m}^{3}$ de água tratada. Os diagramas de coagulação-floculação-flotação apresentaram regiões de turbidez remanescente com áreas bem mais reduzidas se comparadas aos diagramas de coagulação-floculação-sedimentação, sendo que não foram atingidos valores de turbidez remanescente menores que 1,5\%. Os menores valores de turbidez remanescente para o processo de flotação foram encontrados utilizando-se como coagulante a mistura Procytrat 100A + Procytrat 300, sendo a opção mais econômica alcançada para pH igual a 3,3, dosagem de $60 \mathrm{mg} / 1$ e turbidez remanescente igual a $1,6 \%$, com custo de $\mathrm{R} \$ 0,33 / \mathrm{m}^{3}$ de água tratada. De um modo geral, para todos os coagulantes testados, as regiões escolhidas nos diagramas de coagulação-floculação-flotação, cujos valores de turbidez remanescente foram menores, estavam concentradas em valores de $\mathrm{pH}$ baixos $(3,2$ a 5,5), dosagens de coagulante reduzidas $(10$ a $80 \mathrm{mg} / \mathrm{l})$ e dosagens de alcalinizante também reduzidas $\left(0\right.$ a $60 \mathrm{mg} / \mathrm{l}$ de $\left.\mathrm{Ca}(\mathrm{OH})_{2}\right)$. Esse comportamento foi contrário ao apresentado pelos diagramas coagulação-floculação-sedimentação cujos valores de turbidez remanescente foram menores em valores de $\mathrm{pH}$ mais altos $(6,5$ a 8,5), maiores dosagens de coagulante (40 a $380 \mathrm{mg} / \mathrm{l})$ e altas dosagens de alcalinizante $\left(100 \mathrm{a} 400 \mathrm{mg} / \mathrm{l} \mathrm{de} \mathrm{Ca}(\mathrm{OH})_{2}\right)$.

Palavras chave: esgoto industrial; água residuária industrial; coagulação; precipitação; sedimentação; flotação; aluminato de sódio; cloreto férrico; policloreto de alumínio. 



\begin{abstract}
LOPES, M. A. Evaluation of different coagulants for solids removal by flotation and sedimentation of wastewater from a metal-mechanic industry. 2011. p. Dissertation (Mestrado). Department of Hydraulics and Sanitation. Engineering School of São Carlos. Universidade de São Paulo. 192p. São Carlos, SP.

One approach to minimize the consumption of drinking water and effluent disposal is the reuse of water within the plant through advanced treatment techniques such as reverse osmosis system, however, this system requires an affluent with a low amount of solids and other requirements. The wastewater used in this study comes from a metalworking company that uses coagulation-flocculation-sedimentation process as a way to remove the solids before a reverse osmosis system. The purpose of this study was to evaluate three different coagulants (sodium aluminate, ferric chloride and a mixture of two commercial coagulants, Procytrat $100 \mathrm{~A}$ and Procytrat 300) in the process of coagulation-flocculation and separation of solids from the liquid phase by sedimentation and dissolved air flotation and also compare the approximate costs of the processes involved. Jar tests and flotatests were performed and the coagulation-flocculation diagrams were built. In the coagulation-flocculation diagrams were selected areas of higher solids removal. Through the chosen regions, comparisons were made of removal efficiency and cost study for each coagulant. It was found that the diagrams of coagulation-flocculation-sedimentation presented the areas of higher turbidity remaining area with less than $2 \%$, mainly for the coagulants ferric chloride and the mixture Procytrat $100 \mathrm{~A}+$ Procytrat 300, reaching values close to $0.5 \%$. The most economical option was achieved at a cost of ferric chloride at a dosage of $200 \mathrm{mg} / \mathrm{l}, \mathrm{pH} 8.3$, and the remaining turbidity equal to $0.6 \%$, from $\mathrm{R} \$ 0.47 / \mathrm{m} 3$ treated water. The diagrams of coagulation-flocculation-flotation showed regions with turbidity remaining areas much reduced compared to the diagrams of coagulation-flocculation-sedimentation, and the turbidity remaining values were more than $1.5 \%$. The lower values of turbidity remaining for the flotation process were found using the mixture Procytrat 100A + Procytrat 300, and the most economical option was reached for a $\mathrm{pH}$ of 3.3 , dosage of $60 \mathrm{mg} / \mathrm{l}$ and remaining turbidity equal to e $1.6 \%$, at a cost of $\mathrm{R} \$ 0.33 / \mathrm{m} 3$ of treated water. In general, for all coagulants tested, the selected regions in the diagrams of coagulation-flocculation-flotation, whose remaining turbidity values were lower, were concentrated in low $\mathrm{pH}$ values (3.2 to 5.5), dosages of coagulant reduced (10 to $80 \mathrm{mg} / \mathrm{l}$ ) and dosages of alkaline also reduced $\left(0\right.$ to $60 \mathrm{mg} / \mathrm{l}$ of $\left.\mathrm{Ca}(\mathrm{OH})_{2}\right)$. This behavior was contrary to the diagrams presented by coagulation-flocculation-sedimentation whose remaining turbidity values were lower in higher $\mathrm{pH}$ values (6.5 to 8.5), larger amounts of coagulant (40 to $380 \mathrm{mg} / \mathrm{l})$ and high doses of alkaline (100 to $\left.400 \mathrm{mg} / \mathrm{l} \mathrm{Ca}(\mathrm{OH})_{2}\right)$.
\end{abstract}

Key Words: industrial wastewater; coagulation; precipitation; sedimentation; flotation, ferric chloride; sodium aluminate; ferric chloride; polyaluminum choride. 



\section{LISTA DE FIGURAS}

Figura 1.1- Sistemas de tratamento físico-químico para efluente industrial propostos nessa pesquisa

Figura 3.1- Tamanho de partículas dos constituintes do esgoto e faixa de atuação das unidades de tratamento por tamanho de partículas

Figura 3.2- Diagrama de equilíbrio heterogêneo do $\mathrm{Al}(\mathrm{OH})_{3}$

Figura 3.3- Diagrama de equilíbrio heterogêneo do $\mathrm{Fe}(\mathrm{OH})_{3}$ 33

Figura 3.4- Diagrama de coagulação para remoção de turbidez com do sulfato de alumínio de água "preparada” com caulinita.

Figura 3.5- Definição esquemática da formação de pontes entre partículas com aplicação de polímeros orgânicos. 40

Figura 3.6- Flotação por ar dissolvido, com recirculação pressurizada (FAD), aplicada ao tratamento físico-químico de águas residuárias.

Figura 3.7- Distribuição de tamanho de bolhas produzidas por válvula agulha e bocal tipo WRC.

Figura 3.8. Configuração de bocal onde D3=5 x D2.

Figura 4.1- Layout da E.T.E.

Figura 4.2- Fluxograma de tratamento da E.T.E.

Figura 4.3- Tanque de homogeneização aerado de $1000 \mathrm{~m}^{3}$ da E.T.E. 
Figura 4.5- Jar Test com seis "jarros” (Ética) utilizado para os ensaios de laboratório. .53

Figura 4.6- Flotateste utilizado para os ensaios em escala de laboratório 54

Figura 5.1- Valores da condutividade nos 4 pontos de coleta de amostras da E.T.E. 67

Figura 5.2- Valores de turbidez nos 4 pontos de coleta de amostras da E.T.E. .68

Figura 5.3- Valores de $\mathrm{pH}$ nos 4 pontos de coleta de amostras da E.T.E. .69

Figura 5.4- Valores da temperatura nos 4 pontos de coleta de amostras da E.T.E. 70

Figura 5.5- Valores da vazão nos ponto 1 de coleta de amostra da E.T.E 71

Figura 5.6- Diagrama de coagulação-floculação-sedimentação do efluente: percentuais de Turbidez remanescente para o coagulante aluminato de sódio 80

Figura 5.7- Diagrama de coagulação-floculação-sedimentação do efluente: percentuais de Turbidez remanescente para o coagulante cloreto férrico .85

Figura 5.8- Diagrama de coagulação-floculação-sedimentação do efluente: percentuais de Turbidez remanescente para o coagulante Procytrat 110A + Procytrat 300 .....91

Figura 5.9- Diagrama de coagulação-floculação-flotação do efluente: percentuais de Turbidez remanescente para o coagulante aluminato de sódio. 97

Figura 5.10- Diagrama de coagulação-floculação-flotação do efluente: percentuais de Turbidez remanescente para o coagulante cloreto férrico. 102

Figura 5.11- Diagrama de coagulação-floculação-sedimentação do efluente: percentuais de Turbidez remanescente para o coagulante Procytrat 110A + Procytrat 300 .. 108 
Figura 5.12- Custo por $\mathrm{m}^{3}$ dos três coagulantes e alcalinizante utilizados nesse estudo, de acordo com a dosagem empregada.

Figura 5.13- Exemplo: diagrama de coagulação-floculação-sedimentação do efluente: percentuais de Turbidez remanescente para o coag. aluminato de sódio

Figura 5.14- Comparação de custos entre a separação de sólidos por sedimentação (Vs: 1,0 $\mathrm{cm} / \mathrm{min}$ ) e flotação por ar dissolvido (Vf: $5,0 \mathrm{~cm} / \mathrm{min}$ ), de acordo com a eficiência de remoção de turbidez do efluente industrial por coagulação/precipitação com aluminato de sódio.

Figura 5.15- Comparação de custos entre a separação de sólidos por sedimentação (Vs: 1,0 $\mathrm{cm} / \mathrm{min}$ ) e flotação por ar dissolvido (Vf: $5,0 \mathrm{~cm} / \mathrm{min}$ ), de acordo com a eficiência de remoção de turbidez do efluente industrial por coagulação/precipitação com cloreto férrico.

Figura 5.16- Comparação de custos entre a separação de sólidos por sedimentação (Vs: 1,0 $\mathrm{cm} / \mathrm{min}$ ) e flotação por ar dissolvido (Vf: $5,0 \mathrm{~cm} / \mathrm{min}$ ), de acordo com a eficiência de remoção de turbidez do efluente industrial por coagulação/precipitação com Procytrat $110 \mathrm{~A}+$ Procytrat 300 118 


\section{LISTA DE QUADROS}

Quadro 3.1- Produtos Químicos Inorgânicos mais usados para coagulação em processos de tratamento de água e efluentes 36

Quadro 3.2- Valores típicos para tempo de detenção e gradiente G para mistura e floculação em efluentes

Quadro 3.3- Características de forma e sedimentação de partículas encontradas no tratamento de água e efluentes

Quadro 4.1 - Coagulantes e alcalinizante utilizados nos ensaios de coagulação-floculação com a água residuária da E.T.E. .55

Quadro 5.1 - Resumo dos parâmetros operacionais encontrados nos ensaios de floculaçãocoagulação. 109 


\section{LISTA DE TABELAS}

Tabela 3.1 - Classificação das partículas do esgoto por faixa de tamanho

Tabela 3.2 - Estimativa da concentração e da distância média entre as microbolhas de ar, presentes no início de uma unidade FAD, em função do diâmetro das microbolhas

Tabela 3.3 - Velocidades de ascensão do agregado floco-bolha a $20^{\circ} \mathrm{C}$

Tabela 4.1 - Etapas de coagulação-floculação-sedimentação com efluente da ETE. 58

Tabela 4.2 - Etapas de coagulação-floculação-flotação com efluente da ETE 60

Tabela 5.1 - Caracterização da água residuária bruta. Amostra coletada no tanque de homogeinização de $1000 \mathrm{~m}^{3}$. 72

Tabela 5.2 - Valores de turbidez e condutividade remanescente para etapa 1 dos ensaios preliminares de coagulação-floculação-sedimentação com o coagulante aluminato de sódio 75

Tabela 5.3 - Valores de turbidez e condutividade remanescente para a etapa 2 dos ensaios preliminares de coagulação-floculação-sedimentação com o coagulante aluminato de sódio 76

Tabela 5.4 - Valores de turbidez e condutividade remanescente para a etapa 3 dos ensaios preliminares de coagulação-floculação-sedimentação com o coagulante aluminato de sódio 77

Tabela 5.5 - Regiões dos diagramas de coagulação-floculação-sedimentação com aluminato de sódio e valores percentuais de turbidez remanescente.

Tabela 5.6 - Valores de turbidez e condutividade remanescente para etapa 1 dos ensaios preliminares de coagulação-floculação-sedimentação com o coagulante cloreto férrico

Tabela 5.7 - Valores de turbidez e condutividade remanescente para a etapa 2 dos ensaios preliminares de coagulação-floculação-sedimentação com o coagulante cloreto férrico 
Tabela 5.8 - Valores de turbidez e condutividade remanescente para a etapa 3 dos ensaios preliminares de coagulação-floculação-sedimentação com o coagulante cloreto férrico. 83

Tabela 5.9 - Regiões dos diagramas de coagulação-floculação-sedimentação com cloreto férrico e valores percentuais de turbidez remanescente 84

Tabela 5.10 - Valores de turbidez e condutividade remanescente para etapa 1 dos ensaios preliminares de coagulação-floculação-sedimentação com o coagulante Procytrat 110A + Procytrat 300 87

Tabela 5.11 - Valores de turbidez e condutividade remanescente para a etapa 2 dos ensaios preliminares de coagulação-floculação-sedimentação com o coagulante Procytrat 110A + Procytrat 300 88

Tabela 5.12 - Valores de turbidez e condutividade remanescente para a etapa 3 dos ensaios preliminares de coagulação-floculação-sedimentação com o coagulante Procytrat 110A + Procytrat 300 89

Tabela 5.13 - Regiões dos diagramas de coagulação-floculação-sedimentação com Procytrat $110 \mathrm{~A}+$ Procytrat 300 e valores percentuais de turbidez remanescente 90

Tabela 5.14 - Valores de turbidez e condutividade remanescente para a etapa 1 dos ensaios preliminares de coagulação-floculação-flotação com o coagulante aluminato de sódio .93

Tabela 5.15 - Valores de turbidez e condutividade remanescente para a etapa 2 dos ensaios preliminares de coagulação-floculação-flotação com o coagulante aluminato de sódio 94

Tabela 5.16 - Valores de turbidez e condutividade remanescente para a etapa 3 dos ensaios preliminares de coagulação-floculação-flotação com o coagulante aluminato de sódio 95

Tabela 5.17 - Regiões dos diagramas de coagulação-floculação-flotação com aluminato de sódio e valores percentuais de turbidez remanescente 96 
Tabela 5.18 - Valores de turbidez e condutividade remanescente para etapa 1 dos ensaios preliminares de coagulação-floculação-flotação com o coagulante cloreto férrico

Tabela 5.19 - Valores de turbidez e condutividade remanescente para a etapa 2 dos ensaios preliminares de coagulação-floculação-flotação com o coagulante cloreto férrico 100

Tabela 5.20 - Valores de turbidez e condutividade remanescente para a etapa 3 dos ensaios preliminares de coagulação-floculação-flotação com o coagulante cloreto férrico 100

Tabela 5.21 - Regiões dos diagramas de coagulação-floculação-flotação com cloreto férrico e valores percentuais de turbidez remanescente.

Tabela 5.22 - Valores de turbidez e condutividade remanescente para etapa 1 dos ensaios preliminares de coagulação-floculação-flotação com o coagulante Procytrat 110A + Procytrat 300 104

Tabela 5.23 - Valores de turbidez e condutividade remanescente para a etapa 2 dos ensaios preliminares de coagulação-floculação-flotação com o coagulante Procytrat 110A + Procytrat 300

Tabela 5.24 - Valores de turbidez e condutividade remanescente para a etapa 3 dos ensaios preliminares de coagulação-floculação-flotação com o coagulante Procytrat 110A + Procytrat 300 106

Tabela 5.25 - Regiões dos diagramas de coagulação-floculação-flotação com Procytrat 110A + Procytrat 300 e valores percentuais de turbidez remanescente 107

Tabela 5.26 - Informações e preços dos coagulantes e alcalinizante 111

Tabela 5.27 - Avaliação dos custos do processo de sedimentação em função do coagulante utilizado no processo 114

Tabela 5.28 - Avaliação dos custos do processo de flotação em função do coagulante utilizado no processo. 


\section{LISTA DE ABREVIATURAS E SIGLAS}

APHA - American Public Health Association

AWWA- American Water Works Association

DBO- Demanda Bioquímica de Oxigênio $\left(\mathrm{mg} \mathrm{O}_{2} / \mathrm{L}\right)$

DC- Dosagem de coagulante $(\mathrm{mg} / \mathrm{l})$

DQO - Demanda Química de Oxigênio $\left(\mathrm{mg} \mathrm{O}_{2} / \mathrm{L}\right)$

EESC - Escola de Engenharia de São Carlos

ETE- Estação de Tratamento de Esgoto

FAD- Flotação por Ar Dissolvido

N.A.- Não se aplica

LATAR- Laboratório Avançado de Tratamento de Água e Reuso

LD- Limite de detecção

PAC- Poly Aluminium Chloride (Policloreto de alumínio)

SDF- Sólidos Dissolvidos Fixos (mg/L)

SDT- Sólidos Dissolvidos Totais (mg/L)

SDV- Sólidos Dissolvidos Voláteis (mg/L)

SF- Sólidos Fixos (mg/L)

SM- Standard Methods for the Examination of Water and Wastewater

SS- Sólidos Sedimentáveis (mg/L)

SSF- Sólidos Suspensos Fixos (mg/L)

SST- Sólidos Suspensos Totais (mg/L)

SSV- Sólidos Suspensos Voláteis (mg/L)

ST- Sólidos Totais (mg/L)

SV- Sólidos Voláteis (mg/L)

USP- Universidade de São Paulo

V.M.P.- Valor Máximo Permitido

WEF- Water Environment Federation

WRC- Water Research Centre 


\section{LISTA DE SÍMBOLOS}

$\mathbf{C}_{\mathbf{T}, \mathbf{A l}}$ - Concentração total de alumínio (mg/l)

$\mathbf{C}_{\mathbf{T}, \mathbf{F e}}$ - Concentração total de ferro (mg/l)

G- Gradiente de velocidade média $\left(\mathrm{s}^{-1}\right)$

P- Potência necessária (W)

$\boldsymbol{\mu}$ - Viscosidade dinâmica (N.s/m²)

Nb- Número de bolhas por ml de suspensão

$\Delta \mathbf{b}$ - Distância entre as microbolhas (mm)

$\boldsymbol{V}_{\mathbf{b}}$ - Velocidade de ascensão do agregado floco-bolha $\left(\mathrm{m} \cdot \mathrm{h}^{-1}\right)$

Gf- Gradiente de velocidade média na floculação $\left(\mathrm{s}^{-1}\right)$

Gm- Gradiente de velocidade média na mistura rápida $\left(\mathrm{s}^{-1}\right)$

pH- Potencial Hidrogeniônico

Psat- Pressão de saturação (kPa)

Tsat- Tempo de saturação (min)

R- Razão de circulação (\%)

Tf- Tempo de floculação (s)

Tm- Tempo de mistura rápida (s)

Tflot- Tempo de flotação (s)

Vf- Velocidade de flotação $\left(\mathrm{cm} \cdot \mathrm{min}^{-1}\right)$

Vs- Velocidade de sedimentação $\left(\mathrm{cm} \cdot \mathrm{min}^{-1}\right)$ 


\section{SUMÁRIO}

3.2.1 Mecanismos da coagulação...................................................................... 28

3.2.2 Diagrama de solubilidade do alumínio.......................................................... 29

3.2.3 Diagrama de solubilidade do ferro........................................................... 32

3.2.4 Diagrama de coagulação......................................................................... 33

3.2.5 Produtos químicos empregados.................................................................. 35

Operações de mistura rápida e floculação....................................................... 37

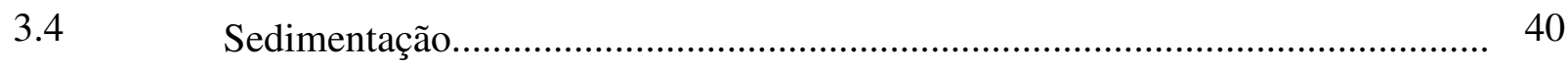

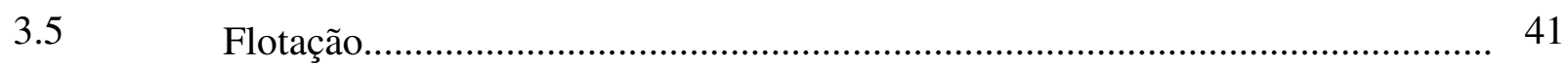

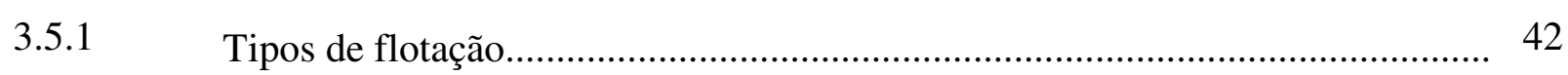

3.5.1.1 Flotação por ar dissolvido......................................................................... 43

3.5.1.1.1 Fatores que afetam a eficiência da FAD ........................................................ 44

3.5.1.1.1.1 Pressão de saturação................................................................................... 44

3.5.1.1.1.2 Distribuição do tamanho de microbolhas.......................................................... 44

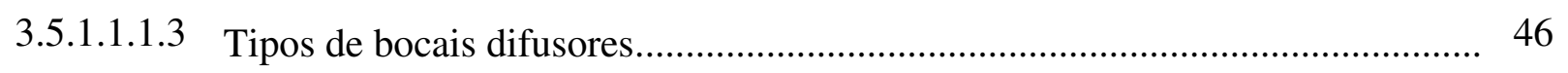

3.5.1.1.1.4 Quantidade de ar fornecida ao processo.......................................................... 47

3.5.2 Coagulação e floculação em sistemas de flotação por ar dissolvido.................. 48

$4 \quad$ MATERIAIS E MÉTODOS................................................................................. 50

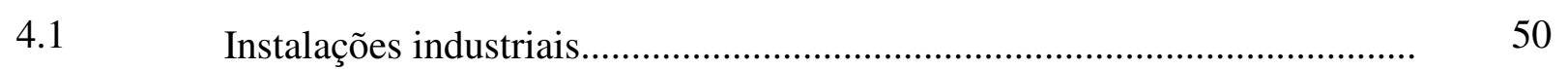

Reatores em escala de bancada................................................................. 52

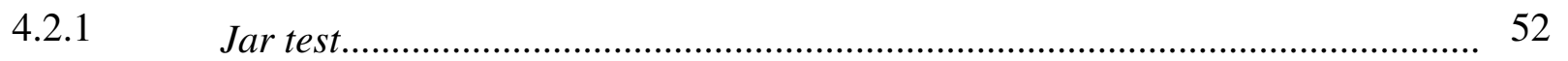

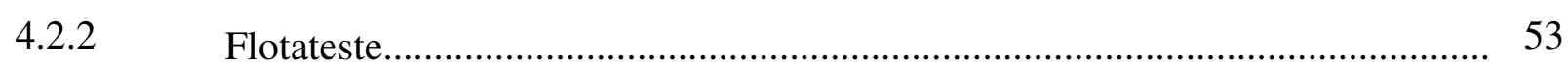

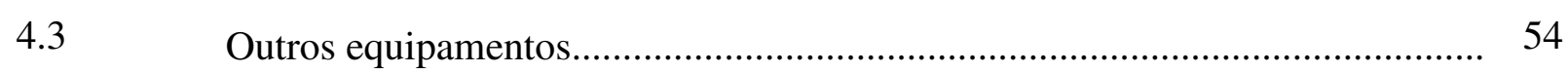

$4.4 \quad$ Produtos químicos utilizados.................................................................... 55

Caracterização da água residuária industrial.................................................. 56

4.6 Ensaios de coagulação-floculação com o efluente da ETE................................ 57

4.6.1 Ensaios de coagulação-floculação-sedimentação com o efluente da ETE......... 57

4.6.1.1 Investigação do par pH-DC aproximado..................................................... 58 
4.6.1.2 Investigação dos parâmetros de mistura rápida.............................................. 58

4.6.1.3 Investigação dos parâmetros de floculação................................................... 59

4.6.1.4 Diagramas de coagulação-floculação-sedimentação........................................ 59

4.6.2 Ensaios de coagulação-floculação-flotação com o efluente da ETE.................. 59

4.6.2.1 Investigação do par pH-DC aproximado....................................................... 60

4.6.2.2 Investigação dos parâmetros de floculação.................................................... 60

4.6.2.3 Investigação da quantidade de ar fornecida..................................................... 61

4.6.2.4 Diagramas de coagulação-floculação-flotação............................................... 61

4.7 Procedimentos para realização dos ensaios de coagulação-floculaçãosedimentação em unidade de jar test..

4.8 Procedimentos para ensaios de coagulação-floculação-flotação em unidade de

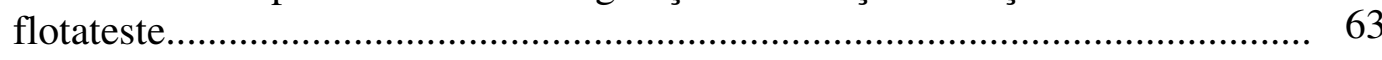

RESULTADOS E DISCUSSÕES..

M.1 Monitoramento dos parâmetros da E.T.E..................................................... 66

Ensaios de coagulação-floculação-sedimentação............................................. 73

5.2.1 Resultados dos ensaios de coagulação-floculação-sedimentação para o coagulante aluminato de sódio..

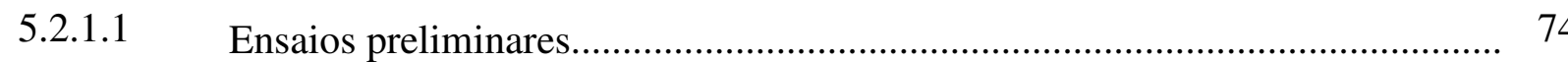

5.2.1.2 Diagrama de coagulação-floculação-sedimentação para o coagulante aluminato de sódio

5.2.2 Resultados dos ensaios de coagulação-floculação-sedimentação para o coagulante cloreto férrico

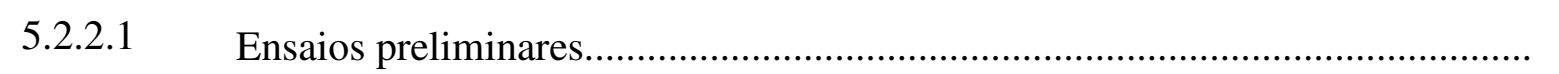

5.2.2.2 Diagrama de coagulação-floculação-sedimentação para o coagulante cloreto férrico.

5.2.3 Resultados dos ensaios de coagulação-floculação-sedimentação para o coagulante Procytrat 110A + Procytrat 300

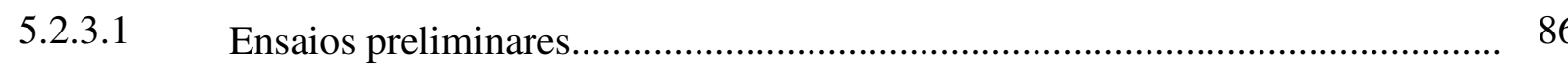

5.2.3.2 Diagrama de coagulação-floculação-sedimentação para o coagulante Procytrat $110 \mathrm{~A}+$ Procytrat 300 ......

5.3 Ensaios de coagulação-floculação-flotação.

5.3.1 Resultados dos ensaios de coagulação-floculação-flotação para o coagulante aluminato de sódio

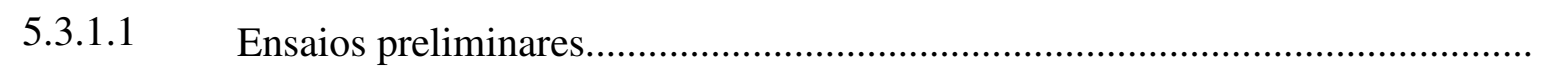

5.3.1.2 Diagrama de coagulação-floculação-flotação para o coagulante aluminato de sódio. 
5.3.2 Resultados dos ensaios de coagulação-floculação- flotação para o coagulante cloreto férrico.

5.3.2.1 Ensaios preliminares.......................................................................... 98

5.3.2.2 Diagrama de coagulação-floculação- flotação para o coagulante cloreto férrico.

5.3.3 Resultados dos ensaios de coagulação-floculação- flotação para o coagulante Procytrat $110 \mathrm{~A}+$ Procytrat 300 .

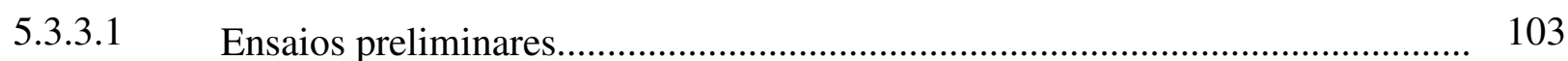

5.3.3.2 Diagrama de coagulação-floculação- flotação para o coagulante Procytrat

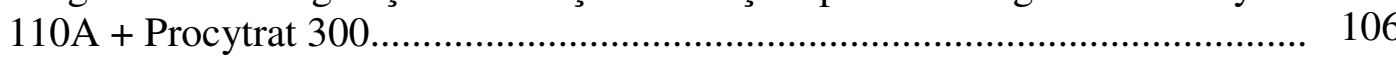

5.4 Resumo dos resultados dos ensaios de coagulação-floculação......................... 109

5.5 Determinação do custo "aproximado" para os melhores pares pH/dosagem de coagulante para cada ensaio de coagulação-floculação-sedimentação/flotação.

5.5.1 Determinação do "melhor" coagulante em ensaios de coagulação-floculaçãosedimentação.

5.5.2 Determinação do "melhor" coagulante em ensaios de coagulação-floculaçãoflotação.

5.5.3 Comparação dos custos entre os processos de sedimentação e flotação.

Apêndice A Amostragem para caracterização da água residuária industrial.

Apêndice B

Resultados dos ensaios de coagulação-floculação-sedimentação para o coagulante aluminato de sódio.

Apêndice C Resultados dos ensaios de coagulação-floculação-sedimentação para o coagulante cloreto férrico..

Apêndice D

Resultados dos ensaios de coagulação-floculação-sedimentação para o coagulante Procytrat 110A + Procytrat 300 .

Apêndice E Resultados dos ensaios de coagulação-floculação-flotação para o coagulante aluminato de sódio.

Apêndice F Resultados dos ensaios de coagulação-floculação-flotação para o coagulante cloreto férrico......

Apêndice G Resultados dos ensaios de coagulação-floculação-flotação para o coagulante Procytrat $110 \mathrm{~A}+$ Procytrat 300 .

Apêndice $\mathrm{H}$ Memória de cálculo do custo com energia elétrica para a flotação por ar dissolvido. 


\section{INTRODUÇÃO}

A necessidade de minimizar o consumo de água potável e o descarte de efluentes tem se popularizado no meio industrial e sua aplicação vem crescendo com o passar dos anos influenciada por fatores como a efetivação da cobrança pela captação de água dos corpos hídricos e do descarte de efluentes, o custo ascendente da água potável e as exigências na legislação de emissão de efluentes e disposição no meio natural.

A utilização de água pela indústria pode ocorrer de diversas formas, tais como: incorporação ao produto, lavagens de máquinas, tubulações e pisos, águas de sistemas de resfriamento e geradores de vapor, águas utilizadas diretamente nas etapas do processo industrial ou incorporadas aos produtos. Exceto pelos volumes de águas incorporados aos produtos e pelas perdas por evaporação, as águas tornam-se contaminadas por resíduos do processo industrial ou pelas perdas de energia térmica, originando assim os efluentes líquidos.

Além da pressão da sociedade, a indústria e seus gestores sentem que os despejos industriais significam em última análise, perdas de insumo e energia, que os recursos naturais são limitados e que ao se prosseguir usando-os na mesma intensidade, a sobrevivência do planeta Terra e dos seus ocupantes torna-se ameaçada, no médio prazo. Surge a necessidade de se rever processos visando minimizar o consumo e o desperdício, evitando assim as perdas e diminuindo o volume de despejo a ser tratado e posteriormente lançado nos corpos hídricos.

Uma das abordagens para minimizar o volume de captação de água potável e o descarte de efluentes é o reuso da água dentro da unidade industrial.

No caso de efluentes de indústrias metal-mecânica contendo alta carga poluidora, o reuso da água sem tratamento específico pode ser inviável. Torna-se, então, imprescindível à aplicação de técnicas avançadas para o tratamento deste tipo de água residuária. Com a remoção destes poluentes, abre-se a possibilidade de reutilização do efluente no processo industrial ou em usos menos exigentes da planta.

O sistema avançado que utiliza osmose reversa é um processo de separação em que um solvente é separado de um soluto por uma membrana permeável ao solvente e impermeável ao soluto. Isso ocorre quando se aplica uma grande pressão sobre este meio aquoso, o que contraria o fluxo natural da osmose. Por essa razão o processo é denominado osmose reversa. As membranas do processo de osmose reversa exigem um alto grau de qualidade do afluente. $\mathrm{O}$ afluente deve possuir baixa concentração de sólidos, cloro, ferro, sulfatos, cálcio, magnésio, microrganismos e outras substâncias que podem causar a 
degradação ou entupimento das membranas do sistema ("fouling") e assim afetar o desempenho do equipamento e a qualidade do efluente para reuso e para que isso não ocorra é necessário que as operações de tratamento localizadas antes do sistema de osmose reversa produzam uma água de acordo com os padrões exigidos pelo sistema. No caso da empresa estudada é utilizado um processo físico-químico antes do sistema de osmose reversa.

Esse trabalho contribuirá no sentido de avaliar as condições atuais de tratamento e através da utilização de diagramas de coagulação-floculação e da investigação da eficiência de coagulantes e processos de separação dos sólidos, fornecer ferramentas para aumento de sua eficiência e da qualidade da água para o sistema de osmose reversa. Foram utilizados nesse trabalho três diferentes coagulantes - aluminato de sódio, cloreto férrico e uma mistura de dois coagulantes comerciais que utilizam o policloreto de alumínio como substância principal.

No tratamento físico-químico, a previsão das dosagens ótimas de coagulante e/ou polímeros auxiliadores torna-se bastante difícil, pois a água afluente ao sistema pode sofrer variações instantâneas de qualidade (turbidez, alcalinidade, cor, etc) e alterações das propriedades superficiais das partículas, o que exigiria ajustes nas quantidades dos produtos químicos envolvidos no processo. Uma das ferramentas que podem ajudar na previsão e controle é a construção de diagramas de coagulação-floculação. Essa ferramenta permite definir as áreas ótimas de tratamento através da determinação dos pares de valores de dosagem de coagulante e pH em que se verifica a maior remoção de impurezas em questão.

A separação dos flocos formados nos ensaios de coagulação-floculação desse trabalho foi realizada pelos processos de sedimentação e flotação, pois se pretende verificar também qual o método mais eficiente de separação para a água residuária industrial.

Para determinadas taxas de escoamento, a utilização da sedimentação pode apresentar custos de implantação mais baixos em relação à flotação e com eficiências bem próximas, por isso é geralmente utilizada, porém, dependendo da qualidade exigida para o efluente, a utilização da flotação, além de apresentar uma eficiência alta na remoção de sólidos suspensos aumentando a qualidade do efluente, apresenta ainda as vantagens de produção de um lodo com teor de umidade baixo, requer menores dosagens de coagulante e auxiliares de floculação (formação de flocos menos densos), apresenta partida rápida, proporciona o arraste de parcela de gases e compostos voláteis e a elevação na concentração de oxigênio dissolvido no efluente final (CAMPOS et al., 1996; REALI et al., 1998; PENETRA, 1998; MARCHIORETTO, 1999; CARVALHO, 2003; PENETRA 2003; PINTO FILHO e BRANDÃO, 2001; AISSE et al., 2001, entre outros). As desvantagens na utilização 
da flotação são os custos elevados de implantação e operação, principalmente com energia elétrica e a necessidade de funcionários bem qualificados devido à complexidade operacional (AISSE et al., 2001).

A avaliação do tratamento com os diferentes coagulantes nos sistemas propostos na Figura 1.1 foi realizada através de ensaios em reatores de bancada, com separação dos sólidos por sedimentação (jar test) e flotação (flotateste). A definição das condições mais favoráveis para cada condição de tratamento foi realizada juntamente com uma análise dos custos envolvendo somente os produtos químicos utilizados nos processos e energia elétrica no caso do processo de separação por flotação e a partir disso foram discutidos os melhores sistemas para o tratamento da água residuária industrial.

\section{a) Coagulação-Floculação-Sedimentação}

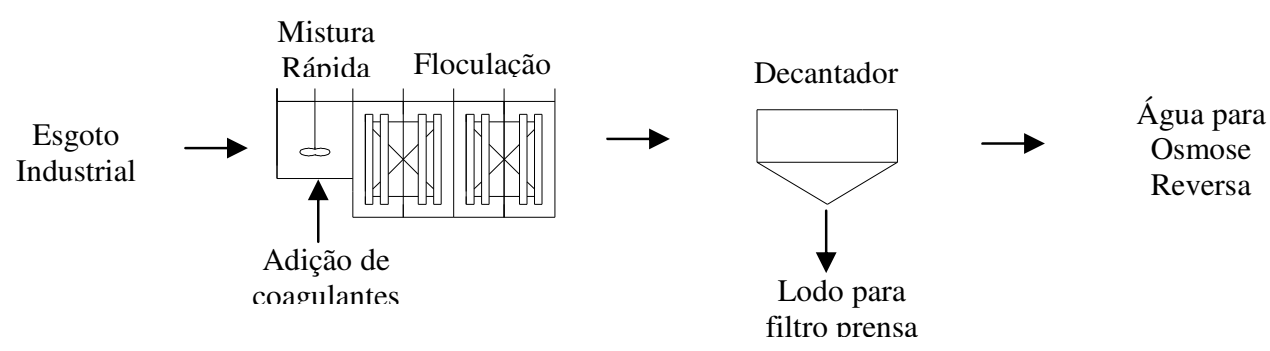

\section{b) Coagulaçãa-Floculação-Flotação}

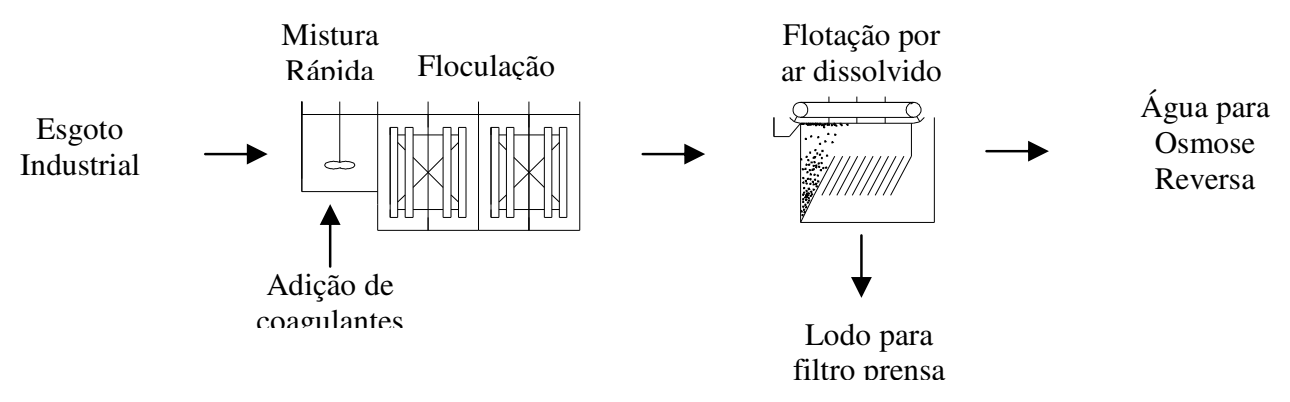

Figura 1.1 - Sistemas de tratamento físico-químico para água residuária industrial propostos nessa pesquisa. 


\section{OBJETIVOS}

O principal objetivo desse trabalho foi avaliar três diferentes coagulantes (aluminato de sódio, cloreto férrico e uma mistura de dois coagulantes comerciais (Procytrat 100A e Procytrat 300) em processos de coagulação-floculação e separação de sólidos da fase líquida por sedimentação e flotação por ar dissolvido.

Para que o objetivo principal seja alcançado, foram considerados os seguintes objetivos específicos:

- Para três diferentes coagulantes, investigar as condições operacionais (dosagem de coagulante, $\mathrm{pH}$ de coagulação, parâmetros de mistura rápida, floculação e separação de sólidos) mais adequadas para a remoção de sólidos da água residuária em estudo, utilizando unidades em escala de laboratório para separação de sólidos por sedimentação (jar test) e flotação (flotateste);

- Obter os diagramas de coagulação-floculação para a água residuária de acordo com cada coagulante e processo de separação de sólidos;

- Comparar os custos dos diferentes coagulantes estudados em cada processo de separação de sólidos (flotação e sedimentação), considerando também para o processo de flotação, o custo da energia elétrica; 


\section{REVISÃO BIBLIOGRÁFICA}

Neste capítulo foram feitas algumas considerações sobre a importância das características das partículas encontradas no esgoto, os principais produtos químicos utilizados no tratamento de águas residuárias industriais, os aspectos fundamentais da coagulação e da precipitação com o uso de sais metálicos e as principais características dos processos de separação de sólidos por sedimentação e flotação por ar dissolvido (FAD).

\subsection{Partículas}

A distribuição de tamanho das partículas interfere no desempenho de praticamente todos os tipos de processos e operações empregados no tratamento de esgoto (SANTOS et al., 2004). Nas estações de tratamento, geralmente os processos e operações atuam dentro de determinadas faixas de tamanho específico das partículas e a sua distribuição varia bastante durante a passagem do líquido pelas unidades do sistema de tratamento. Na Tabela 3.1 são apresentadas as classificações de partículas por faixa de tamanho, proposta por Rudolfs e Balmat (1952) e pela Standart Methods for the Examination of Water and Wastewater (APHA/AWWA/WEF, 1998) e na Figura 3.1, são apresentadas as faixas de tamanho de partículas de alguns constituintes do esgoto e as tecnologias de tratamento mais efetivas para cada uma delas.

Tabela 3.1 - Classificação das partículas do esgoto por faixa de tamanho.

\begin{tabular}{|c|c|c|}
\hline \multirow{2}{*}{$\begin{array}{c}\text { Faixa de tamanho das } \\
\text { partículas }\end{array}$} & \multicolumn{2}{|c|}{ Classificação de partículas por faixa de tamanho } \\
\hline & Rudolfs e Balmat (1952) & APHA/AWWA/WEF (1998) \\
\hline$<0,001 \mu \mathrm{m}$ & Solúveis & \multirow{2}{*}{ Dissolvidos } \\
\hline $0,001 \mu \mathrm{m}$ a $1 \mu \mathrm{m}$ & Coloidais & \\
\hline $1 \mu \mathrm{m}$ a $100 \mu \mathrm{m}$ & Supra-Coloidais & \multirow{2}{*}{ Suspensos ${ }^{*}$} \\
\hline$>100 \mu \mathrm{m}$ & Sedimentáveis & \\
\hline
\end{tabular}




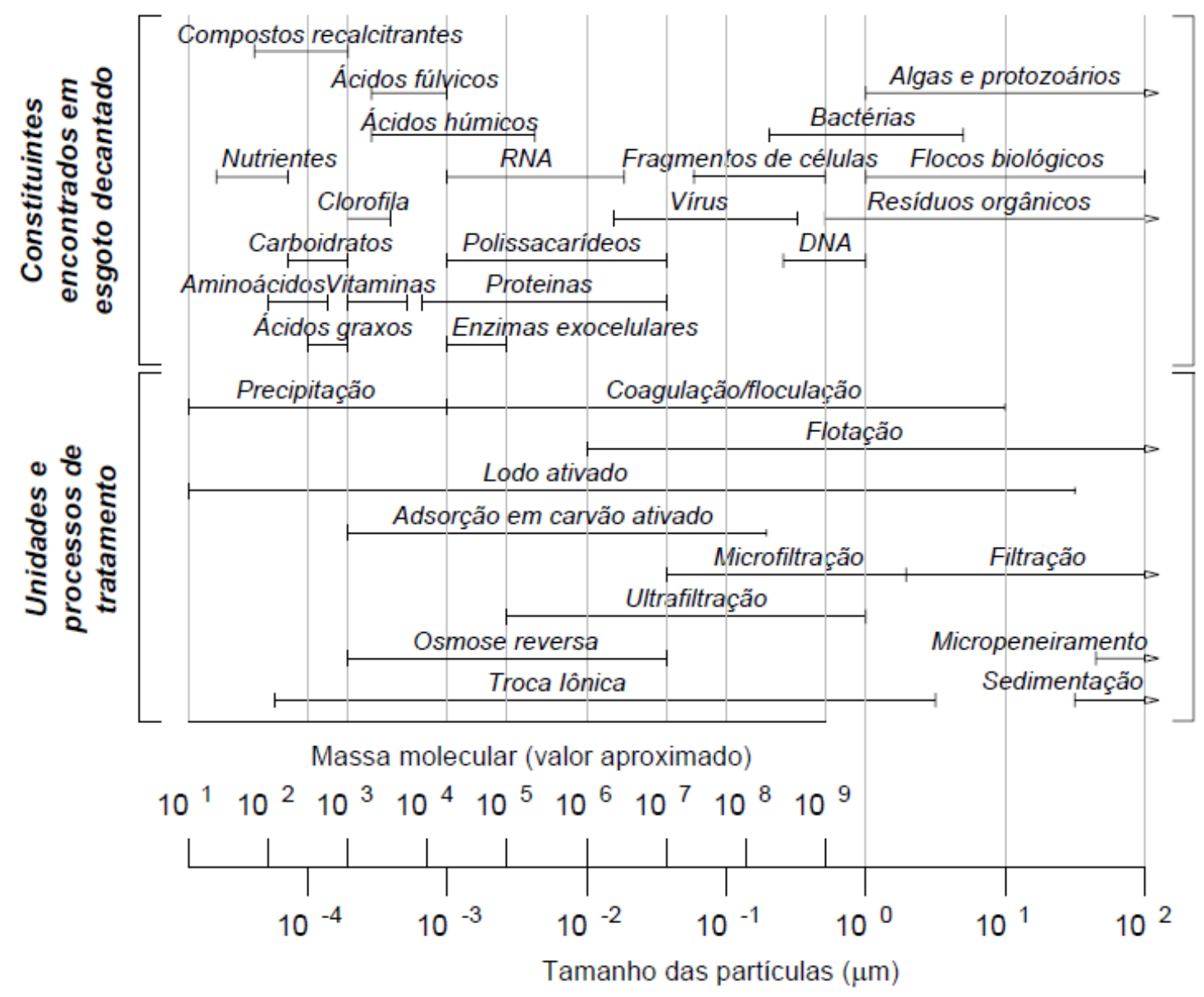

Figura 3.1 - Tamanho de partículas dos constituintes do esgoto e faixa de atuação das unidades de tratamento por tamanho de partículas

Fonte: adaptado de Levine et al., 1985

\subsection{Coagulação e floculação}

Segundo Odegaard (1979), o processo de formação e separação dos flocos pode ser dividido em três etapas: coagulação/precipitação, floculação e separação (sedimentação, flotação ou filtração). A formação de flocos ocorre em todas as etapas, mas a formação inicial ocorre na primeira etapa. As partículas presentes nas águas residuárias variam entre $0,005 \mu \mathrm{m}$ e cerca de $100 \mu \mathrm{m}$. Após a coagulação, as partículas possuem tamanhos na faixa entre $0,5 \mu \mathrm{m}$ e $5 \mu \mathrm{m}$ e são denominadas partículas primárias. Na segunda etapa (floculação), em função das colisões promovidas entre as partículas primárias, são formados flocos maiores, na faixa entre $100 \mu \mathrm{m}$ e $5000 \mu \mathrm{m}$. A primeira etapa (coagulação) ocorre em questão de segundos e relacionase com a química do processo, nas reações do coagulante com a água e na formação de 
espécies hidrolisadas com carga positiva e depende do cátion e do $\mathrm{pH}$ final da mistura, nas outras duas etapas (floculação e separação dos flocos), etapas que demandam tempo superior a alguns minutos, prevalecem os aspectos físicos do processo

$\mathrm{Na}$ coagulação, a desestabilização química é conseguida através da adição de produtos químicos desestabilizantes (coagulantes), que aumentam a tendência de agregação dos colóides. Os coagulantes mais comuns são sais de ferro ou de alumínio, cal e polímeros orgânicos sintéticos (REALI et al., 1999). Esses produtos possuem cargas positivas e neutralizam as cargas das partículas em suspensão, normalmente negativas, proporcionando a formação de flocos.

No caso de tratamento de água é importante considerar os colóides hidrófilos e hidrófobos. Os colóides hidrófilos são compostos de grupos polares, solúveis em água, que atraem para próximo de si, moléculas do meio dispersante, formando uma película que exerce ação protetora, tornando os colóides bastante estáveis dificultando sua coagulação e floculação. Graxas, óleos, sabões e detergentes pertencem a este grupo, quando dispersos em água. Colóides hidrófobos não têm afinidade com a água, pois sua fase dispersa é constituída de material insolúvel em água. Esses colóides geralmente ocorrem em maior quantidade que os hidrófilos em meio aquoso. Suas propriedades eletrocinéticas estão relacionadas ao Potencial Zeta (AZEVEDO NETTO et al., 1979).

Idealmente, a condição ótima de coagulação vai ocorrer quando o Potencial Zeta for zero: isto é definido como ponto isoelétrico. A coagulação em termos práticos usualmente ocorre dentro de uma faixa deste potencial que varia entre $\pm 0,50 \mathrm{mV}$ (ECKENFELDER, 1989), mas em certos casos nota-se a tendência de aglomeração à medida que o Potencial Zeta atinge $10 \mathrm{mV}$ ou menos.

A floculação tem como objetivo agregar o maior número de partículas primárias desestabilizadas/precipitadas em flocos para que sejam separados por sedimentação ou flotação (CARVALHO, 2003).

$\mathrm{Na}$ floculação, a agitação na água deve ser tal que crie gradientes de velocidade que causem turbulência capaz de provocar choques ou colisões entre as partículas coaguladas e as existentes em suspensão e no estado coloidal da água. Estes gradientes são limitados para que não ultrapassem a capacidade de resistência do cisalhamento destas partículas (LEME, 1979).

De forma um pouco mais aprofundada, pode-se dizer que existem dois tipos de floculação: a microfloculação e a macrofloculação. A distinção entre estes dois tipos de floculação está baseada no tamanho das partículas envolvidas. A microfloculação, também conhecida como floculação pericinética, é o termo usado para referir-se a agregação de 
partículas provocada pelo Movimento Browniano das moléculas. Sua faixa de atuação é significante para partículas com tamanho entre 0,001 e $1 \mu \mathrm{m}$. Na macrofloculação, ou floculação ortocinética, a faixa de atuação é para partículas acima de 1 ou $2 \mu \mathrm{m}$. A macrofloculação pode ser provocada por (1) gradiente de velocidade induzido e (2) diferencial de sedimentação (METCALF \& EDDY, 2003).

\subsubsection{Mecanismos de coagulação}

Há quatro mecanismos diferentes de coagulação: compressão da camada difusa; adsorção e neutralização de cargas; varredura; adsorção e formação de pontes. Segundo Odegaard (1979), com exceção do primeiro, todos esses mecanismos podem ocorrer no tratamento de águas residuárias.

Adsorção e neutralização de cargas: Algumas espécies químicas são capazes de serem adsorvidas na superfície das partículas coloidais. Como tais espécies são de carga contrária à da superfície dos colóides, ocorrerá a desestabilização. Esta desestabilização é causada pelo coagulante em dosagens bem inferiores às do mecanismo de dupla camada (MENDES, 1989).

Existe uma relação estequiométrica entre a concentração dos colóides e a quantidade necessária de espécies desestabilizantes por adsorção e a superdosagem de espécies adsorvíveis pode causar a reversão da carga superficial das partículas coloidais (DI BERNARDO, 2005).

Varredura: Quando um sal metálico (como cloreto férrico ou sulfato de alumínio) é usado como coagulante em concentração suficientemente alta para causar a rápida precipitação do hidróxido metálico $\left(\mathrm{Al}(\mathrm{OH})_{3}\right.$ ou $\left.\mathrm{Fe}(\mathrm{OH})_{3}\right)$, as partículas coloidais podem ser "capturadas" por estes precipitados quando estes são formados. Se quantidade suficiente de sal metálico for adicionada, grandes quantidades de flocos do hidróxido metálico são formadas e, à medida que sedimentam, "varrem" a água contendo partículas coloidais (ODEGAARD, 1978).

Adsorção e formação de pontes: Segundo Mendes (1989), este mecanismo é desenvolvido por intermédio da utilização de compostos orgânicos (polímeros) sintéticos ou naturais, utilizados como coagulantes; podem apresentar sítios ionizáveis ao longo de suas cadeias podendo ser classificados como: 
- catiônicos: possuem sítios ionizáveis positivos;

- aniônicos: possuem sítios ionizáveis negativos;

- não iônicos: não possuem sítios ionizáveis;

- anfolíticos: possuem sítios ionizáveis positivos e negativos.

Os polímeros catiônicos tendem a atuar na neutralização das cargas negativas dos colóides das águas residuárias e, geralmente, têm peso molecular da ordem de $10^{5}$. Os polímeros não iônicos e aniônicos atuam na formação de pontes partícula-polímero-partícula e requerem peso molecular maior que $10^{6}$ para serem efetivos (ODEGAARD, 1979).

\subsubsection{Diagrama de solubilidade do alumínio}

Quando é adicionado um coagulante químico na estação de tratamento, algumas espécies hidrolisadas poderão estar presentes para um determinado valor de $\mathrm{pH}$. Em seguida mostram-se algumas reações de hidrólise em temperatura de $25^{\circ} \mathrm{C}$.

\section{Equações de hidrólise das espécies:}

Log K

$\begin{array}{ccccccccc}\mathrm{Al}^{3+} & + & \mathrm{H}_{2} \mathrm{O} & \rightleftarrows & \mathrm{Al}^{3}(\mathrm{OH})^{2+} & + & \mathrm{H}^{+} & -5,02 \\ 2 \mathrm{Al}^{3+} & + & 2 \mathrm{H}_{2} \mathrm{O} & \rightleftarrows & \mathrm{Al}_{2}(\mathrm{OH})_{2}{ }^{4+} & + & 2 \mathrm{H}^{+} & -6,27 \\ 6 \mathrm{Al}^{3+} & + & 15 \mathrm{H}_{2} \mathrm{O} & \rightleftarrows & \mathrm{Al}_{6}(\mathrm{OH})_{15}{ }^{3+} & + & 15 \mathrm{H}^{+} & -47,00 \\ 8 \mathrm{Al}^{3+} & + & 20 \mathrm{H}_{2} \mathrm{O} & \rightleftarrows & \mathrm{Al}_{8}(\mathrm{OH})_{20}{ }^{5+} & + & 20 \mathrm{H}^{+} & -68,70 \\ \mathrm{Al}(\mathrm{OH})_{3(\mathrm{p})} & + & & \rightleftarrows & \mathrm{Al}^{3+} & + & 3 \mathrm{OH}^{-} & -32,34 \\ \mathrm{Al}^{3+} & + & 4 \mathrm{H}_{2} \mathrm{O} & \rightleftarrows & \mathrm{Al}^{2}(\mathrm{OH})_{4}{ }^{-} & + & 4 \mathrm{H}^{+} & -23,57\end{array}$




\section{Construção do diagrama de solubilidade}

a) Espécie $\mathrm{Al}(\mathrm{OH})^{2+}$

\begin{tabular}{|c|c|c|c|c|c|c|c|}
\hline $\mathrm{Al}^{3+}$ & + & $\mathrm{H}_{2} \mathrm{O}$ & $\rightleftarrows$ & $\mathrm{Al}(\mathrm{OH})^{2+}$ & + & $\mathrm{H}^{+}$ & $-5,02$ \\
\hline $\mathrm{Al}(\mathrm{OH})_{3(\mathrm{p})}$ & + & & $\rightleftarrows$ & $\mathrm{Al}^{3+}(\mathrm{aq})$ & + & $3 \mathrm{OH}^{-}(\mathrm{aq})$ & $-32,34$ \\
\hline $\mathrm{H}^{+}$ & + & $\mathrm{OH}^{-}$ & $\rightleftarrows$ & $\mathrm{H}_{2} \mathrm{O}$ & & & $-14,00$ \\
\hline $\mathrm{Al}(\mathrm{OH})_{3(\mathrm{p})}$ & & & $\rightleftarrows$ & $\mathrm{Al}(\mathrm{OH})^{2+}$ & + & $2 \mathrm{OH}^{-}$ & $(\log K=?)$ \\
\hline
\end{tabular}

Do sistema de das três equações de hidrólise, resulta:

$$
\begin{aligned}
& 10^{-5,02}=\frac{\left[\mathrm{Al}(\mathrm{OH})^{2+}\right]\left[\mathrm{H}^{+}\right]}{\left[\mathrm{Al} l^{3+}\right]} \\
& 10^{-32,34}=\frac{\left[\mathrm{Al}^{3+}\right]\left[\mathrm{OH}^{-}\right]^{3}}{\left[\mathrm{Al}(\mathrm{OH})_{3(p)}\right]} \\
& 10^{-14}=\frac{\left[\mathrm{H}^{+}\right]\left[\mathrm{OH}^{-}\right]}{\left[\mathrm{H}_{2} \mathrm{O}\right]}
\end{aligned}
$$

Considerando que a atividade do precipitado $\mathrm{Al}(\mathrm{OH})_{3(\mathrm{p})}$ seja igual a unidade para que a constante de equilíbrio seja expressa em termos da espécie solúvel de $\mathrm{Al}^{3+}$ e $\mathrm{H}^{+}$e, tomando-se o logaritmo de ambos os lados da equação (3.10), obtém-se:

$\log K=\log \left\lfloor A l(O H)^{2+}\right\rfloor+2 \log \left[O H^{-}\right\rfloor$

O mesmo procedimento, aplicando-se às equações 3.8, 3.9 e 3.10, fornece:

$-23,36=\log \left[\mathrm{Al}(\mathrm{OH})^{2+}\right]+2 \log \left[\mathrm{OH}^{-}\right]$

e

$$
\log \left[H^{+}\right]=-14-\log \left[O H^{-}\right] \text {e } p H=-\log \left[O H^{-}\right]
$$

Logo:

$\log \left[A l(O H)^{2+}\right\rfloor=4,64-2 p H$ 
b) Espécie $\mathrm{Al}^{+3}$

$$
\begin{array}{ll}
\text { b) }{\text { Espécie } \mathbf{A l}^{+3}}^{\mathbf{3}} & \log \left[A l^{3+}\right]=9,66-3 p H \\
\text { c) Espécie } \mathbf{A l}_{\mathbf{6}}(\mathbf{O H})_{\mathbf{1 5}}{ }^{3+} & \log \left[A l_{6}(\mathrm{OH})_{15}^{3+}\right]=10,96-3 p H \\
\text { d) Espécie } \mathbf{A l}_{\mathbf{8}}(\mathbf{O H})_{\mathbf{2 0}}{ }^{{ }^{++}} & \log \left[A l_{13}(\mathrm{OH})_{35}^{5+}\right]=8,58-4 p H \\
\text { e) Espécie } \mathbf{A l}_{\mathbf{2}}(\mathbf{O H})_{\mathbf{2}}{ }^{{ }^{+}} & \log \left[A l_{2}(\mathrm{OH})_{2}^{4+}\right]=13,05-4 \mathrm{pH}
\end{array}
$$$$
\text { d) Espécie } \mathbf{A l}_{\mathbf{8}}(\mathbf{O H})_{\mathbf{2 0}}{ }^{4+} \quad \log \left[A l_{13}(O H)_{35}^{5+}\right]=8,58-4 p H
$$$$
\text { f) Espécie } \mathrm{Al}(\mathrm{OH})_{4}^{-} \quad \log \left[\mathrm{Al}(\mathrm{OH})_{4}^{-}\right]=p H-13,91
$$

Utilizando-se as equações de 3.12 a 3.17, segue na Figura 3.2, o diagrama das espécies hidrolisadas de alumínio em função do pH.

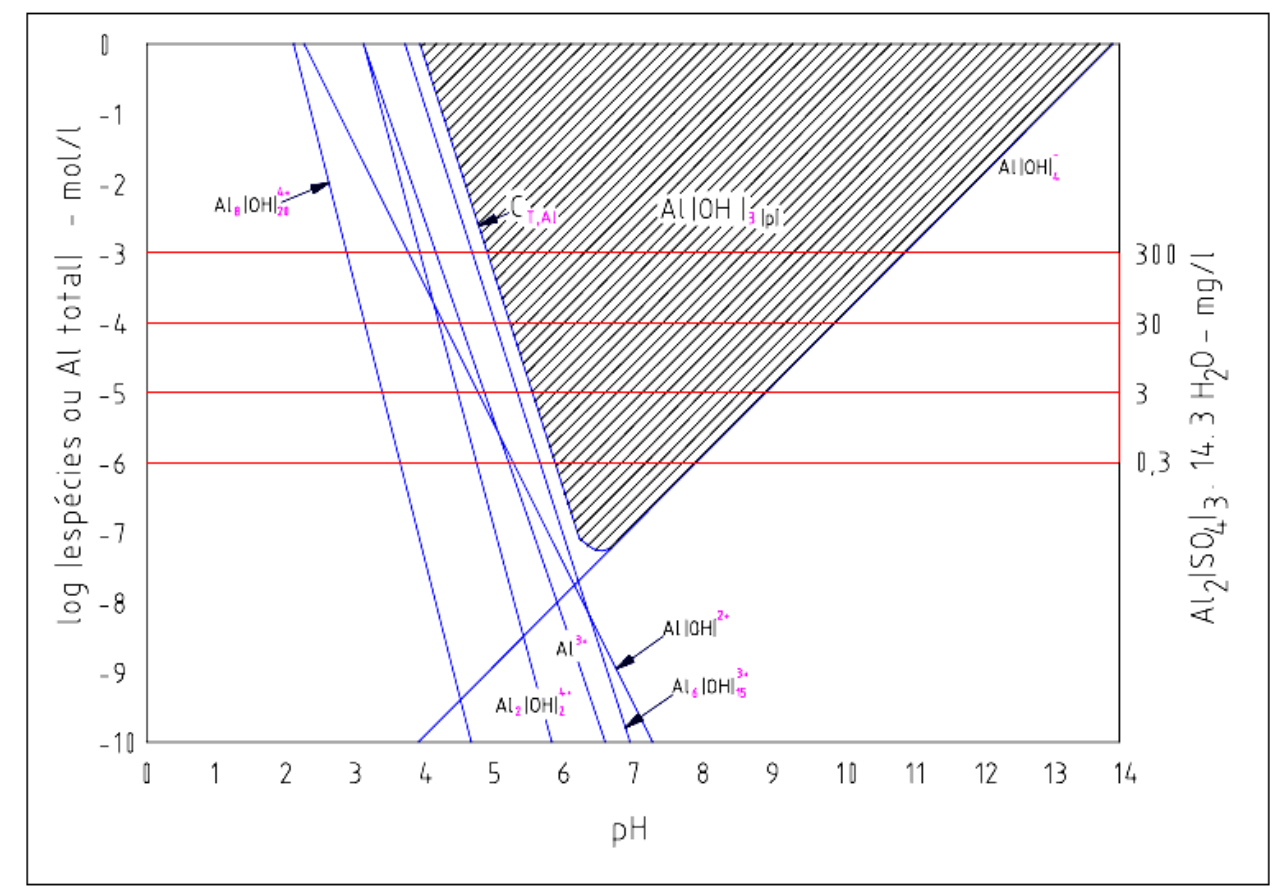

Figura 3.2 - Diagrama de equilíbrio heterogêneo do $\mathrm{Al}(\mathrm{OH})_{3}$ Fonte: Di Bernardo, 2005

A concentração de alumínio total é dada pela seguinte expressão:

$$
C_{T, A l}=\left[A l(O H)^{2+}\right]+\left[A l^{3+}\right]+6\left[A l_{6}(\mathrm{OH})_{15}\right]+8\left[A l_{8}(\mathrm{OH})_{20}^{4+}\right]+2\left[A l_{2}(\mathrm{OH})_{2}^{4+}\right]+\left[\mathrm{Al}(\mathrm{OH})_{4}\right]
$$

Para cada valor de $\mathrm{pH}$, substituir seu valor nas equações e obter o valor de cada espécie. Substituir estes valores na equação acima $\left(\mathrm{C}_{\mathrm{T}, \mathrm{Al}}\right)$ e efetuar a soma. Na sequência aplicar o logaritmo (base 10) no valor obtido. Assim para um valor de pH, é obtido o valor da concentração total de alumínio e refazendo-se os cálculos para os demais valores de pH, são 
obtidos os respectivos valores da concentração total de alumínio e então pode ser traçada a região que delimita a formação do precipitado.

\subsubsection{Diagrama de solubilidade do ferro}

Em seguida mostram-se algumas reações de hidrólise em temperatura de $25^{\circ} \mathrm{C}$.

Equações de hidrólise das espécies

$\begin{array}{cccccccc}\mathrm{Fe}(\mathrm{OH})_{3(\mathrm{p})} & + & & \rightleftarrows & & & & \log \mathrm{K} \\ \mathrm{Fe}^{3+} & + & \mathrm{H}_{2} \mathrm{O} & \rightleftarrows & \mathrm{Fe}^{3+}(\mathrm{aq}) & + & 3 \mathrm{OH}^{-}(\mathrm{aq}) & -37,50 \\ \mathrm{Fe}^{3+} & + & 2 \mathrm{H}_{2} \mathrm{O} & \rightleftarrows & \mathrm{Fe}(\mathrm{OH})^{2+} & + & \mathrm{H}^{+} & -3,00 \\ 2 \mathrm{Fe}^{3+} & + & 2 \mathrm{H}_{2} \mathrm{O} & \rightleftarrows & \mathrm{Fe}(\mathrm{OH})_{2}{ }^{+} & + & 2 \mathrm{H}^{+} & -6,40 \\ \mathrm{Fe}^{3+} & + & 4 \mathrm{H}_{2} \mathrm{O} & \rightleftarrows & \mathrm{Fe}(\mathrm{OH})_{2}{ }^{4+} & + & 2 \mathrm{H}^{+} & -3,10 \\ \mathrm{Fe}^{3+} & + & 3 \mathrm{H}_{2} \mathrm{O} & \rightleftarrows & \mathrm{Fe}(\mathrm{OH})_{2}{ }^{-} & + & 4 \mathrm{H}^{+} & -23,50 \\ & & & & \mathrm{Fe}(\mathrm{OH})_{3}{ }^{\circ} & + & 3 \mathrm{H}^{+} & -13,50\end{array}$

\section{Construção do diagrama de solubilidade}
a) Espécie $\mathrm{Fe}(\mathrm{OH})^{2+}$
$\log \left[\mathrm{Fe}(\mathrm{OH})^{2+}\right]=1,5-2 \mathrm{pH}$
b) Espécie $\mathrm{Fe}(\mathrm{OH})_{2}{ }^{+}$
$\log \left[\mathrm{Fe}(\mathrm{OH})_{2}{ }^{+}\right]=1,9-\mathrm{pH}$
c) Espécie $\mathrm{Fe}_{2}(\mathrm{OH})_{2}{ }^{4+}$
$\log \left[\mathrm{Fe}_{2}(\mathrm{OH})_{2}{ }^{4+}\right]=5,9-4 \mathrm{pH}$
d) Espécie $\mathrm{Fe}(\mathrm{OH})_{4}{ }^{-}$
$\log \left[\mathrm{Fe}(\mathrm{OH})_{4}{ }^{-}=\mathrm{pH}-19\right.$
e) Espécie $\mathrm{Fe}^{3+}$
$\log \left[\mathrm{Fe}^{3+}\right]=4,5-3 \mathrm{pH}$
f) Espécie $\mathrm{Fe}(\mathrm{OH})_{3}{ }^{0}$
$\log \left[\mathrm{Fe}(\mathrm{OH})_{3}{ }^{0}\right]=-9,0$

Utilizando-se as equações de número 3.24 a 3.29, o diagrama das espécies hidrolisadas de ferro é construído em função do pH, conforme mostra a Figura 3.3. 


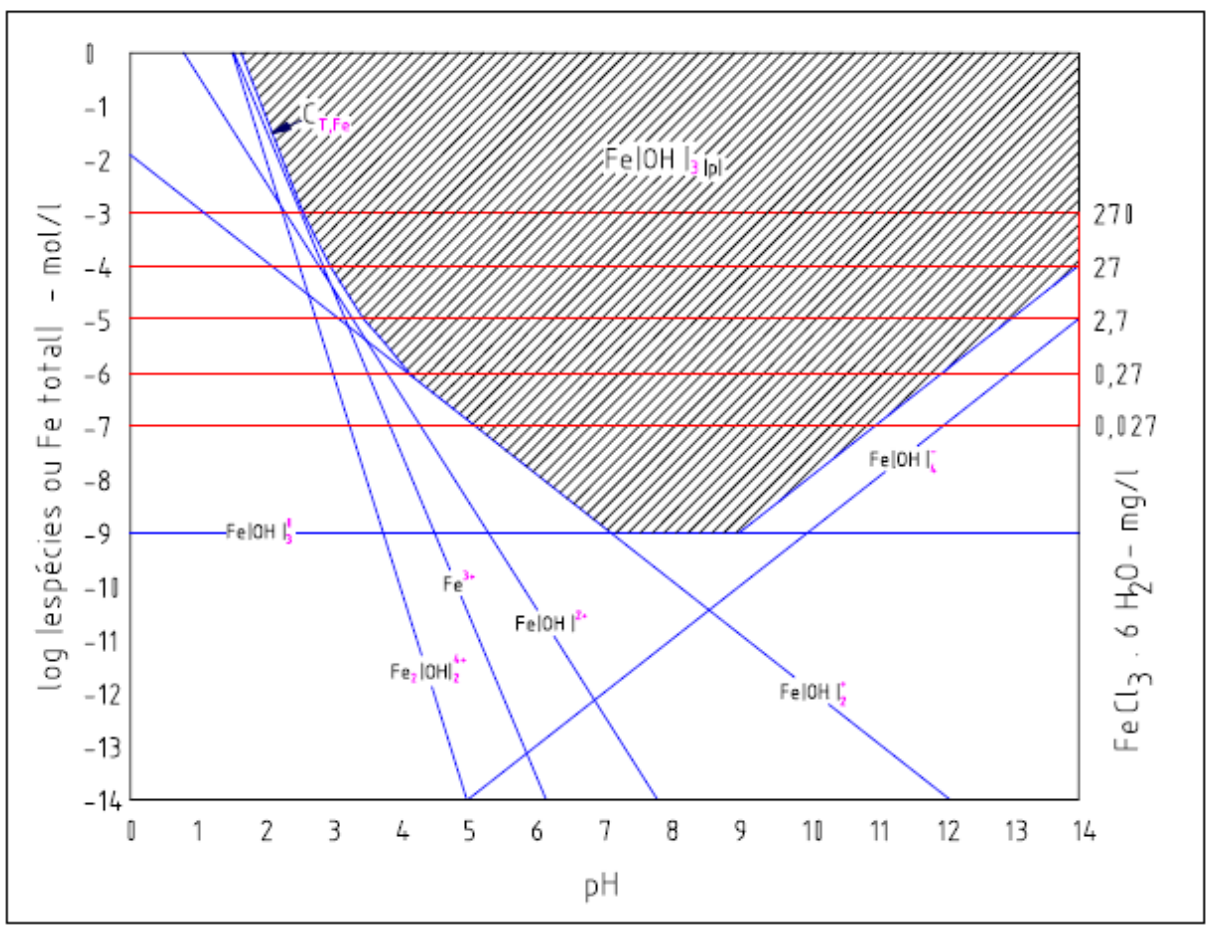

Figura 3.3 - Diagrama de equilíbrio heterogêneo do $\mathrm{Fe}(\mathrm{OH})_{3}$ Fonte: Di Bernardo, 2005

A concentração de ferro total é dada pela seguinte expressão:

$C_{T, F e}=\left[\mathrm{Fe}(\mathrm{OH})_{4}{ }^{-}\right\rfloor+\left[\mathrm{Fe}^{3+}\right]+2\left[\mathrm{Fe}_{2}(\mathrm{OH})_{2}{ }^{4+}\right\rfloor+\left[\mathrm{Fe}(\mathrm{OH})_{2}^{+}\right]+\left[\mathrm{Fe}(\mathrm{OH})^{2+}\right]$

\subsubsection{Diagrama de coagulação}

Amirtharajah e Mills (1982), com base em dados de vários autores, desenvolveram o diagrama de coagulação para o sulfato de alumínio (Figura 3.4). Esses diagramas permitem estimar valores de $\mathrm{pH}$ e dosagens de coagulante, para os quais a coagulação seria otimizada. Esses diagramas também foram estudados para o cloreto férrico, em diversas águas e por diversos autores.

Na Figura 3.4 pode-se notar regiões distintas para diferentes mecanismos de coagulação já citados no item 3.2.1. 


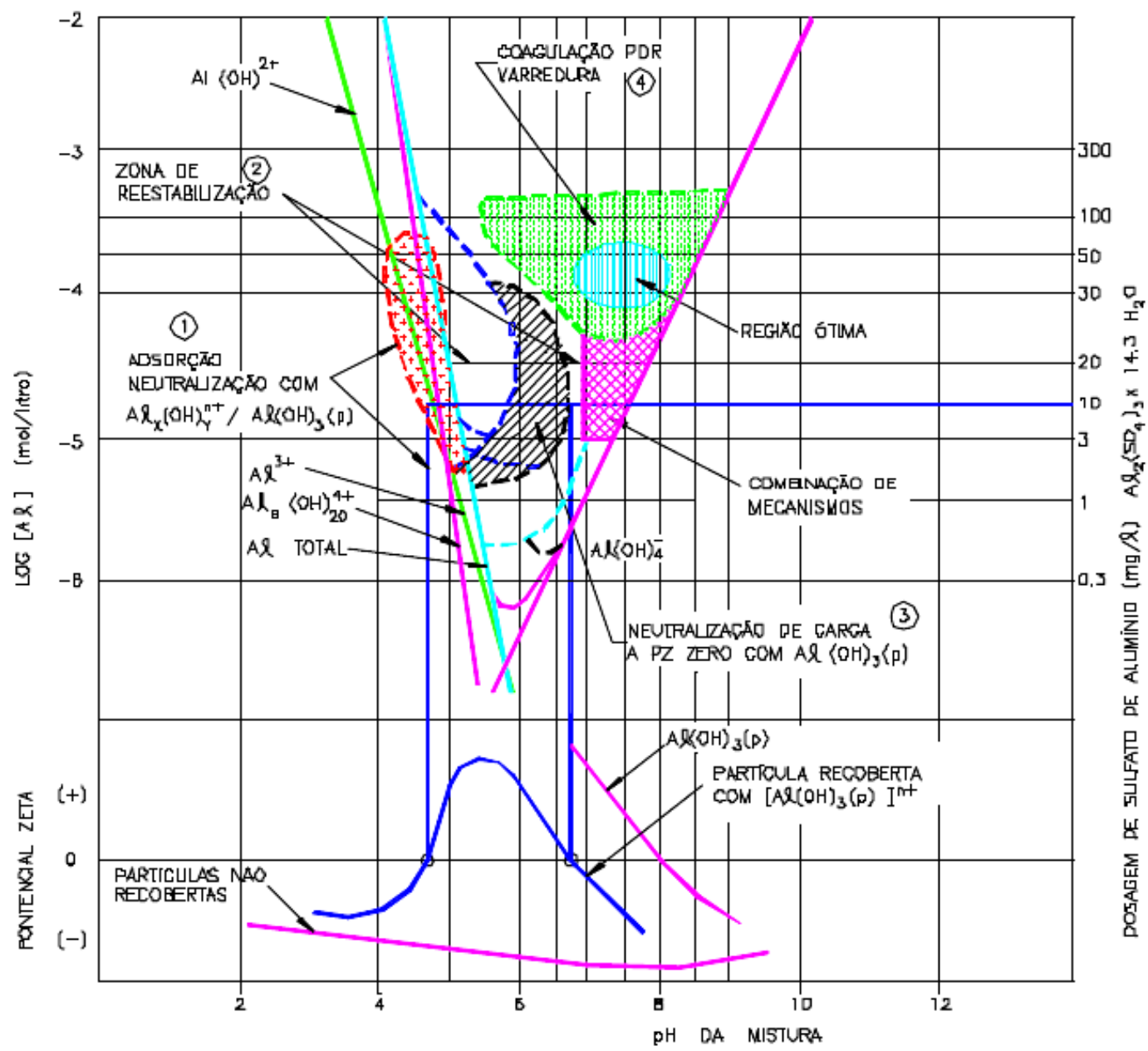

Figura 3.4 - Diagrama de coagulação para remoção de turbidez com do sulfato de alumínio de água "preparada" com caulinita.

Fonte: Amirtharajah e Mills, 1982

Região 1- Região onde prevalece a neutralização de cargas pelas espécies hidrolisadas positivas de alumínio, que são adsorvidas na superfície dos colóides.

Região 2- Zona caracterizada pela reestabilização.

Região 3- Região denominada de "corona". Nesta região, o potencial zeta atinge seu máximo. Quando o valor de $\mathrm{pH}$ está em torno de 6,9 e dosagem de coagulante $10 \mathrm{mg} / \mathrm{l}$ e o valor do potencial zeta aproxima-se de zero.

Região 4- Região onde predomina a coagulação pelo mecanismo de varredura. Nessa região os flocos possuem um tamanho maior quando comparado aos flocos das outras regiões. 


\subsubsection{Produtos químicos empregados}

Existem vários tipos de coagulantes disponíveis no mercado, porém os mais conhecidos e utilizados estão divididos em quatro grandes categorias: cal; sais de alumínio, tal como sulfato de alumínio, aluminato de sódio, cloreto de alumínio; sais de ferro como sulfato férrico, cloreto férrico e sulfato ferroso e polímeros.

O hidróxido de cálcio (cal) é utilizado como coagulante e alcalinizante, apesar de ele não ser considerado um coagulante verdadeiro. Este pode reagir com a alcalinidade do bicarbonato e precipitar o carbonato de cálcio e com orto-fosfato para precipitar hidroxiapatita de cálcio (ECKENFELDER, 1989), além de reduzir sólidos suspensos, a turbidez, a concentração de metais pesados e a população de vírus e bactérias. O efluente tratado com cal apresenta alto $\mathrm{pH}$, mas este pode ser diminuído por recarbonatação ou por adição de ácido. As dosagens requeridas dependem basicamente da dureza e da alcalinidade da água, sendo normais doses variando entre 200 e $400 \mathrm{mg} / \mathrm{L}$, em $\mathrm{pH}$ em torno de 11,0 (MANCUSO e SANTOS, 2003).

O sal de alumínio normalmente utilizado é o sulfato de alumínio, que reage tanto com a alcalinidade como com fósforo e outros compostos como sulfetos, por exemplo. Além de possuir baixo custo, fácil transporte e manejo e grande disponibilidade. A dosagem necessária de sulfato de alumínio para remoção de fósforo, por exemplo, é maior que a estequiometricamente requerida, em razão da reação com a alcalinidade (MANCUSO e SANTOS, 2003). O aluminato de sódio é uma fonte alternativa, mas é raramente utilizado no tratamento de água, mas freqüentemente na remoção de fósforo. Seu preço é mais alto que o sulfato de alumínio. O aluminato de sódio é disponível na forma líquida e na forma sólida. $\mathrm{Na}$ forma sólida ele contém 23-33\% de alumínio e na forma líquida o teor de alumínio está entre 0,21 e $0,27 \mathrm{Kg} / \mathrm{l}$. O aluminato de sódio é uma substância alcalina e causa um aumento nos valores de $\mathrm{pH}$ quando adicionado a águas residuárias.

O policloreto de alumínio, é um sal de alumínio prepolimerizado de fórmula bruta $\mathrm{Al}_{\mathrm{n}}(\mathrm{OH})_{\mathrm{m}} \mathrm{Cl}_{3 \mathrm{n}-\mathrm{m}}$, na qual a relação $\mathrm{m} / 3 \mathrm{n} \times 100$ representa a basicidade do produto. Em função dessa basicidade, o policloreto de alumínio, durante a hidrólise libera, em igualdade de dosagem de íons metálicos, uma quantidade de ácido consideravemente menor do que o cloreto de alumínio e dos coagulantes tradicionais como sulfato de alumínio e cloreto férrico. Isso provoca uma menor variação do $\mathrm{pH}$ do meio tratado ou um menor consumo de neutralizante. Apresenta vantagens em relação a outros coagulantes inorgânicos não 
prepolimerizados devido a sua maior concentração de elemento ativo $\left(\mathrm{Al}_{2} \mathrm{O}_{3}\right)$. O policloreto de alumínio também é conhecido como PAC (Poly Aluminium Chloride) trabalha em um mais ampla faixa de $\mathrm{pH}$, se comparado com o sulfato de alumínio ou outros floculantes. $\mathrm{O}$ policloreto de alumínio é geralmente eficaz em uma faixa de $\mathrm{pH}$ compreendida entre 6 e 9, mas em alguns casos ele funciona bem em faixas que vão de pH 5 até pH 10.

Os sais de ferro, principalmente o cloreto férrico, são bastante eficientes na remoção de sólidos suspensos e fósforo do efluente. A utilização de cloreto férrico também elimina fosfatos e uma boa parte de metais pesados (mercúrio, chumbo) ou venenosos (arsênio, selênio, bário) quando a coagulação é realizada em valores elevados de pH. Outros metais como ferro e manganês também podem ser eliminados com o uso do cloreto férrico. (PAVANELLI,2001). Estes sais normalmente são dosados conjuntamente com a cal ou hidróxido de sódio, que ajudam na produção dos flocos e aumentam o pH da água. O cloreto férrico produz bons flocos em amplo intervalo de $\mathrm{pH}$ e sua dosagem para permitir a precipitação de hidróxidos é cerca de 10 mg/L (MANCUSO, 2003).

$\mathrm{O}$ sulfato ferroso é muito útil para tratar águas que apresentam $\mathrm{pH}$ elevado, enquanto que o sulfato férrico é conveniente para o tratamento de águas altamente coloridas ou ácidas (AZEVEDO NETTO et al., 1979).

O Quadro 3.1 apresenta algumas características, apenas orientativas, de alguns tipos de coagulantes utilizados no tratamento de água e efluentes.

\begin{tabular}{|l|c|c|c|c|c|}
\hline \multicolumn{1}{|c|}{ Substância química } & Fórmula & $\begin{array}{c}\text { Forma } \\
\text { disponível }\end{array}$ & $\mathbf{p H}$ & $\begin{array}{c}\text { Dosagem } \\
(\mathbf{p p m})\end{array}$ & $\begin{array}{c}\text { pH de } \\
\text { atuação }\end{array}$ \\
\hline Sulfato de alumínio & $\mathrm{Al}_{2}\left(\mathrm{SO}_{4}\right)_{2}$ & $\begin{array}{c}\text { Líquido e } \\
\text { massa sólida }\end{array}$ & 3,5 & 20 a 60 & 5,5 a 7,0 \\
\hline Cloreto de alumínio & $\mathrm{AlCl}_{3}$ & Líquido & $(1)$ & $(1)$ & $(1)$ \\
\hline Hidróxido de cálcio (cal) & $\mathrm{Ca}(\mathrm{OH})_{2}$ & Pó e pasta & $(1)$ & $(1)$ & $(1)$ \\
\hline Cloreto férrico & $\mathrm{FeCl}_{3}$ & $\begin{array}{c}\text { Líquido e } \\
\text { massa sólida }\end{array}$ & 3 a 4 & 30 a 80 & 8,0 a 9,4 \\
\hline Sulfato férrico & $\mathrm{Fe}_{2}\left(\mathrm{SO}_{4}\right)_{3}$ & Granular & 3 a 4 & 30 a 80 & 8,0 a 9,4 \\
\hline Sulfato ferroso & $\mathrm{Fe}_{2} \mathrm{SO}_{4} \cdot 7 \mathrm{H}_{2} \mathrm{O}$ & Granular & $(1)$ & $(1)$ & 8,0 a 9,4 \\
\hline Aluminato de sódio & $\mathrm{Na}_{2} \mathrm{AlO}_{4}$ & $\begin{array}{c}\text { Líquido e } \\
\text { Floco }\end{array}$ & 11 a 12 & 10 a 30 & 5,5 a 7,0 \\
\hline
\end{tabular}

Quadro 3.1 - Produtos químicos inorgânicos mais usados para coagulação em processos de tratamento de água e efluentes

FONTE: Adaptado de METCALF \& EDDY (2003), DEGANI (1981) E AZEVEDO NETTO et al., (1979)

(1) Não informado

O grau de clarificação do efluente final depende da quantidade utilizada de coagulante e do cuidado com que o processo é operado. É possível obter efluentes bastante clarificados, livres da matéria orgânica em suspensão ou em estado coloidal. Os produtos 
químicos adicionados às águas residuárias interagem com as substâncias que estão normalmente presentes no meio, por meio das reações abaixo (METCALF \& EDDY, 2003):

Hidróxido de cálcio (cal): Quando a cal é adicionada ao efluente, ocorrem as seguintes reações:

$\mathrm{Ca}(\mathrm{OH})_{2}+\mathrm{H}_{2} \mathrm{CO}_{3} \leftrightarrow \mathrm{CaCO}_{3}+2 \mathrm{H}_{2} \mathrm{O}$ (3.30)

$\mathrm{Ca}(\mathrm{OH})_{2}+\mathrm{Ca}\left(\mathrm{HCO}_{3}\right)_{2} \leftrightarrow \mathrm{CaCO}_{3}+2 \mathrm{H}_{2} \mathrm{O}(3.31)$

Cloreto férrico: As reações para o cloreto férrico no tratamento de águas residuárias são:

$\mathrm{FeCl}_{3}+3 \mathrm{H}_{2} \mathrm{O} \leftrightarrow \mathrm{Fe}(\mathrm{OH})_{3}+3 \mathrm{H}^{+}+3 \mathrm{Cl}^{-}(3.32)$

$3 \mathrm{H}^{+}+3 \mathrm{HCO}_{3}^{-} \leftrightarrow 3 \mathrm{H}_{2} \mathrm{CO}_{3}(3.33)$

O conhecimento da solubilidade das diversas espécies hidrolisadas de ferro, presentes em diferentes valores de $\mathrm{pH}$, é de grande importância, pois os mecanismos da coagulação dependem da concentração de cada espécie na solução.

Quando o cloreto férrico e a cal são utilizados simultaneamente, a reação básica resultante é:

$2 \mathrm{FeCl}_{3}+3 \mathrm{Ca}(\mathrm{OH})_{2} \leftrightarrow 2 \mathrm{Fe}(\mathrm{OH})_{3}+3 \mathrm{CaCl}_{2}$ (3.34)

Aluminato de sódio: As reações para o aluminato de sódio no tratamento de águas residuárias são:

$\mathrm{Na}_{2} \mathrm{Al}_{2} \mathrm{O}_{4}+4 \mathrm{H}_{2} \mathrm{O} \rightarrow 2 \mathrm{NaOH}+2 \mathrm{Al}(\mathrm{OH})_{3}(3.35)$

$2 \mathrm{NaOH}+\mathrm{Ca}\left(\mathrm{HCO}_{3}\right)_{2} \rightarrow \mathrm{CaCO}_{3}+\mathrm{Na}_{2} \mathrm{CO}_{3}+2 \mathrm{H}_{2} \mathrm{O}$

ou:

$\mathrm{Na}_{2} \mathrm{Al}_{2} \mathrm{O}_{4}+\mathrm{Ca}\left(\mathrm{HCO}_{3}\right)_{2}+2 \mathrm{H}_{2} \mathrm{O} \rightarrow 2 \mathrm{Al}(\mathrm{OH})_{3}+\mathrm{CaCO}_{3}+\mathrm{Na}_{2} \mathrm{CO}_{3}$

\subsection{Operações de mistura rápida e floculação}

Segundo Di Bernardo (2005), nas estações de tratamento de água, a operação unitária de mistura é usada com duas finalidades:

- mistura rápida: responsável pela mistura dos produtos químicos na água para ocorrência da coagulação; 
- mistura lenta: responsável pela agregação das partículas desestabilizadas, com formação de flocos.

Em se tratando de líquidos pouco viscosos, a mistura em regime turbulento é comumente encontrado nas operações unitárias de mistura rápida e floculação.

A mistura rápida visa conduzir os constituintes, neste caso os coagulantes e seus auxiliares, em câmaras de mistura rápida, a um estado de uniformidade desejada promovendo uma coagulação homogênea. Esta mistura intensa é que assegura uma distribuição uniforme do coagulante na água, colocando-o em contato com as partículas existentes em suspensão (LEME, 1979). A inexistência dessa mistura intensa e adequada implica em que parte da água receba superdosagem, enquanto que outras partes sejam insuficientemente tratadas, prejudicando o tratamento.

Os sistemas de floculação são classificados em hidráulicos ou mecanizados. Os primeiros possuem alguns inconvenientes, como: pouca flexibilidade em relação à variação de vazão, impossibilidade de ajustar o gradiente de velocidade e perda de carga relativamente alta. Por outro lado, apresentam algumas vantagens: menores custos de implantação e manutenção e não exigem pessoal qualificado para operação (DI BERNARDO, 2005).

Fazendo mistura com rotor mecânico em reatores ou câmaras de mistura, é possível obter circulação e cisalhamento do fluído. A potência atribuída por unidade de volume pode ser usada como estimativa da efetividade da mistura, baseado no raciocínio de que maior potência aplicada cria mais turbulência, e mais turbulência resulta em melhor mistura. Camp e Stein (1946, citado por: METCALF \& EDDY, 2003) estudaram a fundamentação e o efeito do gradiente de velocidade em vários tipos de tanques de coagulação e desenvolveram a Equação 3.37 para ser usada em projeto e operação de sistemas que utilizam dispositivo por mistura mecânica.

$$
G=\sqrt{\frac{P}{\mu \times V}}
$$

Onde: $\mathrm{G}=$ Gradiente de velocidade média, $\mathrm{T}^{-1}, 1 / \mathrm{s}$;

$\mathrm{P}=$ Potência necessária, $\mathrm{W}$;

$\mu=$ Viscosidade dinâmica, N.s.m ${ }^{-2}$;

$\mathrm{V}=$ Volume do floculador, $\mathrm{m}^{3}$. 
Valores típicos para G usados em várias operações de mistura são apresentados no Quadro 3.2.

\begin{tabular}{|l|c|c|}
\hline \multirow{2}{*}{ Mrocesso } & \multicolumn{2}{c|}{ Faixa de valores } \\
\cline { 2 - 3 } & Mempo de detenção & Valor G (s $\mathbf{s}^{-1}$ ) \\
\hline \multicolumn{1}{|c|}{ Floculação } & $5-30$ segundos & $500-1500$ \\
\hline $\begin{array}{l}\text { Operações típicas de mistura rápida em } \\
\text { tratamento de efluentes. }\end{array}$ & $<1$ segundo & $1500-6000$ \\
\hline $\begin{array}{l}\text { Mistura rápida para efetivo contato } \\
\text { inicial e dispersão de produtos } \\
\text { químicos. }\end{array}$ & $<1$ segundo & $2500-7500$ \\
\hline $\begin{array}{l}\text { Mistura rápida de produtos químicos } \\
\text { para processos de filtração por contato. }\end{array}$ & & $50-100$ \\
\hline & $30-60$ minutos & $25-150$ \\
\hline $\begin{array}{l}\text { Processo típico de floculação usado em } \\
\text { tratamento de efluentes. }\end{array}$ & $2-10$ minutos & $25-250$ \\
\hline $\begin{array}{l}\text { Floculação em processos de filtração } \\
\text { direta. }\end{array}$ & $2-5$ minutos & \\
\hline $\begin{array}{l}\text { Floculação em processos de filtração } \\
\text { por contato. }\end{array}$ & & \\
\hline
\end{tabular}

Quadro 3.2 - Valores típicos para tempo de detenção e gradiente $\mathrm{G}$ para mistura e floculação em efluentes.

FONTE: Adaptado de METCALF \& EDDY, 2003

Amirtharajah (1989), ao estudar a influência dos valores de gradiente de velocidade para a mistura rápida $(\mathrm{Gm})$, relata que os melhores resultados no tratamento, com cloreto férrico, de partículas com tamanho médio de $3 \mathrm{~mm}$, foram conseguidos com Gm entre 700 e $1000 \mathrm{~s}^{-1}$, ou acima de $3500 \mathrm{~s}^{-1}$. Quando o tamanho médio das partículas foi aumentado para $6 \mu \mathrm{m}$, os valores ótimos de $\mathrm{Gm}$ variaram entre 800 e $1000 \mathrm{~s}^{-1}$ e acima de $3000 \mathrm{~s}^{-1}$. Quanto ao uso de polímeros orgânicos, o referido autor explica que os mecanismos de coagulação resultantes da adição desses polímeros são a neutralização de cargas e a formação de pontes entre partículas (Figura 3.5). Os valores elevados de gradiente de mistura rápida não são essenciais para uma coagulação eficiente quando os polímeros são utilizados, pois diferentemente dos coagulantes inorgânicos (sais de ferro ou de alumínio, por exemplo), não ocorrem reações de adsorção dos colóides e de precipitação dos hidróxidos, reações competitivas entre si. Além disso, valores elevados de gradiente de velocidade podem provocar quebra dos flocos, diminuindo a eficiência da coagulação/floculação. Desta forma, o autor indica valores de gradiente de mistura rápida entre 400 e $650 \mathrm{~s}^{-1}$ e tempo de mistura rápida entre 30 e $60 \mathrm{~s}$. 


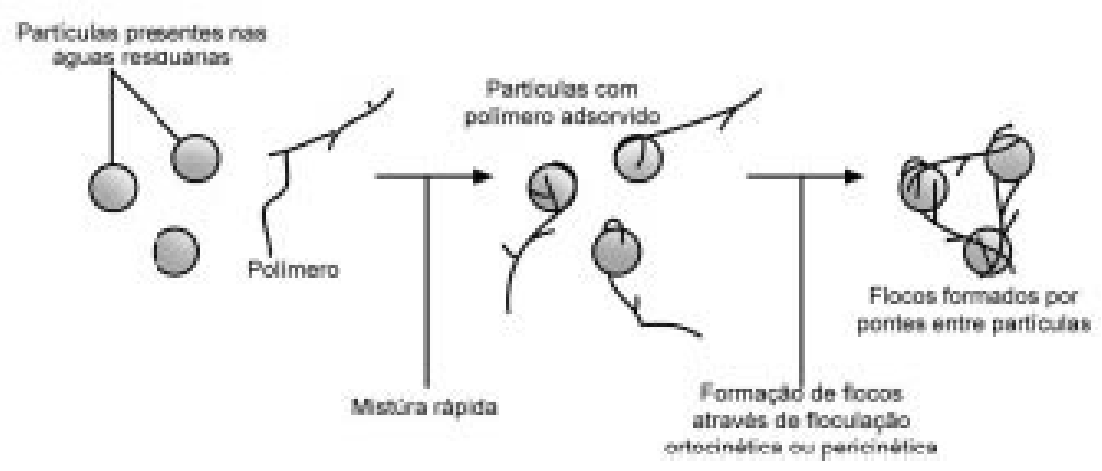

Figura 3.5. Definição esquemática da formação de pontes entre partículas com aplicação de polímeros orgânicos.

Fonte: METCALF \& EDDY (2003)

\subsection{Sedimentação}

A sedimentação ou decantação é o fenômeno físico em que as partículas em suspensão apresentam movimento descendente em meio líquido de menor massa específica, devido à ação da gravidade. (DI BERNARDO, 2005).

Os objetivos e aplicações da sedimentação é a retirada de partículas finas como areia, SST e flocos formados por coagulação química de materiais e organismos de difícil sedimentação. A sedimentação também e usada para criar um lodo mais concentrado de sólidos com possibilidade de ser manuseado e tratado mais facilmente (AZEVEDO NETTO et al., 1979; METCALF \& EDDY, 2003).

Segundo as características das partículas a serem removidas, o processo de sedimentação pode ser classificado em quatro tipos (GREGORY E ZABEL, 1990; METCALF \& EDDY, 2003):

- Tipo 1: sedimentação de partículas discretas, pouco concentradas na água, em que a floculação e a ação entre as partículas são desprezíveis;

- Tipo 2: sedimentação de partículas em baixa concentração ou floculenta, na qual as partículas continuam a se agregar à medida que o processo de sedimentação ocorre, fazendo com que a velocidade de sedimentação também aumente;

- Tipo 3: sedimentação impedida ou por zona, na qual a concentração de partículas é grande, o que favorece os efeitos de interação e a formação de uma interface bem definida entre o líquido clarificado e os sólidos que sedimentam; 
- Tipo 4: sedimentação por compressão, na qual a concentração de partículas é grande, ocorrendo à sedimentação por camadas.

Do ponto de vista do tratamento de água para o abastecimento industrial, o tipo de sedimentação que prevalece é o tipo 2 , pois a concentração de partículas que interagem à medida que sedimentam é baixa. Os sólidos formados no processo de floculação quando a água é mantida por um período de tempo suficientemente adequado (tempo de detenção hidráulico) em um dispositivo denominado sedimentador ou decantador (MIERZWA, 2005).

As partículas relativamente grandes (diâmetro acima de $10 \mathrm{~mm}$ ) precipitam-se com um movimento acelerado, e podem ser calculada através da lei de Newton). As partículas relativamente pequenas (diâmetro inferior a $0,1 \mathrm{~mm}$ ), no seu movimento de deposição, atingem um regime de equilíbrio e apresentam velocidade constante, sendo seu movimento calculado através das leis de Allen e Stokes (MACEDO FILHO e BRANCO, 1964).

As partículas extremamente pequenas, da ordem de milésimos de milímetros ou menores, são objetos do movimento browniano contínuo, não sendo sedimentáveis. No caso de remoção de material coloidal, recorre-se à precipitação química ou coagulação (AZEVEDO NETTO et al., 1979). O Quadro 3.3 apresenta algumas características de forma e sedimentação das partículas mais comumente encontradas no tratamento de água e efluentes.

\begin{tabular}{|l|c|c|c|}
\hline Tipo de partícula & Dimensão $(\mathbf{m m})$ & $\begin{array}{c}\text { Área superficial } \\
(\mathbf{m} 2)\end{array}$ & $\begin{array}{c}\text { Tempo de sedimentação } \\
\text { para o percurso de 1 metro }\end{array}$ \\
\hline Areia fina & 0,20 & - & 40 segundos \\
\hline Areia & 0,10 & - & 2 minutos \\
\hline Silte & 0,01 & 0,314 & 108 minutos \\
\hline Bactérias & 0,001 & 3,14 & 180 horas \\
\hline Material Coloidal & 0,0001 & 31,4 & 755 dias \\
\hline
\end{tabular}

Quadro 3.3 - Características de forma e sedimentação de partículas encontradas no tratamento de água e efluentes.

FONTE: Adaptado de NALCO (1988) e AZEVEDO NETTO et al. (1979).

\subsection{Flotação}

A flotação é um processo que envolve três fases: líquida, sólida e gasosa. É utilizado para separar partículas suspensas ou materiais graxos ou oleosos de uma fase líquida. A separação é produzida pela combinação de bolhas de gás, geralmente o ar, com a partícula, 
resultando num agregado, cuja densidade é menor que a do líquido e, portanto, sobe à superfície do mesmo, podendo ser coletada em uma operação de raspagem superficial (METCALF \& EDDY, 2003).

\subsubsection{Tipos de flotação}

Existe uma variedade de técnicas para introduzir as bolhas de ar necessárias para a separação sólido-líquido por flotação e, exceto a flotação gravitacional natural, onde as partículas tem peso específico menor que o líquido que as contêm, os processos de flotação podem ser classificados de acordo com o método de produção das bolhas. As técnicas mais utilizadas são a eletroflotação, autoflotação, flotação por ar disperso e flotação por ar dissolvido (FAD) (AISSE et al., 2001).

A eletroflotação é um processo utilizado para tratamento de efluentes radioativos, despejos com tintas e emulsões de pintura, no qual a obtenção das bolhas de $\mathrm{H}_{2}$ e $\mathrm{O}_{2}$ é feita por eletrólise da água.

Em suspensões de algas, pode ocorrer a autoflotação, caso elas se tornem suficientemente supersaturadas com o oxigênio dissolvido da fotossíntese.

$\mathrm{Na}$ flotação por ar disperso, a formação de bolhas de ar é feita por agitação do líquido, à pressão atmosférica, e os diâmetros das bolhas produzidas são relativamente grandes, cerca de $1.000 \mu \mathrm{m}$, quando comparados com o tamanho dos sólidos (MAIA \& BEZERRA, 1981).

$\mathrm{Na}$ flotação por ar dissolvido, as bolhas são produzidas pela supersaturação do líquido, com o ar, podendo ser efetuada a vácuo ou a pressão. Na flotação por ar dissolvido por pressurização, ou simplesmente flotação por ar dissolvido (FAD), o ar é injetado na entrada de uma câmara de saturação, enquanto o líquido se encontra sob pressão. No interior dessa câmara ocorre a dissolução de ar na massa líquida pressurizada, sendo, em seguida, o líquido exposto a condições atmosféricas. A redução brusca de pressão provoca o desprendimento do ar na forma de minúsculas bolhas, que aderem às partículas em suspensão, flutuando à superfície. A flotação por ar dissolvido (FAD) permite maior flexibilidade ao processo, porque pode utilizar uma faixa de pressão maior, possibilitando um controle mais eficiente da quantidade de ar desprendido que, aliado ao pequeno tamanho das bolhas, constitui a principal vantagem no tratamento de efluentes (AISSE et al., 2001). 


\subsubsection{Flotação por ar dissolvido}

Os sistemas de FAD são utilizados de três formas, dependendo do método de pressurização empregado:

a) Sistema de flotação com pressurização total da vazão afluente;

b) Sistema de flotação com pressurização parcial da vazão afluente;

c) Sistema de flotação por ar dissolvido com recirculação pressurizada (FAD).

A modalidade mais comumente empregada no tratamento de esgotos sanitários e de águas para abastecimento é a flotação por ar dissolvido com recirculação pressurizada. Nessa técnica ocorre a pressurização de uma parcela do afluente já clarificado, recirculando e misturando a mesma com o afluente. Esta variação é aconselhável nos casos onde estão presentes no afluente, partículas frágeis (flocos, por exemplo), as quais sejam suscetíveis de quebra de estrutura ao passarem pela bomba.

A Figura 3.6 ilustra um esquema típico de sistema FAD aplicada ao tratamento de águas residuárias precedido de coagulação química.

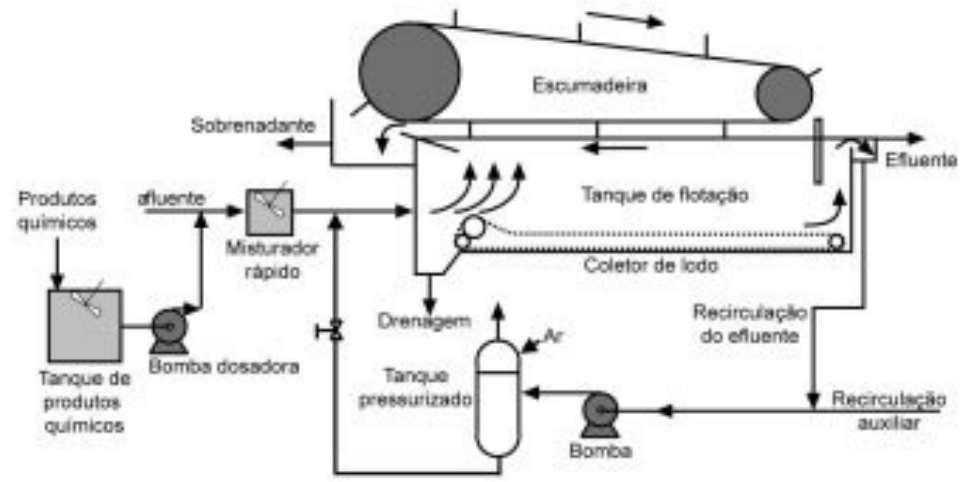

Figura 3.6 - Flotação por ar dissolvido, com recirculação pressurizada (FAD), aplicada ao tratamento físico-químico de águas residuárias

Fonte: Metcalf \& Eddy, 2003 


\subsubsection{1- Fatores que afetam a eficiência da FAD}

Dentre os principais fatores que afetam a eficiência do processo FAD, podem-se citar a pressão de saturação, a distribuição do tamanho de microbolhas de ar, tipos de bocais difusores e a quantidade de ar fornecida ao sistema.

\subsection{Pressão de saturação}

De Rijk et al. (1994) realizaram experimentos para determinar a influência de diferentes pressões de saturação na distribuição do tamanho de microbolhas de ar na FAD. Constatou-se que altas pressões produzem pequenas bolhas, sendo que para pressões acima de 5,0 atm, houve um pequeno efeito na distribuição do tamanho de microbolhas de ar na FAD.

Han, Kim T. e Kim J. (2007) realizaram ensaios com água sintética (turbidez de 20 NTU) em diferentes pressões de saturação (2,0; 3,0 e 5atm). Amostras de 20ml eram coletadas e injetadas em uma célula de PVC, na qual uma câmara digital equipada com um microscópio realizava a captura das imagens, para posterior análise computacional. As seguintes conclusões foram obtidas desse trabalho: a) quanto menor a pressão, mais amplo a distribuição do tamanho das bolhas e menor a proporção do número de bolhas; b) um aumento na pressão de saturação gera um aumento na eficiência do processo, diminuindo o tamanho das bolhas e o tamanho crítico dos flocos; c) quanto maior a concentração em volume das bolhas, maior a eficiência sobre todos os tamanhos de partículas.

\subsection{Distribuição do tamanho de microbolhas}

É importante que a "nuvem" de microbolhas de ar produzidas na entrada das unidades FAD seja uniformemente distribuída, permitindo que essas microbolhas exerçam seu papel com o máximo de eficiência. A principal função das microbolhas de ar no processo FAD é, conforme já comentado, diminuir a densidade dos conjuntos "flocos + bolhas" em relação à densidade da água e, dessa forma, quanto maior o volume de bolhas ligadas aos flocos (ou sólidos), menor a densidade relativa e maior a velocidade ascendente dos conjuntos "flocos + bolhas". Outras funções secundárias das microbolhas, quando o processo FAD é empregado para tratamento de esgotos, são o aumento do nível de oxigênio dissolvido no esgoto tratado, além do arraste de parcela dos gases odoríferos para fora do efluente final. (AISSE et al., 2001). 
A título de ilustração da importância do tamanho das microbolhas atuantes no processo FAD, na Tabela 3.2 são mostrados valores de concentração de microbolhas (Nb, em $\mathrm{n}^{\circ}$ de bolhas por $\mathrm{ml}$ de suspensão no interior da zona de reação). Para o cálculo dessas grandezas, foi utilizada a modelação do processo de flotação proposto por Reali (1991 e 1994).

Tabela 3.2 - Estimativa da concentração e da distância média entre as microbolhas de ar, presentes no início de uma unidade FAD, em função do diâmetro das microbolhas

\begin{tabular}{c|c|c}
\hline $\begin{array}{c}\text { Diâmetro das microbolhas } \\
(\mathbf{m m})\end{array}$ & $\begin{array}{c}\text { Concentração }(\mathbf{N b}): \mathbf{n}^{\circ} \text { de } \\
\text { bolhas por ml de suspensão }\end{array}$ & $\begin{array}{c}\text { Distância }(\Delta \mathbf{b}) \text { entre as } \\
\text { microbolhas }(\mathbf{m m})\end{array}$ \\
\hline 0,01 & 18.000 .000 & 0,04 \\
\hline 0,03 & 670.000 & 0,12 \\
\hline 0,05 & 150.000 & 0,20 \\
\hline 0,07 & 50.000 & 0,28 \\
\hline 0,10 & 18.000 & 0,40 \\
\hline
\end{tabular}

Notas: Sistema FAD com as seguintes características: pressão de saturação de $450 \mathrm{kPa}$; $95 \%$ de eficiência no sistema de saturação; $15 \%$ de recirculação pressurizada; temperatura do líquido igual a $20^{\circ} \mathrm{C}$.

Fonte: Cálculos efetuados com base no modelo proposto por Reali (1991)

Com relação aos dados mostrados na Tabela 3.2, pode ser visto que, para a flotação por ar dissolvido, quanto menor o tamanho médio das microbolhas de ar geradas no interior do flotador, mais eficiente será o processo, pois maior será a probabilidade de colisão entre as bolhas de ar e os flocos em suspensão e maior também a chance de se ter uma ligação mais estável entre as microbolhas e os flocos. Esse último fato é devido à velocidade ascensional, que cresce diretamente com o quadrado do diâmetro das microbolhas. Assim, bolhas maiores tenderão a se desprender mais facilmente da superfície dos flocos, após a colisão, devido às suas maiores velocidades ascensionais (REALI, 1991).

Segundo Ettelt (1964), bolhas de ar menores necessitam deslocar menos líquido da superfície dos sólidos (flocos) aos quais devam aderir, sendo, portanto, mais fácil sua aderência que a das bolhas maiores. Ademais, devido às menores velocidades ascensionais das bolhas menores, as mesmas apresentam maior tempo de permanência no interior do flotador, melhorando apreciavelmente a oportunidade de contato entre as bolhas e os flocos a serem removidos. 
A título de ilustração, pode ser destacado que, para uma bolha de ar com diâmetro igual a um décimo do diâmetro de outra bolha, equivaleria um tempo de detenção 100 vezes maior que o tempo de detenção relativo à bolha maior.

A distribuição de tamanho de microbolhas de ar geradas numa unidade FAD depende da taxa de aglutinação. Essa taxa pode ser influenciada por vários fatores como a pressão no interior da câmara de saturação, temperatura do líquido, $\mathrm{pH}$ da suspensão, tipo de bocal e concentração de agentes tenso-ativos.

Com o objetivo de determinar os tamanhos de bolhas na FAD indicaram que estas se

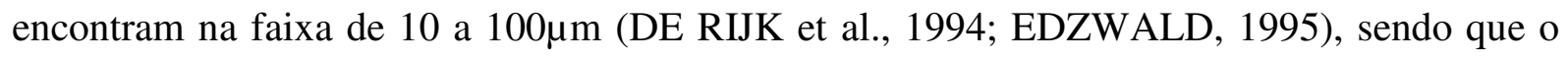

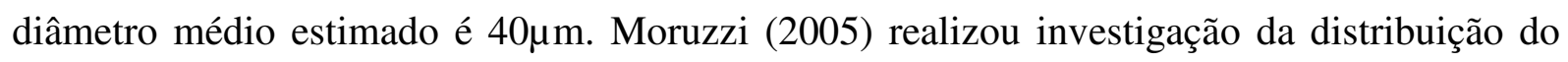
tamanho de microbolhas de ar em sistemas FAD, o aparato experimental também utilizou uma câmara digital, conjunto de lentes para ampliação e plano de laser. A distribuição do tamanho de microbolhas encontrados estava de acordo com os descritos na literatura (10 a $120 \mu \mathrm{m})$

\subsection{Tipos de bocais difusores}

Os dispositivos de despressurização, chamados de bocais difusores, são os responsáveis pela definição da distribuição de tamanhos da microbolhas de ar no flotador.

Zabel (1984) analisou a influência de dois diferentes tipos de bocais difusores (WRC e válvula agulha) no tamanho das microbolhas (Figura 3.7) e verificou que para ambos os

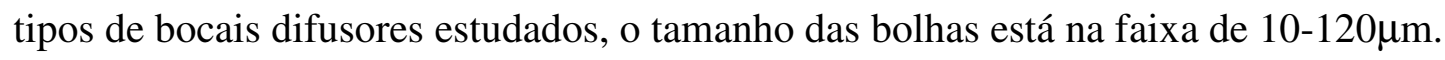

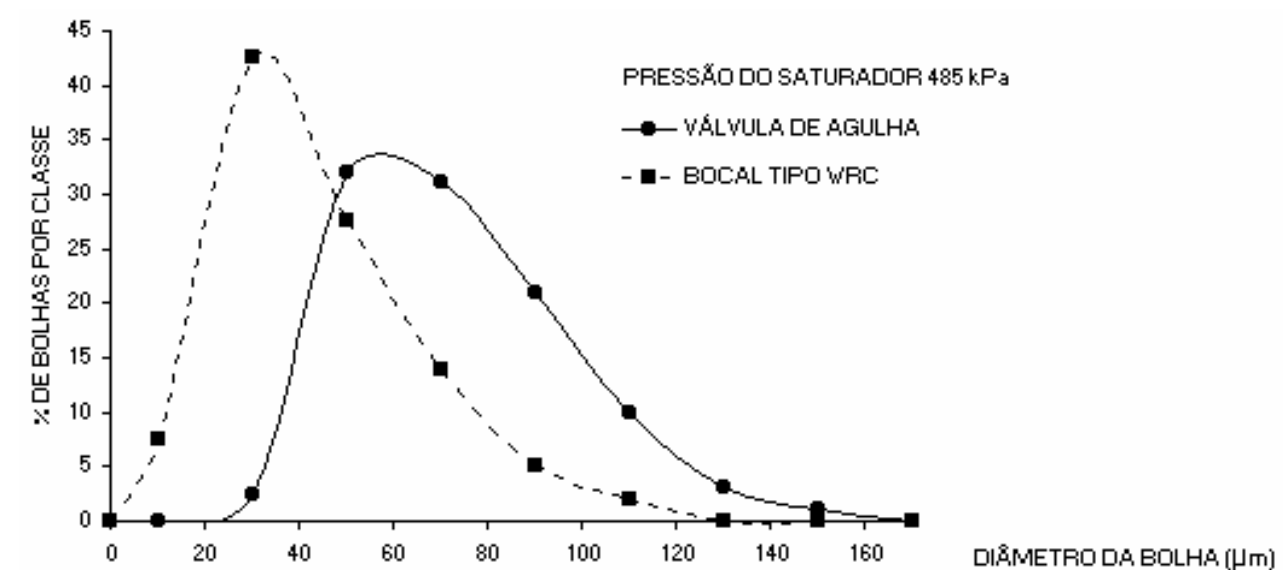

Figura 3.7 - Distribuição de tamanho de bolhas produzidas por válvula agulha e bocal tipo WRC. (Adaptado: Zabel, 1984). 
Zhang, Leppinen e Dalziel (2007) realizaram ensaios para desenvolvimento de um projeto de um bocal ideal para FAD (Figura 3.8). Após a escolha da configuração ótima do bocal (D1=1mm; L1=14mm; D2=5mm; L2=50mm) adicionou-se um envoltório externo onde D3=5xD2 para reduzir o nível de turbulência na parte final do bocal. $\mathrm{O}$ estudo concluiu que o novo bocal pode ser operado em baixas pressões, reduzindo em $30 \%$ o consumo de energia. A utilização desse bocal permite que $20 \%$ a mais de água possa ser tratada.

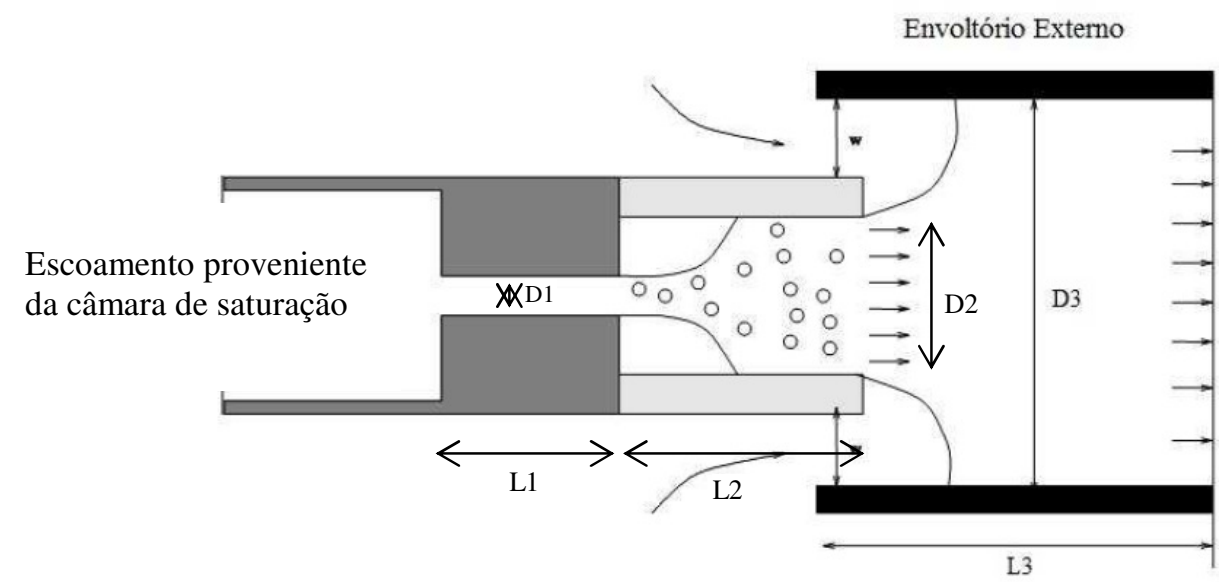

Figura 3.8 - Configuração de bocal onde D3=5 x D2 Adaptado: Zhang, Leppinen e Dalziel.

\subsection{Quantidade de ar fornecida ao processo}

A quantidade de ar fornecida à câmara de flotação pode ser variada mediante alteração da pressão na câmara de saturação, da fração de recirculação ou por ambas. Zabel (1985) realizou experimentos utilizando diferentes tipos de águas, variando a taxa de recirculação pelo uso de diferentes tamanhos de bocais e pressões de saturação. Os ensaios demonstraram que a qualidade da água depende somente da quantidade total de ar fornecido e não da recirculação e pressão de saturação analisados isoladamente. 


\subsubsection{Coagulação e floculação em sistemas de flotação por ar dissolvido}

Zabel (1984) explica que, no tratamento de água em geral, o pH de coagulação deve ser otimizado, para que se obtenha eficiente clarificação do efluente, o que pode ser feito através de adição de um ácido ou de uma base. A recomendação também é válida para os sistemas de flotação por ar dissolvido (FAD). As condições de dosagem ótima de coagulante podem ser determinadas em equipamentos de flotação, em escala de laboratório, e verificadas em escala real, uma vez que os tempos de detenção hidráulica nos sistemas de FAD são relativamente curtos (aproximadamente uma hora). Ainda mais importante do que a dosagem de coagulante, são as condições de agitação e a manutenção do valor de pH de coagulação adequado. A maioria dos sistemas de FAD são equipados com agitadores rápidos em tanques de mistura rápida. Em sistemas de grande porte, para garantia de coagulação eficiente, a mistura pode ser realizada ao longo da tubulação afluente, com aplicação do coagulante inline, por meio de dispositivos adequados.

Quanto à floculação de água bruta antecedendo a flotação, Zabel (1984) comenta que a agitação fornecida deve ser suficiente para promover a colisão das partículas primárias, visando o crescimento do floco. As unidades de floculação são constituídas, geralmente, por dois ou mais tanques de volumes iguais, associados a equipamentos de agitação lenta. $\mathrm{O}$ tempo de floculação depende das características da água bruta, mas, em geral, assume valores entre 12 a 20 min.

O referido autor comenta que, em estudo realizado, o valor otimizado de gradiente médio de velocidade de floculação foi de $70 \mathrm{~s}^{-1}$. Uma alternativa para a agitação mecânica é a agitação hidráulica, realizada na tubulação afluente ao sistema. Com isso, o tempo de floculação poderia ser reduzido para cinco minutos, mas o gradiente médio de velocidade deveria ser elevado para $150 \mathrm{~s}^{-1}$.

Edzwald (2007) verificou que para flocos com tamanhos superiores a $100 \mu \mathrm{m}$ atingirem altas velocidades de ascensão, é necessária a adesão de múltiplas bolhas em sua superfície. Para flocos com tamanhos inferiores a $100 \mu \mathrm{m}$ a adesão de uma única bolha é suficiente para o floco atingir uma alta velocidade de ascensão. $O$ autor defende que o tamanho ideal para os flocos encontra-se na faixa de 20 e $50 \mu \mathrm{m}$ (Tabela 3.3). 
Tabela 3.3 - Velocidades de ascensão do agregado floco-bolha a $20^{\circ} \mathrm{C}$ (adaptado Edzwald, 2007)

\begin{tabular}{ccc}
\hline $\begin{array}{c}\text { Diâmetro da partícula } \\
(\mu \mathrm{m})\end{array}$ & $\begin{array}{c}\text { Adesão de uma } \\
\text { bolha }\end{array}$ & $\begin{array}{c}\text { Adesão de } \\
\text { múltiplas bolhas* }\end{array}$ \\
\cline { 2 - 3 } 10 & 19.5 & $19.5(1)$ \\
30 & 19.3 & $19.3(1)$ \\
50 & 17.4 & $17.4(1)$ \\
100 & 9.9 & $9.9(1)$ \\
150 & 4.5 & $16.1(3)$ \\
200 & 0.9 & $22.5(6)$ \\
\hline *Número aderido é metade do número máximo que pode aderir e é \\
mostrado em ()
\end{tabular}




\section{MATERIAIS E MÉTODOS}

Os ensaios de coagulação-floculação-sedimentação em unidade de batelada em escala de laboratório (jar test) e de coagulação-floculação-flotação também em unidade de batelada em escala de laboratório (flotateste) foram realizados no Laboratório Avançado de Tratamento de Água e Reuso (LATAR) na EESC/USP.

\subsection{Instalações industriais}

A estação de tratamento de efluentes da empresa do ramo metal-mecânico está em operação desde 1986. A estação recebe toda a água residuária da empresa e o seu efluente é encaminhado para a rede pública de esgoto. A Figura 4.1 apresenta o layout da estação de tratamento de efluentes.

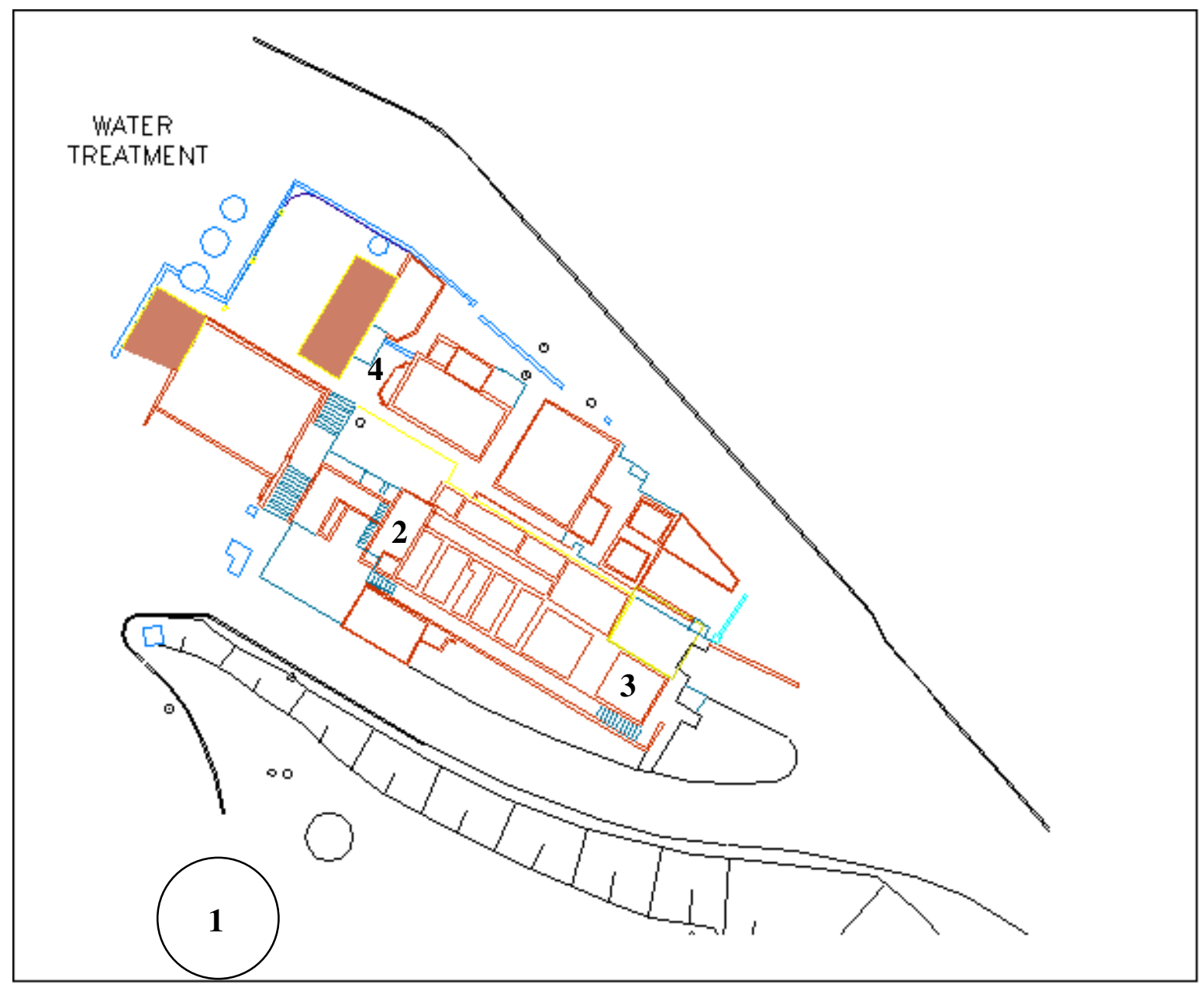

Figura 4.1 - Layout da E.T.E.

Legenda: 1- Tanque de homogeinização; 2- Flotador; 3- Decantador lamelar; 4- Osmose Reversa 
Na Figura 4.2 é apresentado um fluxograma do tratamento atual do esgoto industrial e nele são indicados as principais vazões e operações da estação. Foram indicados também os pontos de coleta de amostras para caracterização da água residuária (pontos 1, 2, 3 e 4).

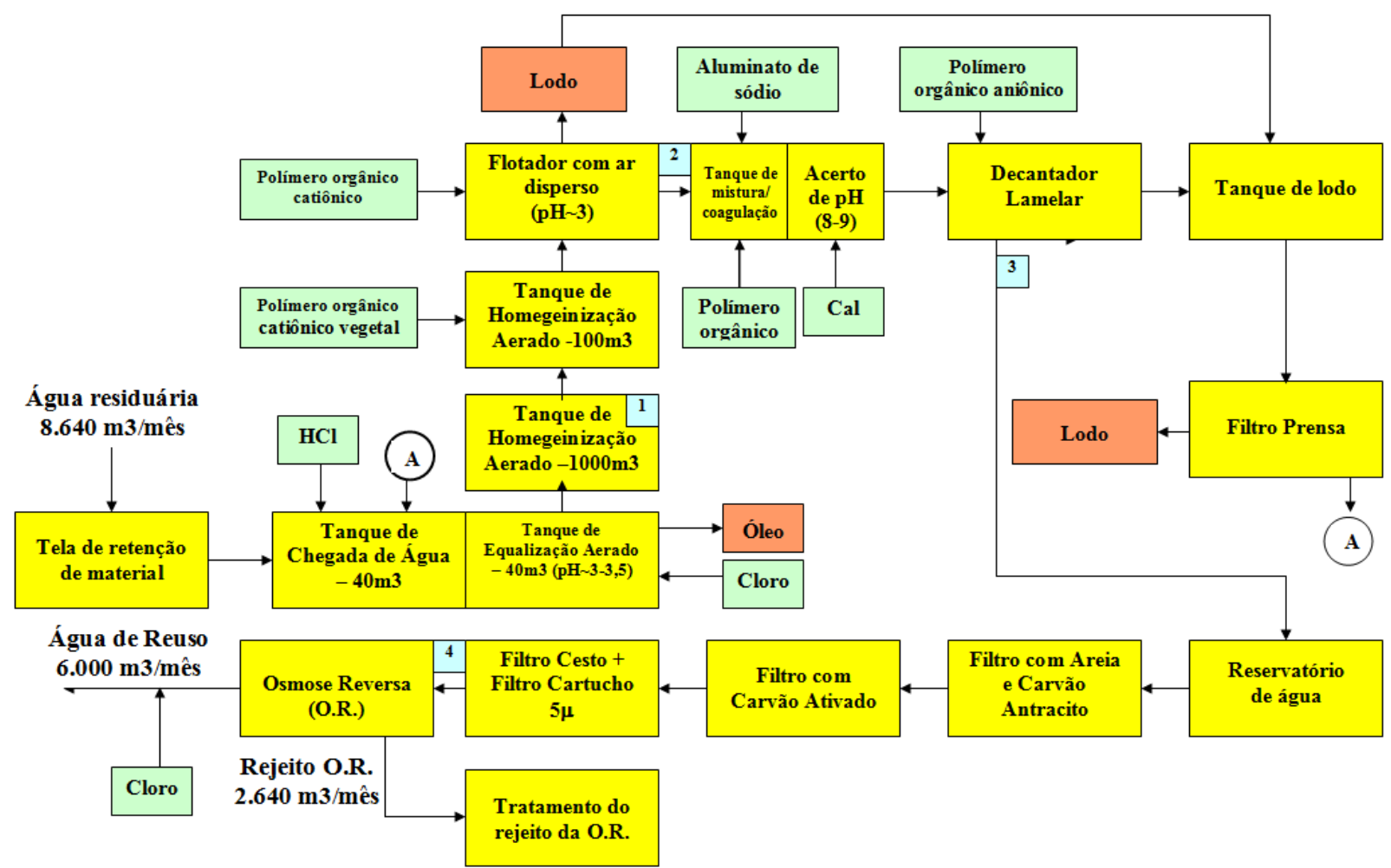

Figura 4.2 - Fluxograma de tratamento da E.T.E.

Legenda: Ponto 1- No tanque de homogeneização de 1.000 .000 litros; Ponto 2- Na saída do flotador; Ponto 3-

Na saída do decantador; Ponto 4- Na entrada do sistema de osmose reversa

Nas Figuras 4.3 e 4.4, pode-se observar o tanque de homogeinização e os tanques de coagulação, floculação e sedimentação da empresa.

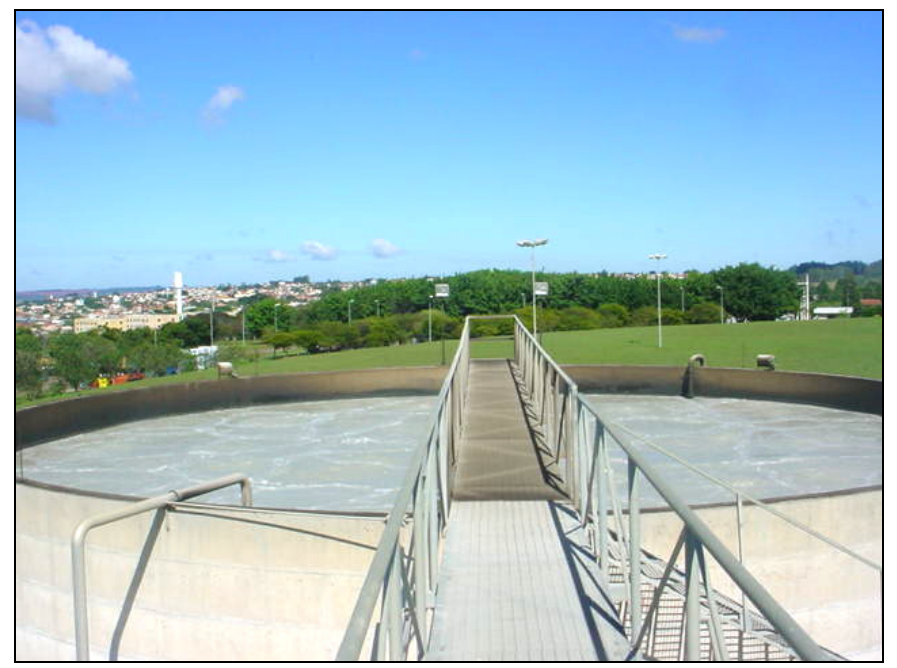

Figura 4.3 - Tanque de homogeinização aerado de $1000 \mathrm{~m}^{3}$ da E.T.E. 


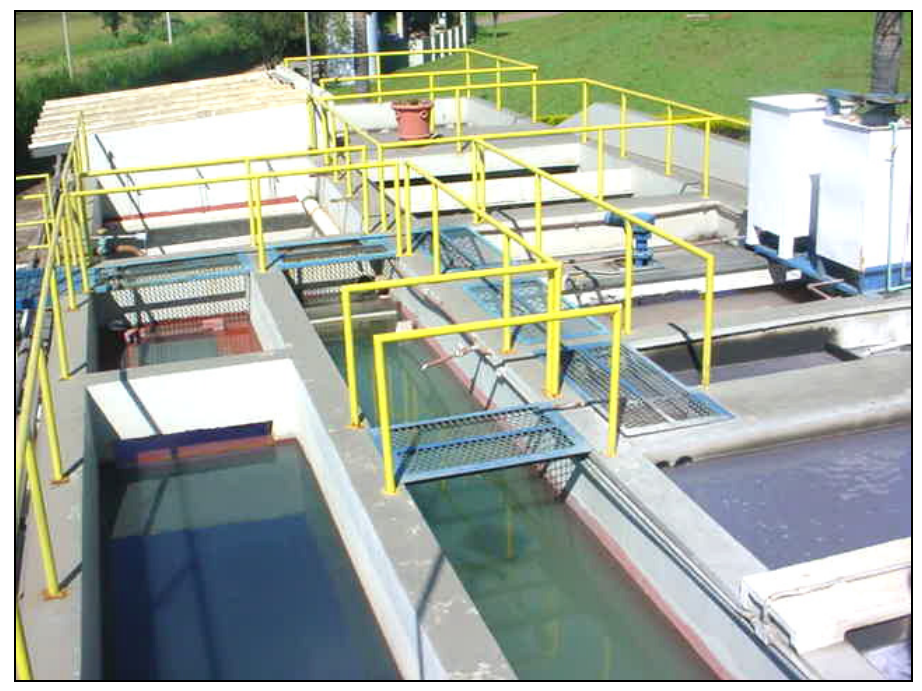

Figura 4.4 - Tanques de coagulação, floculação e sedimentação da E.T.E.

\subsection{Reatores em escala de bancada}

Além das unidades de tratamento de esgoto em que foram coletados os afluentes utilizados nesse trabalho, também foram utilizadas as instalações experimentais existentes no Laboratório de Tratamento Avançado e Reuso de Águas - LATAR/SHS/EESC/USP. Essas instalações consistiram em uma unidade para ensaios de coagulação-floculação-sedimentação (jar test) e uma unidade para ensaios de coagulação-floculação-flotação (flotateste), ambas em escala de bancada e com operação em batelada.

\subsubsection{Jar test}

O equipamento possui seis recipientes graduados onde cada um possui um volume útil aproximado de 2 litros. O equipamento jar test possui paletas giratórias com ajuste de rotação onde é possível regular os gradientes de velocidade. O equipamento possui também dispositivos para coleta simultânea de amostras. Nessa unidade foram empregadas as etapas de mistura rápida, mistura lenta (floculação) e sedimentação. Na Figura 4.5 é apresentada uma imagem do equipamento jar test utilizado nessa pesquisa para execução dos testes. 


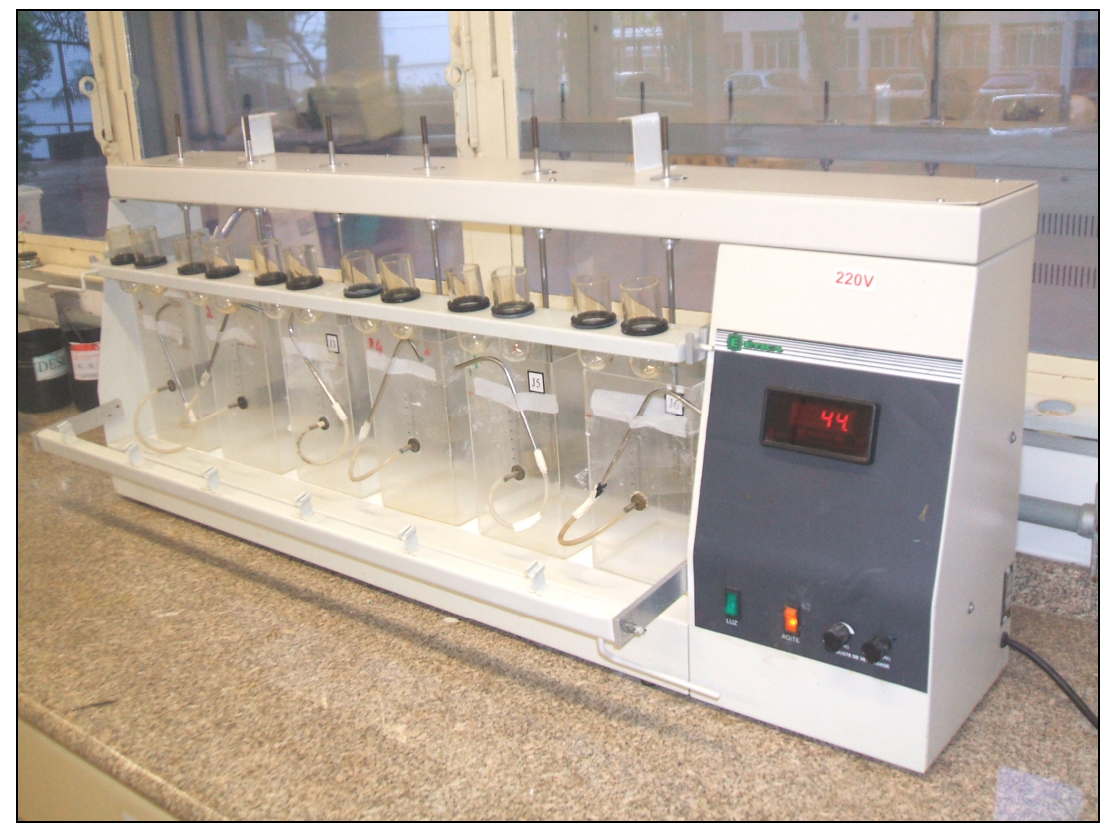

Figura 4.5 - Jar test com seis “jarros” (Ética) utilizado nos os ensaios de laboratório.

No item 4.7 está descrito o procedimento experimental para os ensaios de coagulação-floculação-sedimentação, realizados no equipamento jar test.

\subsubsection{Flotateste}

Nos ensaios de flotação por ar dissolvido foi utilizada a unidade de bancada denominada "flotateste", desenvolvida pelo Prof. Marco Antonio Penalva Reali. Na Figura 4.6 é apresentada a imagem do equipamento utilizado para execução dos testes de flotateste. 

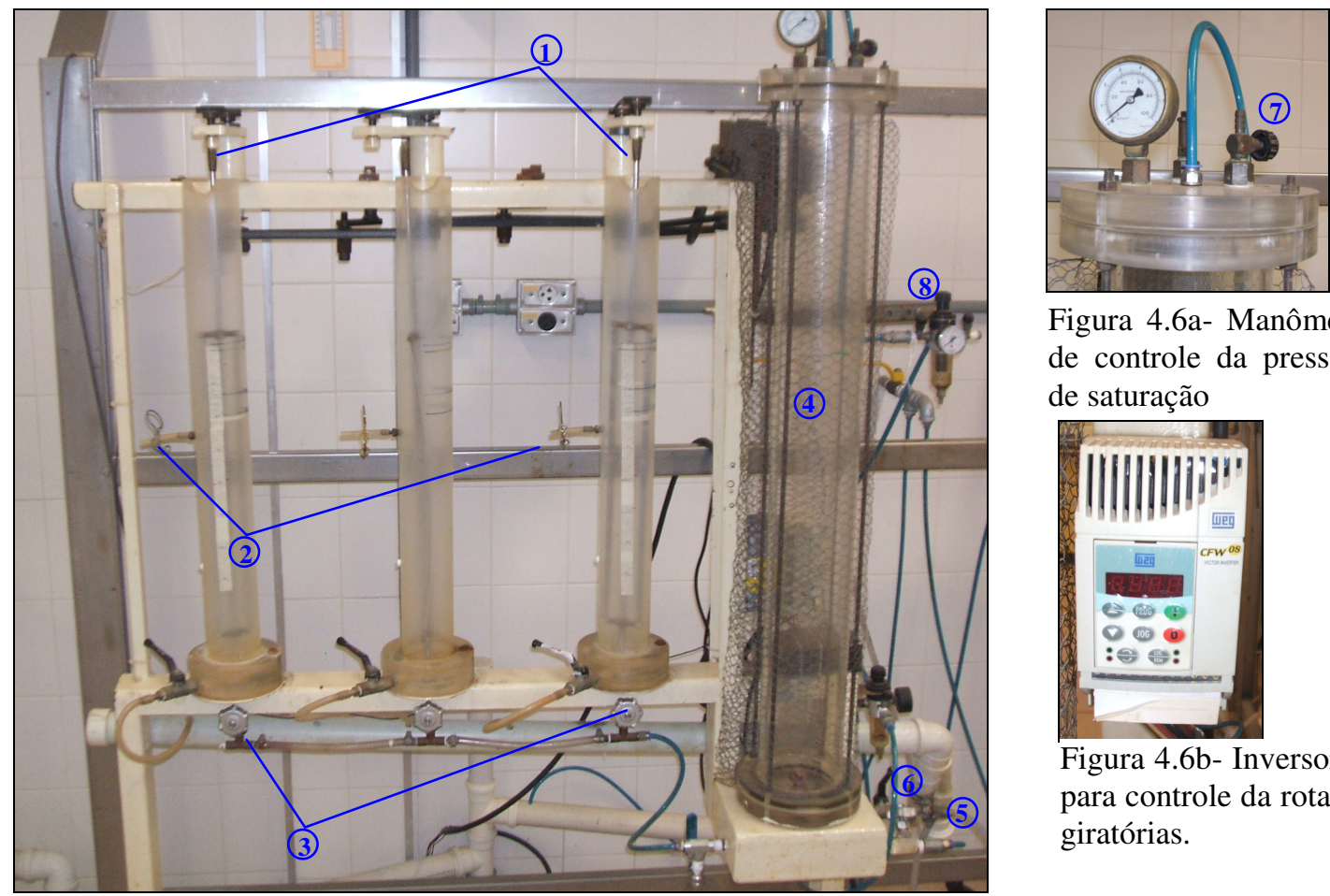

Figura 4.6a- Manômetro e válvula de controle da pressão na câmara de saturação

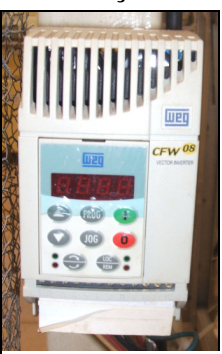

Figura 4.6b- Inversor de frequiência para controle da rotação das paletas giratórias.

Figura 4.6 - Flotateste utilizado para os ensaios em escala de laboratório.

Legenda: 1- Paletas giratórias; 2- Pontos de coleta de amostras; 3- Registros de controle para água saturada; 4Câmara de saturação; 5- Válvula para controle da injeção de ar na câmara de saturação; 6- Válvula para controle da entrada de água na câmara de saturação; 7- Válvula para controle da pressão no interior da câmara de saturação; 8- Válvula para manutenção da pressão durante coleta de amostras.

A unidade de flotateste apresenta três colunas cilíndricas independentes entre si e ligadas a uma câmara de saturação. A pressão de saturação foi controlada através da válvula e manômetro situados acima da câmara de saturação (Figura 4.6a). Cada coluna apresenta um volume útil de aproximadamente 2 litros e é equipada com agitador próprio com paletas giratórias. A regulagem dos gradientes de velocidade foi feito através do controle da rotação das paletas giratórias através de um inversor de frequiência (Figura 4.6b). No flotateste, em função da sua configuração, foram realizadas as etapas de floculação e flotação. As etapas de mistura rápida foram feitas em reator separado (jar test) e posteriormente colocadas as amostras no flotateste.

No item 4.8 está descrito o procedimento experimental para os ensaios de coagulação-floculação-flotação, realizados no equipamento flotateste.

\subsection{Outros equipamentos}

Além do jar test e flotateste, foram utilizados os seguintes equipamentos:

- Condutivímetro modelo DM-31- Digimed;

- pHmetro modelo DM-20- Digimed; 
- Turbidímetro modelo 2100P- Hach Company;

- Balança analítica modelo BP211D- Sartorius AG com precisão de 0,01mg;

- Cronômetro digital com precisão de $0,01 \mathrm{~s}$;

- Termômetro de bulbo.

\subsection{Produtos químicos utilizados}

Os coagulantes e alcalinizante utilizados nesse trabalho estão no Quadro 4.1:

\begin{tabular}{|c|c|c|c|c|}
\hline Produto & $\begin{array}{c}\text { Nome comercial } \\
\text { do produto }\end{array}$ & Fabricante & $\begin{array}{c}\text { Substância } \\
\text { principal }\end{array}$ & $\begin{array}{l}\text { Fórmula } \\
\text { química }\end{array}$ \\
\hline Coagulante 1 & Não informado ${ }^{1}$ & Não informado ${ }^{1}$ & $\begin{array}{c}\text { Aluminato de } \\
\text { sódio líquido } 40 \% \\
\left(\mathrm{Al}_{2} \mathrm{O}_{3}-25 \%\right)\end{array}$ & $\mathrm{Na}_{2} \mathrm{Al}_{2} \mathrm{O}_{4}$ \\
\hline Coagulante 2 & $\begin{array}{l}\text { Cloreto de Ferro } \\
\text { (ICO) } 6 \mathrm{H} 2 \mathrm{O} \\
\text { P.A.-A.C.S. }\end{array}$ & $\begin{array}{c}\text { Labsynth } \\
\text { Produtos para } \\
\text { Laboratório Ltda. }\end{array}$ & $\begin{array}{l}\text { Cloreto férrico } \\
\text { hexahidratado }\end{array}$ & $\mathrm{FeCl}_{3 .} 6 \mathrm{H}_{2} \mathrm{O}$ \\
\hline \multirow[b]{2}{*}{ Coagulante 3} & Procytrat $100 \mathrm{~A}$ & $\begin{array}{c}\text { Procytek } \\
\text { Indústria e } \\
\text { Comércio Ltda. }\end{array}$ & $\begin{array}{c}\text { Polímero de } \\
\text { oxicloreto de } \\
\text { alumínio }\left(\mathrm{Al}_{2} \mathrm{O}_{3^{-}}\right. \\
11 \%)\end{array}$ & $\mathrm{Al}_{\mathrm{n}}(\mathrm{OH})_{\mathrm{m}} \mathrm{Cl}_{3 \mathrm{n}-\mathrm{m}}$ \\
\hline & Procytrat 300 & $\begin{array}{c}\text { Procytek } \\
\text { Indústria e } \\
\text { Comércio Ltda. }\end{array}$ & $\begin{array}{c}\text { Policloretos de } \\
\text { alumínio } \\
\text { hidroxilados } \\
\text { cationizados } \\
\left(\mathrm{Al}_{2} \mathrm{O}_{3}-23 \%\right)\end{array}$ & $\mathrm{Al}_{\mathrm{n}}(\mathrm{OH})_{\mathrm{m}} \mathrm{Cl}_{3 \mathrm{n}-\mathrm{m}}$ \\
\hline Alcalinizante & $\begin{array}{l}\text { Hidróxido de } \\
\text { cálcio PA - } \\
\text { A.C.S. }\end{array}$ & $\begin{array}{c}\text { Labsynth } \\
\text { Produtos para } \\
\text { Laboratório Ltda. }\end{array}$ & $\begin{array}{l}\text { Hidróxido de } \\
\text { cálcio }\end{array}$ & $\mathrm{Ca}(\mathrm{OH})_{2}$ \\
\hline
\end{tabular}

Quadro 4.1 - Coagulantes e alcalinizante utilizados nos ensaios de coagulação-floculação com a água residuária da E. T.E.

\footnotetext{
${ }^{1}$ A divulgação do nome do produto e do fabricante não foram autorizados pelo fornecedor,
} por isso daqui em diante o coagulante 1 será chamado aluminato de sódio. 
As "soluções-mãe" para cada coagulante e para o alcalinizante foram preparadas na concentração de 40g/l.

O coagulante 3 é uma mistura de dois produtos comerciais (Procytrat 100A e Procytrat 300) cuja formulação é sigilosa, mas possuem como substância principal, o policloreto de alumínio (PAC). Diante das características da água residuária utilizada nesse estudo, o fornecedor dos dois produtos integrantes do coagulante 3 sugeriu que eles fossem misturados na proporção de 70\%- Procytrat 100A e 30\%- Procytrat 300. Essa mistura foi avaliada nesse estudo.

\subsection{Caracterização da água residuária industrial}

Antes da realização dos ensaios de coagulação-floculação e caracterização da água residuária, foi verificada a variabilidade das características do esgoto industrial.

Após análise preliminar da variabilidade das vazões e do levantamento dos dados dos processos industriais determinou-se o período de amostragem. As amostras foram coletadas ao longo de 24 horas em intervalos de quatro horas, durante 11 dias (03/05/10 a 08/05/10 e de 10/05/10 a 14/05/10) em 4 pontos diferentes da estação de tratamento de efluentes (Figura 4.1).

Os pontos de amostragem escolhidos foram:

- Ponto 1: No tanque de homogeinização de 1 milhão de litros;

- Ponto 2: Na saída do flotador;

- Ponto 3: Na saída do decantador;

- Ponto 4: Na entrada do sistema de osmose reversa;

O período de amostragem iniciou no dia 03 de maio de 2010 as 14:00h e terminou no dia 14 de maio de 2010 as 10:00h.

A coleta de amostras foi feita manualmente e nas amostras coletadas foram realizadas as seguintes análises: temperatura, condutividade, $\mathrm{pH}$ e turbidez.

As vazões do efluente foram medidas nos mesmos intervalos das coletas de amostras.

Após o período de amostragem foi realizada a caracterização do efluente. $\mathrm{Na}$ caracterização foram analisados os seguintes parâmetros: 
- Físicos e organolépticos: Cor aparente, turbidez, Condutividade elétrica e pH;

- $\underline{\mathrm{DBO} \text { e DQO}}$

- Químicos:

a) Compostos orgânicos: Óleos e Graxas, Surfactantes;

b) Compostos inorgânicos: Sulfatos, Fosfato total, Cloretos, Carbonatos, Bicarbonatos, Boro, Sulfetos, N (amoniacal), N (nitrito), N (nitrato), N (molecular), Metais (Manganês, Níquel, Ferro, Cobre, Cromo, Alumínio, Sódio, Potássio, Cálcio, Magnésio);

- Sólidos: ST, SF, SV, SDT (SDF+SDV), SST (SSF+SSV) e SS.

As amostras utilizadas no trabalho de caracterização foram mantidas em ambiente refrigerado até a sua análise no laboratório do departamento de Hidráulica e Saneamento da EESC-USP- São Carlos.

Tanto a coleta quanto as análises das amostras seguiram os métodos descritos no Standart Methods for the Examination Water and Wastewater (APHA/AWWA/WEF, 2005). Os resultados das análises e procedimentos utilizados estão descritos na Tabela 5.1 (p. 72).

\subsection{Ensaios de coagulação-floculação com o efluente da ETE.}

A seguir, são discriminados os parâmetros operacionais investigados e as respostas obtidas nos ensaios de coagulação- floculação-sedimentação e coagulação-floculação-flotação realizados na água residuária em estudo.

\subsubsection{Ensaios de coagulação-floculação-sedimentação com o efluente da ETE.}

Os ensaios de coagulação-floculação-sedimentação com a água residuária industrial foram realizados no equipamento jar test (Figura 4.5) e divididos em 4 etapas conforme a sequência apresentada na Tabela 4.1. 
Tabela 4.1 - Etapas de coagulação-floculação-sedimentação com efluente da ETE

\begin{tabular}{|c|c|c|c|c|c|}
\hline \multicolumn{2}{|c|}{ Etapa } & Descrição & $\begin{array}{c}\text { Parâmetros } \\
\text { variados }\end{array}$ & $\begin{array}{c}\text { Parâmetros } \\
\text { mantidos fixos }\end{array}$ & $\begin{array}{c}\text { Análises realizadas } \\
\text { (respostas) }\end{array}$ \\
\hline \multirow{3}{*}{ 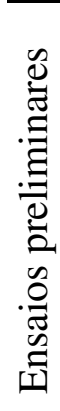 } & 1 & $\begin{array}{c}\text { Investigação do par pH-DC } \\
\text { aproximado }\end{array}$ & $\mathrm{pH}, \mathrm{DC}, \mathrm{Vs}_{\mathrm{s}}$ & Gm, Tm, Gf e Tf & $\begin{array}{c}\text { Turbidez, } \\
\text { condutividade }\end{array}$ \\
\hline & 2 & $\begin{array}{c}\text { Investigação dos parâmetros } \\
\text { de mistura rápida }\end{array}$ & Gm e Tm & $\begin{array}{c}\text { DC, pH, Gf, Tf e } \\
\text { Vs }\end{array}$ & $\begin{array}{c}\text { Turbidez, } \\
\text { condutividade }\end{array}$ \\
\hline & 3 & $\begin{array}{c}\text { Investigação dos parâmetros } \\
\text { de floculação }\end{array}$ & Gf e Tf & $\begin{array}{c}\text { DC, pH, Gf, Tf e } \\
\text { VS }\end{array}$ & $\begin{array}{c}\text { Turbidez, } \\
\text { condutividade }\end{array}$ \\
\hline & Diagramas de coagulação & $\mathrm{pH}$ e $\mathrm{DC}$ & $\begin{array}{c}\text { Gm, Tm, Gf, Tf e } \\
\text { Vs }\end{array}$ & $\begin{array}{c}\text { Turbidez, } \\
\text { condutividade }\end{array}$ \\
\hline
\end{tabular}

Legenda: Gm:gradiente de velocidade média na mistura rápida; Tm: tempo de mistura rápida; Gf: gradiente de velocidade média na floculação; Tf: tempo de floculação; Vs: velocidade de sedimentação; DC: dosagem de coagulante.

\subsubsection{Investigação do par pH-DC aproximado.}

Na primeira etapa foi obtido o par pH-DC (dosagem de coagulante) aproximado para utilização nos ensaios posteriores. Os parâmetros de mistura rápida, floculação e sedimentação (Gm, Tm, Gf, Tf) foram mantidos constantes e com seus valores arbitrados ou retirados da literatura (GUIMARÃES, 1987; MENDES, 1989; SANTOS, 2001). O melhor valor do par $\mathrm{pH}-\mathrm{DC}$ foi aquele que obteve melhor resposta na análise de turbidez e condutividade.

\subsubsection{Investigação dos parâmetros de mistura rápida.}

$\mathrm{Na}$ segunda etapa, foram investigados os parâmetros de mistura rápida (Gm e Tm) sendo que os outros parâmetros foram mantidos constantes e com seus valores arbitrados ou retirados da literatura (GUIMARÃES, 1987; MENDES, 1989; SANTOS, 2001). A determinação desses parâmetros foi feita variando-se o valor de Tm para cada valor de Gm 
estudado. Os melhores valores para os parâmetros de mistura rápida foram aqueles que obtiverem as melhores respostas nas análises de turbidez e condutividade.

\subsubsection{Investigação dos parâmetros de floculação}

Na terceira etapa, já com os valores dos parâmetros de mistura rápida (Gm e Tm), definidos, foram investigados os parâmetros de floculação (Gf e Tf) sendo que os outros parâmetros foram mantidos constantes e com seus valores arbitrados ou retirados da literatura (GUIMARÃES, 1987; MENDES, 1989; SANTOS, 2001). Nessa etapa, em cada ensaio, foi variado o valor de Tf para cada valor de Gf estudado. Os melhores valores para os parâmetros de floculação foram aqueles que obtiverem as melhores respostas nas análises de turbidez e condutividade.

\subsubsection{Diagramas de coagulação-floculação-sedimentação}

Na quarta etapa, para a construção do diagrama de coagulação, foram utilizados os melhores valores dos parâmetros de mistura rápida e floculação (Gm, Tm, Gf, Tf) obtidos na segunda e terceira etapa e foram variados o $\mathrm{pH}$ (com a dosagem de hidróxido de cálcio) e a dosagem de coagulante (DC). A velocidade de sedimentação (Vs) também foi mantida constante. O procedimento para elaboração dos diagramas foi adaptado dos trabalhos de AMIRTHARAJAH e MILLS (1982), JOHNSON e AMIRTHARAJAH (1983) e GUIMARÃES e MENDES (1989). Conforme o trabalho de SANTOS (2006), os diagramas foram obtidos através da interpolação linear dos resultados das análises de turbidez remanescente utilizando o método geoestatístico "Kriging", através do programa computacional Surfer®.

\subsubsection{Ensaios de coagulação-floculação-flotação com o efluente da ETE.}

Os ensaios de coagulação-floculação-flotação com a água residuária industrial foram realizados nos equipamentos de jar test e flotateste (Figuras 4.5 e 4.6) e divididos em 4 etapas conforme a sequência apresentada na Tabela 4.2. 
Tabela 4.2 - Etapas de coagulação-floculação-flotação com efluente da ETE

\begin{tabular}{|c|c|c|c|c|c|}
\hline \multicolumn{2}{|c|}{ Etapa } & Descrição & $\begin{array}{c}\text { Parâmetros } \\
\text { variados }\end{array}$ & $\begin{array}{c}\text { Parâmetros } \\
\text { mantidos fixos }\end{array}$ & $\begin{array}{c}\text { Análises realizadas } \\
\text { (respostas) }\end{array}$ \\
\hline \multirow{3}{*}{ 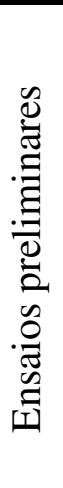 } & 1 & $\begin{array}{c}\text { Investigação do par pH- } \\
\text { DC aproximado }\end{array}$ & $\mathrm{pH}, \mathrm{DC}, \mathrm{Vf}$ & $\begin{array}{c}\text { Gm, Tm, Gf , Tf, } \\
\text { R, Psat e Tsat }\end{array}$ & $\begin{array}{c}\text { Turbidez, } \\
\text { condutividade }\end{array}$ \\
\hline & 2 & $\begin{array}{l}\text { Investigação dos } \\
\text { parâmetros de floculação }\end{array}$ & Gf, Tf e Vf & $\begin{array}{c}\text { DC, pH, Gm, Tm, } \\
\text { R, Psat e Tsat }\end{array}$ & $\begin{array}{c}\text { Turbidez, } \\
\text { condutividade }\end{array}$ \\
\hline & 3 & $\begin{array}{l}\text { Investigação da } \\
\text { quantidade de ar } \\
\text { fornecida }\end{array}$ & $\mathrm{Re} V f$ & $\begin{array}{l}\text { DC, pH, Gm, Tm, } \\
\text { Gf, Tf, Psat e Tsat }\end{array}$ & $\begin{array}{l}\text { Turbidez, } \\
\text { condutividade }\end{array}$ \\
\hline & & Diagramas de coagulação & $\mathrm{pH}, \mathrm{DC}, \mathrm{Vf}$ & $\begin{array}{c}\text { Gm, Tm, Gf, Tf, R, } \\
\text { Psat e Tsat }\end{array}$ & $\begin{array}{c}\text { Turbidez, } \\
\text { condutividade }\end{array}$ \\
\hline
\end{tabular}

Legenda: Gm:gradiente de velocidade média na mistura rápida; Tm: tempo de mistura rápida; Gf: gradiente de velocidade média na floculação; Tf: tempo de floculação; DC: dosagem de coagulante; Vf: velocidade de flotação; R: razão de circulação; Psat: pressão de saturação; Tsat: tempo de saturação.

\subsubsection{Investigação do par pH-DC aproximado.}

Na primeira etapa foi obtido o par pH-DC (dosagem de coagulante) aproximado para utilização nos ensaios posteriores. Os parâmetros de mistura rápida, floculação e flotação (Gm, Tm, Gf, Tf, R, Psat e Tsat) foram mantidos constantes e com seus valores arbitrados ou retirados da literatura. Foram utilizadas nessa etapa duas velocidades de flotação (Vf). O melhor valor do par $\mathrm{pH}-\mathrm{DC}$ foi aquele que obteve melhor resposta na análise de turbidez e condutividade.

\subsubsection{Investigação dos parâmetros de floculação}

$\mathrm{Na}$ segunda etapa, como a mistura rápida foi feita em separado e no mesmo equipamento de jar test utilizado no item 4.6.1.2, foram mantidos para os ensaios de flotação os mesmos valores dos parâmetros de mistura rápida obtidos no item 4.6.1.2. 
Foram obtidos nessa etapa os parâmetros de floculação (Gf, Tf ), sendo que os outros parâmetros foram mantidos constantes e com seus valores arbitrados ou retirados da literatura. Os melhores valores para os parâmetros de floculação e quantidade de ar fornecida foram aqueles que obtiverem as melhores respostas nas análises de turbidez e condutividade.

\subsubsection{Investigação da quantidade de ar fornecida}

Com os valores mais adequados dos parâmetros de floculação, foi obtida na terceira etapa, a quantidade de ar fornecida ou taxa de recirculação (R). Devido a dificuldade na recirculação do próprio efluente produzido no flotador, foi utilizada água da rede de abastecimento. Os resultados obtidos de turbidez e condutividade foram corrigidos devido a diluição das amostras.

\subsubsection{Diagramas de coagulação-floculação-flotação}

Na quarta etapa, para a construção do diagrama de coagulação, foram utilizados os melhores valores dos parâmetros de mistura rápida, floculação e taxa de recirculação $(\mathrm{Gm}$, Tm, Gf, Tf e R) obtidos nas etapas anteriores e foram variados o $\mathrm{pH}$ (com a dosagem de hidróxido de cálcio), a dosagem de coagulante (DC) e a velocidade de flotação (Vf). O procedimento para elaboração dos diagramas foi o mesmo utilizado no item 4.6.1.4.

\subsection{Procedimentos para realização dos ensaios de coagulação-floculação-sedimentação em unidade de jar test}

O procedimento experimental para os ensaios de coagulação-floculaçãosedimentação, realizados em equipamento jar test, foi baseado em GUIMARÃES (1987), MENDES (1989) e DI BERNARDO (2005), conforme descrito a seguir: 
a) homogeneizava-se a "amostra bruta" e colocavam-se porções da mesma nos reatores (jarros) do jar test, enchendo-os simultaneamente, para assegurar a homogeneidade das amostras em todos os jarros, até a obtenção de 2 litros por jarro;

b) colocavam-se os volumes de solução-mãe do coagulante em estudo (40g/L), correspondentes às dosagens de produtos químicos, nos recipientes apropriados do jar test (cubetas frontal);

c) acionava-se o equipamento de agitação ajustando a rotação para cerca de $40 \mathrm{rpm}$ (agitação lenta) e determinam-se, diretamente das amostras nos jarros, os valores de temperatura, $\mathrm{pH}$ e condutividade da amostra bruta;

Obs. A temperatura não foi controlada (ie. as amostras não forma aquecidas ou resfriadas) no decorrer dos ensaios de coagulação-floculação, entretanto, em todos os ensaios apresentou apenas pequena variação $\left( \pm 1^{\circ} \mathrm{C}\right)$.

d) nos ensaios em que foi variado o pH, ajustava-se a rotação para cerca de $100 \mathrm{rpm}$ e adicionavam-se os volumes de hidróxido de cálcio (40g/l) pré-estabelecidos. Não foram utilizadas soluções ácidas, pois a amostra bruta já estava ácida com $\mathrm{pH}$ menor que 3,6 .

e) a seguir, ajustava-se a rotação no jar test para o valor correspondente ao gradiente de velocidade médio na mistura rápida $(\mathrm{Gm})$, adicionava-se a cada jarro o volume preestabelecido de coagulante contido nas cubetas de suporte frontal e disparava-se o cronômetro;

f) depois de decorrido o tempo de mistura rápida $(\mathrm{Tm})$, reduzia-se a rotação do equipamento para o valor correspondente ao gradiente de velocidade médio na floculação (Gf);

g) durante a floculação eram feitas leituras de $\mathrm{pH}$ e condutividade nas amostras contidas em cada um dos jarros;

h) Após o tempo de floculação (Tf), desligava-se o equipamento ou, se o tempo de floculação variasse de um jarro para outro, suspendia-se a paleta do jarro cujo tempo de floculação fosse atingido;

i) Coletavam-se as amostras decantadas após tempo conveniente, de acordo com a(s) velocidade(s) de sedimentação desejada(s); 
Obs. Como o ponto de coleta de amostra no jar test utilizado situava-se $7,5 \mathrm{~cm}$ abaixo da superfície do líquido, quando a velocidade de sedimentação (Vs) desejada era, por exemplo, de 1,0 cm/min., o tempo de sedimentação (Ts) era de 7,5 min. após o desligamento do agitador. Contudo, como a coleta da amostra do efluente final (aproximadamente $50 \mathrm{~mL}$ ) durava cerca de 20 s, a coleta iniciava-se 10 s antes e prolongava-se 10 s além do valor de Ts. Além disso, cerca de 2s antes do início da coleta do efluente final, descartava-se um pequeno volume do mesmo, para que amostra coletada não sofresse influência do esgoto acumulado na mangueira de coleta.

j) após a coleta das amostras, eram feitas determinações de turbidez e condutividade.

\subsection{Procedimentos para ensaios de coagulação-floculação-flotação em unidade de flotateste}

Os ensaios de coagulação-floculação-flotação, com utilização do flotateste, foram adaptados dos procedimentos descritos por Reali (1991), Penetra (1998), Di Bernardo (2005), conforme discriminado a seguir:

\section{Etapa 1: saturação da água}

a) enchia-se a câmara de saturação com água de abastecimento até cerca de 6 litros;

b) abria-se o registro para entrada de ar comprimido (item 5 da Figura 4.6) pela parte inferior da câmara de saturação e regulava-se o registro de controle de saída (item 7 da Figura 4.6) de ar para que a pressão no interior da câmara permanecesse em $500 \mathrm{kPa}$ durante o período de saturação;

c) saturava-se a água nas condições descritas por 10 minutos;

d) fechava-se simultaneamente o registro de controle de saída e de injeção de ar da câmara de saturação (itens 5 e 7 da Figura 4.6) e abria-se a válvula reguladora de pressão (item 8 da Figura 4.6), a qual tinha a função de manter a pressão em $500 \pm 10$ kPa no interior da câmara durante a injeção de água saturada nas colunas de flotação; após isso, iniciava-se o ensaio de flotação.

\section{Etapa 2: ensaio de flotação}

Obs. conforme descrito anteriormente, a mistura rápida era feita no equipamento jar test, após o que as amostras "coaguladas” eram despejadas nas colunas de flotação do flotateste. 
e) homogeneizava-se a "amostra bruta" e colocavam-se porções da mesma nos reatores (jarros) do jar test, enchendo-os simultaneamente, para assegurar a homogeneidade das amostras nos jarros (eram usados 2 jarros), até a obtenção de 2 litros por jarro;

f) colocavam-se os volumes de solução-mãe do coagulante em estudo (40g/L) correspondentes às dosagens de produtos químicos, nos recipientes apropriados do jar test (cubetas de suporte frontal);

g) acionava-se o equipamento de agitação ajustando a rotação para cerca de $40 \mathrm{rpm}$ (agitação lenta) e determinavam-se, diretamente das amostras nos jarros, os valores de temperatura, $\mathrm{pH}$ e condutividade da amostra bruta;

Obs. A temperatura não foi controlada (ie., as amostras não foram aquecidas ou resfriadas) no decorrer dos ensaios de coagulação-floculação, entretanto, em todos os ensaios apresentou apenas pequena variação $\left( \pm 1^{\circ} \mathrm{C}\right)$.

h) nos ensaios em que foi variado o pH, ajustava-se a rotação para cerca de $100 \mathrm{rpm}$ e adicionavam-se os volumes de hidróxido de cálcio $(40 \mathrm{~g} / \mathrm{l})$ à dosagem préestabelecida;

i) a seguir, ajustava-se a rotação no jar test para o valor correspondente ao gradiente de velocidade médio na mistura rápida $(\mathrm{Gm})$, adicionava-se a cada jarro o volume preestabelecido de coagulante contido nas cubetas de suporte frontal e disparava-se o cronômetro;

j) decorrido o tempo de mistura rápida, desligava-se a agitação do jar test e despejava-se cada amostra "coagulada" nas colunas de flotação e a seguir a agitação era acionada através do inversor de frequiência (Figura 4.6b), sendo que a rotação das paletas para a etapa de floculação já havia sido previamente ajustada para o gradiente de velocidade desejado. Com o restante de solução "coagulada" que ficava no jarro do jar test, foram coletadas amostras para determinação do $\mathrm{pH}$;

Obs. A amostra "coagulada" era despejada até se atingir um nível inicial $\left(\mathrm{n}_{1}\right)$, previamente marcado na coluna do flotateste. Esse nível dependia de qual o volume necessário para injeção de água saturada, ou seja, da razão de recirculação (R) empregada no ensaio, que determinava o nível final após injeção de água saturada $\left(\mathrm{n}_{2}\right)$.

k) após concluída a floculação, desligavam-se os agitadores, retiravam-se as paletas de agitação e abriam-se, cautelosamente, os registros de agulha (item 3 da Figura 4.6) que 
permitiam a entrada de água saturada em cada coluna de flotação, até se atingir o nível final $\left(\mathrm{n}_{2}\right)$, quando se começava a marcar o tempo de flotação;

1) depois de atingidos os tempos de flotação desejados (equivalentes ás velocidades de flotação previamente estabelecidas), coletavam-se amostras de cerca de $50 \mathrm{~mL}$;

Obs. Como o ponto de coleta da amostra no flotateste utilizado situava-se $35 \mathrm{~cm}$ acima do ponto de liberação da água saturada, quando a velocidade de flotação (Vf) desejada era, por exemplo, de $10 \mathrm{~cm} / \mathrm{min}$. o tempo de flotação (Tflot) era de 3,5 min. Contudo, como a coleta da amostra do efluente final (aproximadamente $50 \mathrm{~mL}$ ) durava cerca de 20s, a coleta iniciava-se 10s antes e prolongava-se 10s além do valor de Tflot. Além disso, cerca de 2 s antes do início da coleta do efluente final, descartava-se um pequeno volume do mesmo, para que a amostra coletada não sofresse influência do esgoto acumulado na mangueira de coleta.

m) após a coleta, eram feitas determinações de turbidez e condutividade. 


\section{RESULTADOS E DISCUSSÕES}

\subsection{Monitoramento dos parâmetros da E.T.E.}

Nas Figuras 5.1, 5.2, 5.3 e 5.4 podem ser observados os resultados das análises de condutividade, turbidez, $\mathrm{pH}$ e temperatura das amostras coletadas ao longo de 24 horas em intervalos de quatro horas, durante 11 dias (03/05/10 a 08/05/10 e de 10/05/10 a 14/05/10) em 4 pontos diferentes da estação de tratamento de efluentes (Figura 4.2):

- Ponto 1: No tanque de homogeinização de 1 milhão de litros;

- Ponto 2: Na saída do flotador;

- Ponto 3: Na saída do decantador;

- Ponto 4: Na entrada do sistema de osmose reversa;

Os dados coletados podem ser observados no Apêndice A.

Verifica-se nas Figuras 5.1, 5.2, 5.3 que os parâmetros analisados nas amostras coletadas no local escolhido (tanque de homogeinização) são praticamente estáveis. Na Figura 5.4 verifica-se a queda na temperatura (em torno de $4^{\circ} \mathrm{C}$ ) em todas as amostras entre os dias 08/05/10 e 10/05/10 provavelmente devido a queda da temperatura ambiente devido a estação do ano em que foi feito o monitoramento (outono).

Nas Figuras 5.1 e 5.2, são apresentados os valores de condutividade e turbidez em quatro pontos da E.T.E.. Observa-se nessas figuras que os valores de condutividade e turbidez da água residuária nos quatro pontos de coleta apresentam os maiores valores e uma instabilidade as Segundas-feiras (03/05/10 e 10/05/10). A instabilidade do efluente no início das semanas possivelmente ocorre em consequência do descarte de banhos ácidos e alcalinos na indústria nos finais de semana, período onde ocorre a parada da produção e que a indústria utiliza para manutenções e limpeza nos banhos de tratamento de superfície. Observa-se também nessas Figuras que a partir das Quartas-feiras o efluente já apresenta uma estabilidade maior. Devido a essa instabilidade dos parametros de análise no início das semanas, optou-se nesse estudo pela coleta de amostras as Sextas-feiras.

Na Figura 5.5, observa-se a pequena variabilidade da vazão durante o período de monitoramento. 

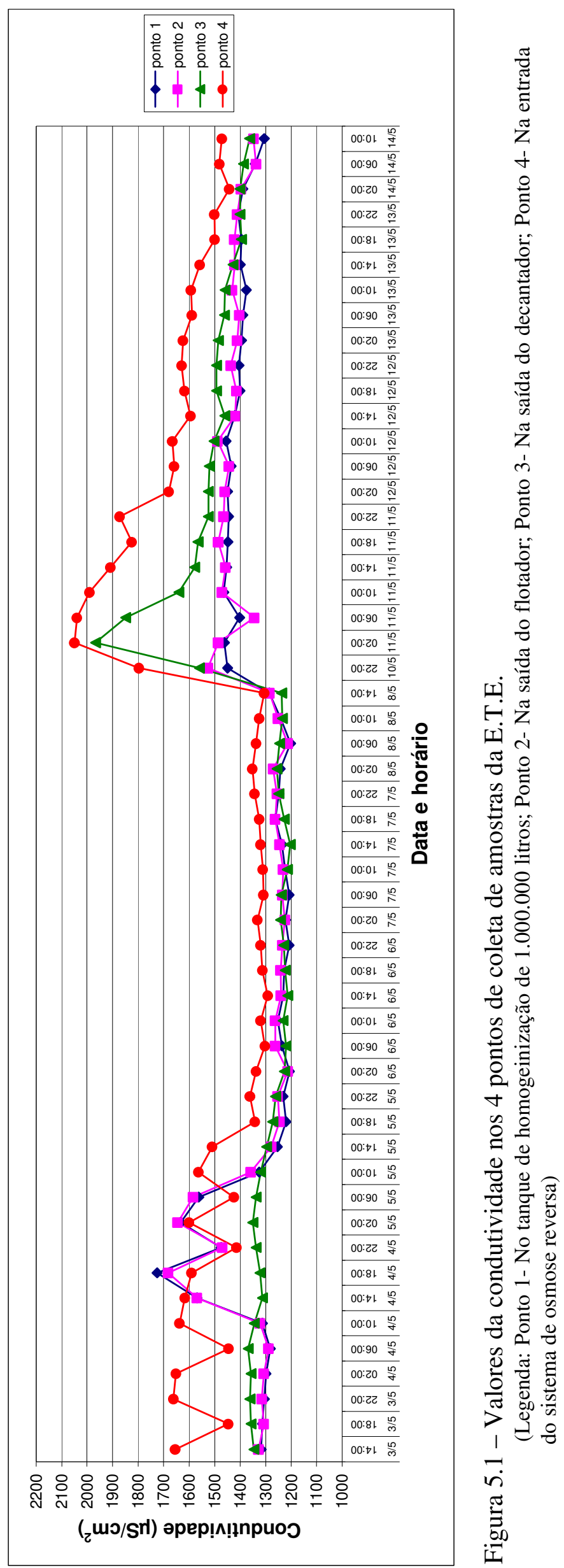


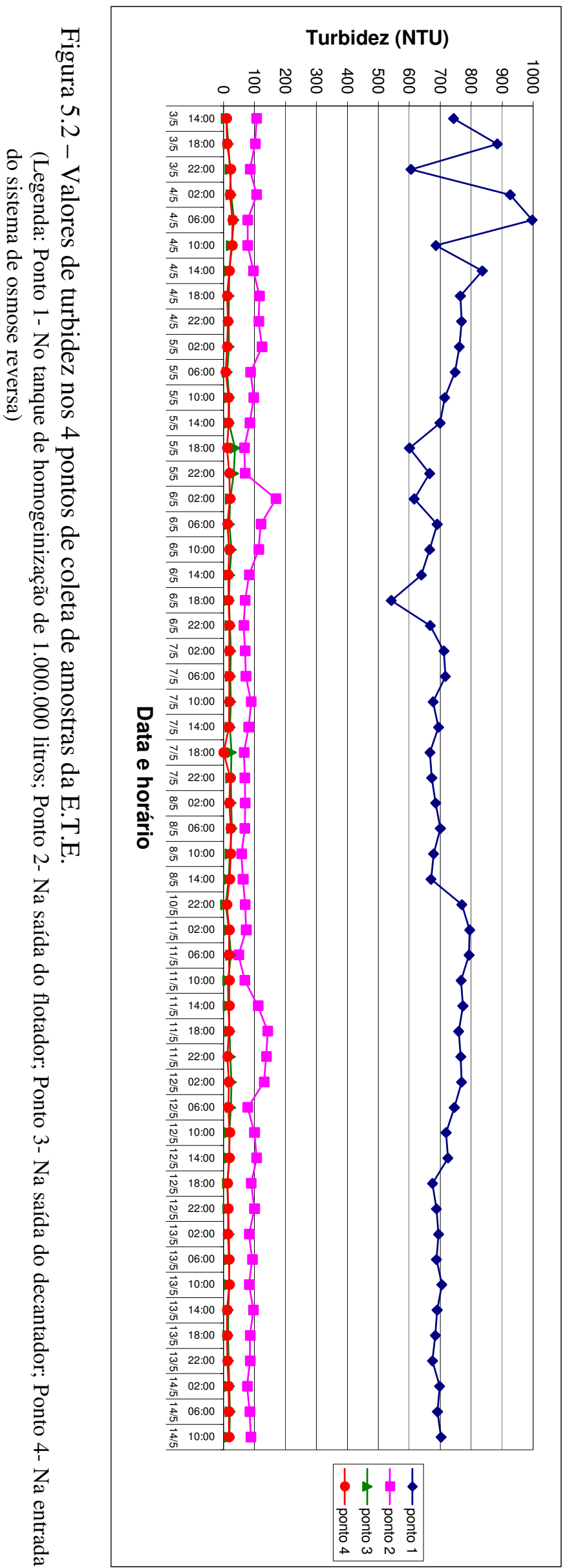



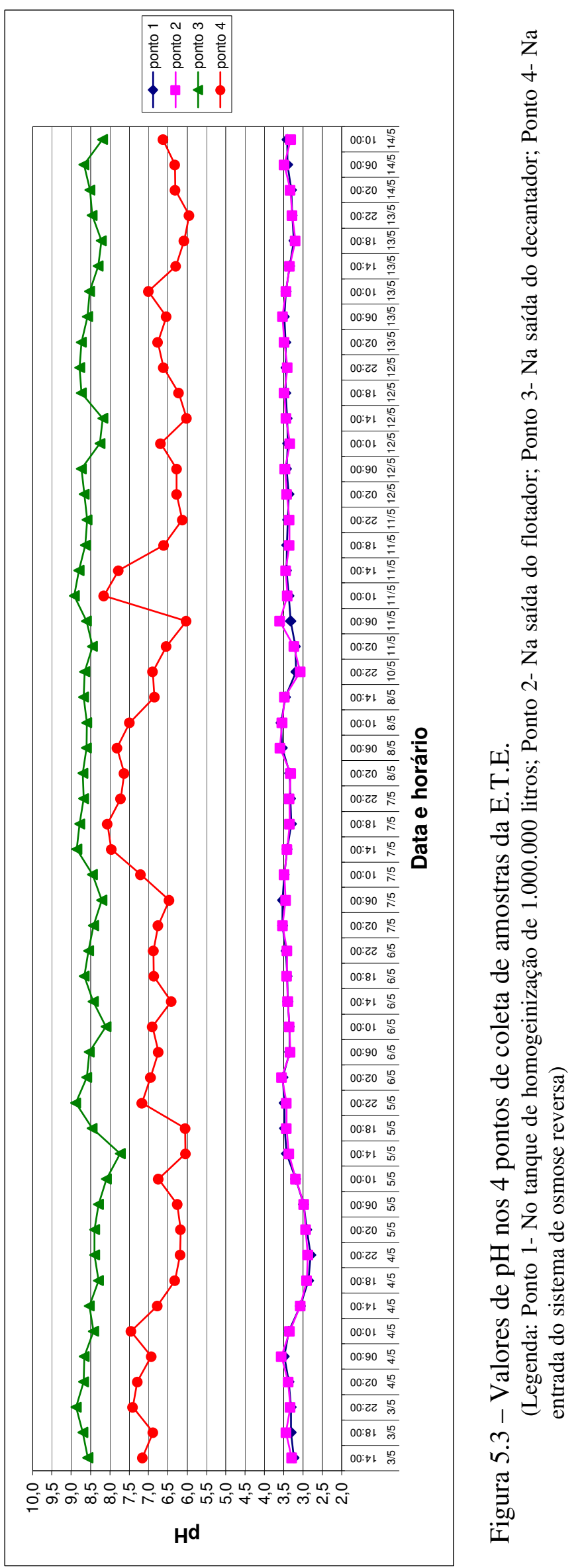


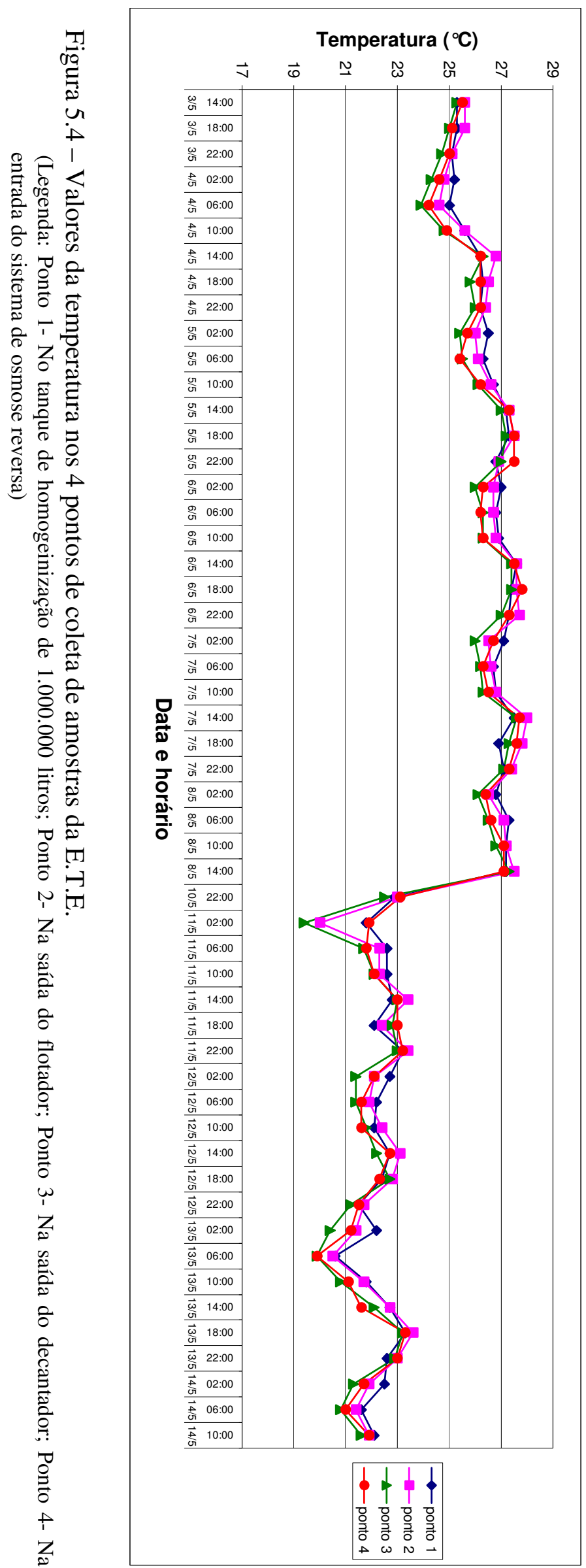




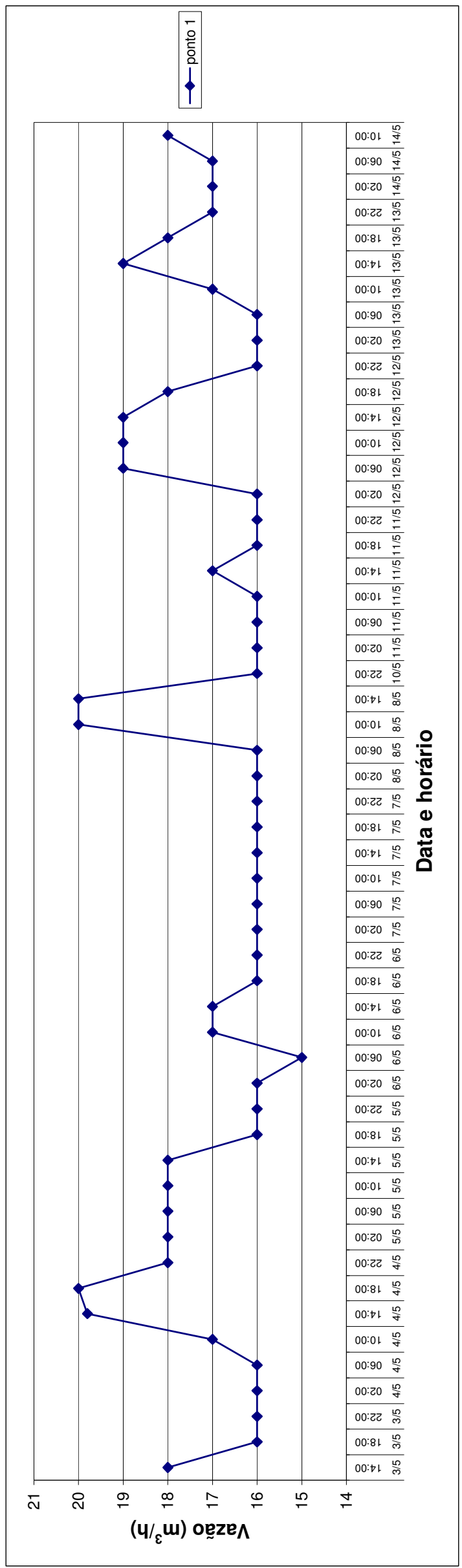

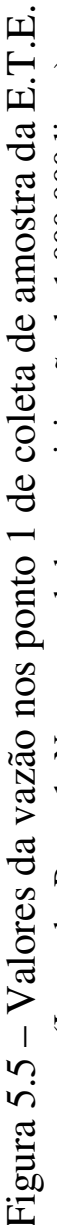


Após o período de monitoramento foi realizada a caracterização da água residuária bruta. Segue na Tabela 5.1 os resultados da caracterização:

Tabela 5.1 - Caracterização da água residuária bruta. Amostra coletada no tanque de homogeinização de $1000 \mathrm{~m}^{3}$.

\begin{tabular}{|c|c|c|c|c|c|}
\hline PARÂMETRO & RESULTADO & $\begin{array}{c}\text { UNIDADE } \\
\text { DE MEDIDA }\end{array}$ & $\begin{array}{l}\text { LIMITE DE } \\
\text { DETECÇÃO }\end{array}$ & $\begin{array}{l}\text { MÉTODO DE } \\
\text { REFERÊNCIA }\end{array}$ & $\begin{array}{c}\text { DATA DO } \\
\text { ENSAIO }\end{array}$ \\
\hline Alumínio & 3,34 & $\mathrm{mg} \mathrm{L}^{-1}$ & 0,01 & SM $3111 \mathrm{D}$ & $16 / 06 / 2010$ \\
\hline Arsênio & $<\mathrm{LD}$ & $\mathrm{mg} \mathrm{L}^{-1}$ & 0,0001 & SM 3114 B & $16 / 06 / 2010$ \\
\hline Bário & $<\mathrm{LD}$ & $\mathrm{mg} \mathrm{L}^{-1}$ & 0,05 & SM $3111 \mathrm{D}$ & $16 / 06 / 2010$ \\
\hline Bicarbonato & Zero & $\mathrm{mg} \mathrm{L}^{-1}$ & 1,0 & SM $2320 \mathrm{~B}$ & $11 / 06 / 2010$ \\
\hline Boro & 10,4 & $\mathrm{mg} \mathrm{L}^{-1}$ & 0,1 & SM 4500-B C & $16 / 06 / 2010$ \\
\hline Cádmio & 0,004 & $\mathrm{mg} \mathrm{L}^{-1}$ & 0,0006 & SM 3111 B & $16 / 06 / 2010$ \\
\hline Cálcio & 308,5 & $\mathrm{mg} \mathrm{L}^{-1}$ & 0,001 & SM $3111 \mathrm{D}$ & $16 / 06 / 2010$ \\
\hline Carbonato & Zero & $\mathrm{mg} \mathrm{L}^{-1}$ & 1,0 & SM $2320 \mathrm{~B}$ & $11 / 06 / 2010$ \\
\hline Chumbo & 0,01 & $\mathrm{mg} \mathrm{L}^{-1}$ & 0,01 & SM 3111 B & $16 / 06 / 2010$ \\
\hline Cianeto & 0,026 & $\mathrm{mg} \mathrm{L}^{-1}$ & 0,001 & SM 4500-CNळE & $14 / 06 / 2010$ \\
\hline Cloreto & 260 & $\mathrm{mg} \mathrm{L}^{-1}$ & 0,1 & $\mathrm{SM} 4500-\mathrm{Cl} \mathrm{C}$ & $11 / 06 / 2010$ \\
\hline Cobre & 0,591 & $\mathrm{mg} \mathrm{L}^{-1}$ & 0,003 & SM $3111 \mathrm{~b}$ & $16 / 06 / 2010$ \\
\hline Condutividade Elétrica & 1360 & $\mu \mathrm{S} \mathrm{cm}^{-1}$ & 1 & SM-2510-B & $11 / 06 / 2010$ \\
\hline Cor Aparente & 1590 & $\mathrm{u} \mathrm{H}$ & 1 & SM $2120 \mathrm{C}$ & $11 / 06 / 2010$ \\
\hline Cromo Hexavalente & $<\mathrm{LD}$ & $\mathrm{mg} \mathrm{L}^{-1}$ & 0,01 & SM 3500-Cr B & $16 / 06 / 2010$ \\
\hline Cromo Total & 0,153 & $\mathrm{mg} \mathrm{L}^{-1}$ & 0,005 & SM $3111 \mathrm{~B}$ & $16 / 06 / 2010$ \\
\hline DBO & 352 & $\mathrm{mg} \mathrm{L}^{-1}$ & 1 & SM $5210 \mathrm{~B}$ & $16 / 06 / 2010$ \\
\hline DQO & 1428 & $\mathrm{mg} \mathrm{L}^{-1}$ & 1 & SM 5220 D & $11 / 06 / 2010$ \\
\hline Estanho & 0,03 & $\mathrm{mg} \mathrm{L}^{-1}$ & 0,001 & SM $3111 \mathrm{D}$ & $16 / 06 / 2010$ \\
\hline Estrôncio & 0,585 & $\mathrm{mg} \mathrm{L}^{-1}$ & 0,05 & SM $3111 \mathrm{D}$ & $16 / 06 / 2010$ \\
\hline Ferro & 2,010 & $\mathrm{mg} \mathrm{L}^{-1}$ & 0,005 & SM $3111 \mathrm{~B}$ & $16 / 06 / 2010$ \\
\hline Fenóis & 0,091 & $\mathrm{mg} \mathrm{L}^{-1}$ & 0,001 & SM $5530 \mathrm{D}$ & $14 / 06 / 2010$ \\
\hline Fluoreto & 2,65 & $\mathrm{mg} \mathrm{L}^{-1}$ & 0,01 & SM 4500-Fo D & $14 / 06 / 2010$ \\
\hline Fosfato Total & 69 & $\mathrm{mg} \mathrm{L}^{-1}$ & 0,1 & SM 4500-P E & $11 / 06 / 2010$ \\
\hline Magnésio & 2,90 & $\mathrm{mg} \mathrm{L}^{-1}$ & 0,001 & SM 3111 B & $16 / 06 / 2010$ \\
\hline Manganês & 4,37 & $\mathrm{mg} \mathrm{L}^{-1}$ & 0,003 & SM 3111 B & $16 / 06 / 2010$ \\
\hline Mercúrio & $<\mathrm{LD}$ & $\mathrm{mg} \mathrm{L}^{-1}$ & 0,0001 & SM 3112 B & $16 / 06 / 2010$ \\
\hline Níquel & 0,304 & $\mathrm{mg} \mathrm{L}^{-1}$ & 0,008 & SM 3111 B & $11 / 06 / 2010$ \\
\hline Nitrato (como N) & 4,18 & $\mathrm{mg} \mathrm{L}^{-1}$ & 0,01 & $\mathrm{SM} 4500-\mathrm{NO}_{3} \dot{\circ} \mathrm{B}$ & $11 / 06 / 2010$ \\
\hline Nitrito (como N) & 0,001 & $\mathrm{mg} \mathrm{L}^{-1}$ & 0,001 & $\mathrm{SM} 4500-\mathrm{NO}_{2} \circ \mathrm{B}$ & $11 / 06 / 2010$ \\
\hline Nitrogênio Amoniacal & 12 & $\mathrm{mg} \mathrm{L}^{-1}$ & 0,01 & $\mathrm{SM} 4500-\mathrm{NH}_{3} \mathrm{D}$ & $11 / 06 / 2010$ \\
\hline Nitrogênio Total & 79 & $\mathrm{mg} \mathrm{L}^{-1}$ & 1 & SM 4500-N B & $11 / 06 / 2010$ \\
\hline Óleos e Graxas & 92 & $\mathrm{mg} \mathrm{L}^{-1}$ & 2 & SM $5520 \mathrm{D}$ & $14 / 06 / 2010$ \\
\hline $\mathrm{pH}$ & 3,27 & N.A. & 0 a 14 & SM $4500-\mathrm{H}^{+} \mathrm{B}$ & $11 / 06 / 2010$ \\
\hline Potássio & 23,0 & $\mathrm{mg} \mathrm{L}^{-1}$ & 0,1 & SM 3500-K B & $16 / 06 / 2010$ \\
\hline Prata & 0,012 & $\mathrm{mg} \mathrm{L}^{-1}$ & 0,001 & SM 3111 B & $16 / 06 / 2010$ \\
\hline Selênio & $<\mathrm{LD}$ & $\mathrm{mg} \mathrm{L}^{-1}$ & 0,001 & SM 3114 B & $16 / 06 / 2010$ \\
\hline Sílica & 100,5 & $\mathrm{mg} \mathrm{L}^{-1}$ & 0,1 & SM 3114-B & $11 / 06 / 2010$ \\
\hline Sódio & 202,0 & $\mathrm{mg} \mathrm{L}^{-1}$ & 0,1 & SM 3500-Na-B & $14 / 06 / 2010$ \\
\hline Sulfato & 4 & $\mathrm{mg} \mathrm{L}^{-1}$ & 1 & $\mathrm{SM} 4500-\mathrm{SO}_{4}{ }^{2-} \mathrm{E}$ & $11 / 06 / 2010$ \\
\hline Sulfeto & $<\mathrm{LD}$ & $\mathrm{mg} \mathrm{L}^{-1}$ & 0,001 & SM 4500-S ${ }^{2-} \mathrm{D}$ & $11 / 06 / 2010$ \\
\hline Surfactantes & 0,25 & $\mathrm{mg} \mathrm{L}^{-1}$ & 0,1 & SM $5540 \mathrm{C}$ & $14 / 06 / 2010$ \\
\hline Turbidez & 335 & NTU & 0,1 & SM $2130 \mathrm{~B}$ & $11 / 06 / 2010$ \\
\hline Zinco & 0,631 & $\mathrm{mg} \mathrm{L}^{-1}$ & 0,002 & SM $3111 \mathrm{~B}$ & $16 / 06 / 2010$ \\
\hline Sólidos Sedimentáveis & 0,2 & $\mathrm{mg} \mathrm{L}^{-1}$ & 0,1 & SM $2540 \mathrm{~F}$ & $11 / 06 / 2010$ \\
\hline Sólidos Totais & 1460 & $\mathrm{mg} \mathrm{L}^{-1}$ & 1 & SM $2540 \mathrm{~B}$ & $11 / 06 / 2010$ \\
\hline Sólidos Totais Fixos & 551 & $\mathrm{mg} \mathrm{L}^{-1}$ & 1 & SM $2540 \mathrm{E}$ & $11 / 06 / 2010$ \\
\hline Sólidos Totais Voláteis & 909 & $\mathrm{mg} \mathrm{L}^{-1}$ & 1 & SM $2540 \mathrm{E}$ & $11 / 06 / 2010$ \\
\hline Sólidos Suspensos Totais & 182 & $\mathrm{mg} \mathrm{L}^{-1}$ & 1 & SM $2540 \mathrm{D}$ & $11 / 06 / 2010$ \\
\hline Sólidos Suspensos Fixos & 60 & $\mathrm{mg} \mathrm{L}^{-1}$ & 1 & SM $2540 \mathrm{E}$ & $11 / 06 / 2010$ \\
\hline Sólidos Suspensos Voláteis & 122 & $\mathrm{mg} \mathrm{L}^{-1}$ & 1 & SM $2540 \mathrm{E}$ & $11 / 06 / 2010$ \\
\hline Sólidos Dissolvidos Totais & 1278 & $\mathrm{mg} \mathrm{L}^{-1}$ & 1 & SM $2540 \mathrm{C}$ & $11 / 06 / 2010$ \\
\hline Sólidos Dissolvidos Fixos & 491 & $\mathrm{mg} \mathrm{L}^{-1}$ & 1 & SM $2540 \mathrm{C}$ & $11 / 06 / 2010$ \\
\hline Sólidos Dissolvidos Voláteis & 787 & $\mathrm{mg} \mathrm{L}^{-1}$ & 1 & SM $2540 \mathrm{C}$ & $11 / 06 / 2010$ \\
\hline
\end{tabular}

Legenda: SM-Standard Methods for the Examination of Water and Wastewater, 21 edição, 2005.

LD- Limite de Detecção

N.A.- Não se aplica 
Observa-se na Tabela 5.1 que a relação DQO/DBO próxima a 4,0 foi elevada e o valor encontrado para Sólidos Dissolvidos Totais (SDT) $(1278 \mathrm{mg} / \mathrm{l})$ foi bem maior que o valor encontrado para Sólidos Suspensos Voláteis (SSV) $(122 \mathrm{mg} / \mathrm{l})$ indicando que a fração inerte (não biodegradável) era elevada indicando que o tratamento físico-químico seria um dos mais indicados para esse tipo de efluente.

Podemos verificar também na Tabela 5.1 a alta quantidade de óleos e graxas (92mg/l), sílica $(100,5 \mathrm{mg} / \mathrm{l})$, ferro $(2,010 \mathrm{mg} / \mathrm{l})$, manganês $(4,37 \mathrm{mg} / \mathrm{l})$ e boro $(10,4 \mathrm{mg} / \mathrm{l})$, componentes característicos de efluentes industriais de empresas metal-mecânicas que possuem vários tipos de tratamento de superfície. O efluente contendo boro, presente em fluxos de solda e em determinados óleos refrigerantes sintéticos utilizados na usinagem de peças, devido ao seu tamanho, é de difícil tratamento e mesmo o sistema de osmose reversa possui baixa eficiência no seu tratamento, por isso esse contaminante é monitorado constantemente para que não ultrapasse o limite máximo permitido para lançamento $(5 \mathrm{mg} / \mathrm{l})$.

\subsection{Ensaios de coagulação-floculação-sedimentação}

Os dados resultantes dos ensaios de coagulação-floculação-sedimentação estão nos Apêndices B a D, como segue:

Apêndice B - Resultados dos ensaios de coagulação-floculação-sedimentação para o coagulante aluminato de sódio

Apêndice C - Resultados dos ensaios de coagulação-floculação-sedimentação para o coagulante cloreto férrico

Apêndice D - Resultados dos ensaios de coagulação-floculação-sedimentação para o coagulante Procytrat 100A + Procytrat 300 


\subsubsection{Resultados dos ensaios de coagulação-floculação-sedimentação para o coagulante aluminato de sódio}

\subsubsection{Ensaios preliminares}

Na primeira etapa dos ensaios preliminares de coagulação-floculação-sedimentação utilizando-se como coagulante o aluminato de sódio foi escolhido o melhor par pH-DC (dosagem de coagulante) para utilização nos ensaios posteriores. Foram realizados 3 ensaios, onde foram mantidos constantes os parâmetros de mistura rápida e floculação $(\mathrm{Gm}, \mathrm{Tm}$, Gf, Tf) e houve variação dos valores de pH, DC e Vs.

Foram considerados nesses ensaios duas velocidades de sedimentação (Vs), $2 \mathrm{~cm} / \mathrm{min}$ e $1 \mathrm{~cm} / \mathrm{min}$, mas como os resultados de turbidez e condutividade remanescente para Vs igual a $2 \mathrm{~cm} / \mathrm{min}$ foram elevados, foram analisados nessa etapa somente os dados obtidos para Vs igual a $1 \mathrm{~cm} / \mathrm{min}$. Esse fato se repetiu também nos outros ensaios de coagulação-floculaçãosedimentação com outros coagulantes, por isso consideraremos nesse trabalho, para os ensaios de coagulação-floculação-sedimentação, somente os valores obtidos para Vs igual a $1 \mathrm{~cm} / \mathrm{min}$, embora os dados referentes a ensaios com Vs igual a $2 \mathrm{~cm} / \mathrm{min}$ podem ser vistos nos Apêndices desse trabalho.

Na Tabela 5.2 observa-se que os valores de condutividade remanescente foram elevados em função das próprias características do tratamento físico-químico que utiliza coagulantes que contêm sais metálicos e acabam aumentando a quantidade de íons em solução e consequentemente a condutividade. Esse fato se repetirá em outros ensaios, por isso priorizaremos nesse trabalho os resultados da turbidez remanescente na escolha dos melhores pares pH-DC. O melhor resultado de turbidez remanescente $(2,6 \%)$ foi encontrado para DC igual a 200mg/l e pH igual a 7,2, mas como há a necessidade de aumentar-se o pH em torno de 8,5 em função de sua queda nas etapas posteriores ao tratamento na E.T.E., optou-se pela dosagem de aluminato de sódio de $200 \mathrm{mg} / \mathrm{l}$ e $\mathrm{pH}$ em torno de 8,5 onde o valor de turbidez remanescente ficou em $6,2 \%$. 
Tabela 5.2 - Valores de turbidez e condutividade remanescente para etapa 1 dos ensaios preliminares de coagulação-floculação-sedimentação com o coagulante aluminato de sódio

\begin{tabular}{c|c|c|c}
\hline $\begin{array}{c}\text { Dosagem de Aluminato } \\
\text { de sódio (mg/l) }\end{array}$ & $\mathbf{p H}$ & $\begin{array}{c}\text { Turbidez } \\
\text { remanescente (\%) }\end{array}$ & $\begin{array}{c}\text { Condutividade } \\
\text { remanescente (\%) }\end{array}$ \\
\hline 80 & 5,0 & 88,0 & 93 \\
\hline 80 & 7,2 & 4,0 & 98 \\
\hline 80 & 8,6 & 7,6 & 96 \\
\hline 140 & 4,7 & 93,2 & 91 \\
\hline 140 & 7,0 & 4,0 & 100 \\
\hline 140 & 8,5 & 7,6 & 95 \\
\hline 200 & 4,8 & 43,5 & 91 \\
\hline 200 & 7,2 & 2,6 & 100 \\
\hline $\mathbf{2 0 0}$ & $\mathbf{8 , 5}$ & $\mathbf{6 , 2}$ & $\mathbf{9 7}$ \\
\hline 260 & 5,5 & 7,2 & 91 \\
\hline 260 & 6,8 & 4,1 & 99 \\
\hline 260 & 8,5 & 4,1 & 97 \\
\hline 320 & 5,7 & 4,8 & 91 \\
\hline 320 & 6,4 & 4,2 & 98 \\
\hline 320 & 8,5 & 4,1 & 97 \\
\hline 380 & 6,1 & 3,9 & 99 \\
\hline 380 & 6,4 & 4,3 & 97 \\
\hline 380 & 8,5 & 3,9 & \\
\hline
\end{tabular}

$\mathrm{Na}$ segunda etapa foram realizados 3 ensaios, nos quais foram investigados os parâmetros de mistura rápida $(\mathrm{Gm}$ e $\mathrm{Tm})$ mais adequados, enquanto os demais parâmetros (Gf, Tf, pH, DC) foram mantidos fixos. Como na etapa anterior, foram estudadas também duas velocidades de sedimentação (Vs), porém foram considerados apenas os valores para Vs igual a $1 \mathrm{~cm} / \mathrm{min}$ enquanto os outros resultados para $V s$ igual a $2 \mathrm{~cm} / \mathrm{min}$ estão descritos no Apêndice B. Foram testados os seguintes valores de gradiente de mistura rápida $(\mathrm{Gm}): 500 \mathrm{~s}^{-1}$, $800 \mathrm{~s}^{-1}$ e $1000 \mathrm{~s}^{-1}$. Para cada valor de Gm foram testados os seguintes valores de Tm: $5 \mathrm{~s}$, 10s, 15s, 30s, 60s e 90s. Foram considerados mais adequados, os parâmetros de mistura rápida que forneceram as melhores médias dos resultados de turbidez remanescente.

$\mathrm{Na}$ Tabela 5.3, observa-se que os valores escolhidos para Gm e Tm foram $800 \mathrm{~s}^{-1}$ e $5 \mathrm{~s}$ respectivamente. 
Tabela 5.3 - Valores de turbidez e condutividade remanescente para a etapa 2 dos ensaios preliminares de coagulação-floculação-sedimentação com o coagulante aluminato de sódio

\begin{tabular}{c|c|c|c|c}
\hline $\mathbf{G m}\left(\mathbf{s}^{\mathbf{- 1}}\right)$ & $\mathbf{T m}(\mathbf{s})$ & $\mathbf{p H}$ & $\begin{array}{c}\text { Turbidez } \\
\text { remanescente (\%) }\end{array}$ & $\begin{array}{c}\text { Condutividade } \\
\text { remanescente (\%) }\end{array}$ \\
\hline 500 & 5 & 8,6 & 5,7 & 99 \\
\hline 500 & 10 & 8,6 & 5,8 & 99 \\
\hline 500 & 15 & 8,5 & 6,3 & 99 \\
\hline 500 & 30 & 8,6 & 6,4 & 99 \\
\hline 500 & 60 & 8,6 & 7,0 & 98 \\
\hline 500 & 90 & 8,6 & 7,3 & $\mathbf{1 0 1}$ \\
\hline $\mathbf{8 0 0}$ & $\mathbf{5}$ & $\mathbf{8 , 6}$ & $\mathbf{6 , 0}$ & 101 \\
\hline 800 & 10 & 8,6 & 6,1 & 101 \\
\hline 800 & 15 & 8,6 & 6,0 & 101 \\
\hline 800 & 30 & 8,6 & 7,3 & 101 \\
\hline 800 & 60 & 8,6 & 6,3 & 102 \\
\hline 800 & 90 & 8,6 & 8,1 & 102 \\
\hline 1000 & 5 & 8,6 & 5,4 & 102 \\
\hline 1000 & 10 & 8,7 & 7,0 & 102 \\
\hline 1000 & 15 & 8,6 & 7,8 & 102 \\
\hline 1000 & 30 & 8,6 & 7,4 & 102 \\
\hline 1000 & 60 & 8,6 & 10,4 & \\
\hline 1000 & 90 & 8,6 & 8,5 & \\
\hline
\end{tabular}

$\mathrm{Na}$ terceira etapa foram realizados 3 ensaios, nos quais foram investigados os parâmetros de floculação (Gf e Tf) mais adequados, enquanto os demais parâmetros (Gm, $\mathrm{Tm}, \mathrm{pH}, \mathrm{DC}$ ) foram mantidos fixos. Como na etapa anterior, foram estudadas também duas velocidades de sedimentação (Vs), porém foram cconsiderados apenas os valores para Vs igual a $1 \mathrm{~cm} / \mathrm{min}$ enquanto os outros resultados para $V s$ igual a $2 \mathrm{~cm} / \mathrm{min}$ estão descritos no Apêndice B. Foram testados os seguintes valores de gradiente de floculação (Gf): $25 \mathrm{~s}^{-1}, 50 \mathrm{~s}^{-1}$ e $75 \mathrm{~s}^{-1}$. Para cada valor de Gf foram testados os seguintes valores de Tm: 5min, 10min, 20min, 30min, 40min e 60min. Foram considerados mais adequados, os parâmetros de floculação que forneceram as melhores médias dos resultados de turbidez remanescente.

$\mathrm{Na}$ Tabela 5.4, observa-se que os valores escolhidos para Gf e Tf foram $50 \mathrm{~s}^{-1} \mathrm{e}$ $10 \mathrm{~min}$ respectivamente. 
Tabela 5.4 - Valores de turbidez e condutividade remanescente para a etapa 3 dos ensaios preliminares de coagulação-floculação-sedimentação com o coagulante aluminato de sódio

\begin{tabular}{c|c|c|c|c}
\hline $\mathbf{G f}\left(\mathbf{s}^{-\mathbf{1}}\right)$ & Tf (min) & $\mathbf{p H}$ & $\begin{array}{c}\text { Turbidez } \\
\text { remanescente (\%) }\end{array}$ & $\begin{array}{c}\text { Condutividade } \\
\text { remanescente (\%) }\end{array}$ \\
\hline 25 & 5 & 8,23 & 3,7 & 102 \\
\hline 25 & 10 & 8,29 & 2,3 & 102 \\
\hline 25 & 20 & 8,32 & 2,5 & 102 \\
\hline 25 & 30 & 8,31 & 3,5 & 101 \\
\hline 25 & 40 & 8,31 & 3,6 & 101 \\
\hline 25 & 60 & 8,28 & 4,3 & 102 \\
\hline 50 & 5 & 8,25 & 1,9 & 99 \\
\hline $\mathbf{5 0}$ & $\mathbf{1 0}$ & $\mathbf{8 , 2 5}$ & $\mathbf{2 , 7}$ & $\mathbf{1 0 0}$ \\
\hline 50 & 20 & 8,26 & 3,3 & 100 \\
\hline 50 & 30 & 8,25 & 3,5 & 100 \\
\hline 50 & 40 & 8,28 & 4,5 & 100 \\
\hline 50 & 60 & 8,29 & 5,1 & 100 \\
\hline 75 & 5 & 8,24 & 2,3 & 101 \\
\hline 75 & 10 & 8,27 & 2,3 & 101 \\
\hline 75 & 20 & 8,29 & 4,0 & 100 \\
\hline 75 & 30 & 8,28 & 4,1 & 100 \\
\hline 75 & 40 & 8,27 & 4,7 & 101 \\
\hline 75 & 60 & 8,25 & 6,1 & 101 \\
\hline
\end{tabular}

\subsubsection{Diagrama de coagulação-floculação-sedimentação para o coagulante aluminato de sódio}

$\mathrm{Na}$ quarta etapa, para a construção do diagrama de coagulação, foram realizados 7 ensaios onde foram utilizados os valores dos parâmetros de mistura rápida e floculação $(\mathrm{Gm}$, Tm, Gf, Tf) obtidos na segunda e terceira etapa e foram variados o $\mathrm{pH}$ (com a dosagem de hidróxido de cálcio) e a dosagem do coagulante (DC), nesse caso, aluminato de sódio.

Foram considerados também nesses ensaios duas velocidades de sedimentação (Vs), $2 \mathrm{~cm} / \mathrm{min}$ e $1 \mathrm{~cm} / \mathrm{min}$, mas como os resultados de turbidez e condutividade remanescente para Vs igual a $2 \mathrm{~cm} / \mathrm{min}$ foram elevados, foram analisados nessa etapa somente os dados obtidos para Vs igual a $1 \mathrm{~cm} / \mathrm{min}$ enquanto que os dados relativos a $\mathrm{Vs}$ igual a $2 \mathrm{~cm} / \mathrm{min}$ podem ser observados no Apêndice B.

Na Figura 5.6 é apresentado o diagrama de coagulação do efluente relativo a análise de turbidez para o coagulante aluminato de sódio. Os números inscritos sobre os pontos obtidos (marcados no diagrama em forma de “•”) indicam os percentuais de turbidez 
remanescente, para os respectivos valores de $\mathrm{pH}$ e dosagem de coagulante. Por exemplo, no diagrama da Figura 5.6, relativo a turbidez, para a dosagem de $260 \mathrm{mg} / 1$ de aluminato de sódio e pH de 7,36, o efluente obtido após o ensaio de coagulação-floculação-sedimentação apresentou turbidez remanescente igual a 1,3\% da turbidez da amostra bruta (solução do tanque de homogeinização da E.T.E.), ou seja, nesse ensaio, a eficiência de remoção de turbidez foi de $98,7 \%$.

A partir dos valores de percentuais remanescentes, foram interpoladas as linhas contínuas que aparecem nos diagramas, semelhantes a "curvas de nível", delimitadoras das regiões de "mesma" eficiência de remoção do parâmetro estudado. Essas linhas foram traçadas utilizando-se o programa computacional Surfer ${ }^{\circledR}$. Contudo, em virtude dos erros inerentes aos ensaios e as análises laboratoriais, essas curvas devem ser interpretadas como aproximações, desenhadas apenas para facilitar a visualização das regiões dos diagramas, e que, portanto, não demarcam precisamente as fronteiras dessas regiões.

Além das linhas interpoladas (contínuas), na Figura 5.6, observam-se linhas tracejadas nas quais são indicadas as dosagens (em $\mathrm{mg} / \mathrm{l})$ de $\mathrm{Ca}(\mathrm{OH})_{2}$, utilizado para que o pH da amostra fosse variado.

As regiões hachuradas foram divididas em regiões retangulares para melhor visualização das faixas de $\mathrm{pH}$ e dosagem de coagulante que forneceram eficiências de remoção de turbidez maiores que $98 \%$ (sedimentação) .

Os diagramas de coagulação-floculação para o parâmetro condutividade não foram construídos nesse trabalho, pois as eficiências de remoção dos íons e consequentemente, da condutividade, foram muito baixas para todos os coagulantes testados, chegando várias vezes a atingir valores de condutividade remanescente acima de $100 \%$, ou seja, a condutividade da amostra tratada foi maior que a condutividade da amostra bruta. Esse fato já foi comentado anteriormente e pode ser explicado pela natureza do próprio tratamento que utiliza coagulantes e alcalinizante inorgânico, que podem aumentar a quantidade de íons em solução e consequentemente da condutividade.

A forma de apresentação dos diagramas de coagulação descrita nos últimos cinco parágrafos para a Figura 5.6 é também empregada em todos os demais diagramas apresentados no presente texto.

A Tabela 5.5 fornece os resultados das faixas otimizadas de $\mathrm{pH}$ e dosagens de coagulante. Observa-se na Tabela 5.5 que as maiores eficiencias de remoção de turbidez, são obtidas na faixa de $\mathrm{pH}$ de 7,3 a 8,5 , sendo que a maior eficiencia de remoção $(1,3 \%)$ foram atingidas nas regiões 1 e 3 . Na região 1 , temos uma dosagem menor de coagulante $(260 \mathrm{mg} / \mathrm{l})$ 
e consequentemente teremos um consumo menor de coagulante se comparada a região 3 cuja dosagem de coagulante é $320 \mathrm{mg} / 1$, porém na região 1 teremos que adicionar posteriormente no tratamento, mais hidróxido de cálcio para elevar o $\mathrm{pH}$ para o intervalo de 8,3 a 8,5 (pH desejado na saída do decantador) enquanto que na região 3 o pH $(7,91)$ está mais próximo do desejado. A escolha da condição mais adequada, será feita mais adiante neste texto (item 5.5 p.110).

Tabela 5.5 - Regiões dos diagramas de coagulação-floculação-sedimentação com aluminato de sódio e valores percentuais de turbidez remanescente

\begin{tabular}{|c|c|c|c|c|c|c|}
\hline \multirow[b]{2}{*}{ Região } & \multicolumn{2}{|c|}{\begin{tabular}{|c} 
Faixas de $\mathrm{pH}-\mathrm{DC}$ para turbidez \\
remanescente $<2 \%$
\end{tabular}} & \multicolumn{4}{|c|}{ Melhores pontos dentro das faixas pH-DC } \\
\hline & \begin{tabular}{|c|} 
pH de \\
coagulação \\
\end{tabular} & $\begin{array}{c}\text { Dosagem de } \\
\text { aluminato de } \\
\text { sódio }(\mathrm{mg} / \mathrm{l})\end{array}$ & $\begin{array}{c}\text { pH de } \\
\text { coagulação }\end{array}$ & $\begin{array}{l}\text { Dosagem de } \\
\text { aluminato de } \\
\text { sódio }(\mathrm{mg} / \mathrm{l})\end{array}$ & $\begin{array}{l}\text { Dosagem de } \\
\text { hidróxido de } \\
\text { cálcio (mg/l) }\end{array}$ & $\begin{array}{c}\text { Turbidez } \\
\text { remanescente } \\
(\%)\end{array}$ \\
\hline 1 & $7,3-7,5$ & $80-290$ & 7,36 & 260 & 120 & 1,3 \\
\hline 2 & $7,5-7,7$ & $250-380$ & 7,64 & 320 & 120 & 1,8 \\
\hline 3 & $7,7-8,5$ & $316-380$ & 7,91 & 380 & 120 & 1,3 \\
\hline
\end{tabular}




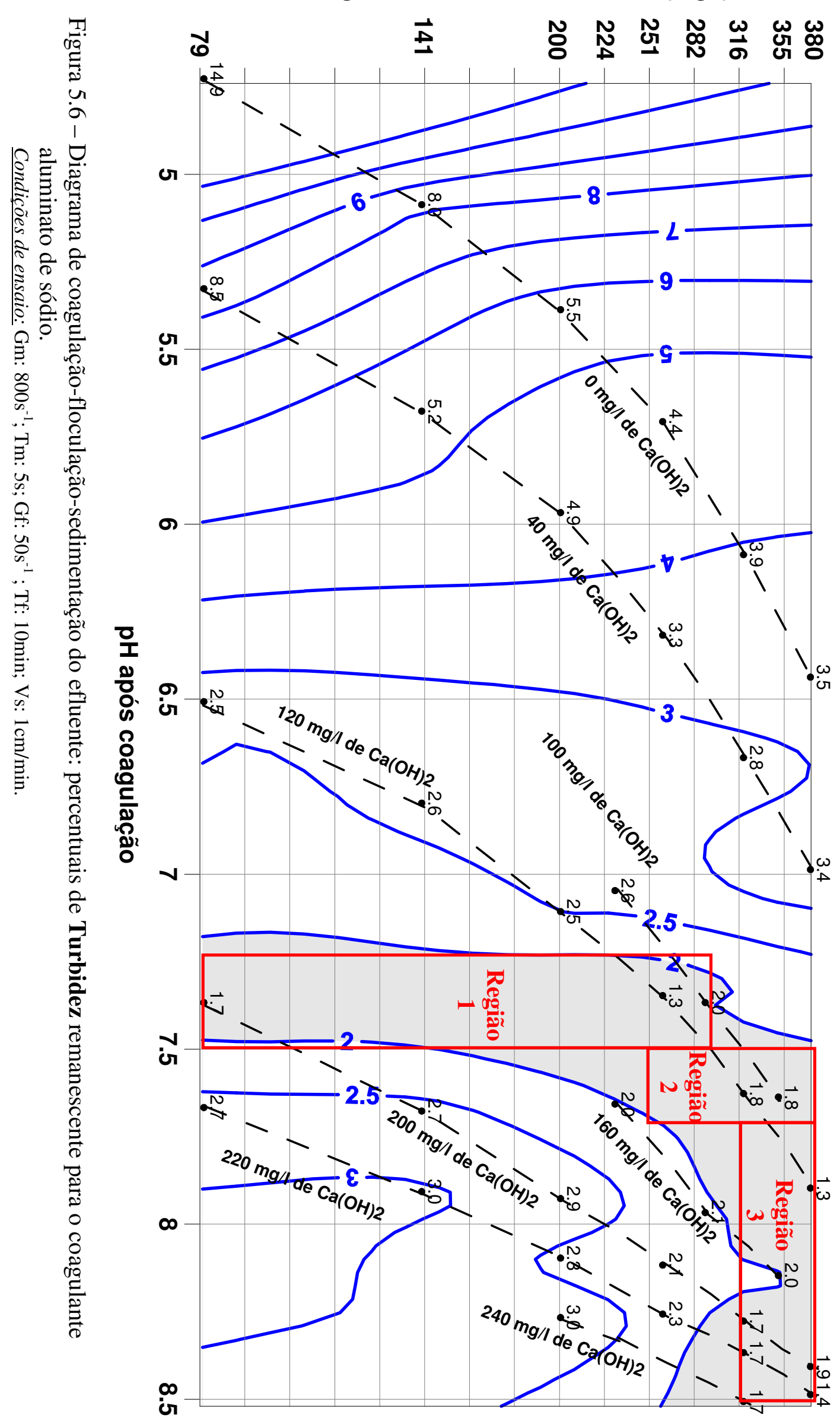




\subsubsection{Resultados dos ensaios de coagulação-floculação-sedimentação para o coagulante cloreto férrico}

\subsubsection{Ensaios preliminares}

Na primeira etapa dos ensaios preliminares de coagulação-floculação-sedimentação utilizando-se como coagulante o cloreto férrico foi escolhido o melhor par pH-DC (dosagem de coagulante) para utilização nos ensaios posteriores. Foi realizado um ensaio, onde foram mantidos constantes os parâmetros de mistura rápida, floculação e sedimentação $(\mathrm{Gm}, \mathrm{Tm}$, Gf, Tf, Vs) e a dosagem de coagulante (DC) e houve variação apenas dos valores de pH. Conforme discutido no item 5.2.1.1, como os resultados de turbidez remanescente para a velocidade de sedimentação (Vs) para $2 \mathrm{~cm} / \mathrm{min}$ foram elevados, optou-se para os ensaios com o coagulante cloreto férrico utilizar somente a velocidade de $1 \mathrm{~cm} / \mathrm{min}$.

Após análise dos resultados obtidos nos ensaios com o coagulante aluminato de sódio e a observação que os melhores resultados de eficiencia de remoção de turbidez ocorreram com dosagens de coagulante acima de 200mg/l, optou-se nesse ensaio pela manutenção da dosagem do coagulante cloreto férrico constante e igual a 260mg/l.

Observa-se na Tabela 5.6 que todos os percentuais de turbidez remanescente ficaram abaixo de $2,0 \%$ e o melhor resultado $(0,9 \%)$ foi encontrado para DC igual a $260 \mathrm{mg} / \mathrm{l} \mathrm{e} \mathrm{pH}$ igual a 8,1, mas como há a necessidade de elevarmos o pH em torno de 8,5 em função de sua queda nas etapas posteriores ao tratamento físico-químico na E.T.E., optou-se para utilização nos ensaios das etapas 2 e 3 a dosagem de cloreto férrico de $200 \mathrm{mg} / \mathrm{l} \mathrm{e} \mathrm{pH} \mathrm{em} \mathrm{torno} \mathrm{de} \mathrm{8,5.}$

Tabela 5.6 - Valores de turbidez e condutividade remanescente para etapa 1 dos ensaios preliminares de coagulação-floculação-sedimentação com o coagulante cloreto férrico

\begin{tabular}{c|c|c|c}
\hline $\begin{array}{c}\text { Dosagem de Cloreto } \\
\text { férrico (mg/l) }\end{array}$ & $\mathbf{p H}$ & $\begin{array}{c}\text { Turbidez } \\
\text { remanescente (\%) }\end{array}$ & $\begin{array}{c}\text { Condutividade } \\
\text { remanescente (\%) }\end{array}$ \\
\hline 260 & 7,0 & 1,8 & 105 \\
\hline 260 & 7,5 & 1,7 & 109 \\
\hline 260 & 7,9 & 1,4 & 113 \\
\hline $\mathbf{2 6 0}$ & $\mathbf{8 , 1}$ & $\mathbf{0 , 9}$ & $\mathbf{1 1 7}$ \\
\hline 260 & 8,3 & 1,2 & 122 \\
\hline 260 & 8,4 & 1,1 & 126 \\
\hline
\end{tabular}


$\mathrm{Na}$ segunda etapa foram realizados 3 ensaios, nos quais foram investigados os parâmetros de mistura rápida ( $\mathrm{Gm}$ e Tm) mais adequados, enquanto os demais parâmetros (Gf, Tf, pH, Vs, DC) foram mantidos fixos. Foram testados os seguintes valores de gradiente de mistura rápida $(\mathrm{Gm}): 500 \mathrm{~s}^{-1}, 800 \mathrm{~s}^{-1}$ e $1000 \mathrm{~s}^{-1}$. Para cada valor de $\mathrm{Gm}$ foram testados os seguintes valores de Tm: 5s, 10s, 15s, 30s, 60s e 90s. Foram considerados mais adequados, os parâmetros de mistura rápida que forneceram as melhores médias dos resultados de turbidez remanescente.

Na Tabela 5.7, observa-se que os valores escolhidos para Gm e Tm foram $800 \mathrm{~s}^{-1}$ e $5 \mathrm{~s}$ respectivamente.

Tabela 5.7 - Valores de turbidez e condutividade remanescente para a etapa 2 dos ensaios preliminares de coagulação-floculação-sedimentação com o coagulante cloreto férrico

\begin{tabular}{c|c|c|c|c}
\hline $\mathbf{G m}\left(\mathbf{s}^{-\mathbf{1}}\right)$ & Tm $(\mathbf{s})$ & $\mathbf{p H}$ & $\begin{array}{c}\text { Turbidez } \\
\text { remanescente }(\boldsymbol{\%})\end{array}$ & $\begin{array}{c}\text { Condutividade } \\
\text { remanescente }\left(\boldsymbol{\mu} \mathbf{S} / \mathbf{c m}^{\mathbf{2}}\right)\end{array}$ \\
\hline 500 & 5 & 8,4 & 1,4 & 118 \\
\hline 500 & 10 & 8,4 & 1,7 & 119 \\
\hline 500 & 15 & 8,4 & 2,1 & 119 \\
\hline 500 & 30 & 8,4 & 2,9 & 120 \\
\hline 500 & 60 & 8,4 & 2,8 & 119 \\
\hline 500 & 90 & 8,4 & 2,3 & 120 \\
\hline $\mathbf{8 0 0}$ & $\mathbf{5}$ & $\mathbf{8 , 6}$ & $\mathbf{1 , 4}$ & $\mathbf{1 1 5}$ \\
\hline 800 & 10 & 8,6 & 1,7 & 116 \\
\hline 800 & 15 & 8,6 & 2,1 & 116 \\
\hline 800 & 30 & 8,6 & 2,3 & 116 \\
\hline 800 & 60 & 8,6 & 2,5 & 116 \\
\hline 800 & 90 & 8,6 & 2,5 & 116 \\
\hline 1000 & 5 & 8,5 & 1,6 & 114 \\
\hline 1000 & 10 & 8,5 & 2,0 & 115 \\
\hline 1000 & 15 & 8,5 & 2,8 & 115 \\
\hline 1000 & 30 & 8,5 & 2,5 & 115 \\
\hline 1000 & 60 & 8,5 & 2,7 & 116 \\
\hline 1000 & 90 & 8,6 & 2,8 & \\
\hline
\end{tabular}

$\mathrm{Na}$ terceira etapa foram realizados 3 ensaios, nos quais foram investigados os parâmetros de floculação (Gf e Tf) mais adequados, enquanto os demais parâmetros ( $\mathrm{Gm}$, $\mathrm{Tm}, \mathrm{pH}, \mathrm{Vs}$ e DC) foram mantidos fixos. Foram testados os seguintes valores de gradiente de floculação (Gf): $25 \mathrm{~s}^{-1}, 50 \mathrm{~s}^{-1}$ e $75 \mathrm{~s}^{-1}$. Para cada valor de Gf foram testados os seguintes valores de Tf: $5 \mathrm{~min}, 10 \mathrm{~min}, 20 \mathrm{~min}, 30 \mathrm{~min}, 40 \mathrm{~min}$ e $60 \mathrm{~min}$. Foram considerados mais adequados, os parâmetros de floculação, que forneceram as melhores médias dos resultados de turbidez remanescente. 
$\mathrm{Na}$ Tabela 5.8, observa-se que os valores escolhidos para Gf e Tf foram $25 \mathrm{~s}^{-1}$ e $5 \mathrm{~min}$ respectivamente.

Tabela 5.8 - Valores de turbidez e condutividade remanescente para a etapa 3 dos ensaios preliminares de coagulação-floculação-sedimentação com o coagulante cloreto férrico

\begin{tabular}{c|c|c|c|c}
\hline $\mathbf{G f}\left(\mathbf{s}^{-\mathbf{1}}\right)$ & Tf $(\mathbf{m i n})$ & $\mathbf{p H}$ & $\begin{array}{c}\text { Turbidez } \\
\text { remanescente (\%) }\end{array}$ & $\begin{array}{c}\text { Condutividade } \\
\text { remanescente (\%) }\end{array}$ \\
\hline $\mathbf{2 5}$ & $\mathbf{5}$ & $\mathbf{8 , 5 6}$ & $\mathbf{0 , 5}$ & $\mathbf{1 2 1}$ \\
\hline 25 & 10 & 8,58 & 0,7 & 121 \\
\hline 25 & 20 & 8,61 & 1,0 & 121 \\
\hline 25 & 30 & 8,56 & 0,9 & 121 \\
\hline 25 & 40 & 8,67 & 1,5 & 120 \\
\hline 25 & 60 & 8,48 & 2,0 & 122 \\
\hline 50 & 5 & 8,58 & 0,7 & 119 \\
\hline 50 & 10 & 8,58 & 0,8 & 120 \\
\hline 50 & 20 & 8,57 & 1,3 & 120 \\
\hline 50 & 30 & 8,67 & 1,2 & 120 \\
\hline 50 & 40 & 8,64 & 1,5 & 120 \\
\hline 50 & 60 & 8,62 & 1,7 & 121 \\
\hline 75 & 5 & 8,23 & 1,6 & 120 \\
\hline 75 & 10 & 8,24 & 1,4 & 121 \\
\hline 75 & 20 & 8,22 & 2,0 & 120 \\
\hline 75 & 30 & 8,20 & 2,0 & 121 \\
\hline 75 & 40 & 8,20 & 2,4 & 120 \\
\hline 75 & 60 & 8,20 & 3,0 & \\
\hline
\end{tabular}

\subsubsection{Diagrama de coagulação-floculação-sedimentação para o coagulante cloreto férrico}

$\mathrm{Na}$ quarta etapa, para a construção do diagrama de coagulação, foram realizados 9 ensaios onde foram utilizados os valores dos parâmetros de mistura rápida e floculação (Gm, Tm, Gf, Tf) obtidos na segunda e terceira etapa e foram variados o $\mathrm{pH}$ (com a dosagem de hidróxido de cálcio) e a dosagem do coagulante (DC), nesse caso, cloreto férrico.

Assim como nos ensaios anteriores, a velocidade de sedimentação (Vs) foi mantida constante e igual a $1 \mathrm{~cm} / \mathrm{min}$.

Na Figura 5.7 é apresentado o diagrama de coagulação do efluente relativo a análise de turbidez para o coagulante cloreto férrico. 
A Tabela 5.9 fornece os resultados das faixas otimizadas de $\mathrm{pH}$ e dosagens de coagulante. Observa-se na Tabela 5.9 que as faixas de $\mathrm{pH}$ e concentração de coagulante das maiores eficiencias de remoção de turbidez são mais amplas se comparadas as faixas com o coagulante aluminato de sódio. As maiores eficiências de remoção estão na faixa de $\mathrm{pH}$ de 7,0 a 9,0, sendo que as maiores eficiencias de remoção $(0,5 \%)$ foram atingidas nas regiões 1 e 2 para as dosagens de coagulante de 320 e $380 \mathrm{mg} / \mathrm{l}$ respectivamente.

$\mathrm{Na}$ região 2, temos um ponto com uma eficiencia de remoção um pouco menor $(0,6 \%)$, porém nesse ponto utilizou-se uma dosagem menor de coagulante $(200 \mathrm{mg} / \mathrm{l})$ e o pH já está próximo do desejado $(8,5)$ consequentemente teremos um consumo menor de coagulante se comparada aos outros pontos. A escolha da condição mais adequada, será feita mais adiante neste texto (item 5.5 - p.110).

Tabela 5.9 - Regiões dos diagramas de coagulação-floculação-sedimentação com cloreto férrico e valores percentuais de turbidez remanescente

\begin{tabular}{c|c|c|c|c|c|c}
\hline \multirow{2}{*}{ Região } & $\begin{array}{c}\text { Faixas de pH-DC para turbidez } \\
\text { remanescente }<\mathbf{2 \%}\end{array}$ & \multicolumn{4}{|c}{ Melhores pontos dentro das regiões } \\
\cline { 2 - 7 } & $\mathbf{p H}$ de & $\begin{array}{c}\text { Dosagem de } \\
\text { cloreto férrico } \\
(\mathbf{m g} / \mathbf{l})\end{array}$ & $\mathbf{p H ~ d e}$ & $\begin{array}{c}\text { Dosagem de } \\
\text { cloreto férrico } \\
(\mathbf{m g} / \mathbf{l})\end{array}$ & $\begin{array}{c}\text { Dosagem de } \\
\text { hidróxido de de } \\
\text { cálcio (mg/l) }\end{array}$ & $\begin{array}{c}\text { Turbidez } \\
\text { remanescente } \\
(\%)\end{array}$ \\
\hline $\mathbf{1}$ & $6,7-7,5$ & $140-380$ & 7,5 & 380 & 360 & 0,5 \\
\hline $\mathbf{2}$ & $7,5-8,5$ & $40-380$ & 7,8 & 320 & 360 & 0,5 \\
\hline
\end{tabular}




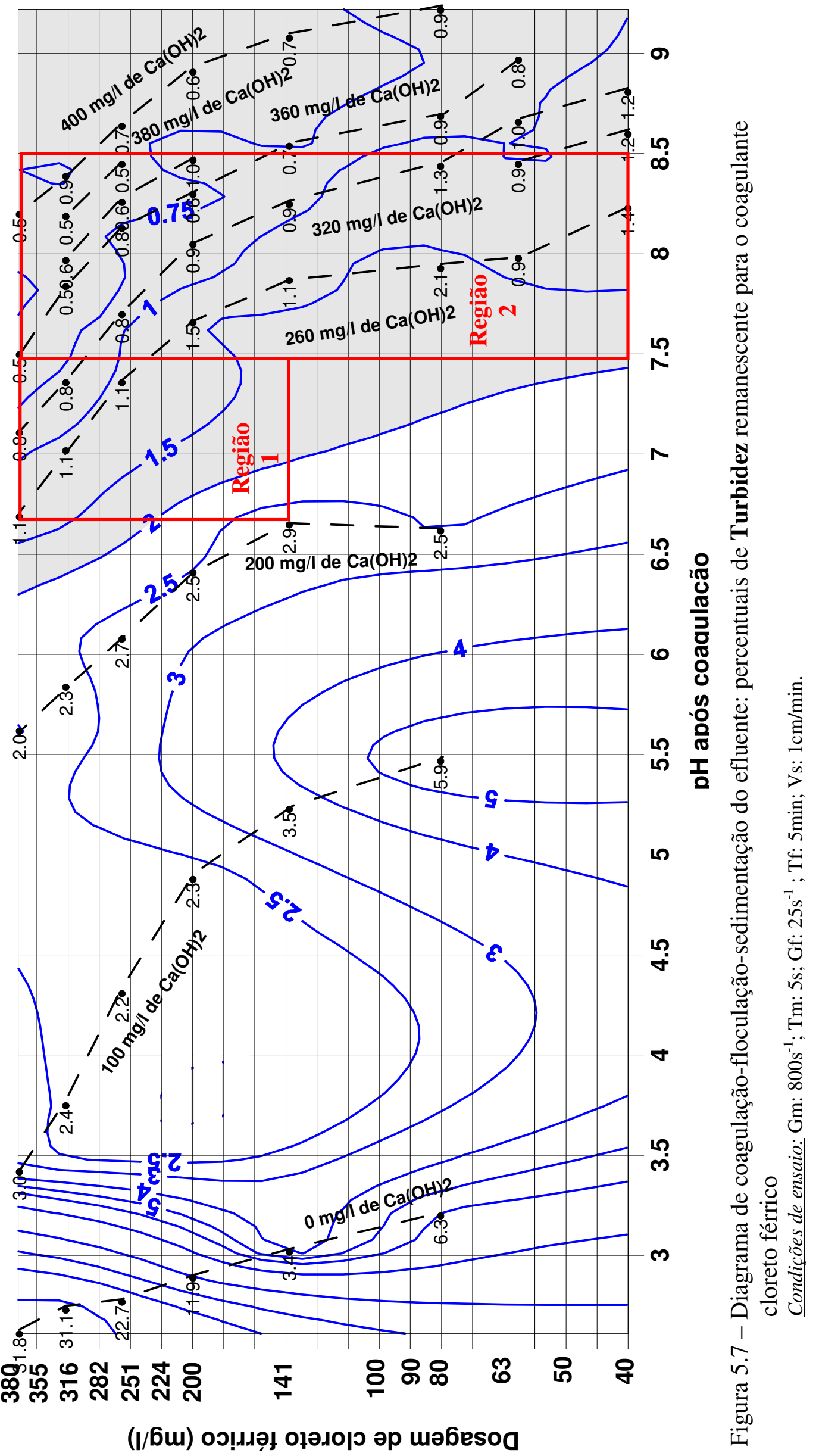




\subsubsection{Resultados dos ensaios de coagulação-floculação-sedimentação para o coagulante Procytrat 100A + Procytrat 300}

\subsubsection{Ensaios preliminares}

Na primeira etapa dos ensaios preliminares de coagulação-floculação-sedimentação utilizando-se como coagulante a mistura dos produtos Procytrat 100A e Procytrat 300, foi escolhido o melhor par pH-DC (dosagem de coagulante) para utilização nos ensaios posteriores. Foi realizado um ensaio, onde foram mantidos constantes os parâmetros de mistura rápida, floculação e sedimentação (Gm, Tm, Gf, Tf, Vs) e houve variação dos valores de $\mathrm{pH}$ e na dosagem de coagulante (DC). Foram estudadas também duas situações para a mistura dos coagulantes. Na situação 1 a mistura foi de 50\%-Procytrat 100A e 50\%-Procytrat 300 e na sistuação 2 a mistura foi de 70\%-Procytrat 100A e 30\%-Procytrat 300.

Conforme discutido no item 5.2.1.1, como os resultados de turbidez remanescente para a velocidade de sedimentação (Vs) para $2 \mathrm{~cm} / \mathrm{min}$ foram elevados, optou-se para os ensaios com o coagulante Procytrat 100A + Procytrat 300 utilizar somente a velocidade de $1 \mathrm{~cm} / \mathrm{min}$.

Observa-se na Tabela 5.10 que os resultados de turbidez remanescente foram muito próximos, mas os melhores resultados foram encontrados para a situação 2 (mistura de 70\%Procytrat $100 \mathrm{~A}+30 \%$ - Procytrat 300) e DC igual a 300mg/l sendo que o par escolhido foi para DC igual a $300 \mathrm{mg} / \mathrm{l}$ e $\mathrm{pH}$ igual a 8,2 que resultou em uma turbidez remanescente de $1,4 \%$. 
Tabela 5.10 - Valores de turbidez e condutividade remanescente para etapa 1 dos ensaios preliminares de coagulação-floculação-sedimentação com o coagulante Procytrat $100 \mathrm{~A}+$ Procytrat 300 .

\begin{tabular}{c|c|c|c|c}
\hline $\begin{array}{c}\text { Dosagem de Procytrat 100A + } \\
\text { Procytrat 300 }\end{array}$ & Situação & $\mathbf{p H}$ & $\begin{array}{c}\text { Turbidez } \\
\text { remanescente (\%) }\end{array}$ & $\begin{array}{c}\text { Condutividade } \\
\text { remanescente (\%) }\end{array}$ \\
\hline 100 & 1 & 7,4 & 2,2 & 99 \\
\hline 100 & 1 & 8,0 & 2,5 & 96 \\
\hline 100 & 1 & 8,7 & 1,1 & 95 \\
\hline 100 & 2 & 7,4 & 3,4 & 98 \\
\hline 100 & 2 & 8,1 & 1,3 & 96 \\
\hline 100 & 2 & 8,6 & 2,3 & 101 \\
\hline 200 & 1 & 7,3 & 1,4 & 99 \\
\hline 200 & 1 & 7,7 & 1,8 & 99 \\
\hline 200 & 1 & 8,5 & 1,6 & 103 \\
\hline 200 & 2 & 7,4 & 1,9 & 100 \\
\hline 200 & 2 & 7,8 & 2,1 & 98 \\
\hline 200 & 2 & 8,4 & 2,1 & 102 \\
\hline 300 & 1 & 7,4 & 1,4 & 101 \\
\hline 300 & 1 & 7,9 & 1,5 & 101 \\
\hline 300 & 1 & 8,4 & 1,4 & 103 \\
\hline 300 & 2 & 7,3 & 1,3 & 102 \\
\hline 300 & 2 & 7,8 & 1,7 & $\mathbf{1 0 3}$ \\
\hline $\mathbf{3 0 0}$ & $\mathbf{2}$ & $\mathbf{8 , 2}$ & $\mathbf{1 , 4}$ & \\
\hline
\end{tabular}

$\mathrm{Na}$ segunda etapa foram realizados 3 ensaios, nos quais foram investigados os parâmetros de mistura rápida $(\mathrm{Gm}$ e $\mathrm{Tm})$ mais adequados, enquanto os demais parâmetros (Gf, Tf, pH, Vs, DC) foram mantidos fixos. Foram testados os seguintes valores de gradiente de mistura rápida $(\mathrm{Gm}): 500 \mathrm{~s}^{-1}, 800 \mathrm{~s}^{-1}$ e $1000 \mathrm{~s}^{-1}$. Para cada valor de $\mathrm{Gm}$ foram testados os seguintes valores de Tm: 5s, 10s, 15s, 30s, 60s e 90s. Foram considerados mais adequados, os parâmetros de mistura rápida que forneceram as melhores médias dos resultados de turbidez remanescente.

Na Tabela 5.11, observa-se que os valores escolhidos para Gm e Tm foram $800 \mathrm{~s}^{-1} \mathrm{e}$ 5 s respectivamente. 
Tabela 5.11 - Valores de turbidez e condutividade remanescente para a etapa 2 dos ensaios preliminares de coagulação-floculação-sedimentação com o coagulante Procytrat $100 \mathrm{~A}+$ Procytrat 300

\begin{tabular}{c|c|c|c|c}
\hline $\mathbf{G m}\left(\mathbf{s}^{-\mathbf{1}}\right)$ & $\mathbf{T m}(\mathbf{s})$ & $\mathbf{p H}$ & $\begin{array}{c}\text { Turbidez } \\
\text { remanescente (\%) }\end{array}$ & $\begin{array}{c}\text { Condutividade } \\
\text { remanescente (\%) }\end{array}$ \\
\hline 500 & 5 & 8,08 & 1,4 & 97 \\
\hline 500 & 10 & 8,15 & 1,3 & 98 \\
\hline 500 & 15 & 8,08 & 1,4 & 98 \\
\hline 500 & 30 & 8,15 & 1,6 & 98 \\
\hline 500 & 60 & 8,07 & 1,9 & 98 \\
\hline 500 & 90 & 8,14 & 2,7 & 98 \\
\hline $\mathbf{8 0 0}$ & $\mathbf{5}$ & $\mathbf{8 , 0 9}$ & $\mathbf{1 , 4}$ & $\mathbf{9 7}$ \\
\hline 800 & 10 & 8,16 & 1,3 & 98 \\
\hline 800 & 15 & 8,11 & 1,1 & 97 \\
\hline 800 & 30 & 8,15 & 1,5 & 97 \\
\hline 800 & 60 & 8,14 & 1,7 & 97 \\
\hline 800 & 90 & 8,13 & 2,3 & 98 \\
\hline 1000 & 5 & 8,15 & 1,1 & 97 \\
\hline 1000 & 10 & 8,23 & 1,2 & 97 \\
\hline 1000 & 15 & 8,22 & 1,4 & 98 \\
\hline 1000 & 30 & 8,32 & 1,6 & 97 \\
\hline 1000 & 60 & 8,17 & 2,0 & 98 \\
\hline 1000 & 90 & 8,33 & 2,1 &
\end{tabular}

$\mathrm{Na}$ terceira etapa foram realizados 3 ensaios, nos quais foram investigados os parâmetros de floculação (Gf e Tf) mais adequados, enquanto os demais parâmetros (Gm, $\mathrm{Tm}, \mathrm{pH}, \mathrm{Vs}$ e DC) foram mantidos fixos. Foram testados os seguintes valores de gradiente de floculação (Gf): $25 \mathrm{~s}^{-1}, 50 \mathrm{~s}^{-1}$ e $75 \mathrm{~s}^{-1}$. Para cada valor de Gf foram testados os seguintes valores de Tf: $5 \mathrm{~min}$, 10min, 20min, 30min, 40min e 60min. Foram considerados mais adequados, os parâmetros de floculação que forneceram as melhores médias dos resultados de turbidez remanescente.

$\mathrm{Na}$ Tabela 5.12, observa-se que os valores escolhidos para Gf e Tf foram $25 \mathrm{~s}^{-1} \mathrm{e}$ 5 min respectivamente. 
Tabela 5.12 - Valores de turbidez e condutividade remanescente para a etapa 3 dos ensaios preliminares de coagulação-floculação-sedimentação com o coagulante Procytrat $100 \mathrm{~A}+$ Procytrat 300 .

\begin{tabular}{c|c|c|c|c}
\hline $\mathbf{G f}\left(\mathbf{s}^{-\mathbf{1}}\right)$ & $\mathbf{T f}(\mathbf{m i n})$ & $\mathbf{p H}$ & $\begin{array}{c}\text { Turbidez } \\
\text { remanescente (\%) }\end{array}$ & $\begin{array}{c}\text { Condutividade } \\
\text { remanescente (\%) }\end{array}$ \\
\hline $\mathbf{2 5}$ & $\mathbf{5}$ & $\mathbf{8 , 0 4}$ & $\mathbf{0 , 8}$ & $\mathbf{9 8 , 3}$ \\
\hline 25 & 10 & 8,16 & 0,8 & 98,3 \\
\hline 25 & 20 & 8,09 & 1,2 & 98,1 \\
\hline 25 & 30 & 8,13 & 1,7 & 98,4 \\
\hline 25 & 40 & 8,11 & 1,9 & 98,6 \\
\hline 25 & 60 & -- & 2,2 & -- \\
\hline 50 & 5 & 8,08 & 0,6 & 97,0 \\
\hline 50 & 10 & 8,06 & 1,2 & 97,5 \\
\hline 50 & 20 & 8,04 & 1,6 & 96,7 \\
\hline 50 & 30 & 8,08 & 1,1 & 97,3 \\
\hline 50 & 40 & 8,05 & 2,5 & 96,9 \\
\hline 50 & 60 & 8,12 & 2,9 & 97,5 \\
\hline 75 & 5 & 8,09 & 0,8 & 96,5 \\
\hline 75 & 10 & 8,18 & 1,5 & 96,2 \\
\hline 75 & 20 & 8,21 & 1,6 & 96,3 \\
\hline 75 & 30 & 8,21 & 1,8 & 95,6 \\
\hline 75 & 40 & 8,22 & 2,7 & 96,1 \\
\hline 75 & 60 & 8,24 & 2,9 & 96,0 \\
\hline
\end{tabular}

\subsubsection{Diagrama de coagulação-floculação-sedimentação para o coagulante Procytrat $100 \mathrm{~A}+$ Procytrat 300}

$\mathrm{Na}$ quarta etapa, para a construção do diagrama de coagulação, foram realizados 8 ensaios onde foram utilizados os valores dos parâmetros de mistura rápida e floculação $(\mathrm{Gm}$, Tm, Gf, Tf) obtidos na segunda e terceira etapa e foram variados o $\mathrm{pH}$ (com a dosagem de hidróxido de cálcio) e a dosagem do coagulante (DC), nesse caso, Procytrat 100A (70\%) + Procytrat $300(30 \%)$.

Assim como nos ensaios anteriores, a velocidade de sedimentação (Vs) foi mantida constante e igual a $1 \mathrm{~cm} / \mathrm{min}$.

Na Figura 5.8 é apresentado o diagrama de coagulação do efluente relativo a análise de turbidez para o coagulante Procytrat 100A + Procytrat 300.

A Tabela 5.13 fornece os resultados das faixas otimizadas de $\mathrm{pH}$ e dosagens de coagulante. Observa-se na Tabela 5.13 que as faixas de $\mathrm{pH}$ e concentração de coagulante das 
maiores eficiëncias de remoção de turbidez são mais amplas se comparadas as faixas com o coagulante aluminato de sódio. As maiores eficiências de remoção estão na faixa de pH de 6,5 a 9,0 , sendo que a maior eficiencia de remoção $(0,5 \%)$ foi atingida na região 1 para a dosagem de coagulante de $320 \mathrm{mg} / 1$ respectivamente.

Na região acima do $\mathrm{pH} 8,5$ a turbidez remanescente atingiu valores abaixo de 0,5\%, porém como o $\mathrm{pH}$ está acima do desejado para o tratamento posterior, seria necessário reduzirmos o pH através da adição de ácido, o que aumentaria o custo do tratamento além de aumentar ainda mais a condutividade, por isso esses valores não são considerados.

A escolha da condição mais adequada, será feita mais adiante neste texto (item 5.5 p.110).

Tabela 5.13 - Regiões dos diagramas de coagulação-floculação-sedimentação com o coagulante Procytrat 100A + Procytrat 300 e valores percentuais de turbidez remanescente

\begin{tabular}{c|c|c|c|c|c|c}
\hline \multirow{2}{*}{ Região } & $\begin{array}{c}\text { Faixas de pH-DC para turbidez } \\
\text { remanescente }<\mathbf{2 \%}\end{array}$ & \multicolumn{4}{c}{ Melhores pontos dentro das regióes } \\
\cline { 2 - 7 } & $\mathbf{p H}$ de & $\begin{array}{c}\text { Dosagem de } \\
\text { hidróxicloreto de } \\
\text { alumínio* }(\mathbf{m g} / \mathbf{l})\end{array}$ & $\mathbf{p H}$ de & $\begin{array}{c}\text { Dosagem de } \\
\text { hidróxicloreto } \\
\text { coagulação } \\
\text { de alumínio* }\end{array}$ & $\begin{array}{c}\text { Dosagem de } \\
\text { hidróxido de } \\
\text { cálcio }(\mathbf{m g} / \mathbf{l})\end{array}$ & $\begin{array}{c}\text { Turbidez } \\
\text { remanescente } \\
(\boldsymbol{\%})\end{array}$ \\
\hline $\mathbf{1}$ & $6,5-8,5$ & $224-380$ & 8,1 & 320 & 260 & 0,5 \\
\hline $\mathbf{2}$ & $7,1-8,5$ & $90-224$ & 8,5 & 140 & 260 & 0,8 \\
\hline $\mathbf{3}$ & $7,5-8,5$ & $40-90$ & 8,2 & 60 & 240 & 1 \\
\hline
\end{tabular}




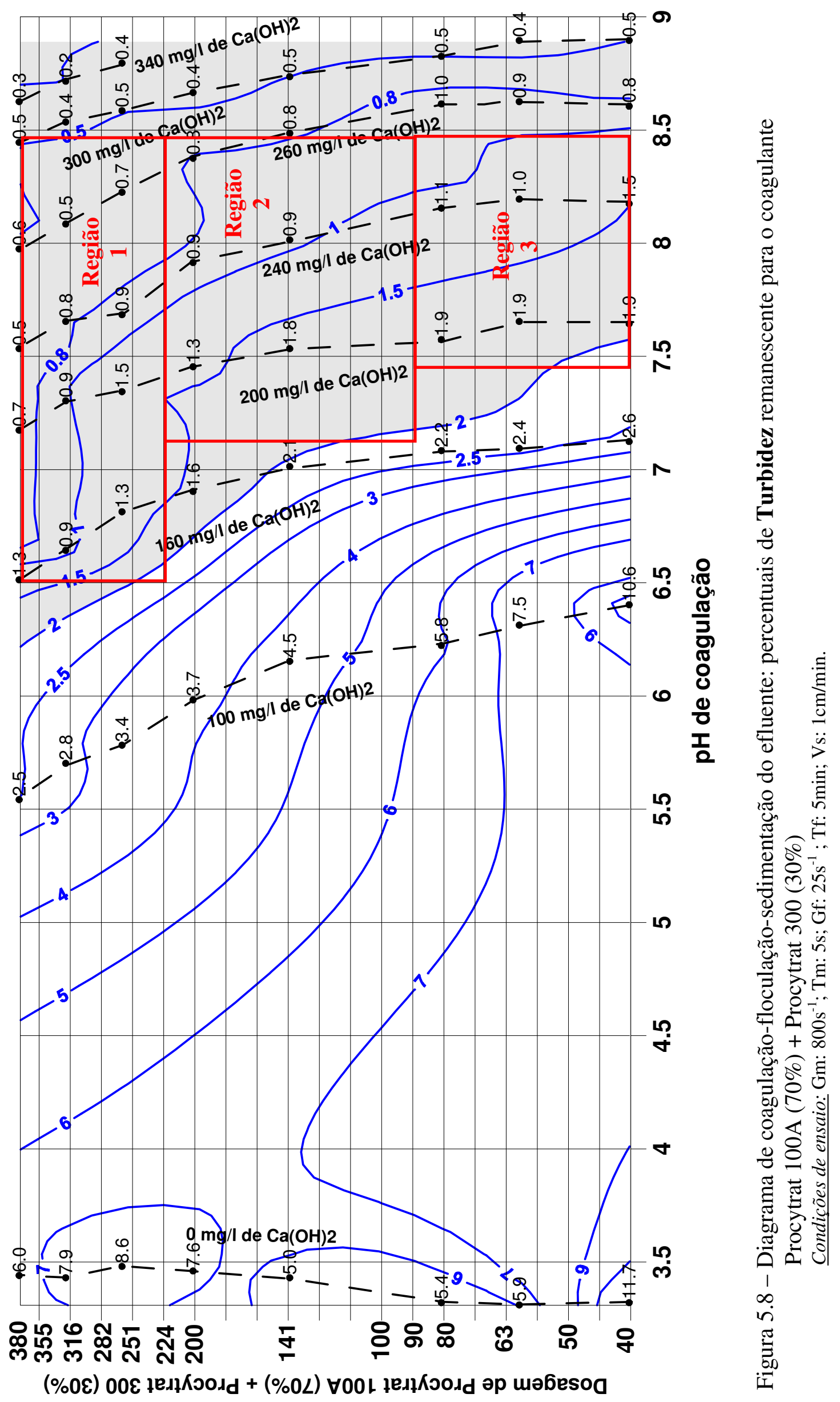




\subsection{Ensaios de coagulação-floculação-flotação}

Os dados resultantes dos ensaios de coagulação-floculação-flotação estão nos Apêndices E a G, como segue:

Apêndice E - Resultados dos ensaios de coagulação-floculação-flotação para o coagulante aluminato de sódio

Apêndice F - Resultados dos ensaios de coagulação-floculação-flotação para o coagulante cloreto férrico

Apêndice G - Resultados dos ensaios de coagulação-floculação-flotação para o coagulante Procytrat $100 \mathrm{~A}+$ Procytrat 300

\subsubsection{Resultados dos ensaios de coagulação-floculação-flotação para o coagulante aluminato de sódio}

\subsubsection{Ensaios preliminares}

$\mathrm{Na}$ primeira etapa dos ensaios preliminares de coagulação-floculação-flotação utilizando-se como coagulante o aluminato de sódio, foi escolhido o melhor par pH-DC (dosagem de coagulante) para utilização nos ensaios posteriores. Foram realizados 16 ensaios, onde foram mantidos constantes os parâmetros de mistura rápida, floculação e flotação $(\mathrm{Gm}$, Tm, Gf, Tf, R, Psat e Tsat) e houve variação na dosagem de coagulante (DC) e nos valores de pH e velocidade de flotação (Vf), mas asssim como já foi discutido no item 5.2.1.1 para os ensaios de sedimentação, os resultados de turbidez remanescente para a velocidade de flotação (Vf) para $10 \mathrm{~cm} / \mathrm{min}$ foram elevados e diante desse motivo optou-se por exibir nesse texto, somente os ensaios onde foram utilizados a velocidade de flotação de $5 \mathrm{~cm} / \mathrm{min}$. Os dados referentes a velocidade de flotação de $10 \mathrm{~cm} / \mathrm{min}$ podem ser observados no Apêndice E.

Conforme pode ser observado na Tabela 5.14, foi escolhido para os ensaios posteriores com o aluminato de sódio a dosagem de coagulante de 20mg/l e pH igual a 5,5 (40 $\mathrm{mg} / \mathrm{l}$ de $\mathrm{Ca}(\mathrm{OH}) 2)$ que gerou um percentual de turbidez remanescente de $14 \%$.

Em virtude da etapa de mistura rápida ser realizada em reator separado (jar test), os valores dos parâmetros de mistura rápida $(\mathrm{Gm}$ e Tm) não foram investigados, porém foram adotados os valores que forneceram bons resultados nos ensaios de sedimentação para o 
aluminato de sódio (item 5.2.1.1) . Foram utilizados os seguintes valores: Gm: $800 \mathrm{~s}^{-1}$ e Tm: $5 s$.

Tabela 5.14 -: Valores de turbidez e condutividade remanescente para etapa 1 dos ensaios preliminares de coagulação-floculação-flotação com o coagulante aluminato de sódio

\begin{tabular}{|c|c|c|}
\hline $\begin{array}{l}\text { Dosagem de Aluminato de } \\
\text { Sódio }(\mathrm{mg} / \mathrm{l})\end{array}$ & pH & Turbidez remanescente (\%) \\
\hline 0 & 3,5 & 53 \\
\hline 0 & 5,1 & 62 \\
\hline 0 & 6,6 & 26 \\
\hline 0 & 8,2 & 34 \\
\hline 20 & 3,9 & 52 \\
\hline 20 & 5,0 & 14 \\
\hline 20 & 5,5 & 14 \\
\hline 20 & 6,8 & 20 \\
\hline 20 & 9,5 & 23 \\
\hline 40 & 5,7 & 17 \\
\hline 60 & 4,8 & 15 \\
\hline 60 & $\overline{5,9}$ & 32 \\
\hline 60 & 7,0 & 41 \\
\hline 60 & 8,5 & 19 \\
\hline 60 & 9,6 & 42 \\
\hline 80 & 5,1 & 15 \\
\hline 100 & $\overline{5,2}$ & 14 \\
\hline 100 & 5,7 & 23 \\
\hline 100 & 6,2 & 20 \\
\hline 100 & 7,3 & 43 \\
\hline 100 & 8,7 & 22 \\
\hline 100 & 9,7 & 24 \\
\hline 200 & 6,0 & 45 \\
\hline 200 & 6,9 & 64 \\
\hline 200 & 8,1 & 34 \\
\hline 200 & 8,9 & 108 \\
\hline 300 & 6,8 & 24 \\
\hline 300 & 7,6 & 58 \\
\hline 300 & 8,9 & 42 \\
\hline 300 & 9,1 & 60 \\
\hline
\end{tabular}

$\mathrm{Na}$ segunda etapa foram realizados 12 ensaios, nos quais foram investigados os parâmetros de floculação (Gf e Tf) mais adequados, enquanto os demais parâmetros (Gm, $\mathrm{Tm}, \mathrm{pH}, \mathrm{R}$, Psat, Tsat e DC) foram mantidos fixos. Assim como nos ensaios anteriores, variou-se a velocidade de flotação (Vf), mas a velocidade escolhida em função dos resultados foi $5 \mathrm{~cm} / \mathrm{min}$. 
A dosagem de aluminato de sódio aplicada nesses ensaios foi de $20 \mathrm{mg} / \mathrm{l}$ e a dosagem de hidróxido de cálcio foi de 40mg/l.

Foram testados os seguintes valores de gradiente de floculação (Gf): $40 \mathrm{~s}^{-1}, 60 \mathrm{~s}^{-1}$, $80 \mathrm{~s}^{-1}, 100 \mathrm{~s}^{-1}$. Para cada valor de Gf foram testados os seguintes valores de Tf: $5 \mathrm{~min}, 10 \mathrm{~min}$, 15min, 20min e 30min. Foram considerados mais adequados, os parâmetros de floculação que forneceram as melhores médias dos resultados de turbidez remanescente.

$\mathrm{Na}$ Tabela 5.15, observa-se que os valores escolhidos para Gf e Tf foram $60 \mathrm{~s}^{-1} \mathrm{e}$ 10min respectivamente.

Tabela 5.15 - Valores de turbidez e condutividade remanescente para a etapa 2 dos ensaios preliminares de coagulação-floculação-flotação com o coagulante aluminato de sódio

\begin{tabular}{c|c|c|c|c}
\hline $\mathbf{G f}\left(\mathbf{s}^{-\mathbf{1}}\right)$ & $\mathbf{T f}(\mathbf{m i n})$ & $\mathbf{p H}$ & $\begin{array}{c}\text { Turbidez } \\
\text { remanescente }(\%)\end{array}$ & $\begin{array}{c}\text { Condutividade } \\
\text { remanescente }\left(\boldsymbol{\mu} \mathbf{S} / \mathbf{c m}^{2}\right)\end{array}$ \\
\hline 40 & 5 & 5,6 & 15,1 & 116 \\
\hline 40 & 10 & 5,6 & 14,0 & 116 \\
\hline 40 & 15 & 5,6 & 14,4 & 115 \\
\hline 40 & 20 & 5,6 & 16,9 & 114 \\
\hline 40 & 30 & 5,6 & 14,2 & 116 \\
\hline 60 & 5 & 5,6 & 13,6 & 115 \\
\hline 60 & 10 & 5,6 & 13,0 & 117 \\
\hline 60 & 15 & 5,6 & 14,3 & 115 \\
\hline 60 & 20 & 5,6 & 13,8 & 116 \\
\hline 60 & 30 & 5,6 & 14,8 & 111 \\
\hline 80 & 5 & 5,6 & 18,5 & 117 \\
\hline 80 & 10 & 5,6 & 14,9 & 118 \\
\hline 80 & 15 & 5,7 & 13,5 & 115 \\
\hline 80 & 20 & 5,6 & 14,9 & 117 \\
\hline 80 & 30 & 5,6 & 14,1 & 115 \\
\hline 100 & 5 & 5,6 & 16,3 & 115 \\
\hline 100 & 10 & 5,6 & 15,0 & 114 \\
\hline 100 & 15 & 5,6 & 12,8 & 118 \\
\hline 100 & 20 & 5,6 & 11,7 & \\
\hline 100 & 30 & 5,6 & 14,0 & \\
\hline
\end{tabular}

$\mathrm{Na}$ terceira etapa foram realizados 3 ensaios, nos quais foi investigada a taxa de recirculação $(\mathrm{R})$ mais adequada, enquanto os demais parâmetros (Gm, Tm, Gf, Tf, Psat, Tsat, pH e DC) foram mantidos fixos. Foi considerada mais adequada, a taxa de recirculação (R) que forneceu o melhor resultado de turbidez remanescente.

$\mathrm{Na}$ Tabela 5.16, observa-se que o valor escolhido para a taxa de recirculação $(\mathrm{R})$ foi de $50 \%$. 
Tabela 5.16 - Valores de turbidez e condutividade remanescente para a etapa 3 dos ensaios preliminares de coagulação-floculação-flotação com o coagulante aluminato de sódio.

\begin{tabular}{c|c|c|c}
\hline $\mathbf{R}(\boldsymbol{\%})$ & $\mathbf{p H}$ & $\begin{array}{c}\text { Turbidez } \\
\text { remanescente }(\boldsymbol{\%})\end{array}$ & $\begin{array}{c}\text { Condutividade } \\
\text { remanescente (\%) }\end{array}$ \\
\hline 20 & 5,2 & 17,5 & 93 \\
\hline 30 & 5,2 & 12,0 & 99 \\
\hline 40 & 5,2 & 13,6 & 104 \\
\hline $\mathbf{5 0}$ & $\mathbf{5 , 2}$ & $\mathbf{1 2 , 4}$ & $\mathbf{1 0 9}$ \\
\hline 70 & 5,2 & 17,5 & 134 \\
\hline
\end{tabular}

\subsubsection{Diagrama de coagulação-floculação-flotação para o coagulante aluminato de sódio}

Na quarta etapa, para a construção do diagrama de coagulação, foram realizados 28 ensaios onde foram utilizados os valores dos parâmetros de mistura rápida, floculação e taxa de recirculação $(\mathrm{Gm}, \mathrm{Tm}, \mathrm{Gf}, \mathrm{Tf}, \mathrm{R})$ obtidos na segunda e terceira etapa e foram variados o pH (com a dosagem de hidróxido de cálcio) e a dosagem do coagulante (DC), nesse caso, aluminato de sódio. A pressão e tempo de saturação (Psat e Tsat) foram mantidas iguais a $500 \mathrm{kPa}$ e $10 \mathrm{~min}$ respectivamente.

Assim como nos ensaios anteriores, a velocidade de flotação (Vf) foi mantida constante e igual a $5 \mathrm{~cm} / \mathrm{min}$.

Na Figura 5.9 é apresentado o diagrama de coagulação do efluente relativo a análise de turbidez para o coagulante aluminato de sódio.

A Tabela 5.17 fornece os resultados das faixas otimizadas de $\mathrm{pH}$ e dosagens de coagulante. Observa-se Tabela 5.17 que as faixas de pH e concentração de coagulante com maiores eficiências de remoção de turbidez são bem menores se comparadas as faixas dos ensaios de sedimentação. As maiores eficiências de remoção também estão em faixas bastante diferentes de $\mathrm{pH}$, sendo que a maior eficiência de remoção $(3,7 \%)$ foi atingida na região 2 para a dosagem de coagulante de $200 \mathrm{mg} / \mathrm{l}$.

$\mathrm{Na}$ região 1 , temos um ponto com uma eficiência de remoção um pouco menor $(4,8 \%)$, porém nesse ponto utilizou-se uma dosagem menor de coagulante $(60 \mathrm{mg} / \mathrm{l})$ e não foi utilizado hidróxido de cálcio, consequentemente teremos um consumo menor de coagulante 
se comparada ao outro ponto. A escolha da condição mais adequada, será feita mais adiante neste texto (item $5.5-$ p.110).

Tabela 5.17 - Regiões dos diagramas de coagulação-floculação-flotação com aluminato de sódio. e valores percentuais de turbidez remanescente

\begin{tabular}{c|c|c|c|c|c|c}
\hline & $\begin{array}{c}\text { Faixas de pH-DC para turbidez } \\
\text { remanescente }<\mathbf{5 \%}\end{array}$ & \multicolumn{5}{c}{ Melhores pontos dentro das regiões } \\
\cline { 2 - 7 } Região & $\mathbf{p H}$ de & $\begin{array}{c}\text { Dosagem de } \\
\text { aluminato de } \\
\end{array}$ & $\mathbf{p H ~ d e}$ & $\begin{array}{c}\text { Dosagem de } \\
\text { aluminato de } \\
\text { sódio }(\mathbf{m g} / \mathbf{l})\end{array}$ & $\begin{array}{c}\text { Dosagem de } \\
\text { hidróxido de } \\
\text { coagulação }\end{array}$ & $\begin{array}{c}\text { Turbidez } \\
\text { remanescente }\end{array}$ \\
\hline $\mathbf{1}$ & $4,4-4,5$ & $60-75$ & 4,45 & 60 & 0 & 4,8 \\
\hline $\mathbf{2}$ & $8,8-8,9$ & $190-210$ & 8,86 & 200 & 240 & 3,7 \\
\hline
\end{tabular}




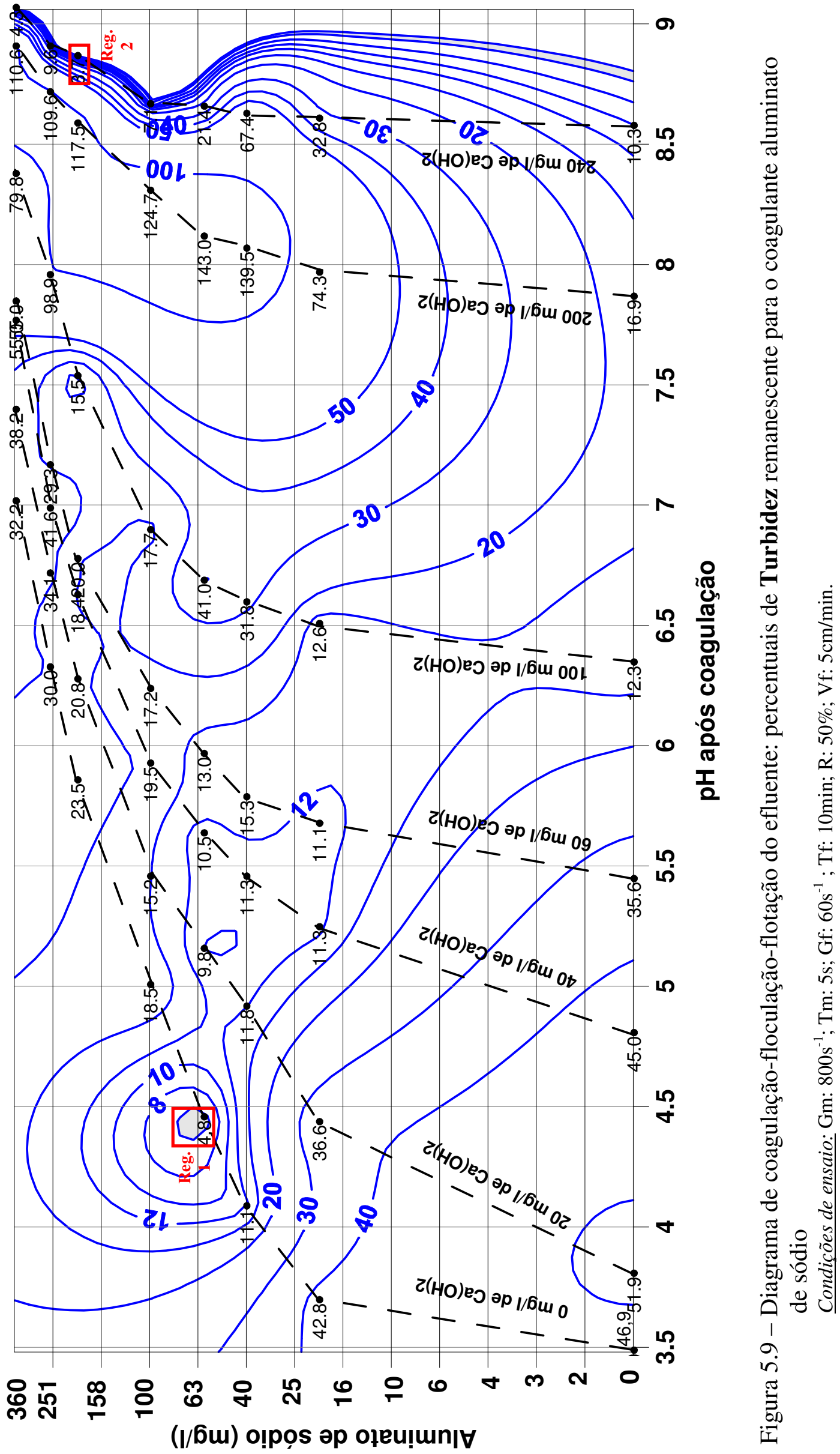




\subsubsection{Resultados dos ensaios de coagulação-floculação-flotação para o coagulante cloreto férrico}

\subsubsection{Ensaios preliminares}

$\mathrm{Na}$ primeira etapa dos ensaios preliminares de coagulação-floculação-flotação utilizando-se como coagulante o cloreto férrico, foi escolhido o melhor par pH-DC (dosagem de coagulante) para utilização nos ensaios posteriores. Foram realizados 12 ensaios, onde foram mantidos constantes os parâmetros de mistura rápida, floculação e flotação $(\mathrm{Gm}, \mathrm{Tm}$, Gf, Tf, R, Psat e Tsat) e houve variação na dosagem de coagulante (DC) e nos valores de pH e velocidade de flotação (Vf), mas asssim como já foi discutido no item 5.2.1.1 para os ensaios de sedimentação, os resultados de turbidez remanescente para a velocidade de flotação (Vf) para $10 \mathrm{~cm} / \mathrm{min}$ foram elevados e diante desse motivo optou-se por exibir nesse texto somente os ensaios onde foram utilizados a velocidade de flotação de $5 \mathrm{~cm} / \mathrm{min}$. Os dados referentes a velocidade de flotação de $10 \mathrm{~cm} / \mathrm{min}$ podem ser observados no Apêndice F.

Observa-se na Tabela 5.18 que nenhum resultado de percentual de turbidez remanescente ficou abaixo de $5 \%$ e que o melhor resultado (8\%) foi encontrado para DC igual a 300mg/l e pH igual a 2,7, mas visando a economia de coagulante e hidróxido de cálcio, foi escolhido para os ensaios posteriores a dosagem de coagulante de 40mg/l e pH igual a 4,7 (40 $\mathrm{mg} / \mathrm{l}$ de $\left.\mathrm{Ca}(\mathrm{OH})_{2}\right)$ que gerou um percentual de turbidez remanescente de $9 \%$.

Em virtude da etapa de mistura rápida ser realizada em reator separado (jar test), os valores dos parâmetros de mistura rápida (Gm e Tm) não foram investigados, porém foram adotados os valores que forneceram bons resultados nos ensaios de sedimentação para o cloreto férrico (item 5.2.2.1) . Foram utilizados os seguintes valores: Gm: 800s ${ }^{-1}$ e Tm: $5 \mathrm{~s}$. 
Tabela 5.18 - Valores de turbidez e condutividade remanescente para etapa 1 dos ensaios preliminares de coagulação-floculação-flotação com o coagulante cloreto férrico

\begin{tabular}{|c|c|c|}
\hline $\begin{array}{l}\text { Dosagem de Cloreto Férrico } \\
\qquad(\mathrm{mg} / \mathrm{l})\end{array}$ & $\mathbf{p H}$ & $\begin{array}{c}\text { Turbidez remanescente } \\
(\%)\end{array}$ \\
\hline 0 & 3,7 & 23 \\
\hline 0 & 5,0 & 14 \\
\hline 0 & 6,1 & 38 \\
\hline 20 & 3,5 & 17 \\
\hline 20 & 4,9 & 9 \\
\hline 20 & 5,3 & 11 \\
\hline 20 & 6,0 & 41 \\
\hline 40 & 3,4 & 12 \\
\hline 40 & 4,7 & 9 \\
\hline 40 & 5,2 & 9 \\
\hline 40 & 5,8 & 37 \\
\hline 100 & 3,1 & 53 \\
\hline 100 & 4,1 & 47 \\
\hline 100 & 5,5 & 28 \\
\hline 200 & 2,9 & 69 \\
\hline 200 & 3,3 & 87 \\
\hline 200 & 5,0 & 92 \\
\hline 300 & 2,7 & 8 \\
\hline 300 & 3,0 & 17 \\
\hline 300 & 4,1 & 81 \\
\hline
\end{tabular}

$\mathrm{Na}$ segunda etapa foram realizados 15 ensaios, nos quais foram investigados os parâmetros de floculação (Gf e Tf) mais adequados, enquanto os demais parâmetros (Gm, $\mathrm{Tm}, \mathrm{pH}, \mathrm{R}$, Psat, Tsat e DC) foram mantidos fixos. Assim como nos ensaios anteriores, variou-se a velocidade de flotação (Vf), mas a velocidade escolhida em função dos resultados foi a velocidade de $5 \mathrm{~cm} / \mathrm{min}$.

A dosagem de cloreto férrico aplicada nesses ensaios foi de $40 \mathrm{mg} / \mathrm{l}$ e a dosagem de hidróxido de cálcio foi de $40 \mathrm{mg} / \mathrm{l}$.

Foram testados os seguintes valores de gradiente de floculação (Gf): $25 \mathrm{~s}^{-1}, 40 \mathrm{~s}^{-1}$, $60 \mathrm{~s}^{-1}, 80 \mathrm{~s}^{-1}, 100 \mathrm{~s}^{-1}$ e $120 \mathrm{~s}^{-1}$. Para cada valor de Gf foram testados os seguintes valores de Tf: $5 \mathrm{~min}$, 10min, 20min e 30min. Foram considerados mais adequados, os parâmetros de floculação que forneceram as melhores médias dos resultados de turbidez remanescente.

$\mathrm{Na}$ Tabela 5.19, observa-se que os valores escolhidos para Gf e Tf foram $100 \mathrm{~s}^{-1} \mathrm{e}$ $10 \mathrm{~min}$ respectivamente. 
Tabela 5.19 - Valores de turbidez e condutividade remanescente para a etapa 2 dos ensaios preliminares de coagulação-floculação-flotação com o coagulante cloreto férrico

\begin{tabular}{|c|c|c|c|c|}
\hline $\mathbf{G f}\left(\mathrm{s}^{-1}\right)$ & Tf (min) & pH & $\begin{array}{c}\text { Turbidez remanescente } \\
(\%)\end{array}$ & $\begin{array}{c}\text { Condutividade } \\
\text { remanescente }(\%)\end{array}$ \\
\hline 25 & 10 & 4,9 & 5,1 & 116 \\
\hline 25 & 20 & 4,9 & 6,2 & 117 \\
\hline 40 & 5 & 4,8 & 5,9 & 118 \\
\hline 40 & 10 & 4,8 & 5,0 & 118 \\
\hline 40 & 15 & 4,7 & 5,1 & 118 \\
\hline 40 & 20 & 4,7 & 4,9 & 117 \\
\hline 40 & 30 & 4,8 & 4,8 & 118 \\
\hline 60 & 10 & 4,9 & 5,6 & 113 \\
\hline 60 & 20 & 4,9 & 5,6 & 118 \\
\hline 80 & 5 & 4,8 & 5,3 & 125 \\
\hline 80 & 10 & 4,8 & 5,5 & 125 \\
\hline 80 & 15 & 4,7 & 5,2 & 125 \\
\hline 80 & 20 & 4,8 & 5,5 & 124 \\
\hline 80 & 30 & 4,8 & 5,2 & 124 \\
\hline 100 & 5 & 4,9 & 4,2 & 120 \\
\hline 100 & 10 & 4,9 & 4,6 & 121 \\
\hline 100 & 15 & 4,9 & 4,9 & 122 \\
\hline 100 & 20 & 4,8 & 4,7 & 121 \\
\hline 100 & 30 & 4,9 & 5,0 & 122 \\
\hline 120 & 5 & 4,9 & 5,3 & 119 \\
\hline 120 & 10 & 4,9 & 5,0 & 119 \\
\hline 120 & 15 & 4,9 & 5,5 & 119 \\
\hline 120 & 20 & 4,9 & 5,3 & 119 \\
\hline 120 & 30 & 4,9 & 4,9 & 118 \\
\hline
\end{tabular}

$\mathrm{Na}$ terceira etapa foram realizados 3 ensaios, nos quais foi investigada a taxa de recirculação (R) mais adequada, enquanto os demais parâmetros (Gm, Tm, Gf, Tf, Psat, Tsat, pH e DC) foram mantidos fixos. Foi considerada mais adequada, a taxa de recirculação (R) que forneceu o melhor resultado de turbidez remanescente.

$\mathrm{Na}$ Tabela 5.20, observa-se que o valores escolhido para a taxa de recirculação $(\mathrm{R})$ foi de $50 \%$.

Tabela 5.20 - Valores de turbidez e condutividade remanescente para a etapa 3 dos ensaios preliminares de coagulação-floculação-flotação com o coagulante cloreto férrico

\begin{tabular}{c|c|c|c}
\hline $\mathbf{R}(\boldsymbol{\%})$ & $\mathbf{p H}$ & $\begin{array}{c}\text { Turbidez } \\
\text { remanescente (\%) }\end{array}$ & $\begin{array}{c}\text { Condutividade } \\
\text { remanescente (\%) }\end{array}$ \\
\hline 10 & 4,6 & 27,9 & 101 \\
\hline 20 & 4,6 & 42,0 & 104 \\
\hline 30 & 4,6 & 10,6 & 109 \\
\hline $\mathbf{5 0}$ & $\mathbf{4 , 6}$ & $\mathbf{5 , 2}$ & $\mathbf{1 2 2}$ \\
\hline 70 & 4,6 & 5,2 & 144 \\
\hline
\end{tabular}




\subsubsection{Diagrama de coagulação-floculação-flotação para o coagulante cloreto férrico}

Na quarta etapa, para a construção do diagrama de coagulação, foram realizados 19 ensaios onde foram utilizados os valores dos parâmetros de mistura rápida, floculação e taxa de recirculação (Gm, Tm, Gf, Tf, R), obtidos na segunda e terceira etapa e foram variados o pH (com a dosagem de hidróxido de cálcio) e a dosagem do coagulante (DC), nesse caso, cloreto férrico. A pressão e tempo de saturação (Psat e Tsat) foram mantidas iguais a 500kPa e 10min respectivamente.

Assim como nos ensaios anteriores, a velocidade de flotação (Vf) foi mantida constante e igual a $5 \mathrm{~cm} / \mathrm{min}$.

Na Figura 5.10 é apresentado o diagrama de coagulação do efluente relativo a análise de turbidez para o coagulante cloreto férrico.

A Tabela 5.21 fornece os resultados das faixas otimizadas de $\mathrm{pH}$ e dosagens de coagulante. Observa-se na Tabela 5.21 que as faixas de pH e concentração de coagulante com maiores eficiências de remoção de turbidez são bem menores se comparadas as faixas dos ensaios de sedimentação. As maiores eficiências de remoção estão na faixa de pH de 3,2 a 5,3 , sendo que a maior eficiência de remoção $(3,5 \%)$ foi atingida na região 1 para a dosagem de coagulante de $60 \mathrm{mg} / 1$.

Na região 2, temos um ponto com uma eficiencia de remoção um pouco menor (4,5\%), porém nesse ponto utilizou-se uma dosagem menor de coagulante $(20 \mathrm{mg} / \mathrm{l})$ e o pH já está mais próximo do desejado $(8,5)$ e consequentemente teremos um consumo menor de coagulante se comparada ao outro ponto. A escolha da condição mais adequada, será feita mais adiante neste texto (item 5.5 - p.110).

Tabela 5.21 - Regiões dos diagramas de coagulação-floculação-flotação com cloreto férrico e valores percentuais de turbidez remanescente

\begin{tabular}{c|c|c|c|c|c|c}
\hline & $\begin{array}{c}\text { Faixas de pH-DC para turbidez } \\
\text { remanescente < 5\% }\end{array}$ & \multicolumn{4}{c}{ Melhores pontos dentro das regiões } \\
\cline { 2 - 7 } Região & $\mathbf{p H}$ de & $\begin{array}{c}\text { Dosagem de } \\
\text { cloreto férrico } \\
(\mathbf{m g} / \mathbf{l})\end{array}$ & $\mathbf{p H ~ d e}$ & $\begin{array}{c}\text { Dosagem de } \\
\text { cloreto férrico } \\
(\mathbf{m g} / \mathbf{l})\end{array}$ & $\begin{array}{c}\text { Dosagem de } \\
\text { hidróxido de } \\
\text { cálcio (mg/l) }\end{array}$ & $\begin{array}{c}\text { Turbidez } \\
\text { remanescente } \\
(\mathbf{\%})\end{array}$ \\
\hline $\mathbf{1}$ & $3,2-4,6$ & $40-60$ & 3,2 & 60 & 0 & 3,5 \\
\hline $\mathbf{2}$ & $4,6-5,3$ & $16-60$ & 5,3 & 20 & 60 & 4,5 \\
\hline
\end{tabular}


Dosagem de cloreto férrico (mg/l)

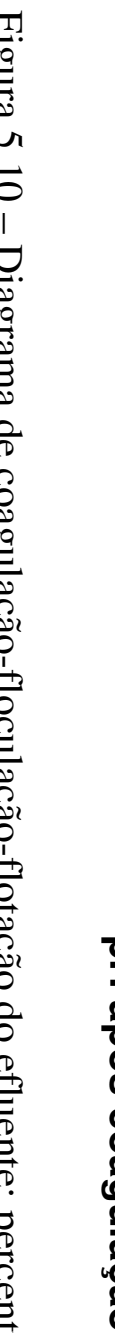

○ $N \omega+\sigma$ ठ

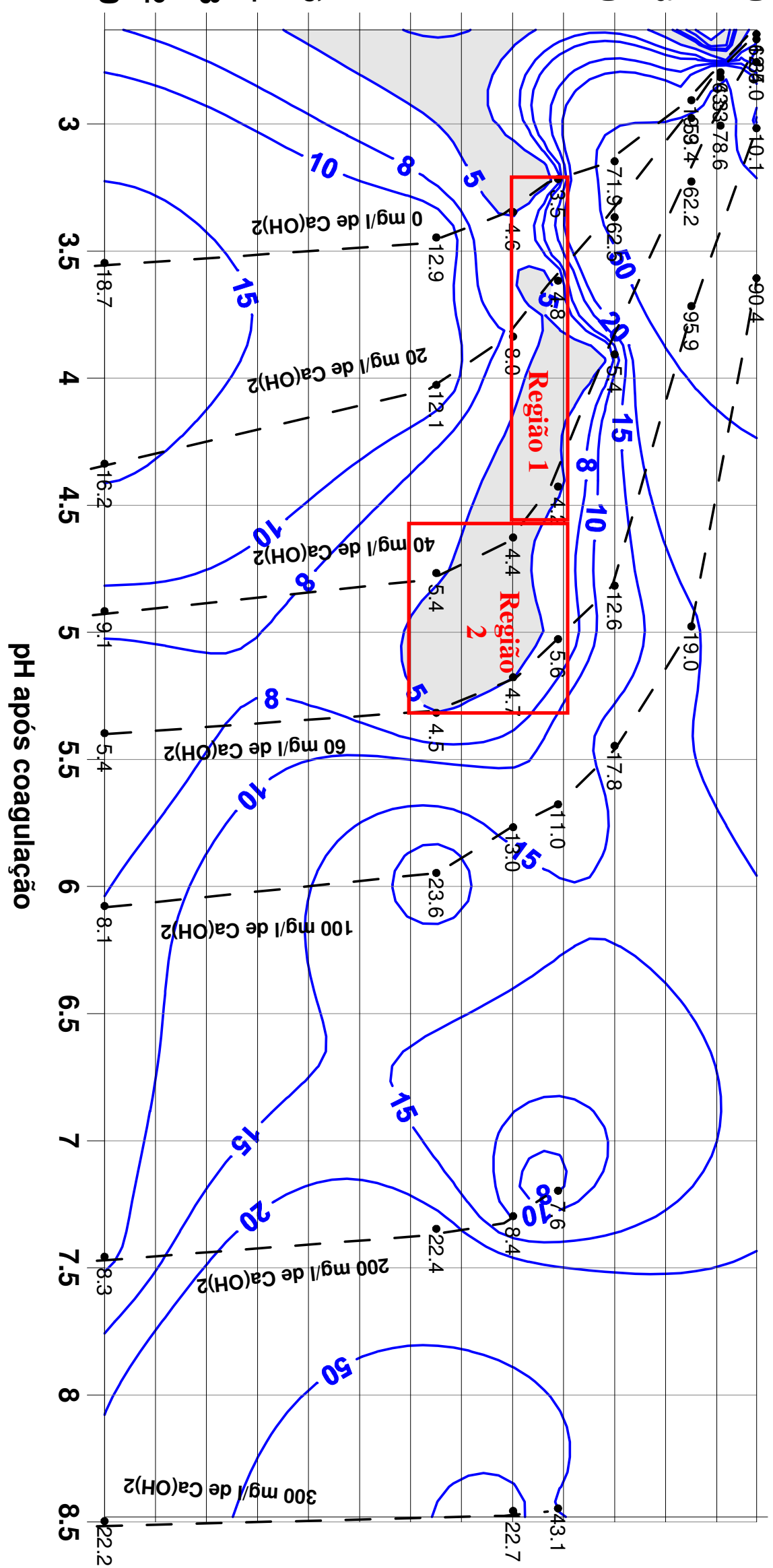




\subsubsection{Resultados dos ensaios de coagulação-floculação-flotação para o coagulante Procytrat 100A + Procytrat 300}

\subsubsection{Ensaios preliminares}

$\mathrm{Na}$ primeira etapa dos ensaios preliminares de coagulação-floculação-flotação utilizando-se como coagulante a mistura dos produtos Procytrat 100A (70\%) e Procytrat 300 (30\%), foi escolhido o melhor par pH-DC (dosagem de coagulante) para utilização nos ensaios posteriores. Foram realizados 13 ensaios, onde foram mantidos constantes os parâmetros de mistura rápida, floculação e flotação (Gm, Tm, Gf, Tf, R, Psat, Tsat) e houve variação na dosagem de coagulante (DC) e nos valores de $\mathrm{pH}$ e velocidade de flotação (Vf), mas asssim como já foi discutido no item 5.2.1.1 para os ensaios de sedimentação, os resultados de turbidez remanescente para a velocidade de flotação (Vf) para $10 \mathrm{~cm} / \mathrm{min}$ foram elevados e diante desse motivo optou-se por exibir nesse texto somente os ensaios onde foram utilizados a velocidade de flotação de $5 \mathrm{~cm} / \mathrm{min}$. Os dados referentes a velocidade de flotação de $10 \mathrm{~cm} / \mathrm{min}$ podem ser observados no Apêndice G.

Observa-se na Tabela 5.22 que o melhor resultado (1,8\%) foi encontrado para DC igual a $200 \mathrm{mg} / \mathrm{l}$ e $\mathrm{pH}$ igual a 4,23, mas visando a economia de coagulante e hidróxido de cálcio, foi escolhido para os ensaios posteriores a dosagem de coagulante de $100 \mathrm{mg} / \mathrm{l} \mathrm{e} \mathrm{pH}$ igual a 3,92 $\left(20 \mathrm{mg} / \mathrm{l}\right.$ de $\left.\mathrm{Ca}(\mathrm{OH})_{2}\right)$ que gerou um percentual de turbidez remanescente de $2,4 \%$. Colaborou também para essa escolha o bom resultado da turbidez remanescente para Vf igual a $10 \mathrm{~cm} / \mathrm{min}$ para esse mesma dosagem que foi de $2,5 \%$.

Em virtude da etapa de mistura rápida ser realizada em reator separado (jar test), os valores dos parâmetros de mistura rápida $(\mathrm{Gm}$ e $\mathrm{Tm})$ não foram investigados, porém foram adotados os valores que forneceram bons resultados nos ensaios de sedimentação para o coagulante Procytrat 100A + Procytrat 300 (item 5.2.3.1) . Foram utilizados os seguintes valores: Gm: $800 \mathrm{~s}^{-1}$ e Tm: $5 \mathrm{~s}$. 
Tabela 5.22 - Valores de turbidez e condutividade remanescente para etapa 1 dos ensaios preliminares de coagulação-floculação-flotação com o coagulante Procytrat $100 \mathrm{~A}+$ Procytrat 300

\begin{tabular}{|c|c|c|}
\hline $\begin{array}{c}\text { Dosagem de Procytrat 100A + } \\
\text { Procytrat } 300(\mathrm{mg} / \mathrm{l})\end{array}$ & pH & $\begin{array}{c}\text { Turbidez remanescente } \\
(\%)\end{array}$ \\
\hline 0 & 4,86 & 8,9 \\
\hline 0 & 6,36 & 16,3 \\
\hline 20 & 3,32 & 7,4 \\
\hline 20 & 4,83 & 5,1 \\
\hline 20 & 6,33 & 7,3 \\
\hline 40 & 3,37 & 2,3 \\
\hline 40 & 4,78 & 3,5 \\
\hline 40 & 6,30 & 10,0 \\
\hline 60 & 3,40 & 2,0 \\
\hline 60 & 3,90 & 2,6 \\
\hline 60 & 4,74 & 3,0 \\
\hline 60 & 6,25 & 6,2 \\
\hline 100 & 3,41 & 2,1 \\
\hline 100 & 3,92 & 2,4 \\
\hline 100 & 4,66 & 2,2 \\
\hline 100 & 6,17 & 17,4 \\
\hline 200 & 3,46 & 4,0 \\
\hline 200 & 3,90 & 3,2 \\
\hline 200 & 4,23 & 1,8 \\
\hline 260 & 3,46 & 3,2 \\
\hline 260 & 4,05 & 13,4 \\
\hline 260 & 5,73 & 61,5 \\
\hline 360 & 3,46 & 2,6 \\
\hline 360 & 3,85 & 89,0 \\
\hline
\end{tabular}

$\mathrm{Na}$ segunda etapa foram realizados 9 ensaios, nos quais foram investigados os parâmetros de floculação (Gf e Tf) mais adequados, enquanto os demais parâmetros (Gm, Tm, pH, R, Psat, Tsat e DC) foram mantidos fixos. Assim como nos ensaios anteriores, variou-se a velocidade de flotação (Vf), mas a velocidade escolhida em função dos resultados foi a velocidade de $5 \mathrm{~cm} / \mathrm{min}$. Os valores para a velocidade de $10 \mathrm{~cm} / \mathrm{min}$ podem ser encontradas no Apêndice G.

A dosagem da mistura Procytrat 100A (70\%) + Procytrat $300(30 \%)$ aplicada nesses ensaios foi de 100mg/l e a dosagem de hidróxido de cálcio foi de 20mg/l.

Foram testados os seguintes valores de gradiente de floculação (Gf): $40 \mathrm{~s}^{-1}, 60 \mathrm{~s}^{-1} \mathrm{e}$ $80 \mathrm{~s}^{-1}$. Para cada valor de Gf foram testados os seguintes valores de Tf: $5 \mathrm{~min}, 10 \mathrm{~min}, 20 \mathrm{~min}$ e 30min. Foram considerados mais adequados, os parâmetros de mistura rápida que forneceram as melhores médias dos resultados de turbidez remanescente. 
$\mathrm{Na}$ Tabela 5.23, observa-se que o menor valor de turbidez remanescente foi de 2,2\%, porém esse valor aumentaria os custos com energia e o tempo de floculação, por isso o valores escolhidos para Gf e Tf foram $60 \mathrm{~s}^{-1}$ e $15 \mathrm{~min}$ respectivamente. Para esses parâmetros o valor de turbidez remanescente foi de $2,8 \%$.

Tabela 5.23 - Valores de turbidez e condutividade remanescente para a etapa 2 dos ensaios preliminares de coagulação-floculação-flotação com o coagulante Procytrat $100 \mathrm{~A}+$ Procytrat 300

\begin{tabular}{c|c|c|c|c}
\hline $\mathbf{G f}\left(\mathbf{s}^{-\mathbf{1}}\right)$ & Tf $(\mathbf{m i n})$ & $\mathbf{p H}$ & $\begin{array}{c}\text { Turbidez } \\
\text { remanescente (\%) }\end{array}$ & $\begin{array}{c}\text { Condutividade } \\
\text { remanescente (\%) }\end{array}$ \\
\hline 40 & 5 & 3,90 & 3,3 & 110,1 \\
\hline 40 & 10 & 3,90 & 3,3 & 109,6 \\
\hline 40 & 15 & 3,88 & 3,0 & 110,2 \\
\hline 40 & 20 & 3,90 & 3,0 & 109,4 \\
\hline 40 & 30 & 3,90 & 3,1 & 103,3 \\
\hline 60 & 5 & 3,91 & 2,9 & 105,3 \\
\hline 60 & 10 & 3,90 & 3,2 & 102,1 \\
\hline $\mathbf{6 0}$ & $\mathbf{1 5}$ & $\mathbf{3 , 9 0}$ & $\mathbf{2 , 8}$ & $\mathbf{1 0 4 , 0}$ \\
\hline 60 & 20 & 3,92 & 2,8 & 104,3 \\
\hline 60 & 30 & 3,91 & 2,4 & 105,3 \\
\hline 80 & 5 & 3,92 & 2,8 & 109,4 \\
\hline 80 & 10 & 3,91 & 2,7 & 108,8 \\
\hline 80 & 15 & 3,94 & 3,1 & 108,3 \\
\hline 80 & 20 & 3,94 & 3,1 & 110,7 \\
\hline 80 & 30 & 3,93 & 2,2 & 110,7 \\
\hline
\end{tabular}

$\mathrm{Na}$ terceira etapa foram realizados 3 ensaios, nos quais foi investigada a taxa de recirculação $(\mathrm{R})$ mais adequada, enquanto os demais parâmetros (Gm, Tm, Gf, Tf, Psat, Tsat, pH e DC) foram mantidos fixos. Foi considerada mais adequada, a taxa de recirculação (R) que forneceu o melhor resultado de turbidez remanescente. Assim como nos ensaios anteriores, variou-se a velocidade de flotação (Vf), mas a velocidade escolhida em função dos resultados foi a velocidade de $5 \mathrm{~cm} / \mathrm{min}$. Os valores para a velocidade de $10 \mathrm{~cm} /$ min podem ser encontradas no Apêndice G.

Na Tabela 5.24, observa-se que o valores escolhido para a taxa de recirculação (R) foi de $40 \%$. 
Tabela 5.24 - Valores de turbidez e condutividade remanescente para a etapa 3 dos ensaios preliminares de coagulação-floculação-flotação com o coagulante Procytrat $100 \mathrm{~A}+$ Procytrat 300

\begin{tabular}{c|c|c|c}
\hline $\mathbf{R}(\boldsymbol{\%})$ & $\mathbf{p H}$ & Turbidez remanescente (\%) & $\begin{array}{c}\text { Condutividade remanescente } \\
(\boldsymbol{\%})\end{array}$ \\
\hline 20 & 3,93 & 13,5 & 1145 \\
\hline 30 & 3,93 & 10,8 & 1174 \\
\hline $\mathbf{4 0}$ & $\mathbf{3 , 9 5}$ & $\mathbf{1 0 , 1}$ & $\mathbf{1 1 9 3}$ \\
\hline 50 & 3,94 & 12,6 & 1282 \\
\hline 70 & 3,95 & 20,0 & 1457 \\
\hline
\end{tabular}

\subsubsection{Diagrama de coagulação-floculação-flotação para o coagulante Procytrat 100A + Procytrat 300}

$\mathrm{Na}$ quarta etapa, para a construção do diagrama de coagulação, foram realizados 20 ensaios onde foram utilizados os valores dos parâmetros de mistura rápida, floculação e taxa de recirculação (Gm, Tm, Gf, Tf, R) obtidos na segunda e terceira etapa e foram variados o pH (com a dosagem de hidróxido de cálcio) e a dosagem do coagulante (DC), nesse caso, Procytrat 100A + Procytrat 300. A pressão e tempo de saturação (Psat e Tsat) foram mantidas iguais a $500 \mathrm{kPa}$ e $10 \mathrm{~min}$ respectivamente.

Assim como nos ensaios anteriores, a velocidade de flotação (Vf) foi mantida constante e igual a $5 \mathrm{~cm} / \mathrm{min}$. Os valores para a velocidade de $10 \mathrm{~cm} / \mathrm{min}$ podem ser encontradas no Apêndice G.

Na Figura 5.11 é apresentado o diagrama de coagulação do efluente relativo a análise de turbidez para o coagulante Procytrat 100A + Procytrat 300.

A Tabela 5.25 fornece os resultados das faixas otimizadas de $\mathrm{pH}$ e dosagens de coagulante. Observa-se na Tabela 5.25 que as faixas de pH e concentração de coagulante com maiores eficiências de remoção de turbidez são bem menores se comparadas as faixas dos ensaios de sedimentação. As maiores eficiências de remoção estão na faixa de $\mathrm{pH}$ de 3,3 a 5,5 , sendo que a maior eficiência de remoção $(1,4 \%)$ foi atingida na região 2 para a dosagem de coagulante de $200 \mathrm{mg} / 1$.

A escolha da condição mais adequada, será feita mais adiante neste texto (item 5.5 p.110). 
Tabela 5.25 - Regiões dos diagramas de coagulação-floculação-flotação com Procytrat 100A + Procytrat 300 e valores percentuais de turbidez remanescente

\begin{tabular}{|c|c|c|c|c|c|c|}
\hline \multirow[b]{2}{*}{ Região } & \multicolumn{2}{|c|}{$\begin{array}{c}\text { Faixas de } \mathrm{pH}-\mathrm{DC} \text { para turbidez } \\
\text { remanescente }<5 \%\end{array}$} & \multicolumn{4}{|c|}{ Melhores pontos dentro das regiões } \\
\hline & $\begin{array}{c}\text { pH de } \\
\text { coagulação }\end{array}$ & \begin{tabular}{|c|} 
Dosagem de \\
hidróxicloreto de \\
alumínio* $(\mathrm{mg} / \mathrm{l})$
\end{tabular} & \begin{tabular}{c|} 
pH de \\
coagulação
\end{tabular} & $\begin{array}{c}\text { Dosagem de } \\
\text { hidróxicloreto de } \\
\text { alumínio* }(\mathrm{mg} / \mathrm{l})\end{array}$ & $\begin{array}{c}\text { Dosagem de } \\
\text { hidróxido de } \\
\text { cálcio }(\mathrm{mg} / \mathrm{l})\end{array}$ & $\begin{array}{c}\text { Turbidez } \\
\text { remanescente } \\
(\%)\end{array}$ \\
\hline 1 & $3,3-5,5$ & $' 10-60$ & 3,3 & 60 & 0 & 1,6 \\
\hline 2 & $3,3-5,3$ & $60-200$ & 4,2 & 200 & 40 & 1,4 \\
\hline
\end{tabular}


Dosagem de Procytrat 100A (70\%) + Procytrat 300 (30\%)

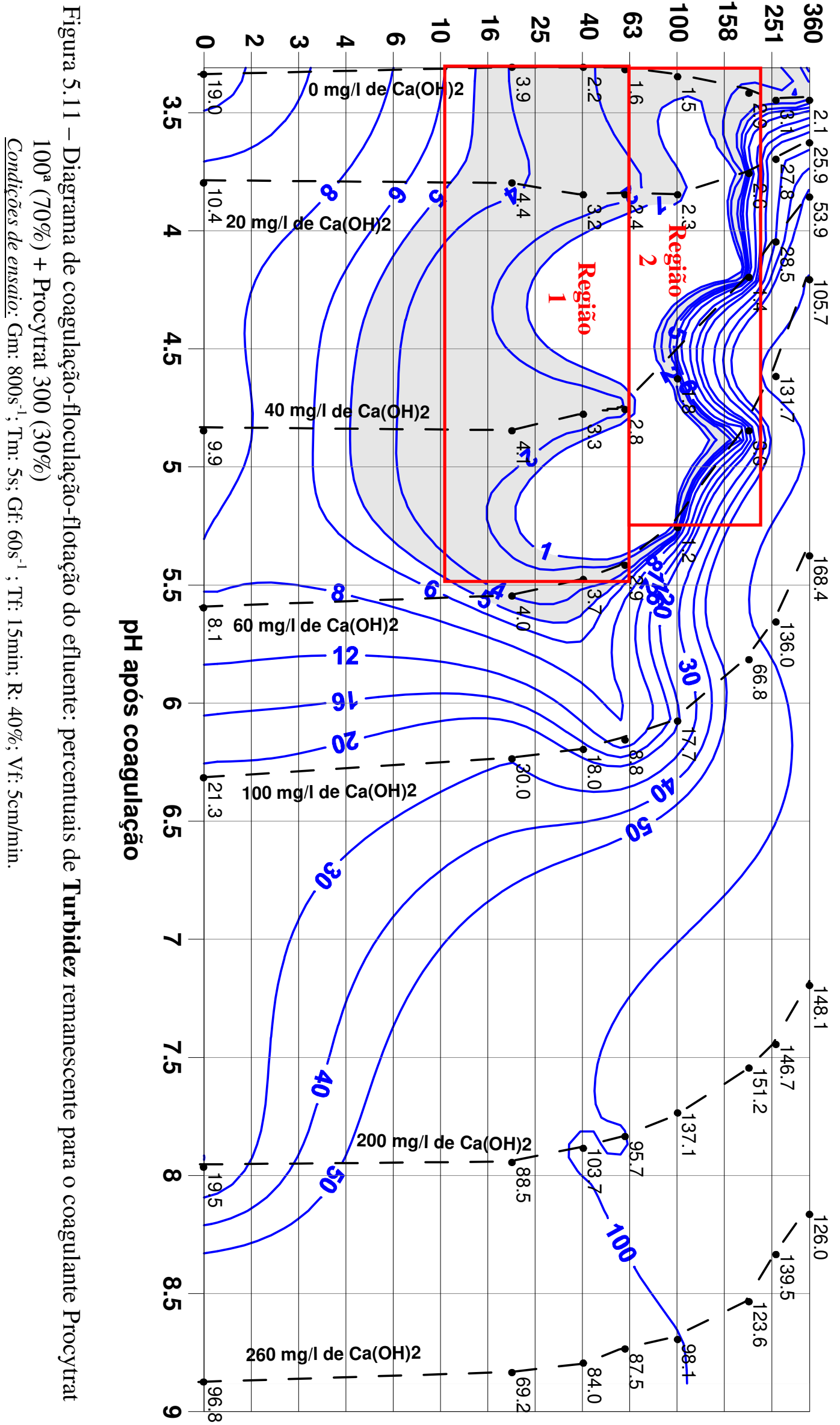




\subsection{Resumo dos resultados dos ensaios de coagulação-floculação}

No Quadro 5.1 pode-se observar um resumo dos parâmetros operacionais encontrados nos ensaios de coagulação-floculação:

\begin{tabular}{|c|c|c|c|c|c|c|c|c|c|c|}
\hline \multirow[b]{2}{*}{ Ensaio } & \multirow[b]{2}{*}{ Coagulante } & \multicolumn{9}{|c|}{ Parâmetros operacionais encontrados } \\
\hline & & $\begin{array}{c}\mathbf{G m} \\
\left(\mathbf{s}^{-1}\right)\end{array}$ & $\begin{array}{c}\mathbf{T m} \\
(\mathrm{s})\end{array}$ & $\begin{array}{l}\text { Gf } \\
\left(\mathrm{s}^{-1}\right)\end{array}$ & $\begin{array}{c}\text { Tf } \\
(\mathrm{min})\end{array}$ & $\begin{array}{c}\text { Vs } \\
(\mathrm{cm} / \mathrm{min})\end{array}$ & $\begin{array}{c}\mathbf{V f} \\
(\mathrm{cm} / \mathrm{min})\end{array}$ & $\begin{array}{l}\mathbf{R} \\
(\%)\end{array}$ & $\begin{array}{l}\text { Psat } \\
\text { (kPa) }\end{array}$ & $\begin{array}{l}\text { Tsat } \\
\text { (min) }\end{array}$ \\
\hline Sedimentação & $\begin{array}{l}\text { Aluminato de } \\
\text { sódio }\end{array}$ & 800 & 5 & 50 & 10 & 1 & - & - & - & - \\
\hline Sedimentação & $\begin{array}{l}\text { Cloreto } \\
\text { férrico }\end{array}$ & 800 & 5 & 25 & 5 & 1 & - & - & - & - \\
\hline Sedimentação & $\begin{array}{c}\text { Procytrat } \\
\text { 100A }(70 \%) \\
+ \text { Procytrat } \\
300(30 \%)\end{array}$ & 800 & 5 & 25 & 5 & 1 & - & - & - & - \\
\hline Flotação & $\begin{array}{l}\text { Aluminato de } \\
\text { sódio }\end{array}$ & $800 *$ & $5^{*}$ & 60 & 10 & - & 5 & 50 & $500^{*}$ & $10 *$ \\
\hline Flotação & $\begin{array}{l}\text { Cloreto } \\
\text { férrico }\end{array}$ & $800 *$ & $5^{*}$ & 100 & 10 & - & 5 & 50 & $500^{*}$ & $10 *$ \\
\hline Flotação & $\begin{array}{l}\text { Procytrat } \\
\text { 100A }(70 \%) \\
+ \text { Procytrat } \\
300(30 \%)\end{array}$ & $800 *$ & $5^{*}$ & 60 & 15 & - & 5 & 40 & $500^{*}$ & $10 *$ \\
\hline
\end{tabular}

Quadro 5.1 - Resumo dos parâmetros operacionais encontrados nos ensaios de floculaçãocoagulação.

Legenda: * valores assumidos ou retirados da literatura

De um modo geral, pode ser verificado no Quadro 5.1, que mesmo com as variações nas características das amostras coletadas para realização dos ensaios, os parâmetros operacionais encontrados não sofreram grandes variações dentro de seus respectivos ensaios. Nos casos onde a diferença entre parâmetros foi um pouco maior, como por exemplo, o gradiente de velocidade para o ensaio de flotação para o coagulante cloreto férrico $\left(100 \mathrm{~s}^{-1}\right)$, o valor de turbidez remanescente encontrado para o tempo de floculação (10min) foi de 4,6\% enquanto que dentro dos mesmos ensaios, para um gradiente de floculação menor $\left(60 \mathrm{~s}^{-1}\right) \mathrm{e}$ 
mesmo tempo de floculação, a turbidez remanescente encontrada foi de 5,6\% (Tabela 5.19), portanto, uma diferença de apenas $1 \%$.

Pode ser observado nos diagramas de coagulação-floculação que a utilização do coagulante aluminato de sódio, assim como descrito na literatura, causa um aumento nos valores de $\mathrm{pH}$ quando adicionado a água residuária, necessitando de uma menor dosagem de hidróxido de cálcio para atingir o $\mathrm{pH}$ considerado como ideal ao final do tratamento, já o cloreto férrico possui um comportamento inverso, devido a liberação dos íons de hidrogênio durante a sua hidrólise. Observou-se também que a adição do Procytrat 100A + Procytrat 300 na água residuária também diminui o seu $\mathrm{pH}$, porém em patamares bem menores se comparados à queda de $\mathrm{pH}$ com o uso do cloreto férrico;

\subsection{Determinação do custo "aproximado" para os melhores pares $\mathrm{pH} / \mathrm{dosagem} \mathrm{de}$ coagulante para cada ensaio de coagulação-floculação-sedimentação/flotação.}

A determinação da dosagem de coagulante e o processo a ser empregado em um sistema de tratamento de efluentes industriais por coagulação/precipitação é bastante complexo devido ao grande número de variáveis envolvidas no processo, tais como: o transporte, outros produtos químicos, preparo da solução, armazenamento, forma de dosagem, metologia de dosagens, disposição do lodo, entre outras. Nesse estudo, por simplicidade, foram considerados somente os custos com os coagulantes e alcalinizante para o processo de separação de sólidos por sedimentação. No processo de flotação, além dos custos com coagulantes e alcalinizante, também foram inclusos os custos com energia elétrica para saturação da água com ar comprimido à pressão de $500 \mathrm{kPa}$. Os cálculos se encontram no Apêndice H.

Na Tabela 5.26 estão os preços dos coagulantes e alcalinizante utilizado nesse estudo. 
Tabela 5.26 - Informações e preços dos coagulantes e alcalinizante.

\begin{tabular}{|c|c|c|c|c|}
\hline \multirow{2}{*}{ Produto } & \multirow{2}{*}{$\begin{array}{c}\text { Nome } \\
\text { comercial do } \\
\text { produto }\end{array}$} & \multirow{2}{*}{ Fornecedor } & \multirow{2}{*}{ Substância principal } & $\begin{array}{c}\text { Preço }^{1} \\
(\mathrm{R} \$ / \mathrm{Kg})\end{array}$ \\
\hline & & & & $\begin{array}{l}\text { Mês ref. } \\
\text { Julho/11 }\end{array}$ \\
\hline Coagulante 1 & $\begin{array}{c}\text { Aluminato de } \\
\text { sódio líquido } \\
40 \%\end{array}$ & Não informado & $\begin{array}{l}\text { Aluminato de sódio } \\
\qquad\left(\mathrm{Al}_{2} \mathrm{O}_{3}-25 \%\right)\end{array}$ & 2,50 \\
\hline Coagulante 2 & $\begin{array}{l}\text { Cloreto férrico } \\
\text { líquido } 40 \%\end{array}$ & OCC Química & Cloreto férrico & 1,10 \\
\hline Coagulante 3 & $\begin{array}{c}\text { Procytrat 100A } \\
\qquad(70 \%)+ \\
\text { Procytrat } 300 \\
(30 \%)\end{array}$ & $\begin{array}{l}\text { Procytek Indústria e } \\
\text { Comércio Ltda. }\end{array}$ & $\begin{array}{l}\text { Polímero de oxicloreto de } \\
\text { aluminio }\left(\mathrm{Al}_{2} \mathrm{O}_{3}-11 \%\right)+ \\
\text { Policloretos de aluminio } \\
\text { hidroxilados cationizados } \\
\qquad\left(\mathrm{Al}_{2} \mathrm{O}_{3}-23 \%\right)\end{array}$ & 3,22 \\
\hline Alcalinizante & $\begin{array}{c}\text { Cal Hidratada } \\
\text { Calcitica }\end{array}$ & $\begin{array}{l}\text { Carbotex Indústria e } \\
\text { Comércio de Cal Ltda. }\end{array}$ & Hidróxido de cálcio & 0,38 \\
\hline
\end{tabular}

Os custos com os produtos químicos variam linearmente com as dosagens empregadas dos mesmos. Na Figura 5.12 pode-se observar a variação do custo por $\mathrm{m}^{3}$ dos três coagulantes utilizados nesse estudo e o baixo custo do coagulante cloreto férrico em relação aos outros dois coagulantes. Observa-se também o custo da cal hidratada que foi utilizada como alcalinizante nesse trabalho. 


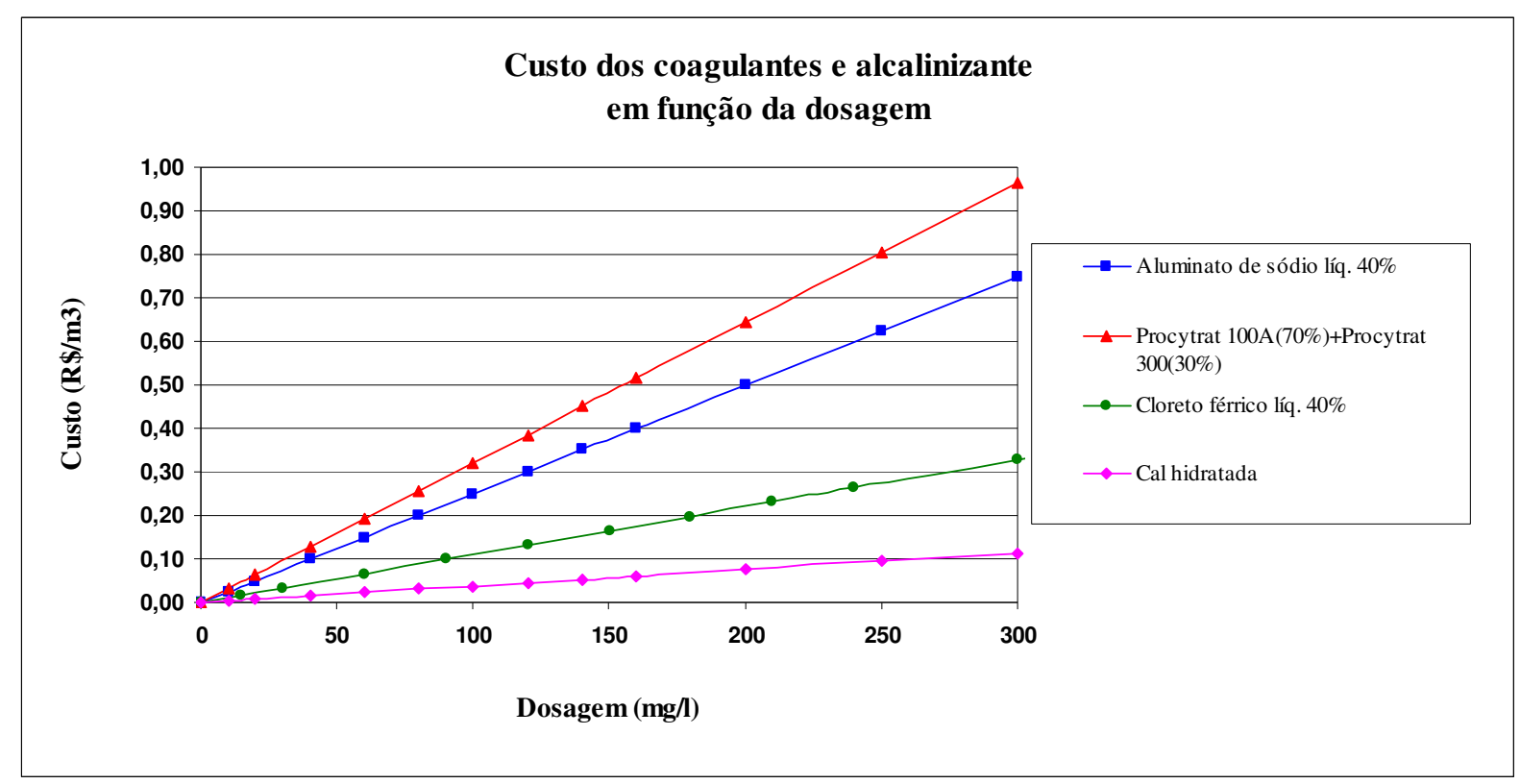

Figura 5.12 - Custo por $\mathrm{m}^{3}$ dos três coagulantes e alcalinizante utilizados nesse estudo, de acordo com a dosagem empregada.

A Figura 5.13 (Diagrama de coagulação-floculação-sedimentação para o coagulante aluminato de sódio) foi utilizada para exemplificar o método escolhido na determinação do melhor coagulante no processo de separação de sólidos por sedimentação ou flotação. As etapas são descritas abaixo:

a) através do diagrama (Figura 5.13) e com o auxílio de funções do software Surfer ${ }^{\circledR}$ foi determinada a região onde o valor de turbidez remanescente foi menor que $2 \%$ (valor máximo considerado para a água residuária após o tratamento físico-químico segundo os padrões exigidos pelo sistema de osmose reversa da empresa em estudo). Devido a baixa eficiência de remoção de turbidez apresentada nos diagramas de coagulação-floculação-flotação, o valor máximo de turbidez remanescente considerado para esses processos foi de $5 \%$. Devido ao formato irregular da região (área hachurada da Figura 5.13), como forma de aproximação, ela foi subdividida e transformada em três regiões retangulares limitadas pelos valores de $\mathrm{pH}$ e dosagem de coagulante;

b) dentro de cada região retangular, foi escolhido o ponto de menor turbidez remanescente, por exemplo, dentro da região 1, foi escolhido a turbidez remanescente de 1,3\%;

c) através do ponto escolhido encontrou-se o seu respectivo par $\mathrm{pH}$ e dosagem de coagulante, 7,4 e 260mg/l respectivamente; 


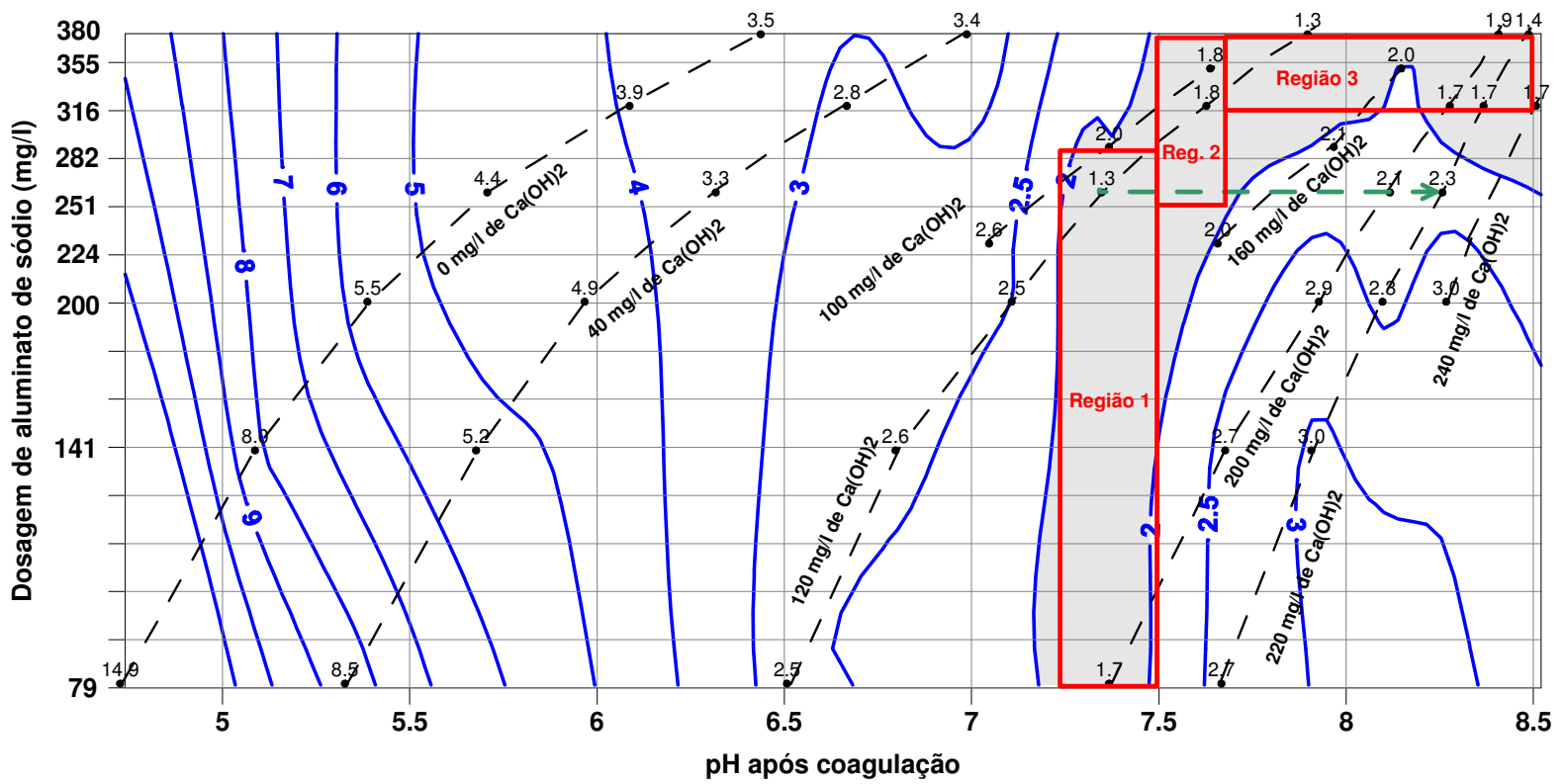

Figura 5.13 - Exemplo: diagrama de coagulação-floculação-sedimentação do efluente: percentuais de Turbidez remanescente para o coagulante aluminato de sódio. Condiçôes de ensaio: $\mathrm{Gm}: 800 \mathrm{~s}^{-1}$; Tm: $5 \mathrm{~s}$; Gf: $50 \mathrm{~s}^{-1}$; Tf: $10 \mathrm{~min}$; Vs: $1 \mathrm{~cm} / \mathrm{min}$.

d) a seguir, foi determinada a dosagem aproximada de alcalinizante necessária para aumentar o pH, após o processo de sedimentação ou flotação. Essa dosagem deve ser suficiente para atingir a faixa de $\mathrm{pH}$ entre 8,3 e 8,5 (faixa de $\mathrm{pH}$ considerada como ideal para a água residuária após o tratamento físico-químico baseado nos valores encontrados nesse ponto durante o período de amostragem na estação de tratamento da empresa (Apêndice A). Essa dosagem aproximada foi determinada traçando-se uma linha horizontal (ver Figura 5.13) do ponto escolhido $(1,3 \%)$ até o ponto dentro da faixa de $\mathrm{pH}$ de $8,3-8,5(2,3 \%)$. Nesse trajeto a dosagem de coagulante é constante;

e) a partir do valor da dosagem de alcalinizante encontrada $(220 \mathrm{mg} / \mathrm{l})$, foi determinada a quantidade de alcalinizante necessária $(100 \mathrm{mg} / \mathrm{l})$;

e) com o custo dos coagulantes, alcalinizante (Tabela 5.26) e o custo de energia elétrica (considerado apenas nos processo de flotação) determinou-se o custo por $\mathrm{m}^{3}$ para os valores de menor turbidez remanescente dentro de cada região escolhida;

A análise do melhor coagulante foi baseada nos seguintes critérios de avaliação:

$1^{\circ}$ - Menor valor de turbidez remanescente;

$2^{\circ}-$ Menor custo por $\mathrm{m}^{3}$; 


\subsubsection{Determinação do "melhor" coagulante em ensaios de coagulação-floculação- sedimentação}

Na Tabela 5.27 podem ser observados os custos por $\mathrm{m}^{3}$ para os pontos de menor valor de turbidez remanescente dentro das regiões escolhidas nos diagramas de coagulaçãofloculação-sedimentação para cada coagulante utilizado nesse estudo.

Tabela 5.27 - Avaliação dos custos do processo de sedimentação em função do coagulante utilizado no processo.

\begin{tabular}{|c|c|c|c|c|c|c|c|}
\hline \multirow[b]{2}{*}{ Coagulante } & \multirow[b]{2}{*}{ Região } & \multicolumn{4}{|c|}{ Melhores pontos dentro das regiões } & \multirow{2}{*}{$\begin{array}{l}\text { Dosagem de } \\
\text { hidróxido de } \\
\text { cálcio p/ atingir } \\
\text { pH 8,3 (mg/l) }\end{array}$} & \multirow[b]{2}{*}{$\begin{array}{l}\text { Custo } \\
\left(\mathbf{R} \$ \mathbf{m}^{3}\right)\end{array}$} \\
\hline & & $\begin{array}{c}\text { pH de } \\
\text { coagulação } \\
\end{array}$ & $\begin{array}{c}\text { Dosagem de } \\
\text { Coagulante } \\
(\mathrm{mg} / \mathrm{l})\end{array}$ & \begin{tabular}{|l} 
Dosagem de \\
hidróxido de \\
cálcio (mg/l) \\
\end{tabular} & \begin{tabular}{|c|}
$\begin{array}{c}\text { Turbidez } \\
\text { remanescente } \\
(\%)\end{array}$ \\
\end{tabular} & & \\
\hline \multirow[t]{3}{*}{ Aluminato de } & 1 & 7,36 & 260 & 120 & 1,3 & 100 & 0,73 \\
\hline & 2 & 7,64 & 320 & 120 & 1,8 & 80 & 0,88 \\
\hline & 3 & 7,91 & 380 & 120 & 1,3 & 80 & 1,03 \\
\hline \multirow[t]{3}{*}{ Cloreto férrico } & 1 & 7,50 & 380 & 360 & 0,5 & 40 & 0,78 \\
\hline & \multirow{2}{*}{2} & 7,84 & 320 & 360 & 0,5 & 20 & 0,68 \\
\hline & & 8,30 & 200 & 360 & 0,6 & 0 & 0,47 \\
\hline \multirow{3}{*}{$\begin{array}{c}\text { Procytrat } \\
\text { 100A + } \\
\text { Procytrat } 300\end{array}$} & 1 & 8,08 & 320 & 260 & 0,5 & 40 & 1,14 \\
\hline & 2 & 8,48 & 140 & 260 & 0,8 & 0 & 0,55 \\
\hline & 3 & 8,19 & 60 & 240 & 1,0 & 10 & 0,29 \\
\hline
\end{tabular}

De acordo com os dados da Tabela 5.27, os menores valores de turbidez remanescente para o processo de sedimentação foram encontrados utilizando-se como coagulante o cloreto férrico, sendo que a opção mais econômica foi alcançada para o pH igual a 8,30 e dosagem de $200 \mathrm{mg} / \mathrm{l}$ de cloreto férrico. O custo para essa configuração foi de $\mathrm{R} \$ 0,47 / \mathrm{m}^{3}$.

Pode-se observar também na Tabela 5.27 que o menor custo foi alcançado utilizando-se o coagulante Procytrat $100 \mathrm{~A}+$ Procytrat $300\left(\mathrm{R} \$ 0,29 / \mathrm{m}^{3}\right)$, porém o valor de turbidez remanescente para esse valor foi mais elevada $(1,0 \%)$. 


\subsubsection{Determinação do "melhor" coagulante em ensaios de coagulação-floculação- flotação}

$\mathrm{Na}$ Tabela 5.28 podem ser observados os custos por $\mathrm{m}^{3}$ para os pontos de menor valor de turbidez remanescente dentro das regiões escolhidas nos diagramas de coagulaçãofloculação-flotação para cada coagulante utilizado nesse estudo.

Tabela 5.28 - Avaliação dos custos do processo de flotação em função do coagulante utilizado no processo.

\begin{tabular}{|c|c|c|c|c|c|c|c|c|}
\hline \multirow[b]{2}{*}{ Coagulante } & \multirow[b]{2}{*}{ Região } & \multicolumn{4}{|c|}{ Melhores pontos dentro das regiões } & \multirow{2}{*}{$\begin{array}{l}\text { Dosagem de } \\
\text { hidróxido de } \\
\text { cálcio p/ atingir } \\
\text { pH } 8,3 \text { (mg/l) }\end{array}$} & \multirow[b]{2}{*}{$\begin{array}{l}\text { Custo } \\
\text { energia } \\
\left(\mathbf{R} \$ \mathbf{m}^{3}\right)\end{array}$} & \multirow[b]{2}{*}{$\begin{array}{l}\text { Custo } \\
\left(\mathbf{R} \$ \mathbf{m}^{3}\right)\end{array}$} \\
\hline & & \begin{tabular}{|c|}
$\mathrm{pH}$ de \\
coagulação \\
\end{tabular} & \begin{tabular}{|c|}
$\begin{array}{c}\text { Dosagem de } \\
\text { Coagulante } \\
(\mathrm{mg} / \mathrm{l})\end{array}$ \\
\end{tabular} & \begin{tabular}{|l} 
Dosagem de \\
hidróxido de \\
cálcio $(\mathrm{mg} / \mathrm{l})$
\end{tabular} & \begin{tabular}{|c|} 
Turbidez \\
remanescente \\
$(\%)$ \\
\end{tabular} & & & \\
\hline Aluminato de & 1 & 4,45 & 60 & 0 & 4,8 & 220 & 0,06 & 0,29 \\
\hline sódio & 2 & 8,86 & 200 & 240 & 3,7 & 0 & 0,06 & 0,65 \\
\hline \multirow[t]{2}{*}{ Cloreto férrico } & 1 & 3,20 & 60 & 0 & 3,5 & 300 & 0,06 & 0,27 \\
\hline & 2 & 5,30 & 20 & 60 & 4,5 & 240 & 0,06 & 0,20 \\
\hline \multirow{2}{*}{$\begin{array}{c}\text { Procytrat 100A } \\
+ \text { Procytrat } \\
300\end{array}$} & 1 & 3,30 & 60 & 0 & 1,6 & 240 & 0,05 & $\mathbf{0 , 3 3}$ \\
\hline & 2 & 4,20 & 200 & 40 & 1,4 & 220 & 0,05 & 0,79 \\
\hline
\end{tabular}

De acordo com os dados da Tabela 5.28, os menores valores de turbidez remanescente para o processo de flotação foram encontrados utilizando-se como coagulante o Procytrat 100A + Procytrat 300, sendo que a opção mais econômica foi alcançada para o pH igual a 3,30 e dosagem de $60 \mathrm{mg} / 1$. O custo para essa configuração foi de $\mathrm{R} \$ 0,33 / \mathrm{m}^{3}$.

O menor custo foi alcançado utilizando-se o coagulante cloreto férrico ( $\left.\mathrm{R} \$ 0,20 / \mathrm{m}^{3}\right)$, porém o valor de turbidez remanescente para esse valor foi mais elevada $(4,5 \%)$.

\subsubsection{Comparação dos custos entre os processos de sedimentação e flotação}

Os valores de turbidez remanescente e custo por $\mathrm{m}^{3}$ nas Tabelas 5.27 e 5.28 indicam que o processo de separação de sólidos por sedimentação parece ser o tratamento que oferece a maior remoção de sólidos e um custo razoável de tratamento, sem considerar outros custos 
envolvidos para a água residuária em estudo. Esse fato pode ser confirmado através das Figuras 5.14 a 5.16 nos quais são apresentadas as curvas de eficiência de remoção de turbidez da água residuária em estudo em função do custo com produtos químicos para a sedimentação ou flotação por ar dissolvido. Para o processo de flotação por ar dissolvido foi considerado também o custo da energia elétrica.

Observa-se que nas Figuras 5.14 e 5.15 que, para os coagulantes aluminato de sódio e cloreto férrico respectivamente, para eficiências de remoção acima de $97 \%$ a separação de sólidos por sedimentação foi a que apresentou os melhores resultados.

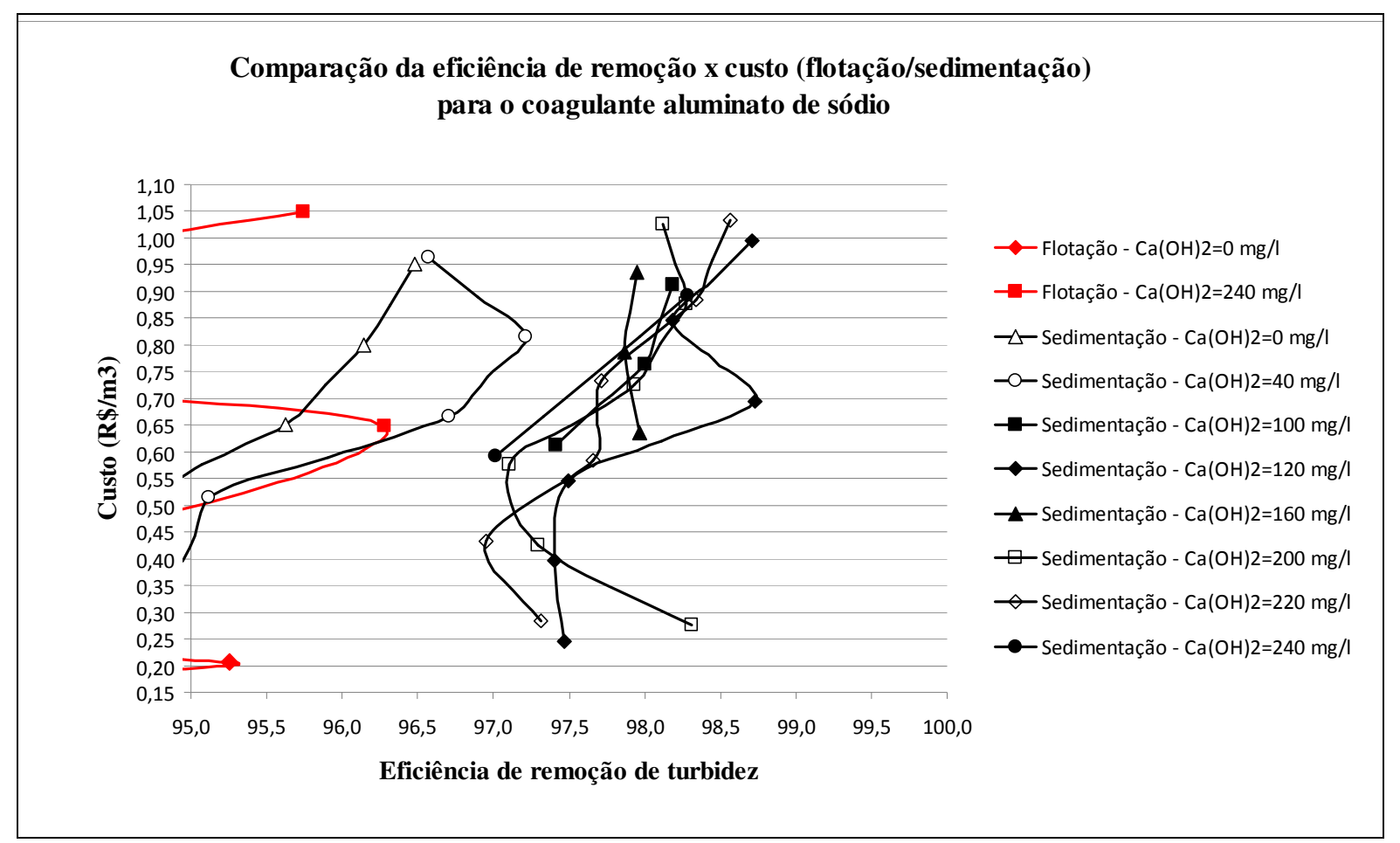

Figura 5.14 - Comparação de custos entre a separação de sólidos por sedimentação (Vs: 1,0 $\mathrm{cm} / \mathrm{min}$ ) e flotação por ar dissolvido (Vf: $5,0 \mathrm{~cm} / \mathrm{min}$ ), de acordo com a eficiência de remoção de turbidez do efluente industrial por coagulação/precipitação com aluminato de sódio. 


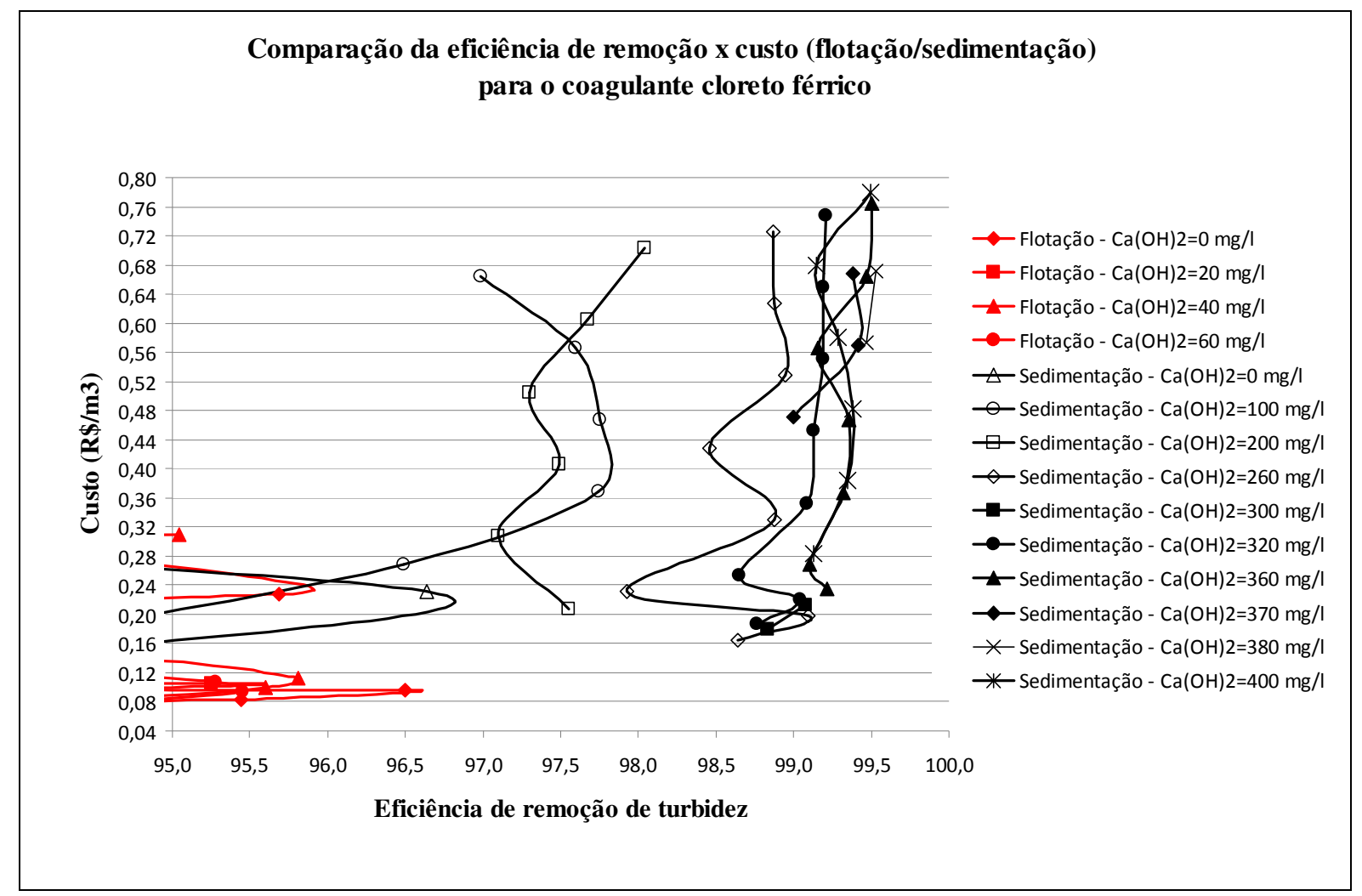

Figura 5.15 - Comparação de custos entre a separação de sólidos por sedimentação (Vs: 1,0 $\mathrm{cm} / \mathrm{min}$ ) e flotação por ar dissolvido (Vf: $5,0 \mathrm{~cm} / \mathrm{min}$ ), de acordo com a eficiência de remoção de turbidez do efluente industrial por coagulação/precipitação com cloreto férrico.

Na Figura 5.16, para o coagulante Procytrat 100A + Procytrat 300, o processo de sedimentação apresentou os melhores resultados para eficiência de remoção acima de 99\%, mas a figura também indica que o processo de flotação por ar dissolvido pode ser utilizado com menor custo para eficiências de remoção de até, 97,8\%, portanto se houver necessidade de remoção até este valor, a flotação pode ser empregada, mas caso sejam necessárias maiores eficiências de remoção, a sedimentação será a alternativa mais econômica. 


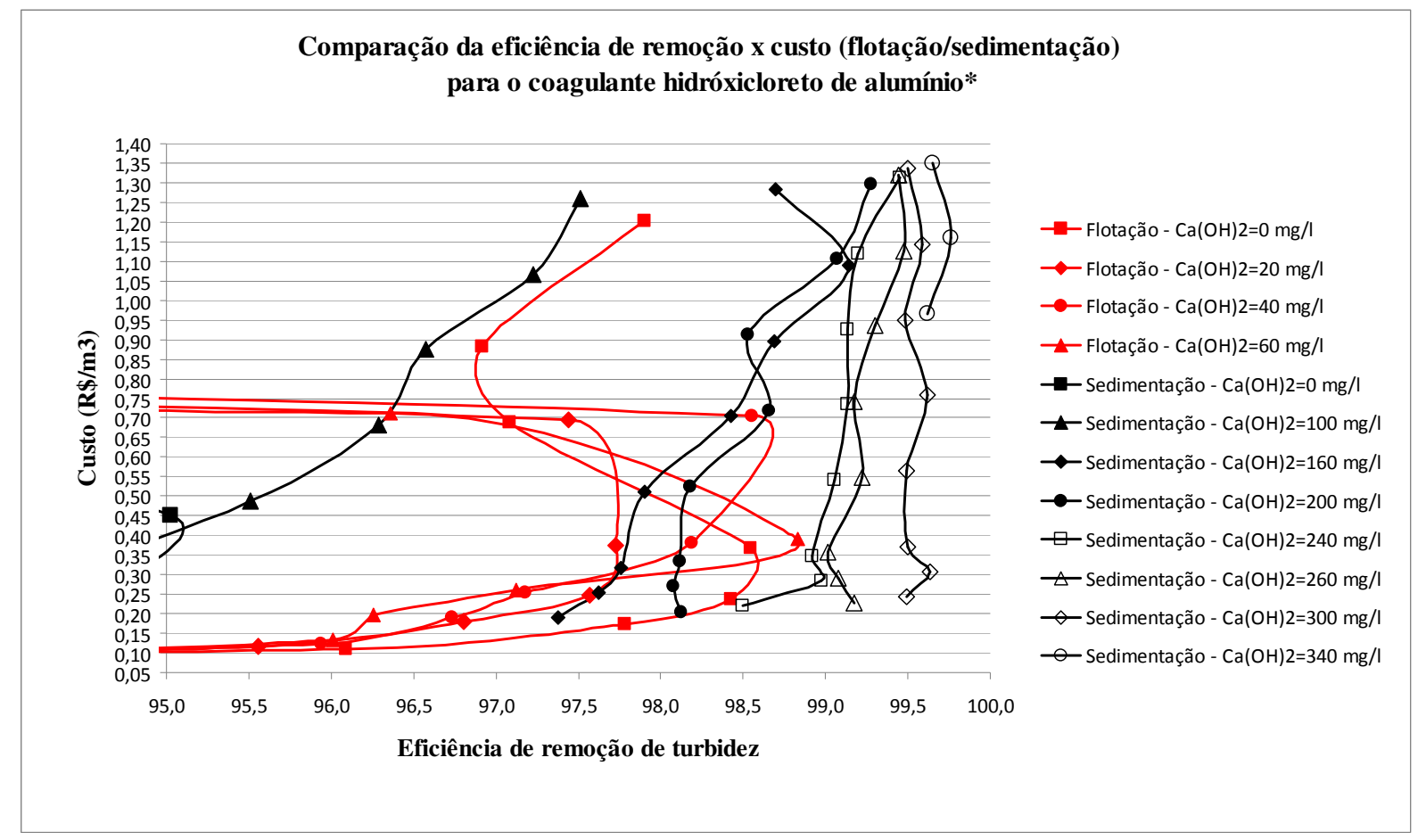

Figura 5.16 - Comparação de custos entre a separação de sólidos por sedimentação (Vs: 1,0 $\mathrm{cm} / \mathrm{min}$ ) e flotação por ar dissolvido (Vf: $5,0 \mathrm{~cm} / \mathrm{min}$ ), de acordo com a eficiência de remoção de turbidez do efluente industrial por coagulação/precipitação com Procytrat 100A + Procytrat 300 .

Observa-se também na Figura 5.16 que, a separação de sólidos por flotação utilizando-se o coagulante Procytrat 100A + Procytrat 300 foi a que obteve as melhores eficiências de remoção se comparamos o mesmo processo utilizando-se os coagulantes aluminato de sódio e cloreto férrico.

Cabe ressaltar que em virtude das simplificações adotadas na análise de custo (que considera apenas os custos com produtos químicos e com energia elétrica) e nos ensaios (realizados em escala de bancada com configurações geométricas diferentes), os resultados obtidos nesse trabalho podem divergir consideravelmente de condições práticas em unidades de sedimentação ou flotação por ar dissolvido. Os resultados apresentados, não podem ser utilizados como valores de referência em termos práticos e servem apenas como orientação. 


\section{6- CONCLUSÕES E RECOMENDAÇÕES}

\subsection{Conclusões}

A partir dos resultados obtidos nos ensaios de coagulação-floculação com a água residuária industrial, chegou-se as seguintes conclusões:

- A utilização do diagrama de coagulação-floculação é uma importante ferramenta para definições, mesmo que aproximadas, de regiões otimizadas de turbidez remanescente e consequentemente economia no consumo de produtos químicos;

- Os diagramas de coagulação-floculação-sedimentação foram os que apresentaram regiões com as maiores áreas de turbidez remanescente menor que $2 \%$, principalmente para os coagulantes cloreto férrico e Procytrat 100A + Procytrat 300, chegando a alcançar valores próximos a 0,5\%, quando utilizado o cloreto férrico como coagulante. Essas regiões, devido as suas faixas de $\mathrm{pH}$ e dosagem de coagulante mais amplas, acabam possibilitando que pequenas variações de $\mathrm{pH}$ ou na dosagem de coagulante, afetem muito pouco os resultados de turbidez remanescente. Do ponto de vista operacional, esse fato oferece uma maior flexibilidade no controle da estação de tratamento, principalmente a que recebe esgoto industrial cujas características podem sofrer alterações repentinas ao longo do dia;

- Os menores valores de turbidez remanescente para o processo de sedimentação foram encontrados utilizando-se como coagulante o cloreto férrico, sendo que a opção mais econômica foi alcançada para o pH igual a 8,30 e dosagem de 200mg/l de cloreto férrico. O custo para essa configuração foi de $\mathrm{R} \$ 0,47 / \mathrm{m}^{3}$;

- Os diagramas de coagulação-floculação-flotação apresentaram regiões de turbidez remanescente com áreas bem mais reduzidas se comparadas aos diagramas de coagulação-floculação-sedimentação, sendo que não foram atingidos valores de 
turbidez remanescente menores que $1,5 \%$, esse fato pode exigir um controle operacional bem mais rígido;

- Os menores valores de turbidez remanescente para o processo de flotação foram encontrados utilizando-se como coagulante o Procytrat 100A + Procytrat 300, sendo que a opção mais econômica foi alcançada para o pH igual a 3,3 e dosagem de 60mg/l. O custo para essa configuração foi de $\mathrm{R} \$ 0,33 / \mathrm{m}^{3}$;

- De um modo geral, para todos os coagulantes testados, as regiões escolhidas nos diagramas de coagulação-floculação-flotação, cujos valores de turbidez remanescente foram menores, estavam concentradas em valores de $\mathrm{pH}$ baixos $(3,2$ a 5,5), dosagens de coagulante reduzidas $(10$ a $80 \mathrm{mg} / \mathrm{l})$ e dosagens de alcalinizante também reduzidas (0 a $60 \mathrm{mg} / 1$ de $\mathrm{Ca}(\mathrm{OH})_{2}$ ). Esse comportamento foi contrário ao apresentado pelos diagramas coagulação-floculação-sedimentação cujos valores de turbidez remanescente foram menores em valores de $\mathrm{pH}$ mais altos (6,5 a 8,5), maiores dosagens de coagulante (40 a 380mg/l) e altas dosagens de alcalinizante (100 a $\left.400 \mathrm{mg} / \mathrm{l} \mathrm{de} \mathrm{Ca}(\mathrm{OH})_{2}\right)$;

- Considerando-se as condições aplicadas nesta pesquisa, a flotação por ar dissolvido não apresentou bons resultados como etapa final de separação, de modo que quanto maior a dosagem de coagulante, menores foram as eficiências de remoção de partículas por flotação.

- De um modo geral, no processo de flotação, apesar dos resultados de remoção de turbidez serem inferiores aos resultados dos ensaios de sedimentação, na média, devido as baixas concentrações de coagulante e alcalinizante utilizados no processo, apresentaram um custo por $\mathrm{m}^{3}$ menor, por isso o processo de flotação poderia ser utilizado como pré-tratamento com baixas dosagens de coagulante e com a finalidade de remoção da maioria dos sólidos e óleo sobrenadante. A quantidade de lodo gerado no tratamento nesse caso poderia ser bem menor, diminuindo os custos com a sua disposição e manuseio. 


\subsection{Recomendações}

Seguem abaixo algumas sugestões e recomendações para futuros trabalhos:

- Baseado nos resultados desse trabalho, recomenda-se realizar estudos em ensaios de bancada (jar test/flotateste) ou em uma unidade piloto utilizando-se do mesmo processo de tratamento da água residuária empregado na E.T.E. da empresa desse estudo, ou seja, utilizar o processo de flotação como pré-tratamento e a sedimentação como última etapa do processo físico-químico de tratamento;

- No processo de remoção de sólidos por flotação, recomenda-se realizar novos estudos utilizando-se como alcalinizante o hidróxido de sódio, pois a cal hidratada além de ser um alcalinizante, também é um coagulante inorgânico e a baixa eficiência de remoção encontrada no processo de flotação em faixas próximas ao $\mathrm{pH} 7$, pode ter sido causada pela formação de uma grande quantidade de flocos e também pelo tamanho dos mesmos, já que a cal hidratada forma flocos maiores por causa da sua bivalência positiva;

- Estudar o uso de auxiliares de coagulação nos processos de sedimentação e flotação. 


\section{REFERÊNCIAS BIBLIOGRÁFICAS}

AISSE, M.M.; JURGENSEN, D.; REALI, M. A. P.; PENETRA R.; ALÉM SOBRINHO, P.; FLORÊNCIO L. (2001) Avaliação do sistema reator RALF e flotação por ar dissolvido, no tratamento de esgoto sanitário. In: Chemicharo, C.A.L. (Coordenador) Pós-tratamento de efluentes de reatores anaeróbios - Coletânea de artigos técnicos- Volume 2, ABES, 2001, Rio de Janeiro.

AMIRTHARAJAH A. Velocity gradients in rapid mix units. In: Seminário Nacional sobre Coagulação e Filtração Direta, Anais, 1989, São Carlos.

AMIRTHARAJAH, A.; MILLS, K.M. (1982) Rapid-mix design for mechanisms of alum coagulation. AWWA Journal, vol.74, n4, p.210-216, Apr.

APHA/AWWA/WEF. Standard Methods for the Examination of Water and Wastewater, $21^{\text {th }}$ ed., Washington, D.C., 2005, USA.

AZEVEDO NETTO, J. M.; MANFRINI, C.; CAMPOS, J. R.; POVINELli, J.; PARLATORE, A. C.; HESPANHOL, I.; ROSSIN, A. C.; YAGUINUMA, S. Técnicas de abastecimento e tratamento de água. $2^{\mathrm{a}}$ ed., v.2, CETESB - Companhia de Tecnologia de Saneamento Ambiental, 1979, São Paulo.

CAMP, T. R.; STEIN, P. C. (1946) Velocity gradients and internal work in fluid motion. Journal Boston Society of Civil Engineers, vol 30, p.209, 1946, citado por: METCALF \& EDDY, INC Wastewater engineering: treatment and reuse, 4th. ed., McGraw-Hill, 2003, New York.

CARVALHO, M.E. Flotação de alta taxa aplicada ao pós-tratamento de efluentes de reatores anaeróbios. Dissertação (Mestrado) - Escola de Engenharia de São Carlos, Universidade de São Paulo, São Carlos, 2003. 
CAMPOS, J.R,; REALI, M.A.P.; DOMBROSKI, S.A.G.; MARCHETTO, M. \& LIMA, M.R.A. Tratamento físico-químico por flotação de efluentes de reatores anaeróbios. In: XXV Congresso Interamericano Ingeniería Sanitária y Ambiental. 1996, México.

DEGAnI, L. F. S. Apostila do Curso de Tratamento de Águas Industriais, Degani Departamento de Divulgação Técnica, 1981, Curitiba.

DI BERNARDO, L. Métodos e Técnicas de Tratamento de Água. Vol. 1, $2^{\mathrm{a}}$ ed., Editora Rima, 2005, São Carlos.

ECKENFELDER JR, W. W. Industrial water pollution control, $2^{\text {nd }}$ ed., McGraw-Hill, 1989, New York.

EDZWALD, J.K. Principles and applications of dissolved air flotation. Water Science and Technology, v. 31, n. 3-4, p.1-23, 1995, Great Britain

EDZWALD, J.K. The science and engineering of dissolved air flotation for drinking water treatment. In: The $5^{\text {th }}$ International Conference on Flotation in Water and Wastewater Systems, 2007, Seul, Korea.

ETTELT, G.A. Activated Sludge Thickening by Dissolved Air Flotation. In:Industrial Waste Conference. Proceedings, Purdue University, 1964, Lafaiatte, Indiana.

GUIMARÃES, A. F. Estudo da coagulação-floculação de água com turbidez ou cor elevada. Dissertação (Mestrado) - Escola de Engenharia de São Carlos, Universidade de São Paulo, São Carlos, 1987.

GREGORY, R.; ZABEL, T. F. Sedimentation and flotation. In: Water quality and treatment a handbook of community water supplies. 4.ed. , McGraw-Hill, 1990, New York.

HAN, M.; KIM, T.; KIM J. Effects of floc and bublle size on the efficiency of the dissolved air flotation (DAF) process. Water Science and Technology, Great Britain, v. 56, n. 10, p. 109-115, 2007 
LEME, F. P. Teoria e técnicas de tratamento de água. CETESB - Companhia de Tecnologia de Saneamento Ambiental, 1979, São Paulo.

LEVINE, A. D.; TCHOBANOGLOUS, G.; ASANO, T. Size distribution of particulate contaminants in wastewater and their impact on treatability. Water Research, v.25, n.08, p.911-922, 1991

MACEDO FILHO, A.; BRANCO, Z. C. Água - Tratamento e Qualidade. USAID -Centro de Publicações Técnicas da Aliança, 1964, Rio de Janeiro.

MAIA, J. C. C.; BEZERRA, J. F. M. Aplicação de flotação por ar dissolvido no tratamento de despejos líquidos industriais. In: XI Congresso Brasileiro de Engenharia Sanitária e Ambiental, Fortaleza, 1981. Anais, ABES, 1981, Fortaleza.

MANCUSO, P. C. S.; SANTOS, H. F. Reuso de Água. NISAM - USP, 2003, Barueri.

MENDES, C.G.N. Estudo da coagulação e floculação de águas sintéticas e naturais com turbidez e cor variáveis. Dissertação (Mestrado em Hidráulica e Saneamento), Departamento de Hidráulica e Saneamento, Escola de Engenharia de São Carlos, Universidade de São Paulo, São Carlos, 1989.

METCALF \& EDDY, INC, Wastewater engineering: treatment and reuse. 4th. ed., McGraw-Hill, 2003, New York.

MIERZWA, J. C. Água na indústria: uso racional e reuso, Oficina dos Textos, 2005, São Paulo.

MORUZZI, R. B. Flotação por ar dissolvido (FAD): Influência da distribuição de tamanho de partículas e do binômio velocidade/tempo de detenção na zona de reação no desempenho do processo. Tese (Doutorado em Hidráulica e Saneamento), Departamento de Hidráulica e Saneamento, Escola de Engenharia de São Carlos, Universidade de São Paulo, São Carlos, 2005.

NALCO Chemical Company. The Nalco water handbook. $2^{\mathrm{a}}$ ed., Editor: Frank N. 
Kemmer, McGraw-Hill, 1988, New York.

ODEGAARD, H. Chemical floc formation in wastewater treatment - an introduction. Prog. Wat. Tech., Supl. 1, p. 103-110, 1979, Pergamon Press.

PAVANELLI G. Eficiência de diferentes tipos de coagulantes na coagulação, floculação e sedimentação de água com cor ou turbidez elevada. Dissertação (Mestrado) - Escola de Engenharia de São Carlos, Universidade de São Paulo, São Carlos, 2001.

PENETRA, R.G. Pós-Tratamento físico-químico por flotação de efluentes de reatores anaeróbios de manta de lodo. Dissertação (Mestrado) - Escola de Engenharia de São Carlos, Universidade de São Paulo, São Carlos, 1998.

PENETRA, R.G. Flotação aplicada ao pós-tratamento do efluente de reator anaeróbio de leito expandido tratando esgoto sanitário. Tese (Doutorado) - Escola de Engenharia de São Carlos, Universidade de São Paulo, São Carlos, 2003

PINTO FILHO, A.C.T.; BRANDÃO, C.C.S. Avaliação do potencial da flotação por ar dissolvido sob pressão como pós - tratamento para efluentes de reatores anaeróbios de fluxo ascendente. In: XXVII Congresso da AIDIS, Porto Alegre-RS, Anais, 8p(I-001), ABES, 2000, Rio de Janeiro.

REALI, M.A.P. Avaliação de um sistema original compacto para clarificação de águas de abastecimento utilizando o processo de flotação e filtração com taxa declinante. Tese (Doutorado) - Escola de Engenharia de São Carlos, Universidade de São Paulo, São Carlos, 1991.

REALI, M.A.P. Proposição de uma equação teórica para o processo de flotação por ar dissolvido. In: XXIV Congresso Interamericano de Ingenieria Sanitaria y Ambiental - AIDIS, Buenos Aires, 1994, Argentina.

REALI, M.A.P.; PENETRA, R.G.; CAMPOS, J.R. Influência da floculação na flotação de efluentes de reatores anaeróbios (UASB): In: XXVI Congresso Interamericano de Ingenieria Sanitaria y Ambiental - AIDIS, 1998, Lima, Peru. 
De RIJK et al. Bubble size in flotation thickening. Water Research. v. 28, n.2, p.465-473, 1994, Great Britain.

RUDOLFS, W.; BALMAT, J.L. Colloids in sewage - I. Separation of sewage colloids aid of the electron microscope. Sewage and Industrial Wastes, v.24, n.03, p.248-256, 1952.

SANTOS, H.R.; PRADO, G.S.; VIDAL, C.M.S.; MORUZZI, R.B.; CAMPOS, J.R. Aplicabilidade das técnicas de determinação de tamanho de partículas em sistemas de tratamento de água e esgoto. Revista Engenharia Sanitária e Ambiental. v.9, n.4, p.291300, Out/Dez, 2004.

SANTOS, H.R. Coagulação/precipitação de efluentes de reator anaeróbio de leito expandido e de sistema de lodo ativado precedido de reator UASB, com remoção de partículas por sedimentação ou flotação Tese (Doutorado) - Escola de Engenharia de São Carlos, Universidade de São Paulo, São Carlos, 2006.

ZABEL, T. Flotation in Water Treatment. In: IVES, K.J. ed. The scientific basis of flotation. NATO Advanced Science Institute on the Scientific Basis of Flotation. Proceedings, Cambridge, Jul, Martinus Nijhoff Publishers, The Hague, p.349-77, 1984, England.

ZABEL, T. The advantages of dissolved air flotation for water treatment. Journal of American Water Works - AWWA, v.77, n.5, p.42-46, 1985, USA.

ZHANG, Y.; LEPPINEN, D. M.; DALZIEL, S.B. A new nozzle for dissolved air flotation. In: The $5^{\text {th }}$ International Conference on Flotation in Water and Wastewater Systems, 2007, Seul, Korea. 


\section{Apêndice A}

Amostragem para caracterização da água residuária industrial 


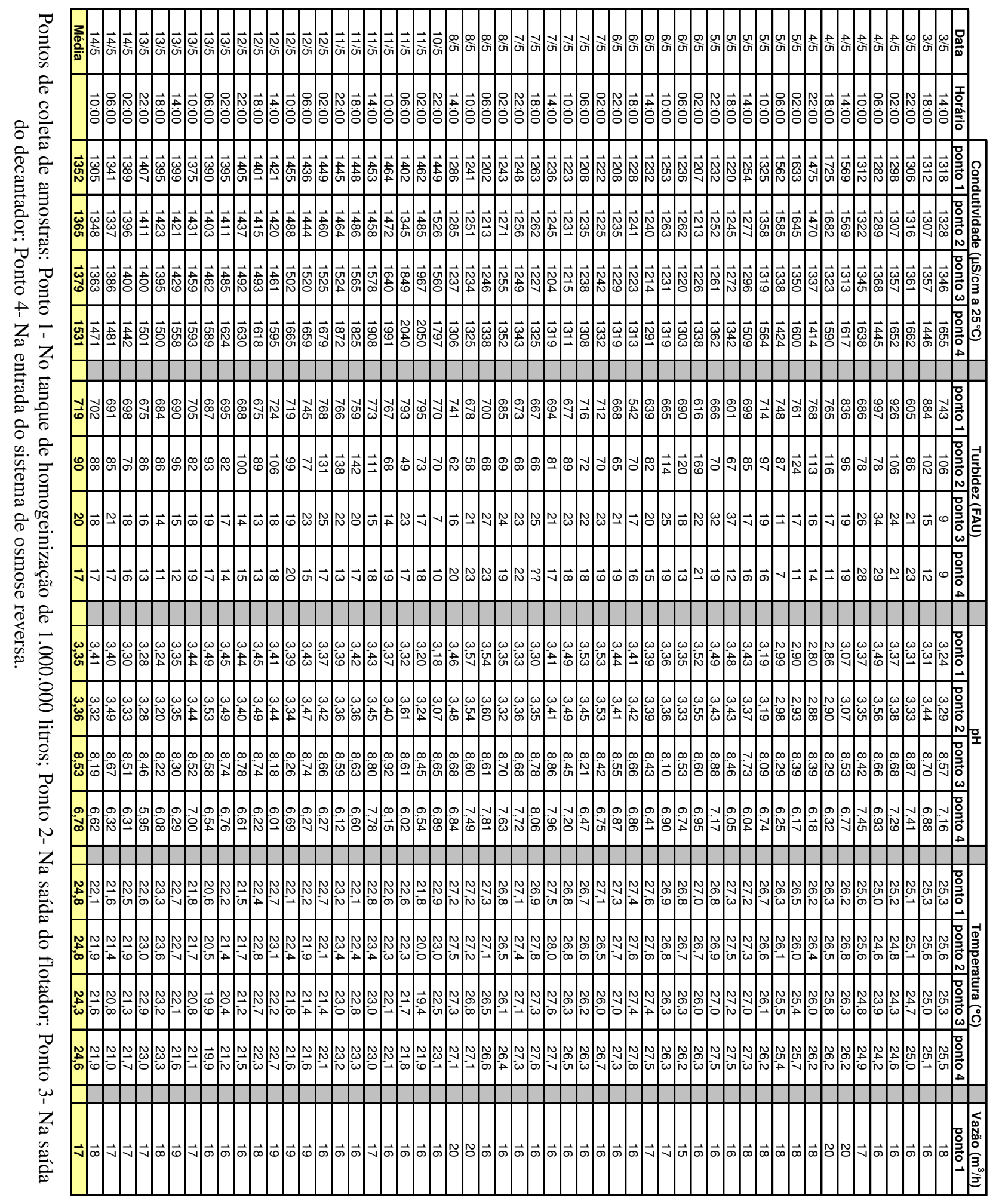




\section{Apêndice B}

Resultados dos ensaios de coagulação-floculação-sedimentação para o coagulante aluminato de sódio 


\section{Ensaios de Coagulação-Floculação-Sedimentação Coagulante: Aluminato de Sódio}

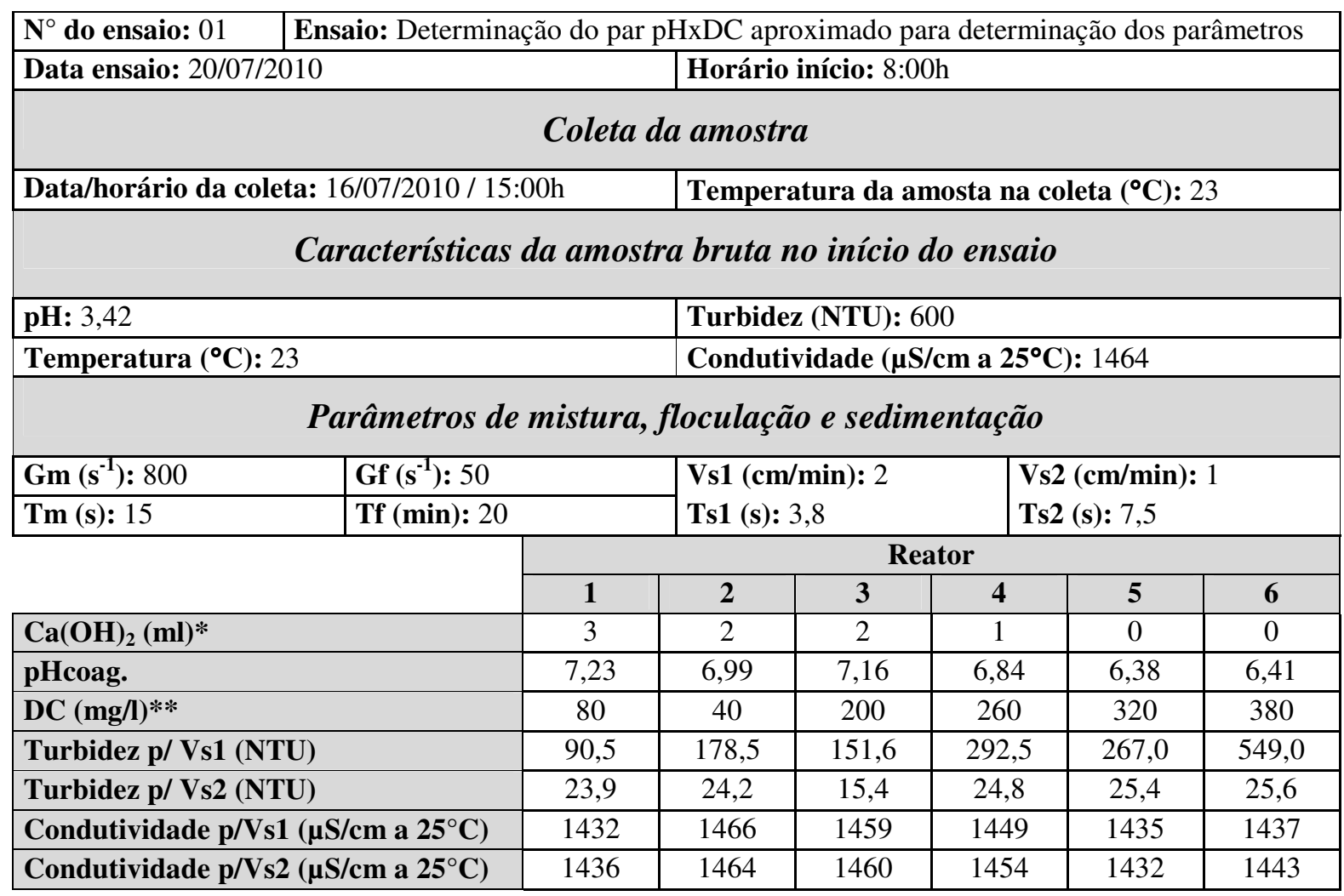

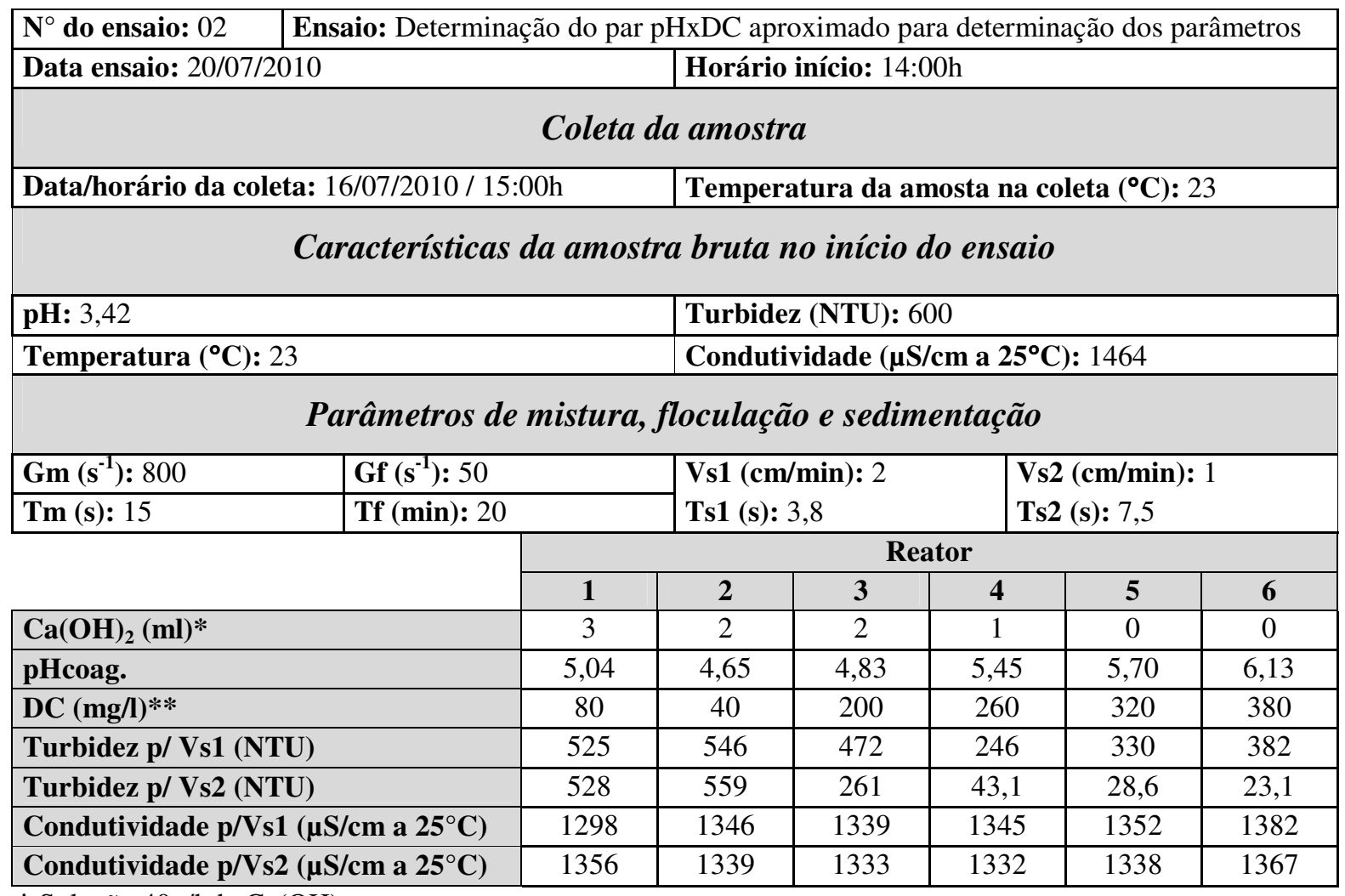

* Solução $40 \mathrm{~g} / \mathrm{l}$ de $\mathrm{Ca}(\mathrm{OH})_{2}$

** Solução 40g/l de aluminato de sódio 


\section{Ensaios de Coagulação-Floculação-Sedimentação Coagulante: Aluminato de Sódio}

\begin{tabular}{|c|c|c|c|c|c|c|c|}
\hline $\mathbf{N}^{\circ}$ do ensaio: 03 & \multicolumn{7}{|c|}{ Ensaio: Determinação do par pHxDC aproximado para determinação dos parâmetros } \\
\hline \multicolumn{3}{|c|}{ Data ensaio: $20 / 07 / 2010$} & \multicolumn{5}{|c|}{ Horário início: $16: 00 \mathrm{~h}$} \\
\hline \multicolumn{8}{|c|}{ Coleta da amostra } \\
\hline \multicolumn{3}{|c|}{ Data/horário da coleta: 16/07/2010 / 15:00h } & \multicolumn{5}{|c|}{ Temperatura da amosta na coleta $\left({ }^{\circ} \mathrm{C}\right): 23$} \\
\hline \multicolumn{8}{|c|}{ Características da amostra bruta no início do ensaio } \\
\hline \multicolumn{3}{|l|}{ pH: 3,42} & \multicolumn{5}{|c|}{ Turbidez (NTU): 600} \\
\hline \multicolumn{3}{|c|}{ Temperatura $\left({ }^{\circ} \mathrm{C}\right): 23$} & \multicolumn{5}{|c|}{ Condutividade $\left(\mu \mathrm{S} / \mathrm{cm}\right.$ a $\left.25^{\circ} \mathrm{C}\right): 1464$} \\
\hline \multicolumn{8}{|c|}{ Parâmetros de mistura, floculação e sedimentação } \\
\hline Gm $\left(\mathbf{s}^{-1}\right): 800$ & Gf $\left(\mathbf{s}^{-1}\right): 50$ & & \multirow{2}{*}{\multicolumn{2}{|c|}{$\begin{array}{l}\text { Vs1 }(\mathbf{c m} / \mathbf{m i n}): 2 \\
\text { Ts1 (s): } 3,8\end{array}$}} & \multirow{2}{*}{\multicolumn{3}{|c|}{$\begin{array}{l}\text { Vs2 (cm/min): } 1 \\
\text { Ts2 (s): } 7,5\end{array}$}} \\
\hline \multirow[t]{3}{*}{ Tm (s): 15} & Tf (min): 20 & & & & & & \\
\hline & & \multicolumn{6}{|c|}{ Reator } \\
\hline & & 1 & 2 & 3 & 4 & 5 & 6 \\
\hline \multicolumn{2}{|l|}{$\mathrm{Ca}(\mathrm{OH})_{2}(\mathrm{ml})^{*}$} & 22 & 20 & 19 & 13 & 16 & 15 \\
\hline \multicolumn{2}{|l|}{ pHcoag. } & 8,59 & 8,48 & 8,48 & 8,48 & 8,46 & 8,51 \\
\hline \multicolumn{2}{|c|}{$\mathrm{DC}(\mathrm{mg} / \mathrm{l}) * *$} & 80 & 40 & 200 & 260 & 320 & 380 \\
\hline \multicolumn{2}{|c|}{ Turbidez p/ Vs1 (NTU) } & 65,2 & 59,6 & 58,8 & 60,3 & 50,2 & 73,5 \\
\hline \multicolumn{2}{|c|}{ Turbidez p/ Vs2 (NTU) } & 45,6 & 45,6 & 37,4 & 24,8 & 24,8 & 23,1 \\
\hline \multicolumn{2}{|c|}{ Condutividade $\mathrm{p} / \mathrm{Vs} 1\left(\mu \mathrm{S} / \mathrm{cm}\right.$ a $\left.25^{\circ} \mathrm{C}\right)$} & 1342 & 1406 & 1412 & 1417 & 1424 & 1422 \\
\hline \multicolumn{2}{|c|}{ Condutividade p/Vs2 $\left(\mu \mathrm{S} / \mathrm{cm}\right.$ a $\left.25^{\circ} \mathrm{C}\right)$} & 1411 & 1397 & 1414 & 1422 & 1425 & 1423 \\
\hline
\end{tabular}

* Solução 40g/l de $\mathrm{Ca}(\mathrm{OH})_{2}$

** Solução 40g/l de aluminato de sódio 


\section{Ensaios de Coagulação-Floculação-Sedimentação Coagulante: Aluminato de Sódio}

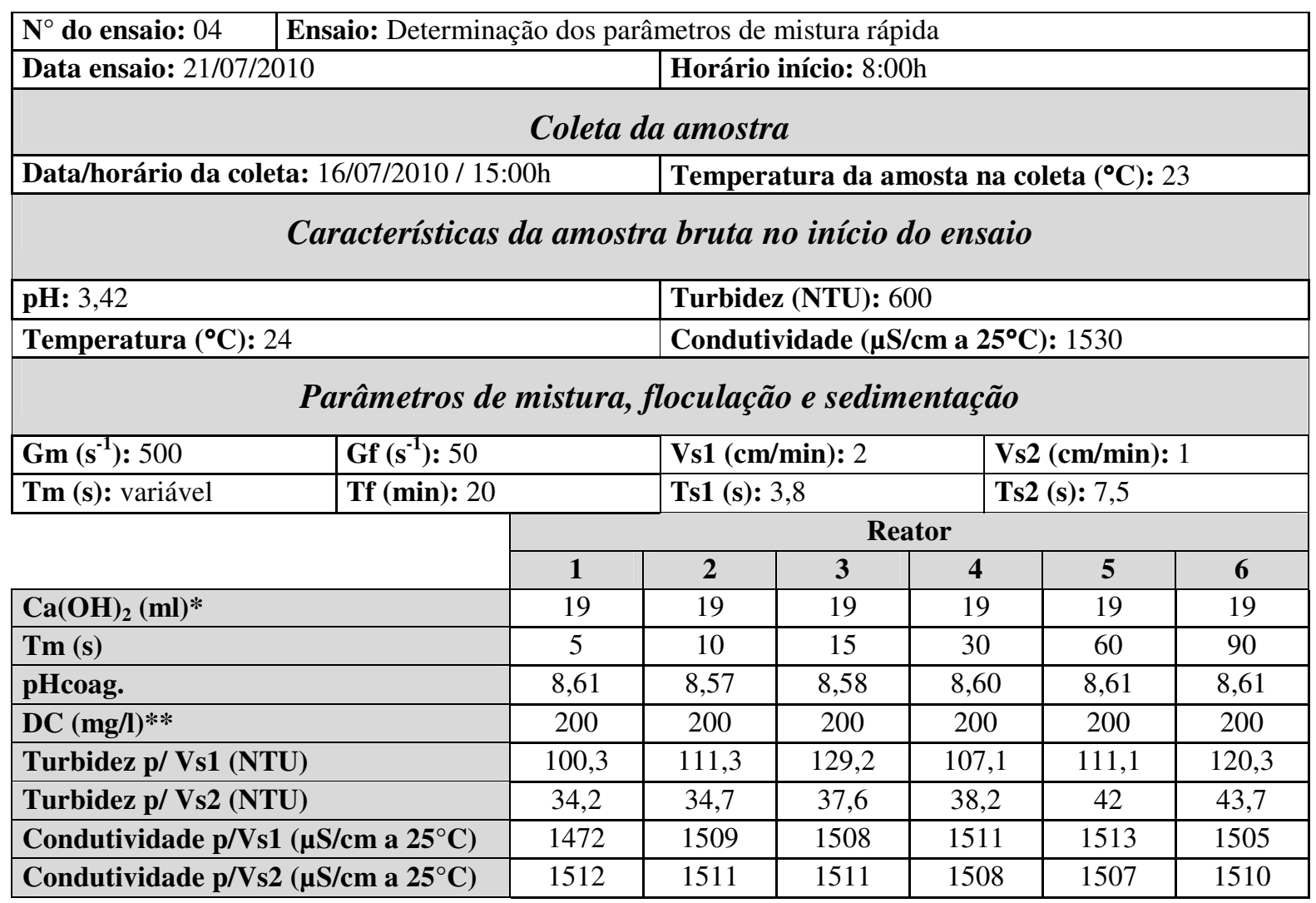

\begin{tabular}{|l|l|l|}
\hline $\mathbf{N}^{\circ}$ do ensaio: 05 & Ensaio: Determinação dos parâmetros de mistura rápida \\
\hline Data & Horário início: $9 \cdot 00 \mathrm{~h}$
\end{tabular}

\begin{tabular}{|l|l}
\hline Data ensaio: $21 / 07 / 2010$ & Horário início: 9:00h
\end{tabular}

\section{Coleta da amostra}

\begin{tabular}{|l|l|}
\hline Data/horário da coleta: $16 / 07 / 2010 / 15: 00 \mathrm{~h}$ & Temperatura da amosta na coleta $\left({ }^{\circ} \mathbf{C}\right): 23$ \\
\hline
\end{tabular}

Características da amostra bruta no início do ensaio

\begin{tabular}{|l|l|}
\hline pH: 3,42 & Turbidez $($ NTU): 600 \\
\hline Temperatura $\left({ }^{\circ} \mathbf{C}\right): 24$ & Condutividade $\left(\boldsymbol{\mu S} / \mathbf{c m ~ a ~} 25^{\circ} \mathbf{C}\right): 1530$ \\
\hline
\end{tabular}

Parâmetros de mistura, floculação e sedimentação

\begin{tabular}{|c|c|c|c|c|c|c|c|}
\hline Gm $\left(\mathbf{s}^{-1}\right): 800$ & \multicolumn{2}{|l|}{ Gf $\left(s^{-1}\right): 50$} & \multirow{2}{*}{\multicolumn{2}{|c|}{$\begin{array}{l}\text { Vs (cm/min): } 2 \\
\text { Ts (s): } 3,8\end{array}$}} & \multirow{2}{*}{\multicolumn{3}{|c|}{$\begin{array}{l}\text { Vs (cm/min): } 1 \\
\text { Ts (s): } 7,5\end{array}$}} \\
\hline Tm (s): variável & \multicolumn{2}{|l|}{ Tf (min): 20} & & & & & \\
\hline & & \multicolumn{6}{|c|}{ Reator } \\
\hline & & 1 & 2 & 3 & 4 & 5 & 6 \\
\hline \multicolumn{2}{|l|}{$\mathrm{Ca}(\mathrm{OH})_{2}(\mathrm{ml})^{*}$} & 19 & 19 & 19 & 19 & 19 & 19 \\
\hline \multicolumn{2}{|l|}{$\operatorname{Tm}(\mathbf{s})$} & 5 & 10 & 15 & 30 & 60 & 90 \\
\hline \multicolumn{2}{|l|}{ pHcoag. } & 8,64 & 8,62 & 8,61 & 8,62 & 8,61 & 8,60 \\
\hline \multicolumn{2}{|l|}{$\mathrm{DC}(\mathrm{mg} / \mathrm{l}) * *$} & 200 & 200 & 200 & 200 & 200 & 200 \\
\hline \multicolumn{2}{|c|}{ Turbidez p/ Vs1 (NTU) } & 59 & 75,8 & 79 & 78,8 & 85,7 & 81,5 \\
\hline \multicolumn{2}{|c|}{ Turbidez p/ Vs2 (NTU) } & 35,7 & 36,5 & 36,1 & 43,9 & 37,6 & 48,5 \\
\hline \multicolumn{2}{|c|}{ Condutividade p/Vs1 $\left(\mu \mathrm{S} / \mathrm{cm}\right.$ a $\left.25^{\circ} \mathrm{C}\right)$} & 1544 & 1550 & 1555 & 1559 & 1556 & 1554 \\
\hline \multicolumn{2}{|c|}{ Condutividade $\mathrm{p} / \mathrm{Vs} 2\left(\mu \mathrm{S} / \mathrm{cm}\right.$ a $\left.25^{\circ} \mathrm{C}\right)$} & 1595 & 1552 & 1549 & 1550 & 1552 & 1552 \\
\hline
\end{tabular}

* Solução 40g/l de $\mathrm{Ca}(\mathrm{OH})_{2}$

** Solução 40g/l de aluminato de sódio 


\section{Ensaios de Coagulação-Floculação-Sedimentação Coagulante: Aluminato de Sódio}

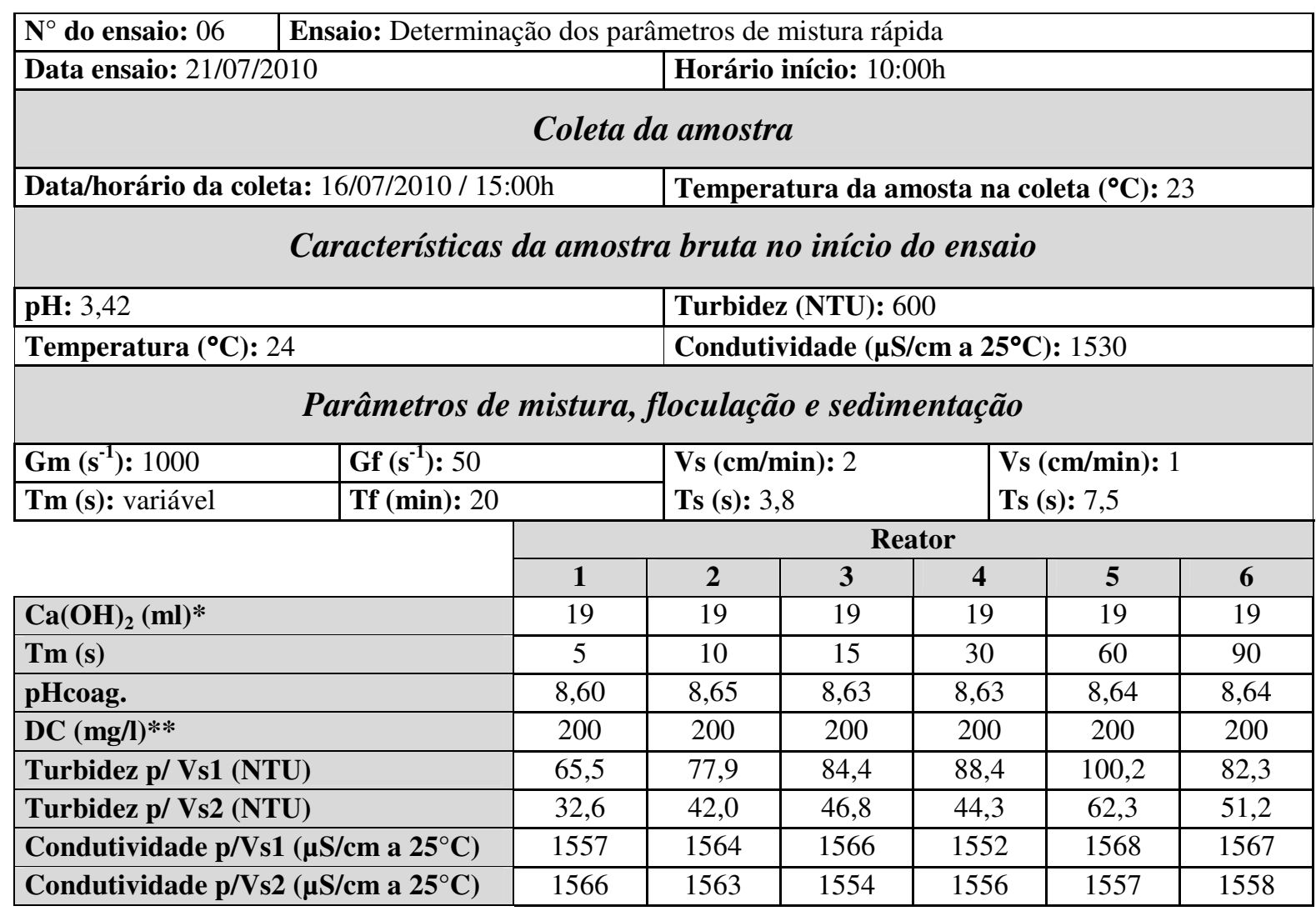

* Solução 40g/l de $\mathrm{Ca}(\mathrm{OH})_{2}$

** Solução 40g/l de aluminato de sódio 


\section{Ensaios de Coagulação-Floculação-Sedimentação Coagulante: Aluminato de Sódio}

\begin{tabular}{|c|c|c|c|c|c|c|c|}
\hline $\mathbf{N}^{\circ}$ do ensaio: 07 & \multicolumn{7}{|c|}{ Ensaio: Determinação dos parâmetros de floculação } \\
\hline \multicolumn{3}{|c|}{ Data ensaio: $21 / 07 / 2010$} & \multicolumn{5}{|c|}{ Horário início: $11: 00 \mathrm{~h}$} \\
\hline \multicolumn{8}{|c|}{ Coleta da amostra } \\
\hline \multicolumn{3}{|c|}{ Data/horário da coleta: $16 / 07 / 2010 / 15: 00 \mathrm{~h}$} & \multicolumn{5}{|c|}{ Temperatura da amosta na coleta $\left({ }^{\circ} \mathbf{C}\right): 23$} \\
\hline \multicolumn{8}{|c|}{ Características da amostra bruta no início do ensaio } \\
\hline \multicolumn{3}{|c|}{ pH: 3,36} & \multicolumn{5}{|c|}{ Turbidez (NTU): 584} \\
\hline Temperatura $\left({ }^{\circ} \mathrm{C}\right.$ & & & \multicolumn{5}{|c|}{ Condutividade $\left(\boldsymbol{\mu S} / \mathrm{cm}\right.$ a $\left.25^{\circ} \mathrm{C}\right): 1539$} \\
\hline \multicolumn{8}{|c|}{ Parâmetros de mistura, floculação e sedimentação } \\
\hline Gm $\left(\mathbf{s}^{-1}\right): 800$ & Gf $\left(\mathbf{s}^{-1}\right): 25$ & & \multirow{2}{*}{\multicolumn{2}{|c|}{$\begin{array}{l}\text { Vs (cm/min): } 2 \\
\text { Ts (s): } 3,8\end{array}$}} & \multirow{2}{*}{\multicolumn{3}{|c|}{$\begin{array}{l}\text { Vs }(\mathbf{c m} / \mathbf{m i n}): 1 \\
\text { Ts }(\mathbf{s}): 7,5\end{array}$}} \\
\hline \multirow[t]{3}{*}{ Tm (s): 5} & Tf (min): va & & & & & & \\
\hline & & \multicolumn{6}{|c|}{ Reator } \\
\hline & & 1 & 2 & 3 & 4 & 5 & 6 \\
\hline \multicolumn{2}{|l|}{$\mathrm{Ca}(\mathrm{OH})_{2}(\mathrm{ml})^{*}$} & 11 & 11 & 11 & 11 & 11 & 11 \\
\hline \multicolumn{2}{|l|}{ Tf (min) } & 5 & 10 & 20 & 30 & 40 & 60 \\
\hline \multicolumn{2}{|l|}{ pHcoag. } & 8,23 & 8,29 & 8,32 & 8,31 & 8,31 & 8,28 \\
\hline \multicolumn{2}{|l|}{ DC $(\mathrm{mg} / \mathrm{l}) * *$} & 200 & 200 & 200 & 200 & 200 & 200 \\
\hline \multicolumn{2}{|c|}{ Turbidez p/ Vs1 (NTU) } & 455 & 383 & 410 & 422 & 356 & 415 \\
\hline \multicolumn{2}{|c|}{ Turbidez p/ Vs2 (NTU) } & 21,5 & 13,2 & 14,7 & 20,2 & 21,2 & 25,4 \\
\hline \multicolumn{2}{|c|}{ Condutividade p/Vs1 $\left(\mu \mathrm{S} / \mathrm{cm}\right.$ a $\left.25^{\circ} \mathrm{C}\right)$} & 1560 & 1564 & 1567 & 1562 & 1565 & 1566 \\
\hline \multicolumn{2}{|c|}{ Condutividade p/Vs2 $\left(\mu \mathrm{S} / \mathrm{cm}\right.$ a $\left.25^{\circ} \mathrm{C}\right)$} & 1570 & 1571 & 1567 & 1559 & 1568 & 1566 \\
\hline
\end{tabular}

\begin{tabular}{|l|l|l|}
\hline $\mathbf{N}^{\circ}$ do ensaio: 08 & Ensaio: Determinação dos parâmetros de floculação \\
\hline Data ensaio: $21 / 07 / 2010$ & Horário início: $14: 00 \mathrm{~h}$ \\
\hline \multicolumn{2}{|c|}{ Coleta da amostra } \\
\hline Data/horário da coleta: $16 / 07 / 2010 / 15: 00 \mathrm{~h}$ & Temperatura da amosta na coleta $\left({ }^{\circ} \mathbf{C}\right): 23$ \\
\hline
\end{tabular}

Características da amostra bruta no início do ensaio

\begin{tabular}{|l|l|}
\hline pH: 3,36 & Turbidez $($ NTU): 584 \\
\hline Temperatura $\left({ }^{\circ} \mathbf{C}\right): 25$ & Condutividade $\left(\boldsymbol{\mu S} / \mathbf{c m ~ a ~}^{25^{\circ}} \mathbf{C}\right): 1539$ \\
\hline
\end{tabular}

Parâmetros de mistura, floculação e sedimentação

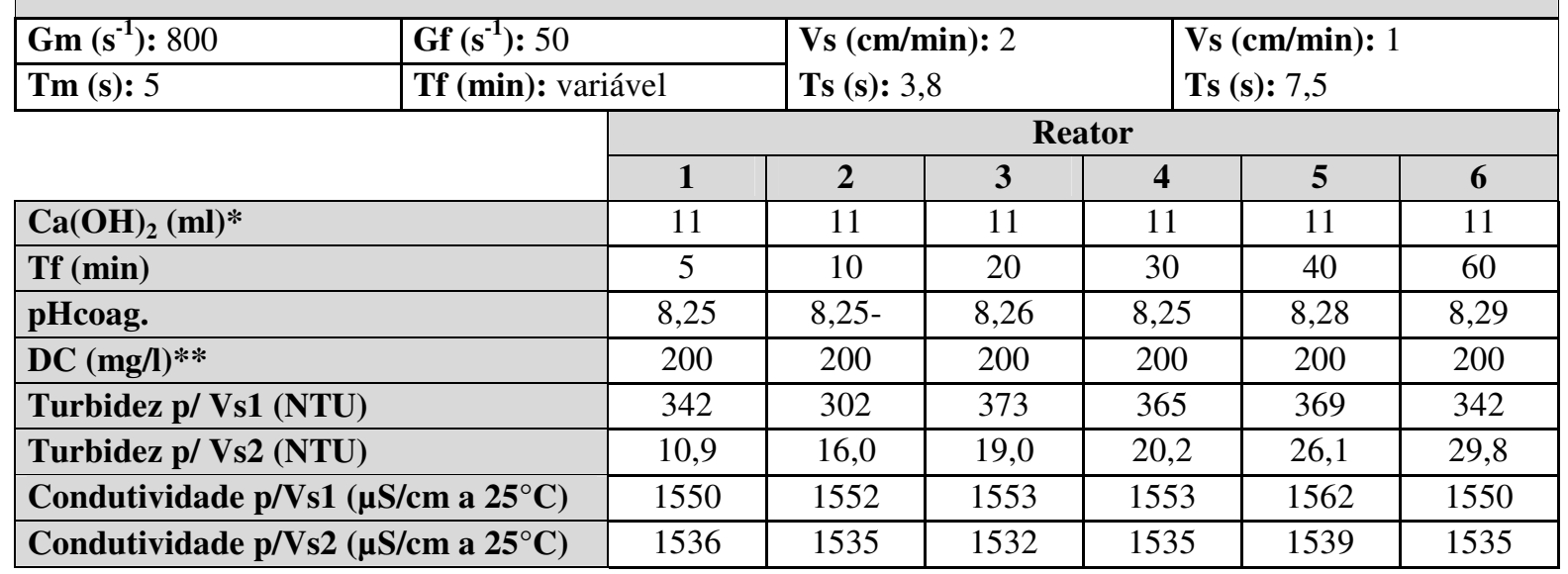

* Solução 40g/l de $\mathrm{Ca}(\mathrm{OH})_{2}$

** Solução 40g/l de aluminato de sódio 


\section{Ensaios de Coagulação-Floculação-Sedimentação Coagulante: Aluminato de Sódio}

\begin{tabular}{|c|c|c|c|c|c|c|c|}
\hline $\mathbf{N}^{\circ}$ do ensaio: 09 & \multicolumn{7}{|c|}{ Ensaio: Determinação dos parâmetros de floculação } \\
\hline \multicolumn{3}{|c|}{ Data ensaio: $21 / 07 / 2010$} & \multicolumn{5}{|c|}{ Horário início: $15: 00 \mathrm{~h}$} \\
\hline \multicolumn{8}{|c|}{ Coleta da amostra } \\
\hline \multicolumn{3}{|c|}{ Data/horário da coleta: $16 / 07 / 2010 / 15: 00 \mathrm{~h}$} & \multicolumn{5}{|c|}{ Temperatura da amosta na coleta $\left({ }^{\circ} \mathbf{C}\right): 23$} \\
\hline \multicolumn{8}{|c|}{ Características da amostra bruta no início do ensaio } \\
\hline \multicolumn{3}{|l|}{ pH: 3,36} & \multicolumn{5}{|c|}{ Turbidez (NTU): 584} \\
\hline \multicolumn{3}{|c|}{ Temperatura $\left({ }^{\circ} \mathrm{C}\right): 25$} & \multicolumn{5}{|c|}{ Condutividade $\left(\boldsymbol{\mu S} / \mathrm{cm}\right.$ a $\left.25^{\circ} \mathrm{C}\right): 1539$} \\
\hline \multicolumn{8}{|c|}{ Parâmetros de mistura, floculação e sedimentação } \\
\hline Gm $\left(\mathbf{s}^{-1}\right): 800$ & \multicolumn{2}{|c|}{ Gf $\left(\mathbf{s}^{-1}\right): 75$} & \multirow{2}{*}{\multicolumn{2}{|c|}{$\begin{array}{l}\text { Vs (cm/min): } 2 \\
\text { Ts (s): } 3,8\end{array}$}} & \multirow{2}{*}{\multicolumn{3}{|c|}{$\begin{array}{l}\text { Vs (cm/min): } 1 \\
\text { Ts }(\mathbf{s}): 7,5\end{array}$}} \\
\hline \multirow[t]{3}{*}{$\operatorname{Tm}(\mathbf{s}): 5$} & \multicolumn{2}{|c|}{ Tf (min): variável } & & & & & \\
\hline & & \multicolumn{6}{|c|}{ Reator } \\
\hline & & 1 & 2 & 3 & 4 & 5 & 6 \\
\hline \multicolumn{2}{|l|}{$\mathrm{Ca}(\mathrm{OH})_{2}(\mathrm{ml})^{*}$} & 11 & 11 & 11 & 11 & 11 & 11 \\
\hline \multicolumn{2}{|l|}{ Tf (min) } & 5 & 10 & 20 & 30 & 40 & 60 \\
\hline \multicolumn{2}{|l|}{ pHcoag. } & 8,24 & 8,27 & 8,29 & 8,28 & 8,27 & 8,25 \\
\hline \multicolumn{2}{|l|}{$\mathrm{DC}(\mathrm{mg} / \mathrm{l}) * *$} & 200 & 200 & 200 & 200 & 200 & 200 \\
\hline \multicolumn{2}{|c|}{ Turbidez p/ Vs1 (NTU) } & 273 & 257 & 331 & 337 & 379 & 383 \\
\hline \multicolumn{2}{|c|}{ Turbidez p/ Vs2 (NTU) } & 13,7 & 13,7 & 23,3 & 24,2 & 27,2 & 35,6 \\
\hline \multicolumn{2}{|c|}{ Condutividade p/Vs1 $\left(\mu \mathrm{S} / \mathrm{cm}^{2} 25^{\circ} \mathrm{C}\right)$} & 1564 & 1564 & 1560 & 1556 & 1563 & 1561 \\
\hline \multicolumn{2}{|c|}{ Condutividade p/Vs2 $\left(\mu \mathrm{S} / \mathrm{cm}\right.$ a $\left.25^{\circ} \mathrm{C}\right)$} & 1549 & 1551 & 1546 & 1544 & 1547 & 1548 \\
\hline
\end{tabular}

* Solução 40g/l de $\mathrm{Ca}(\mathrm{OH})_{2}$

** Solução 40g/l de aluminato de sódio 


\section{Ensaios de Coagulação-Floculação-Sedimentação Coagulante: Aluminato de Sódio}

\begin{tabular}{|c|c|c|c|c|c|c|c|}
\hline $\mathbf{N}^{\circ}$ do ensaio: 10 & \multicolumn{7}{|c|}{ Ensaio: Determinação dos pares pHxDC para construção do Diagrama de Coagulação } \\
\hline \multicolumn{3}{|c|}{ Data ensaio: $23 / 07 / 2010$} & \multicolumn{5}{|c|}{ Horário início: $12: 30 \mathrm{~h}$} \\
\hline \multicolumn{8}{|c|}{ Coleta da amostra } \\
\hline \multicolumn{3}{|c|}{ Data/horário da coleta: $16 / 07 / 2010 / 15: 00 \mathrm{~h}$} & \multicolumn{5}{|c|}{ Temperatura da amosta na coleta $\left({ }^{\circ} \mathbf{C}\right): 23$} \\
\hline \multicolumn{8}{|c|}{ Características da amostra bruta no início do ensaio } \\
\hline \multicolumn{3}{|l|}{ pH: 3,32} & \multicolumn{5}{|c|}{ Turbidez (NTU): 610} \\
\hline \multicolumn{3}{|c|}{ Temperatura $\left({ }^{\circ} \mathrm{C}\right): 24$} & \multicolumn{5}{|c|}{ Condutividade $\left(\mu \mathrm{S} / \mathrm{cm}\right.$ a $\left.25^{\circ} \mathrm{C}\right): 1616$} \\
\hline \multicolumn{8}{|c|}{ Parâmetros de mistura, floculação e sedimentação } \\
\hline Gm $\left(\mathbf{s}^{-1}\right): 800$ & \multicolumn{2}{|l|}{ Gf $\left(\mathbf{s}^{-1}\right): 50$} & \multicolumn{2}{|c|}{ Vs (cm/min): 2} & \multicolumn{3}{|c|}{ Vs (cm/min): 1} \\
\hline \multirow[t]{3}{*}{ Tm (s): 5} & \multicolumn{2}{|l|}{ Tf (min): 10} & \multicolumn{2}{|c|}{ Ts $(\mathbf{s}): 3,8$} & \multicolumn{3}{|c|}{ Ts $(\mathbf{s}): 7,5$} \\
\hline & & \multicolumn{6}{|c|}{ Reator } \\
\hline & & 1 & 2 & 3 & 4 & 5 & 6 \\
\hline \multicolumn{2}{|l|}{$\mathrm{Ca}(\mathrm{OH})_{2}(\mathrm{ml})^{*}$} & 0 & 0 & 0 & 0 & 0 & 0 \\
\hline \multicolumn{2}{|l|}{ pHcoag. } & 4,74 & 5,10 & 5,40 & 5,72 & 6,10 & 6,45 \\
\hline \multicolumn{2}{|c|}{$\mathrm{DC}(\mathrm{mg} / \mathrm{l}) * *$} & 80 & 140 & 200 & 260 & 320 & 380 \\
\hline \multicolumn{2}{|c|}{ Turbidez p/ Vs1 (NTU) } & 235 & 235 & 284 & 341 & 421 & 441 \\
\hline \multicolumn{2}{|c|}{ Turbidez p/ Vs2 (NTU) } & 91,0 & 48,8 & 33,4 & 26,7 & 23,5 & 21,5 \\
\hline \multicolumn{2}{|c|}{ Condutividade p/Vs1 $\left(\mu \mathrm{S} / \mathrm{cm}\right.$ a $\left.25^{\circ} \mathrm{C}\right)$} & 1450 & 1444 & 1444 & 1457 & 1471 & 1476 \\
\hline \multicolumn{2}{|c|}{ Condutividade p/Vs2 $\left(\mu \mathrm{S} / \mathrm{cm}\right.$ a $\left.25^{\circ} \mathrm{C}\right)$} & 1447 & 1441 & 1446 & 1448 & 1462 & 1477 \\
\hline
\end{tabular}

\begin{tabular}{|l|l|}
\hline $\mathbf{N}^{\circ}$ do ensaio: 11 & Ensaio: Determinação dos pares pHxDC para construção do Diagrama de Coagulação \\
\hline
\end{tabular} Data ensaio: 23/07/2010 Horário início: 15:00h

\section{Coleta da amostra}

\begin{tabular}{|l|l|}
\hline Data/horário da coleta: $16 / 07 / 2010 / 15: 00 \mathrm{~h}$ & Temperatura da amosta na coleta $\left({ }^{\circ} \mathrm{C}\right): 23$ \\
\hline
\end{tabular}

\section{Características da amostra bruta no início do ensaio}

\begin{tabular}{|l|l|}
\hline pH: 3,32 & Turbidez $($ NTU): 610 \\
\hline Temperatura $\left({ }^{\circ} \mathbf{C}\right): 24$ & Condutividade $\left(\mu S / \mathbf{c m ~ a ~ 2 5}^{\circ} \mathbf{C}\right): 1616$ \\
\hline
\end{tabular}

Parâmetros de mistura, floculação e sedimentação

\begin{tabular}{|c|c|c|c|c|c|c|c|}
\hline Gm $\left(s^{-1}\right): 800$ & \multicolumn{2}{|l|}{ Gf $\left(s^{-1}\right): 50$} & \multicolumn{3}{|c|}{ Vs (cm/min): 2} & \multicolumn{2}{|c|}{ Vs (cm/min): 1} \\
\hline \multirow[t]{3}{*}{$\operatorname{Tm}(\mathbf{s}): 5$} & \multicolumn{2}{|l|}{ Tf (min): 10} & \multicolumn{3}{|c|}{ Ts (s): 3,8} & \multicolumn{2}{|c|}{ Ts (s): 7,5} \\
\hline & & \multicolumn{6}{|c|}{ Reator } \\
\hline & & 1 & 2 & 3 & 4 & 5 & 6 \\
\hline $\mathrm{Ca}(\mathrm{OH})_{2}(\mathrm{ml})^{*}$ & & 2 & 2 & 2 & 2 & 2 & 2 \\
\hline pHcoag. & & 5,34 & 5,69 & 5,98 & 6,33 & 6,68 & 7,00 \\
\hline $\mathrm{DC}(\mathrm{mg} / \mathrm{l}) * *$ & & 80 & 140 & 200 & 260 & 320 & 380 \\
\hline Turbidez p/ Vs1 (NTU) & & 233 & 251 & 325 & 391 & 431 & - \\
\hline Turbidez p/ Vs2 (NTU) & & 52,1 & 31,9 & 29,8 & 20,1 & 17,0 & 20,9 \\
\hline Condutividade p/Vs1 $(\mu$ & cm a $\left.25^{\circ} \mathrm{C}\right)$ & 1505 & 1500 & 1493 & 1493 & 1497 & - \\
\hline Condutividade p/Vs2 ( $\mu$ & (cm a $\left.25^{\circ} \mathrm{C}\right)$ & 1476 & 1481 & 1485 & 1488 & 1503 & 1520 \\
\hline
\end{tabular}

* Solução 40g/l de $\mathrm{Ca}(\mathrm{OH})_{2}$

** Solução 40g/l de aluminato de sódio 


\section{Ensaios de Coagulação-Floculação-Sedimentação Coagulante: Aluminato de Sódio}

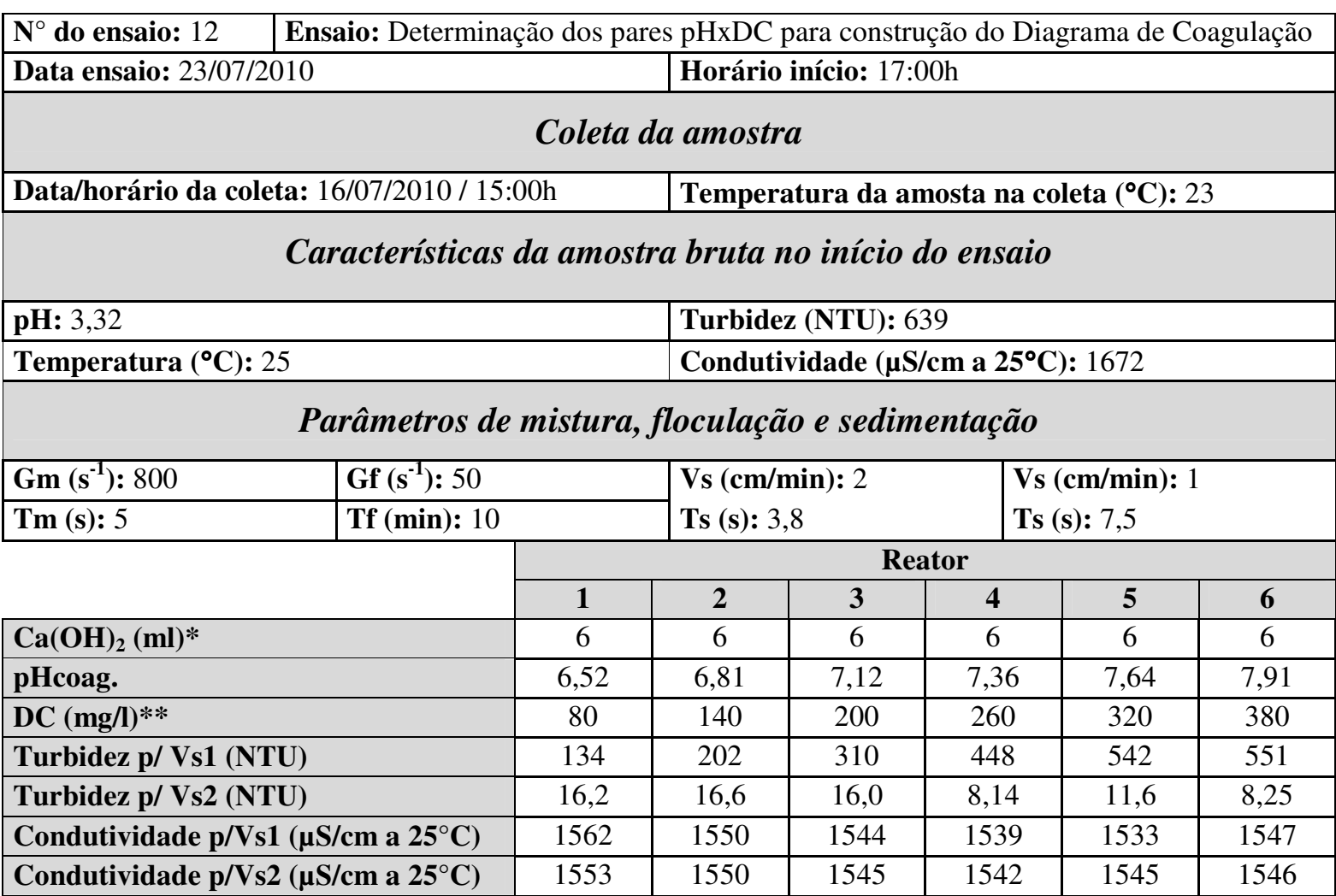

\begin{tabular}{|c|c|}
\hline Ensaio: Determinação & pHxDC para construção do Diagrama de Coagulação \\
\hline Data ensaio: $23 / 07 / 2010$ & Horário início: 19:00h \\
\hline \multicolumn{2}{|c|}{ Coleta da amostra } \\
\hline Data/horário da coleta: 16/07/2010 / 15:00h & Temperatura da amosta na coleta $\left({ }^{\circ} \mathrm{C}\right): 23$ \\
\hline \multicolumn{2}{|c|}{ Características da amostra bruta no início do ensaio } \\
\hline pH: 3,32 & Turbidez (NTU): 639 \\
\hline Temperatura $\left({ }^{\circ} \mathrm{C}\right): 25$ & Condutividade $\left(\mu \mathrm{S} / \mathrm{cm}\right.$ a $\left.25^{\circ} \mathrm{C}\right): 1672$ \\
\hline
\end{tabular}

Parâmetros de mistura, floculação e sedimentação

\begin{tabular}{|c|c|c|c|c|c|c|c|}
\hline Gm $\left(\mathbf{s}^{-1}\right): 800$ & \multirow{2}{*}{\multicolumn{2}{|c|}{$\begin{array}{l}\text { Gf }\left(\mathbf{s}^{-1}\right): 50 \\
\text { Tf }(\mathbf{m i n}): 10\end{array}$}} & \multirow{2}{*}{\multicolumn{2}{|c|}{$\begin{array}{l}\text { Vs (cm/min): } 2 \\
\text { Ts (s): } 3,8\end{array}$}} & \multirow{2}{*}{\multicolumn{3}{|c|}{$\begin{array}{l}\text { Vs (cm/min): } 1 \\
\text { Ts (s): } 7,5\end{array}$}} \\
\hline \multirow{3}{*}{$\operatorname{Tm}(\mathbf{s}): 5$} & & & & & & & \\
\hline & & \multicolumn{6}{|c|}{ Reator } \\
\hline & & 1 & 2 & 3 & 4 & 5 & 6 \\
\hline \multicolumn{2}{|l|}{$\mathrm{Ca}(\mathrm{OH})_{2}(\mathrm{ml})^{*}$} & 10 & 10 & 10 & 10 & 10 & 10 \\
\hline \multicolumn{2}{|l|}{ pHcoag. } & 7,38 & 7,69 & 7,94 & 8,13 & 8,29 & 8,42 \\
\hline \multicolumn{2}{|l|}{$\mathrm{DC}(\mathrm{mg} / \mathrm{l}) * *$} & 80 & 140 & 200 & 260 & 320 & 380 \\
\hline \multicolumn{2}{|l|}{ Turbidez p/ Vs1 (NTU) } & 104 & 215 & 323 & 325 & 356 & 449 \\
\hline \multicolumn{2}{|l|}{ Turbidez p/ Vs2 (NTU) } & 10,8 & 17,3 & 18,5 & 13,2 & 11,0 & 12,0 \\
\hline \multicolumn{2}{|c|}{ Condutividade $\mathrm{p} / \mathrm{Vs} 1\left(\mu \mathrm{S} / \mathrm{cm}\right.$ a $\left.25^{\circ} \mathrm{C}\right)$} & 1574 & 1563 & 1563 & 1563 & 1572 & 1578 \\
\hline \multicolumn{2}{|c|}{ Condutividade $\mathrm{p} / \mathrm{Vs} 2\left(\mu \mathrm{S} / \mathrm{cm}\right.$ a $\left.25^{\circ} \mathrm{C}\right)$} & 1573 & 1566 & 1566 & 1565 & 1570 & 1555 \\
\hline
\end{tabular}

* Solução 40g/l de $\mathrm{Ca}(\mathrm{OH})_{2}$

** Solução 40g/l de aluminato de sódio 


\section{Ensaios de Coagulação-Floculação-Sedimentação Coagulante: Aluminato de Sódio}

\begin{tabular}{|c|c|c|c|c|c|c|c|}
\hline $\mathbf{N}^{\circ}$ do ensaio: 14 & \multicolumn{7}{|c|}{ Ensaio: Determinação dos pares pHxDC para construção do Diagrama de Coagulação } \\
\hline \multicolumn{3}{|c|}{ Data ensaio: $24 / 07 / 2010$} & \multicolumn{5}{|c|}{ Horário início: $12: 00 \mathrm{~h}$} \\
\hline \multicolumn{8}{|c|}{ Coleta da amostra } \\
\hline \multicolumn{3}{|c|}{ Data/horário da coleta: $16 / 07 / 2010 / 15: 00 \mathrm{~h}$} & \multicolumn{5}{|c|}{ Temperatura da amosta na coleta $\left({ }^{\circ} \mathbf{C}\right): 23$} \\
\hline \multicolumn{8}{|c|}{ Características da amostra bruta no início do ensaio } \\
\hline \multicolumn{3}{|l|}{ pH: 3,32} & \multicolumn{5}{|c|}{ Turbidez (NTU): 607} \\
\hline \multicolumn{3}{|c|}{ Temperatura $\left({ }^{\circ} \mathrm{C}\right): 23$} & \multicolumn{5}{|c|}{ Condutividade $\left(\mu \mathrm{S} / \mathrm{cm}\right.$ a $\left.25^{\circ} \mathrm{C}\right): 1566$} \\
\hline \multicolumn{8}{|c|}{ Parâmetros de mistura, floculação e sedimentação } \\
\hline Gm $\left(\mathbf{s}^{-1}\right): 800$ & \multirow{2}{*}{\multicolumn{2}{|c|}{$\begin{array}{l}\text { Gf }\left(\mathbf{s}^{-1}\right): 50 \\
\text { Tf }(\min ): 10 \\
\end{array}$}} & \multirow{2}{*}{\multicolumn{2}{|c|}{$\begin{array}{l}\text { Vs (cm/min): } 2 \\
\text { Ts (s): } 3,8\end{array}$}} & \multirow{2}{*}{\multicolumn{3}{|c|}{$\begin{array}{l}\text { Vs (cm/min): } 1 \\
\text { Ts (s): } 7,5\end{array}$}} \\
\hline \multirow[t]{3}{*}{ Tm (s): 5} & & & & & & & \\
\hline & & \multicolumn{6}{|c|}{ Reator } \\
\hline & & 1 & 2 & 3 & 4 & 5 & 6 \\
\hline \multicolumn{2}{|l|}{$\mathrm{Ca}(\mathrm{OH})_{2}(\mathrm{ml})^{*}$} & 11 & 11 & 11 & 11 & 11 & 11 \\
\hline \multicolumn{2}{|l|}{ pHcoag. } & 7,68 & 7,92 & 8,11 & 8,27 & 8,38 & 8,50 \\
\hline \multicolumn{2}{|c|}{$\mathrm{DC}(\mathrm{mg} / \mathrm{l}) * *$} & 80 & 140 & 200 & 260 & 320 & 380 \\
\hline \multicolumn{2}{|c|}{ Turbidez p/ Vs1 (NTU) } & 182 & 282 & 275 & 273 & 377 & 343 \\
\hline \multicolumn{2}{|c|}{ Turbidez p/ Vs2 (NTU) } & 16,3 & 18,5 & 14,2 & 13,5 & 10,1 & 8,73 \\
\hline \multicolumn{2}{|c|}{ Condutividade $\mathrm{p} / \mathrm{Vs} 1\left(\mu \mathrm{S} / \mathrm{cm}\right.$ a $\left.25^{\circ} \mathrm{C}\right)$} & 1490 & 1492 & - & 1493 & 1504 & 1534 \\
\hline \multicolumn{2}{|c|}{ Condutividade $\mathrm{p} / \mathrm{Vs} 2\left(\mu \mathrm{S} / \mathrm{cm}\right.$ a $\left.25^{\circ} \mathrm{C}\right)$} & 1489 & 1488 & 1491 & 1494 & 1500 & 1544 \\
\hline
\end{tabular}

\begin{tabular}{|l|l|l|}
\hline $\mathbf{N}^{\circ}$ do ensaio: 15 & Ensaio: Determinação dos pares pHxDC para construção do Diagrama de Coagulação \\
\hline
\end{tabular} Data ensaio: $24 / 07 / 2010$

Horário início: $14: 30 \mathrm{~h}$

\section{Coleta da amostra}

\begin{tabular}{|l|l|}
\hline Data/horário da coleta: $16 / 07 / 2010 / 15: 00 \mathrm{~h}$ & Temperatura da amosta na coleta $\left({ }^{\circ} \mathbf{C}\right): 23$ \\
\hline
\end{tabular}

\section{Características da amostra bruta no início do ensaio}

\begin{tabular}{|l|l|}
\hline pH: 3,32 & Turbidez $($ NTU): 600 \\
\hline Temperatura $\left({ }^{\circ} \mathbf{C}\right): 23$ & Condutividade $\left(\boldsymbol{\mu S} / \mathbf{c m ~ a ~ 2 5}{ }^{\circ} \mathbf{C}\right): 1634$ \\
\hline
\end{tabular}

Parâmetros de mistura, floculação e sedimentação

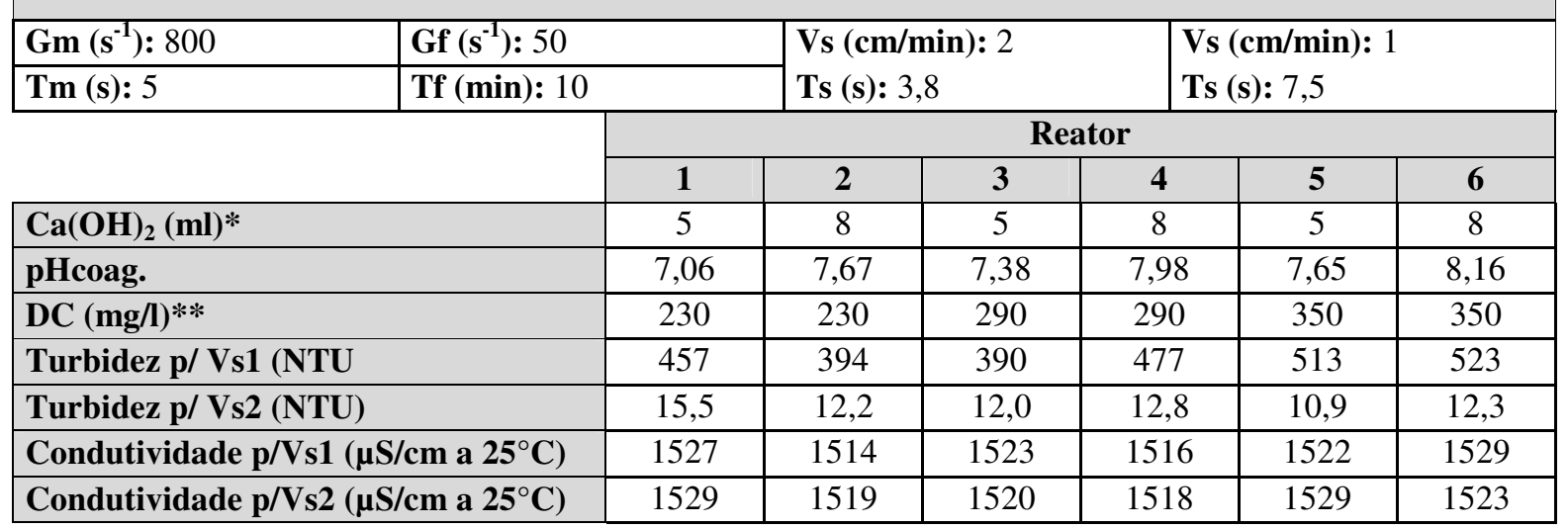

* Solução 40g/l de $\mathrm{Ca}(\mathrm{OH})_{2}$

** Solução 40g/l de aluminato de sódio 


\section{Ensaios de Coagulação-Floculação-Sedimentação Coagulante: Aluminato de Sódio}

\begin{tabular}{|c|c|c|c|c|c|c|c|}
\hline $\mathbf{N}^{\circ}$ do ensaio: 16 & \multicolumn{7}{|c|}{ Ensaio: Determinação dos pares pHxDC para construção do Diagrama de Coagulação } \\
\hline \multicolumn{3}{|c|}{ Data ensaio: $24 / 07 / 2010$} & \multicolumn{5}{|c|}{ Horário início: $16: 30 \mathrm{~h}$} \\
\hline \multicolumn{8}{|c|}{ Coleta da amostra } \\
\hline \multicolumn{3}{|c|}{ Data/horário da coleta: $16 / 07 / 2010 / 15: 00 \mathrm{~h}$} & \multicolumn{5}{|c|}{ Temperatura da amosta na coleta $\left({ }^{\circ} \mathbf{C}\right): 23$} \\
\hline \multicolumn{8}{|c|}{ Características da amostra bruta no início do ensaio } \\
\hline \multicolumn{3}{|l|}{ pH: 3,32} & \multicolumn{5}{|c|}{ Turbidez (NTU): 600} \\
\hline \multicolumn{3}{|c|}{ Temperatura $\left({ }^{\circ} \mathbf{C}\right): 23$} & \multicolumn{5}{|c|}{ 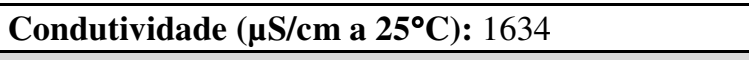 } \\
\hline \multicolumn{8}{|c|}{ Parâmetros de mistura, floculação e sedimentação } \\
\hline Gm $\left(s^{-1}\right): 800$ & & \multicolumn{3}{|c|}{ Gf $\left(\mathbf{s}^{-1}\right): 50$} & \multicolumn{3}{|c|}{ Vs (cm/min): 2} \\
\hline \multirow{3}{*}{\multicolumn{2}{|c|}{ Tm (s): 5}} & 1): 10 & & & $: 3$, & & \\
\hline & & \multicolumn{6}{|c|}{ Reator } \\
\hline & & 1 & 2 & 3 & 4 & 5 & 6 \\
\hline \multicolumn{2}{|l|}{$\mathrm{Ca}(\mathrm{OH})_{2}(\mathrm{ml})^{*}$} & 12 & 12 & & & & \\
\hline \multicolumn{2}{|l|}{ pHcoag. } & 8,28 & 8,52 & & & & \\
\hline \multicolumn{2}{|l|}{$\mathrm{DC}(\mathrm{mg} / \mathrm{l}) * *$} & 200 & 320 & & & & \\
\hline \multicolumn{2}{|c|}{ Turbidez p/ Vs1 (NTU } & 146 & 206 & & & & \\
\hline \multicolumn{2}{|c|}{ Turbidez p/ Vs2 (NTU) } & 17,9 & 10,3 & & & & \\
\hline \multirow{2}{*}{\multicolumn{2}{|c|}{ Condutividade $\mathrm{p} / \mathrm{Vs} 1\left(\mu \mathrm{S} / \mathrm{cm}\right.$ a $\left.25^{\circ} \mathrm{C}\right)$}} & 1519 & 1534 & & & & \\
\hline & & 1517 & 1526 & & & & \\
\hline
\end{tabular}




\section{Apêndice C}

Resultados dos ensaios de coagulação-floculação-sedimentação para o coagulante cloreto férrico 


\section{Ensaios de Coagulação-Floculação-Sedimentação Coagulante: Cloreto Férrico}

\begin{tabular}{|c|c|c|c|c|c|c|}
\hline $\mathbf{N}^{\circ}$ do ensaio: 01 & \multicolumn{6}{|c|}{ Ensaio: Determinação do par pHxDC aproximado para determinação dos parâmetros } \\
\hline \multicolumn{3}{|c|}{\begin{tabular}{|l|l} 
Data ensaio: $04 / 09 / 2010$ & .
\end{tabular}} & \multicolumn{4}{|c|}{ Horário início: 8:00h } \\
\hline \multicolumn{7}{|c|}{ Coleta da amostra } \\
\hline \multicolumn{3}{|c|}{ Data/horário da coleta: 03/09/2010 / 14:00h } & \multicolumn{4}{|c|}{ Temperatura da amosta na coleta $\left({ }^{\circ} \mathrm{C}\right): 26$} \\
\hline \multicolumn{7}{|c|}{ Características da amostra bruta no início do ensaio } \\
\hline \multirow{2}{*}{\multicolumn{3}{|c|}{$\begin{array}{l}\text { pH: } 3,60 \\
\text { Temperatura }\left({ }^{\circ} \mathrm{C}\right): 25\end{array}$}} & & & & \\
\hline & & & \multicolumn{4}{|c|}{ Condutividade $\left(\mu \mathrm{S} / \mathrm{cm}\right.$ a $\left.25^{\circ} \mathrm{C}\right): 1252$} \\
\hline \multicolumn{7}{|c|}{ Parâmetros de mistura, floculação e sedimentação } \\
\hline $\mathbf{G m}\left(\mathbf{s}^{-1}\right): 800$ & \multicolumn{3}{|c|}{ Gf $\left(\mathbf{s}^{-1}\right): 50$} & \multicolumn{3}{|c|}{ Vs (cm/min): 1} \\
\hline \multirow[t]{3}{*}{ Tm (s): 10} & \multicolumn{3}{|c|}{ Tf (min): 10} & \multicolumn{3}{|c|}{ Ts (s): 7,5} \\
\hline & \multicolumn{6}{|c|}{ Reator } \\
\hline & 1 & 2 & 3 & 4 & 5 & 6 \\
\hline $\mathrm{Ca}(\mathrm{OH})_{2}(\mathrm{ml})^{*}$ & 12 & 14 & 16 & 18 & 20 & 22 \\
\hline pHcoag. & 6,95 & 7,49 & 7,92 & 8,11 & 8,27 & 8,37 \\
\hline DC (mg/l)** & 260 & 260 & 260 & 260 & 260 & 260 \\
\hline Turbidez (NTU) & 18,0 & 17,0 & 14,0 & 9,0 & 12,0 & 11,0 \\
\hline Condutividade $\left(\mu \mathrm{S} / \mathrm{cm}\right.$ a $\left.25^{\circ} \mathrm{C}\right)$ & 1315 & 1364 & 1410 & 1468 & 1523 & 1578 \\
\hline
\end{tabular}

* Solução 40g/l de $\mathrm{Ca}(\mathrm{OH})_{2}$

** Solução $40 \mathrm{~g} / 1$ de cloreto férrico 


\section{Ensaios de Coagulação-Floculação-Sedimentação Coagulante: Cloreto Férrico}

\begin{tabular}{|c|c|c|c|c|c|c|}
\hline $\mathbf{N}^{\circ}$ do ensaio: 02 & \multicolumn{6}{|c|}{ Ensaio: Determinação dos parâmetros de mistura rápida } \\
\hline \multicolumn{3}{|c|}{ Data ensaio: $04 / 09 / 10$} & \multicolumn{4}{|c|}{ Horário início: 14:00h } \\
\hline \multicolumn{7}{|c|}{ Coleta da amostra } \\
\hline \multicolumn{3}{|c|}{ Data/horário da coleta: $03 / 09 / 2010 / 14: 00 \mathrm{~h}$} & \multicolumn{4}{|c|}{ Temperatura da amosta na coleta $\left({ }^{\circ} \mathbf{C}\right): 26$} \\
\hline \multicolumn{7}{|c|}{ Características da amostra bruta no início do ensaio } \\
\hline \multirow{2}{*}{\multicolumn{3}{|c|}{$\begin{array}{l}\text { pH: } 3,65 \\
\text { Temperatura }\left({ }^{\circ} \mathbf{C}\right): 25 \\
\end{array}$}} & \multicolumn{4}{|c|}{ Turbidez (NTU): 930} \\
\hline & & & \multicolumn{4}{|c|}{ Condutividade $\left(\boldsymbol{\mu S} / \mathrm{cm}^{2} \mathbf{2 5}^{\circ} \mathrm{C}\right): 1200$} \\
\hline \multicolumn{7}{|c|}{ Parâmetros de mistura, floculação e sedimentação } \\
\hline Gm $\left(\mathbf{s}^{-1}\right): 500$ & \multicolumn{3}{|c|}{ Gf $\left(\mathbf{s}^{-1}\right): 50$} & \multicolumn{3}{|c|}{ Vs (cm/min): 1} \\
\hline \multirow[t]{3}{*}{ Tm (s): variável } & Tf (min): & & & Ts (s): & & \\
\hline & \multicolumn{6}{|c|}{ Reator } \\
\hline & 1 & 2 & 3 & 4 & 5 & 6 \\
\hline $\mathrm{Ca}(\mathrm{OH})_{2}(\mathrm{ml})^{*}$ & 19 & 19 & 19 & 19 & 19 & 19 \\
\hline Tm (s) & 5 & 10 & 15 & 30 & 60 & 90 \\
\hline pHcoag. & 8,38 & 8,37 & 8,39 & 8,40 & 8,36 & 8,35 \\
\hline $\mathrm{DC}(\mathrm{mg} / \mathrm{l})^{* *}$ & 200 & 200 & 200 & 200 & 200 & 200 \\
\hline Turbidez (NTU) & 13,4 & 15,8 & 19,7 & 26,7 & 26 & 21,1 \\
\hline Condutividade $\left(\mu \mathrm{S} / \mathrm{cm}\right.$ a $\left.25^{\circ} \mathrm{C}\right)$ & 1417 & 1425 & 1426 & 1435 & 1430 & 1435 \\
\hline
\end{tabular}

\begin{tabular}{|c|c|}
\hline Ensaio: Determinação & netros de mistura rápida \\
\hline Data ensaio: $04 / 09 / 10$ & Horário início: $16: 00 \mathrm{~h}$ \\
\hline \multicolumn{2}{|c|}{ Coleta da amostra } \\
\hline Data/horário da coleta: 03/09/2010 / 14:00h & Temperatura da amosta na coleta $\left({ }^{\circ} \mathrm{C}\right): 26$ \\
\hline \multicolumn{2}{|c|}{ Características da amostra bruta no início do ensaio } \\
\hline pH: 3,65 & Turbidez (NTU): 930 \\
\hline Temperatura $\left({ }^{\circ} \mathrm{C}\right): 25$ & Condutividade $\left(\mu \mathrm{S} / \mathrm{cm}\right.$ a $\left.25^{\circ} \mathrm{C}\right): 1200$ \\
\hline
\end{tabular}

Parâmetros de mistura, floculação e sedimentação

\begin{tabular}{|c|c|c|c|c|c|c|}
\hline \multirow{4}{*}{$\begin{array}{l}\mathbf{G m}\left(\mathbf{s}^{-1}\right): 800 \\
\mathbf{T m}(\mathbf{s}): \text { variável } \\
\end{array}$} & \multicolumn{3}{|c|}{ Gf $\left(\mathbf{s}^{-1}\right): 50$} & \multicolumn{3}{|c|}{ Vs (cm/min): 1} \\
\hline & \multicolumn{3}{|c|}{ Tf (min): 10} & \multicolumn{3}{|c|}{ Ts (s): 7,5} \\
\hline & \multicolumn{6}{|c|}{ Reator } \\
\hline & 1 & 2 & 3 & 4 & 5 & 6 \\
\hline $\mathrm{Ca}(\mathrm{OH})_{2}(\mathrm{ml})^{*}$ & 19 & 19 & 19 & 19 & 19 & 19 \\
\hline Tm (s) & 5 & 10 & 15 & 30 & 60 & 90 \\
\hline pHcoag. & 8,55 & 8,56 & 8,60 & 8,56 & 8,55 & 8,56 \\
\hline $\mathrm{DC}(\mathrm{mg} / \mathrm{l})^{* *}$ & 200 & 200 & 200 & 200 & 200 & 200 \\
\hline Turbidez (NTU) & 12,8 & 15,8 & 19,2 & 21,0 & 22,8 & 22,8 \\
\hline Condutividade $\left(\mu \mathrm{S} / \mathrm{cm}\right.$ a $\left.25^{\circ} \mathrm{C}\right)$ & 1377 & 1389 & 1389 & 1392 & 1391 & 1390 \\
\hline
\end{tabular}

* Solução 40g/l de $\mathrm{Ca}(\mathrm{OH})_{2}$

** Solução $40 \mathrm{~g} / \mathrm{l}$ de cloreto férrico 


\section{Ensaios de Coagulação-Floculação-Sedimentação Coagulante: Cloreto Férrico}

\begin{tabular}{|c|c|c|c|c|c|c|}
\hline $\mathbf{N}^{\circ}$ do ensaio: 04 & \multicolumn{6}{|c|}{ Ensaio: Determinação dos parâmetros de mistura rápida } \\
\hline Data ensaio: $04 / 09 / 10$ & & \multicolumn{5}{|c|}{\begin{tabular}{l|l} 
& Horário início: $18: 00 \mathrm{~h}$ \\
\end{tabular}} \\
\hline \multicolumn{7}{|c|}{ Coleta da amostra } \\
\hline \multicolumn{3}{|c|}{ Data/horário da coleta: 03/09/2010 / 14:00h } & \multicolumn{4}{|c|}{ Temperatura da amosta na coleta $\left({ }^{\circ} \mathrm{C}\right): 26$} \\
\hline \multicolumn{7}{|c|}{ Características da amostra bruta no início do ensaio } \\
\hline \multirow{2}{*}{\multicolumn{3}{|c|}{$\begin{array}{l}\text { pH: } 3,65 \\
\text { Temperatura }\left({ }^{\circ} \mathrm{C}\right): 25 \\
\end{array}$}} & & & & \\
\hline & & & \multicolumn{4}{|c|}{ Condutividade $\left(\boldsymbol{\mu S} / \mathrm{cm}\right.$ a $\left.25^{\circ} \mathrm{C}\right): 1200$} \\
\hline \multicolumn{7}{|c|}{ Parâmetros de mistura, floculação e sedimentação } \\
\hline $\mathbf{G m}\left(\mathbf{s}^{-1}\right): 1000$ & \multicolumn{3}{|c|}{ Gf $\left(\mathbf{s}^{-1}\right): 50$} & \multicolumn{3}{|c|}{ Vs (cm/min): 1} \\
\hline \multirow[t]{3}{*}{ Tm (s): variável } & Tf (min): & & & Ts (s): 7 & & \\
\hline & \multicolumn{6}{|c|}{ Reator } \\
\hline & 1 & 2 & 3 & 4 & 5 & 6 \\
\hline $\mathrm{Ca}(\mathrm{OH})_{2}(\mathrm{ml})^{*}$ & 19 & 19 & 19 & 19 & 19 & 19 \\
\hline $\operatorname{Tm}(\mathbf{s})$ & 5 & 10 & 15 & 30 & 60 & 90 \\
\hline pHcoag. & 8,48 & 8,48 & 8,49 & 8,46 & 8,51 & 8,60 \\
\hline $\mathrm{DC}(\mathrm{mg} / \mathrm{l}) * *$ & 200 & 200 & 200 & 200 & 200 & 200 \\
\hline Turbidez (NTU) & 15,3 & 18,5 & 26,0 & 23,3 & 24,7 & 25,8 \\
\hline Condutividade $\left(\mu \mathrm{S} / \mathrm{cm}\right.$ a $\left.25^{\circ} \mathrm{C}\right)$ & 1370 & 1380 & 1378 & 1377 & 1378 & 1388 \\
\hline
\end{tabular}




\section{Ensaios de Coagulação-Floculação-Sedimentação Coagulante: Cloreto Férrico}

\begin{tabular}{|c|c|c|c|c|c|c|}
\hline $\mathbf{N}^{\circ}$ do ensaio: 05 & \multicolumn{6}{|c|}{ Ensaio: Determinação dos parâmetros de floculação } \\
\hline \multicolumn{3}{|c|}{ Data ensaio: $05 / 09 / 10$} & \multicolumn{4}{|c|}{ Horário início: $08: 00 \mathrm{~h}$} \\
\hline \multicolumn{7}{|c|}{ Coleta da amostra } \\
\hline \multicolumn{3}{|c|}{ Data/horário da coleta: $03 / 09 / 2010 / 14: 00 \mathrm{~h}$} & \multicolumn{4}{|c|}{ Temperatura da amosta na coleta $\left({ }^{\circ} \mathbf{C}\right): 26$} \\
\hline \multicolumn{7}{|c|}{ Características da amostra bruta no início do ensaio } \\
\hline \multirow{2}{*}{\multicolumn{3}{|c|}{$\begin{array}{l}\text { pH: } 3,70 \\
\text { Temperatura }\left({ }^{\circ} \mathbf{C}\right): 25 \\
\end{array}$}} & \multicolumn{4}{|c|}{ Turbidez (NTU): 930} \\
\hline & & & \multicolumn{4}{|c|}{ 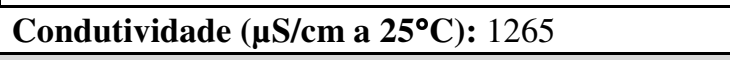 } \\
\hline \multicolumn{7}{|c|}{ Parâmetros de mistura, floculação e sedimentação } \\
\hline Gm $\left(s^{-1}\right): 800$ & \multicolumn{3}{|c|}{ Gf $\left(\mathbf{s}^{-1}\right): 25$} & \multicolumn{3}{|c|}{ Vs (cm/min): 1} \\
\hline \multirow[t]{3}{*}{$\operatorname{Tm}(\mathbf{s}): 5$} & Tf (min): & ável & & Ts (s): & & \\
\hline & \multicolumn{6}{|c|}{ Reator } \\
\hline & 1 & 2 & 3 & 4 & 5 & 6 \\
\hline $\mathrm{Ca}(\mathrm{OH})_{2}(\mathrm{ml})^{*}$ & 19 & 19 & 19 & 19 & 19 & 19 \\
\hline Tf (min) & 5 & 10 & 20 & 30 & 40 & 60 \\
\hline pHcoag. & 8,56 & 8,58 & 8,61 & 8,56 & 8,67 & 8,48 \\
\hline $\mathrm{DC}(\mathrm{mg} / \mathrm{l}) * *$ & 200 & 200 & 200 & 200 & 200 & 200 \\
\hline Turbidez (NTU) & 5,42 & 6,82 & 9,97 & 9,09 & 15,3 & 19,7 \\
\hline Condutividade $\left(\mu \mathrm{S} / \mathrm{cm}\right.$ a $\left.25^{\circ} \mathrm{C}\right)$ & 1526 & 1529 & 1531 & 1533 & 1520 & 1537 \\
\hline
\end{tabular}

\begin{tabular}{|l|l|}
\hline $\mathbf{N}^{\circ}$ do ensaio: 06 & Ensaio: Determinação dos parâmetros de floculação \\
\hline Data ensaio: $05 / 09 / 10$ & Horário início: $10: 00 \mathrm{~h}$ \\
\hline \multicolumn{2}{|c|}{ Coleta da amostra } \\
\hline Data/horário da coleta: $03 / 09 / 2010 / 14: 00 \mathrm{~h}$ & Temperatura da amosta na coleta $\left({ }^{\circ} \mathrm{C}\right): 26$ \\
\hline \multicolumn{2}{|c|}{ Características da amostra bruta no início do ensaio } \\
\hline pH: 3,70 & Turbidez $(\mathbf{N T U}): 930$ \\
\hline Temperatura $\left({ }^{\circ} \mathbf{C}\right): 25$ & Condutividade $\left(\boldsymbol{\mu S} / \mathbf{c m ~ a ~} 25^{\circ} \mathbf{C}\right): 1265$ \\
\hline
\end{tabular}

Parâmetros de mistura, floculação e sedimentação

\begin{tabular}{|c|c|c|c|c|c|c|}
\hline Gm $\left(\mathbf{s}^{-1}\right): 800$ & \multicolumn{3}{|c|}{ Gf $\left(\mathbf{s}^{-1}\right): 50$} & \multicolumn{3}{|c|}{ Vs $(\mathbf{c m} / \mathbf{m i n}): 1$} \\
\hline \multirow[t]{3}{*}{ Tm (s): 5} & Tf $(\min )$ & ável & & Ts (s): 7 & & \\
\hline & \multicolumn{6}{|c|}{ Reator } \\
\hline & 1 & 2 & 3 & 4 & 5 & 6 \\
\hline $\mathrm{Ca}(\mathrm{OH})_{2}(\mathrm{ml})^{*}$ & 19 & 19 & 19 & 19 & 19 & 19 \\
\hline Tf (min) & 5 & 10 & 20 & 30 & 40 & 60 \\
\hline pHcoag. & 8,58 & 8,58 & 8,57 & 8,67 & 8,64 & 8,62 \\
\hline $\mathrm{DC}(\mathrm{mg} / \mathrm{l})^{* * *}$ & 200 & 200 & 200 & 200 & 200 & 200 \\
\hline Turbidez (NTU) & 7,07 & 7,51 & 12,7 & 12,0 & 14,8 & 17,4 \\
\hline Condutividade $\left(\mu \mathrm{S} / \mathrm{cm}\right.$ a $\left.25^{\circ} \mathrm{C}\right)$ & 1507 & 1520 & 1522 & 1516 & 1521 & 1526 \\
\hline
\end{tabular}

* Solução 40g/l de $\mathrm{Ca}(\mathrm{OH})_{2}$

** Solução 40g/l de cloreto férrico 


\section{Ensaios de Coagulação-Floculação-Sedimentação Coagulante: Cloreto Férrico}

\begin{tabular}{|c|c|c|c|c|c|c|}
\hline $\mathbf{N}^{\circ}$ do ensaio: 07 & \multicolumn{6}{|c|}{ Ensaio: Determinação dos parâmetros de floculação } \\
\hline \multicolumn{3}{|l|}{ Data ensaio: $05 / 09 / 10$} & \multicolumn{4}{|c|}{ Horário início: $13: 00 \mathrm{~h}$} \\
\hline \multicolumn{7}{|c|}{ Coleta da amostra } \\
\hline \multicolumn{3}{|c|}{ Data/horário da coleta: 03/09/2010 / 14:00h } & \multicolumn{4}{|c|}{ Temperatura da amosta na coleta $\left({ }^{\circ} \mathrm{C}\right): 26$} \\
\hline \multicolumn{7}{|c|}{ Características da amostra bruta no início do ensaio } \\
\hline \multicolumn{3}{|l|}{ pH: 3,52} & \multicolumn{4}{|c|}{ Turbidez (NTU): 910} \\
\hline \multicolumn{3}{|l|}{ Temperatura $\left({ }^{\circ} \mathrm{C}\right): 25$} & \multicolumn{4}{|c|}{ 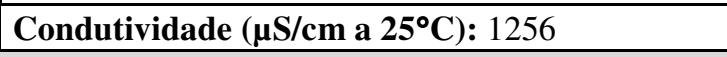 } \\
\hline \multicolumn{7}{|c|}{ Parâmetros de mistura, floculação e sedimentação } \\
\hline Gm $\left(\mathbf{s}^{-1}\right): 800$ & \multicolumn{3}{|c|}{ Gf $\left(s^{-1}\right): 75$} & \multicolumn{3}{|c|}{ Vs (cm/min): 1} \\
\hline \multirow[t]{3}{*}{ Tm (s): 5} & Tf (min) & ável & & Ts (s): 7 & & \\
\hline & \multicolumn{6}{|c|}{ Reator } \\
\hline & 1 & 2 & 3 & 4 & 5 & 6 \\
\hline $\mathrm{Ca}(\mathrm{OH})_{2}(\mathrm{ml})^{*}$ & 19 & 19 & 19 & 19 & 19 & 19 \\
\hline Tf (min) & 5 & 10 & 20 & 30 & 40 & 60 \\
\hline pHcoag. & 8,23 & 8,24 & 8,22 & 8,20 & 8,20 & 8,20 \\
\hline $\mathrm{DC}(\mathrm{mg} / \mathrm{l}) * *$ & 200 & 200 & 200 & 200 & 200 & 200 \\
\hline Turbidez (NTU) & 15,8 & 14,4 & 19,6 & 20,4 & 23,6 & 30,2 \\
\hline Condutividade $\left(\mu \mathrm{S} / \mathrm{cm}\right.$ a $\left.25^{\circ} \mathrm{C}\right)$ & 1504 & 1519 & 1514 & 1513 & 1518 & 1511 \\
\hline
\end{tabular}

* Solução 40g/l de $\mathrm{Ca}(\mathrm{OH})_{2}$

** Solução 40g/l de cloreto férrico 


\section{Ensaios de Coagulação-Floculação-Sedimentação Coagulante: Cloreto Férrico}

\begin{tabular}{|c|c|c|c|c|c|c|}
\hline $\mathbf{N}^{\circ}$ do ensaio: 8 & \multicolumn{6}{|c|}{ Ensaio: Determinação dos pares pHxDC para construção do Diagrama de Coagulação } \\
\hline \multicolumn{3}{|c|}{ Data ensaio: $05 / 09 / 10$} & o iníci & $5: 00 \mathrm{~h}$ & & \\
\hline \multicolumn{7}{|c|}{ Coleta da amostra } \\
\hline \multicolumn{3}{|c|}{ Data/horário da coleta: $03 / 09 / 2010 / 14: 00 \mathrm{~h}$} & \multicolumn{4}{|c|}{ Temperatura da amosta na coleta $\left({ }^{\circ} \mathbf{C}\right): 26$} \\
\hline \multicolumn{7}{|c|}{ Características da amostra bruta no início do ensaio } \\
\hline \multirow{2}{*}{\multicolumn{3}{|c|}{$\begin{array}{l}\text { pH: } 3,52 \\
\text { Temperatura }\left({ }^{\circ} \mathrm{C}\right): 25\end{array}$}} & \multicolumn{4}{|c|}{ Turbidez (NTU): 910} \\
\hline & & & \multicolumn{4}{|c|}{ 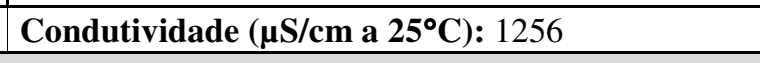 } \\
\hline \multicolumn{7}{|c|}{ Parâmetros de mistura, floculação e sedimentação } \\
\hline Gm $\left(\mathbf{s}^{-1}\right): 800$ & \multicolumn{3}{|c|}{ Gf $\left(\mathbf{s}^{-1}\right): 25$} & \multicolumn{3}{|c|}{ Vs (cm/min): 1} \\
\hline \multirow[t]{3}{*}{ Tm (s): 5} & Tf (min): & & & Ts (s): & & \\
\hline & \multicolumn{6}{|c|}{ Reator } \\
\hline & 1 & 2 & 3 & 4 & 5 & 6 \\
\hline $\mathrm{Ca}(\mathrm{OH})_{2}(\mathrm{ml})^{*}$ & 0 & 0 & 0 & 0 & 0 & 0 \\
\hline pHcoag. & 3,20 & 3,02 & 2,89 & 2,77 & 2,73 & 2,61 \\
\hline $\mathrm{DC}(\mathrm{mg} / \mathrm{l})^{* * *}$ & 80 & 140 & 200 & 260 & 320 & 380 \\
\hline Turbidez (NTU) & 57,1 & 30,6 & 108 & 207 & 283 & 289 \\
\hline Condutividade $\left(\mu \mathrm{S} / \mathrm{cm}\right.$ a $\left.25^{\circ} \mathrm{C}\right)$ & 1417 & 1567 & 1679 & 1833 & 1920 & 2120 \\
\hline
\end{tabular}

\begin{tabular}{|c|c|}
\hline Ensaio: Determinação & pHxDC para construção do Diagrama de Coagulação \\
\hline Data ensaio: $05 / 09 / 10$ & Horário início: $16: 00 \mathrm{~h}$ \\
\hline \multicolumn{2}{|c|}{ Coleta da amostra } \\
\hline Data/horário da coleta: 03/09/2010 / 14:00h & Temperatura da amosta na coleta $\left({ }^{\circ} \mathrm{C}\right): 26$ \\
\hline \multicolumn{2}{|c|}{ Características da amostra bruta no início do ensaio } \\
\hline pH: 3,52 & Turbidez (NTU): 910 \\
\hline Temperatura $\left({ }^{\circ} \mathrm{C}\right): 25$ & Condutividade $\left(\boldsymbol{\mu S} / \mathrm{cm}\right.$ a $\left.25^{\circ} \mathrm{C}\right): 1256$ \\
\hline
\end{tabular}

Temperatura $\left({ }^{\circ} \mathrm{C}\right): 25$

Parâmetros de mistura, floculação e sedimentação

\begin{tabular}{|c|c|c|c|c|c|c|}
\hline $\mathbf{G m}\left(\mathbf{s}^{-1}\right): 800$ & \multicolumn{3}{|c|}{ Gf $\left(s^{-1}\right): 25$} & \multicolumn{3}{|c|}{ Vs (cm/min): 1} \\
\hline \multirow{3}{*}{$\operatorname{Tm}(\mathbf{s}): 5$} & \multicolumn{3}{|c|}{ Tf (min): 5} & \multicolumn{3}{|c|}{ Ts (s): 7,5 } \\
\hline & \multicolumn{6}{|c|}{ Reator } \\
\hline & 1 & 2 & 3 & 4 & 5 & 6 \\
\hline $\mathrm{Ca}(\mathrm{OH})_{2}(\mathrm{ml})^{*}$ & 10 & 10 & 10 & 10 & 10 & 10 \\
\hline pHcoag. & 6,62 & 6,65 & 6,41 & 6,08 & 5,84 & 5,62 \\
\hline $\mathrm{DC}(\mathrm{mg} / \mathrm{l}) * *$ & 80 & 140 & 200 & 260 & 320 & 380 \\
\hline Turbidez (NTU) & 22,3 & 26,4 & 22,8 & 24,6 & 21,2 & 17,8 \\
\hline Condutividade $\left(\mu \mathrm{S} / \mathrm{cm}\right.$ a $\left.25^{\circ} \mathrm{C}\right)$ & 1292 & 1344 & 1377 & 1408 & 1450 & 1476 \\
\hline
\end{tabular}

* Solução 40g/l de $\mathrm{Ca}(\mathrm{OH})_{2}$

** Solução $40 \mathrm{~g} / \mathrm{l}$ de cloreto férrico 


\section{Ensaios de Coagulação-Floculação-Sedimentação Coagulante: Cloreto Férrico}

\begin{tabular}{|c|c|c|c|c|c|c|}
\hline \begin{tabular}{|l|l}
$\mathbf{N}^{\circ}$ do ensaio: 10 & Ensaio: $\mathrm{D}$ \\
\end{tabular} & \multicolumn{6}{|c|}{ Ensaio: Determinação dos pares pHxDC para construção do Diagrama de Coagulação } \\
\hline \multicolumn{3}{|l|}{ Data ensaio: $07 / 09 / 10$} & \multicolumn{4}{|c|}{ Horário início: 14:00h } \\
\hline \multicolumn{7}{|c|}{ Coleta da amostra } \\
\hline Data/horário da coleta: $03 / 09 / 2$ & $0 / 14: 00 \mathrm{~h}$ & \multicolumn{5}{|c|}{ Temperatura da amosta na coleta $\left({ }^{\circ} \mathbf{C}\right): 26$} \\
\hline \multicolumn{7}{|c|}{ Características da amostra bruta no início do ensaio } \\
\hline \multirow{2}{*}{\multicolumn{3}{|c|}{$\begin{array}{l}\text { pH: } 3,58 \\
\text { Temperatura }\left({ }^{\circ} \mathrm{C}\right): 24\end{array}$}} & & & & \\
\hline & & & \multicolumn{4}{|c|}{ 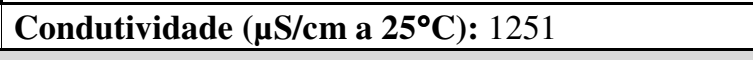 } \\
\hline \multicolumn{7}{|c|}{ Parâmetros de mistura, floculação e sedimentação } \\
\hline Gm $\left(\mathbf{s}^{-1}\right): 800$ & \multicolumn{3}{|c|}{ Gf $\left(\mathbf{s}^{-1}\right): 25$} & \multicolumn{3}{|c|}{ Vs (cm/min): 1} \\
\hline \multirow[t]{3}{*}{ Tm (s): 5} & Tf (min): & & & Ts (s): 7 & & \\
\hline & \multicolumn{6}{|c|}{ Reator } \\
\hline & 1 & 2 & 3 & 4 & 5 & 6 \\
\hline $\mathrm{Ca}(\mathrm{OH})_{2}(\mathrm{ml})^{*}$ & 13 & 13 & 13 & 13 & 13 & 13 \\
\hline pHcoag. & 7,93 & 7,86 & 7,66 & 7,36 & 7,02 & 6,69 \\
\hline DC $(\mathrm{mg} / \mathrm{l}) * *$ & 80 & 140 & 200 & 260 & 320 & 380 \\
\hline Turbidez (NTU) & 18,9 & 10,2 & 14,0 & 9,57 & 10,2 & 10,3 \\
\hline Condutividade $\left(\mu \mathrm{S} / \mathrm{cm}\right.$ a $\left.25^{\circ} \mathrm{C}\right)$ & 1250 & 1312 & 1363 & 1413 & 1468 & 1516 \\
\hline
\end{tabular}

\begin{tabular}{|c|c|c|c|c|c|c|}
\hline $\mathbf{N}^{\circ}$ do ensaio: 11 & \multicolumn{6}{|c|}{ Ensaio: Determinação dos pares pHxDC para construção do Diagrama de Coagulação } \\
\hline \multicolumn{3}{|c|}{ Data ensaio: $05 / 09 / 10$} & \multicolumn{4}{|c|}{ Horário início: $14: 00 \mathrm{~h}$} \\
\hline \multicolumn{7}{|c|}{ Coleta da amostra } \\
\hline \multicolumn{3}{|c|}{ Data/horário da coleta: $03 / 09 / 2010 / 14: 00 \mathrm{~h}$} & \multicolumn{4}{|c|}{ Temperatura da amosta na coleta $\left({ }^{\circ} \mathbf{C}\right): 26$} \\
\hline \multicolumn{7}{|c|}{ Características da amostra bruta no início do ensaio } \\
\hline \multirow{2}{*}{\multicolumn{3}{|c|}{$\begin{array}{l}\text { pH: } 3,6 \\
\text { Temperatura }\left({ }^{\circ} \mathrm{C}\right): 25\end{array}$}} & & & & \\
\hline & & & \multicolumn{4}{|c|}{ Condutividade $\left(\mu \mathrm{S} / \mathrm{cm}\right.$ a $\left.25^{\circ} \mathrm{C}\right): 1219$} \\
\hline \multicolumn{7}{|c|}{ Parâmetros de mistura, floculação e sedimentação } \\
\hline Gm $\left(\mathbf{s}^{-1}\right): 800$ & \multicolumn{3}{|c|}{ Gf $\left(\mathbf{s}^{-1}\right): 25$} & \multicolumn{3}{|c|}{ Vs (cm/min): 1} \\
\hline \multirow[t]{3}{*}{$\operatorname{Tm}(\mathbf{s}): 5$} & Tf (min): & & & Ts (s): & & \\
\hline & \multicolumn{6}{|c|}{ Reator } \\
\hline & 1 & 2 & 3 & 4 & 5 & 6 \\
\hline $\mathrm{Ca}(\mathrm{OH})_{2}(\mathrm{ml})^{*}$ & 5 & 5 & 5 & 5 & 5 & 5 \\
\hline pHcoag. & 5,47 & 5,23 & 4,88 & 4,31 & 3,75 & 3,42 \\
\hline $\mathrm{DC}(\mathrm{mg} / \mathrm{l}) * *$ & 80 & 140 & 200 & 260 & 320 & 380 \\
\hline Turbidez (NTU) & 53,8 & 32,2 & 20,7 & 20,6 & 22,1 & 27,7 \\
\hline Condutividade $\left(\mu \mathrm{S} / \mathrm{cm}\right.$ a $\left.25^{\circ} \mathrm{C}\right)$ & 1228 & 1253 & 1279 & 1329 & 1414 & 1510 \\
\hline
\end{tabular}

* Solução $40 \mathrm{~g} / \mathrm{l}$ de $\mathrm{Ca}(\mathrm{OH})_{2}$

** Solução 40g/l de cloreto férrico 


\section{Ensaios de Coagulação-Floculação-Sedimentação Coagulante: Cloreto Férrico}

\begin{tabular}{|c|c|c|c|c|c|c|}
\hline $\mathbf{N}^{\circ}$ do ensaio: 12 & \multicolumn{6}{|c|}{ Ensaio: Determinação dos pares pHxDC para construção do Diagrama de Coagulação } \\
\hline \multicolumn{3}{|c|}{\begin{tabular}{|l|l|} 
Data ensaio: $07 / 09 / 10$ & 1 \\
\end{tabular}} & o iníci & $6: 00 \mathrm{~h}$ & & \\
\hline \multicolumn{7}{|c|}{ Coleta da amostra } \\
\hline \multicolumn{3}{|c|}{ Data/horário da coleta: $03 / 09 / 2010 / 14: 00 \mathrm{~h}$} & \multicolumn{4}{|c|}{ Temperatura da amosta na coleta $\left({ }^{\circ} \mathbf{C}\right): 26$} \\
\hline \multicolumn{7}{|c|}{ Características da amostra bruta no início do ensaio } \\
\hline \multirow{2}{*}{\multicolumn{3}{|c|}{$\begin{array}{l}\text { pH: } 3,67 \\
\text { Temperatura }\left({ }^{\circ} \mathrm{C}\right): 24\end{array}$}} & \multicolumn{4}{|c|}{ Turbidez (NTU): 904} \\
\hline & & & \multicolumn{4}{|c|}{ 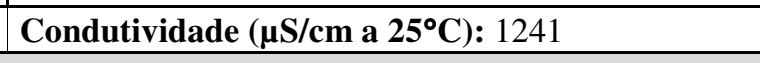 } \\
\hline \multicolumn{7}{|c|}{ Parâmetros de mistura, floculação e sedimentação } \\
\hline Gm $\left(\mathbf{s}^{-1}\right): 800$ & \multicolumn{3}{|c|}{ Gf $\left(\mathbf{s}^{-1}\right): 25$} & \multicolumn{3}{|c|}{ Vs (cm/min): 1} \\
\hline \multirow{3}{*}{ Tm (s): 5} & Tf (min): & & & Ts (s): & & \\
\hline & \multicolumn{6}{|c|}{ Reator } \\
\hline & 1 & 2 & 3 & 4 & 5 & 6 \\
\hline $\mathrm{Ca}(\mathrm{OH})_{2}(\mathrm{ml})^{*}$ & 16 & 16 & 16 & 16 & 16 & 16 \\
\hline pHcoag. & 8,44 & 8,25 & 8,05 & 7,70 & 7,36 & 7,11 \\
\hline $\mathrm{DC}(\mathrm{mg} / \mathrm{l}) * *$ & 80 & 140 & 200 & 260 & 320 & 380 \\
\hline Turbidez (NTU) & 12,2 & 8,29 & 7,87 & 7,36 & 7,36 & 7,20 \\
\hline Condutividade $\left(\mu \mathrm{S} / \mathrm{cm}\right.$ a $\left.25^{\circ} \mathrm{C}\right)$ & 1284 & 1343 & 1392 & 1455 & 1505 & 1551 \\
\hline
\end{tabular}

\begin{tabular}{|c|c|}
\hline Ensaio: Determinação & pHxDC para construção do Diagrama de Coagulação \\
\hline Data ensaio: $07 / 09 / 10$ & Horário início: $16: 00 \mathrm{~h}$ \\
\hline \multicolumn{2}{|c|}{ Coleta da amostra } \\
\hline Data/horário da coleta: 03/09/2010 / 14:00h & Temperatura da amosta na coleta $\left({ }^{\circ} \mathrm{C}\right): 26$ \\
\hline \multicolumn{2}{|c|}{ Características da amostra bruta no início do ensaio } \\
\hline pH: 3,67 & Turbidez (NTU): 904 \\
\hline Temperatura $\left({ }^{\circ} \mathrm{C}\right): 24$ & Condutividade $\left(\boldsymbol{\mu S} / \mathrm{cm}\right.$ a $\left.25^{\circ} \mathrm{C}\right): 1241$ \\
\hline
\end{tabular}

\begin{tabular}{|c|c|c|c|c|c|c|}
\hline \multicolumn{7}{|l|}{ femperatura ( $(\mathrm{C}): 24$} \\
\hline \multicolumn{7}{|c|}{ Parâmetros de mistura, floculação e sedimentação } \\
\hline Gm $\left(\mathbf{s}^{-1}\right): 800$ & \multicolumn{3}{|c|}{ Gf $\left(\mathbf{s}^{-1}\right): 25$} & \multicolumn{3}{|c|}{ Vs $(\mathbf{c m} / \mathbf{m i n}): 1$} \\
\hline \multirow{3}{*}{$\operatorname{Tm}(\mathbf{s}): 5$} & \multicolumn{3}{|c|}{ Tf (min): 5} & \multicolumn{3}{|c|}{ Ts (s): 7,5} \\
\hline & \multicolumn{6}{|c|}{ Reator } \\
\hline & 1 & 2 & 3 & 4 & 5 & 6 \\
\hline $\mathrm{Ca}(\mathrm{OH})_{2}(\mathrm{ml})^{*}$ & 20 & 20 & 20 & 20 & 20 & 20 \\
\hline pHcoag. & 9,22 & 9,08 & 8,91 & 8,64 & 8,39 & 8,20 \\
\hline $\mathrm{DC}(\mathrm{mg} / \mathrm{l})^{* *}$ & 80 & 140 & 200 & 260 & 320 & 380 \\
\hline Turbidez (NTU) & 7,86 & 5,91 & 5,60 & 6,43 & 7,74 & 4,57 \\
\hline Condutividade $\left(\mu \mathrm{S} / \mathrm{cm}\right.$ a $\left.25^{\circ} \mathrm{C}\right)$ & 1237 & 1292 & 1348 & 1406 & 1465 & 1533 \\
\hline
\end{tabular}

* Solução 40g/l de $\mathrm{Ca}(\mathrm{OH})_{2}$

** Solução $40 \mathrm{~g} / \mathrm{l}$ de cloreto férrico 


\section{Ensaios de Coagulação-Floculação-Sedimentação Coagulante: Cloreto Férrico}

\begin{tabular}{|c|c|c|c|c|c|c|}
\hline \begin{tabular}{l|l}
$\mathbf{N}^{\circ}$ do ensaio: 14 & Ensaio: $\mathrm{D}$ \\
\end{tabular} & \multicolumn{6}{|c|}{ Ensaio: Determinação dos pares pHxDC para construção do Diagrama de Coagulação } \\
\hline \multicolumn{3}{|l|}{ Data ensaio: $07 / 09 / 10$} & \multicolumn{4}{|c|}{ Horário início: 17:00h } \\
\hline \multicolumn{7}{|c|}{ Coleta da amostra } \\
\hline Data/horário da coleta: $03 / 09 / 2$ & $0 / 14: 00 \mathrm{~h}$ & \multicolumn{5}{|c|}{ Temperatura da amosta na coleta $\left({ }^{\circ} \mathbf{C}\right): 26$} \\
\hline \multicolumn{7}{|c|}{ Características da amostra bruta no início do ensaio } \\
\hline \multirow{2}{*}{\multicolumn{3}{|c|}{$\begin{array}{l}\text { pH: } 3,64 \\
\text { Temperatura }\left({ }^{\circ} \mathrm{C}\right): 24 \\
\end{array}$}} & & & & \\
\hline & & & \multicolumn{4}{|c|}{ 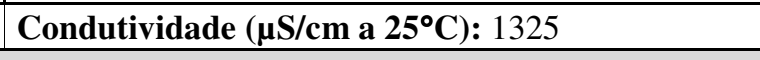 } \\
\hline \multicolumn{7}{|c|}{ Parâmetros de mistura, floculação e sedimentação } \\
\hline Gm $\left(s^{-1}\right): 800$ & \multicolumn{3}{|c|}{ Gf $\left(\mathbf{s}^{-1}\right): 25$} & \multicolumn{3}{|c|}{ Vs (cm/min): 1} \\
\hline \multirow[t]{3}{*}{ Tm (s): 5} & Tf (min): & & & Ts (s): 7 & & \\
\hline & \multicolumn{6}{|c|}{ Reator } \\
\hline & 1 & 2 & 3 & 4 & 5 & 6 \\
\hline $\mathrm{Ca}(\mathrm{OH})_{2}(\mathrm{ml})^{*}$ & 18 & 18 & 18 & 18 & 18 & 18 \\
\hline pHcoag. & 8,69 & 8,54 & 8,30 & 8,13 & 7,84 & 7,50 \\
\hline $\mathrm{DC}(\mathrm{mg} / \mathrm{l}) * *$ & 80 & 140 & 200 & 260 & 320 & 380 \\
\hline Turbidez (NTU) & 7,98 & 6,06 & 5,75 & 7,52 & 4,70 & 4,42 \\
\hline Condutividade $\left(\mu \mathrm{S} / \mathrm{cm}\right.$ a $\left.25^{\circ} \mathrm{C}\right)$ & 13,05 & 13,65 & 14,22 & 14,60 & 15,35 & 15,91 \\
\hline
\end{tabular}

\begin{tabular}{|c|c|c|c|c|c|c|}
\hline $\mathbf{N}^{\circ}$ do ensaio: 15 & \multicolumn{6}{|c|}{ Ensaio: Determinação dos pares pHxDC para construção do Diagrama de Coagulação } \\
\hline \multicolumn{3}{|c|}{\begin{tabular}{|l|l} 
Data ensaio: $07 / 09 / 10$ & 1 \\
\end{tabular}} & o iníci & $9: 00 \mathrm{~h}$ & & \\
\hline \multicolumn{7}{|c|}{ Coleta da amostra } \\
\hline \multicolumn{3}{|c|}{ Data/horário da coleta: $03 / 09 / 2010 / 14: 00 \mathrm{~h}$} & \multicolumn{4}{|c|}{ Temperatura da amosta na coleta $\left({ }^{\circ} \mathbf{C}\right): 26$} \\
\hline \multicolumn{7}{|c|}{ Características da amostra bruta no início do ensaio } \\
\hline \multirow{2}{*}{\multicolumn{3}{|c|}{$\begin{array}{l}\text { pH: } 3,64 \\
\text { Temperatura }\left({ }^{\circ} \mathrm{C}\right): 24\end{array}$}} & & & & \\
\hline & & & \multicolumn{4}{|c|}{ Condutividade $\left(\boldsymbol{\mu S} / \mathbf{c m}\right.$ a $\left.25^{\circ} \mathbf{C}\right): 1306$} \\
\hline \multicolumn{7}{|c|}{ Parâmetros de mistura, floculação e sedimentação } \\
\hline Gm $\left(\mathbf{s}^{-1}\right): 800$ & \multicolumn{3}{|c|}{ Gf $\left(\mathbf{s}^{-1}\right): 25$} & \multicolumn{3}{|c|}{ Vs (cm/min): 1} \\
\hline \multirow[t]{3}{*}{ Tm (s): 5} & Tf (min): & & & Ts (s): & & \\
\hline & \multicolumn{6}{|c|}{ Reator } \\
\hline & 1 & 2 & 3 & 4 & 5 & 6 \\
\hline $\mathrm{Ca}(\mathrm{OH})_{2}(\mathrm{ml})^{*}$ & 13 & 15 & 16 & 18 & 19 & 19 \\
\hline pHcoag. & 7,98 & 8,45 & 8,66 & 8,97 & 8,45 & 8,19 \\
\hline $\mathrm{DC}(\mathrm{mg} / \mathrm{l}) * *$ & 60 & 60 & 60 & 60 & 260 & 320 \\
\hline Turbidez (NTU) & 8,71 & 8,88 & 9,19 & 7,55 & 5,12 & 4,51 \\
\hline Condutividade $\left(\mu \mathrm{S} / \mathrm{cm}\right.$ a $\left.25^{\circ} \mathrm{C}\right)$ & 1269 & 1262 & 1257 & 1258 & 1426 & 1487 \\
\hline
\end{tabular}

* Solução $40 \mathrm{~g} / \mathrm{l}$ de $\mathrm{Ca}(\mathrm{OH})_{2}$

** Solução 40g/l de cloreto férrico 


\section{Ensaios de Coagulação-Floculação-Sedimentação Coagulante: Cloreto Férrico}

\begin{tabular}{|c|c|c|c|c|c|c|}
\hline \begin{tabular}{|l|l}
$\mathbf{N}^{\circ}$ do ensaio: 16 & Ensaio: $\mathrm{D}$ \\
\end{tabular} & \multirow{2}{*}{\multicolumn{6}{|c|}{\begin{tabular}{|l|l}
$\mid \begin{array}{l}\mid l \\
\text { Ensaio: Determinação dos pares pHxDC para construção do Diagrama de Coagulação }\end{array}$ \\
0 & Horário início: $20: 00 \mathrm{~h}$
\end{tabular}}} \\
\hline \begin{tabular}{|l|l|} 
Data ensaio: $07 / 09 / 10$ & \\
\end{tabular} & & & & & & \\
\hline \multicolumn{7}{|c|}{ Coleta da amostra } \\
\hline \multicolumn{3}{|c|}{ Data/horário da coleta: $03 / 09 / 2010 / 14: 00 \mathrm{~h}$} & \multicolumn{4}{|c|}{ Temperatura da amosta na coleta $\left({ }^{\circ} \mathbf{C}\right): 26$} \\
\hline \multicolumn{7}{|c|}{ Características da amostra bruta no início do ensaio } \\
\hline \multirow{2}{*}{\multicolumn{3}{|c|}{$\begin{array}{l}\text { pH: } 3,63 \\
\text { Temperatura }\left({ }^{\circ} \mathrm{C}\right): 24\end{array}$}} & \multicolumn{4}{|c|}{ Turbidez (NTU): 919} \\
\hline & & & \multicolumn{4}{|c|}{ 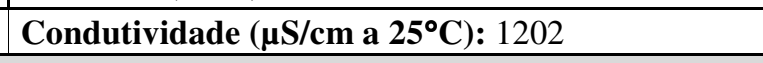 } \\
\hline \multicolumn{7}{|c|}{ Parâmetros de mistura, floculação e sedimentação } \\
\hline $\mathbf{G m}\left(\mathbf{s}^{-1}\right): 800$ & \multicolumn{3}{|c|}{ Gf $\left(\mathbf{s}^{-1}\right): 25$} & \multicolumn{3}{|c|}{ Vs (cm/min): 1} \\
\hline \multirow[t]{3}{*}{$\operatorname{Tm}(\mathbf{s}): 5$} & Tf (min): & & & Ts (s): & & \\
\hline & \multicolumn{6}{|c|}{ Reator } \\
\hline & 1 & 2 & 3 & 4 & 5 & 6 \\
\hline $\mathrm{Ca}(\mathrm{OH})_{2}(\mathrm{ml})^{*}$ & 13 & 15 & 16 & 18,5 & 18,5 & 18,5 \\
\hline pHcoag. & 8,23 & 8,60 & 8,81 & 8,47 & 8,26 & 7,97 \\
\hline $\mathrm{DC}(\mathrm{mg} / \mathrm{l})^{* *}$ & 40 & 40 & 40 & 200 & 260 & 320 \\
\hline Turbidez (NTU) & 12,5 & 10,7 & 11,4 & 9,24 & 5,38 & 5,72 \\
\hline Condutividade $\left(\mu \mathrm{S} / \mathrm{cm}\right.$ a $\left.25^{\circ} \mathrm{C}\right)$ & 1203 & 1200 & 1202 & 1350 & 1407 & 1455 \\
\hline
\end{tabular}

* Solução 40g/l de $\mathrm{Ca}(\mathrm{OH})_{2}$

** Solução 40g/l de cloreto férrico 


\section{Apêndice D}

Resultados dos ensaios de coagulação-floculação-sedimentação para o coagulante Procytrat 100A + Procytrat 300 


\section{Ensaios de Coagulação-Floculação-Sedimentação Coagulante: Procytrat 100A + Procytrat 300}

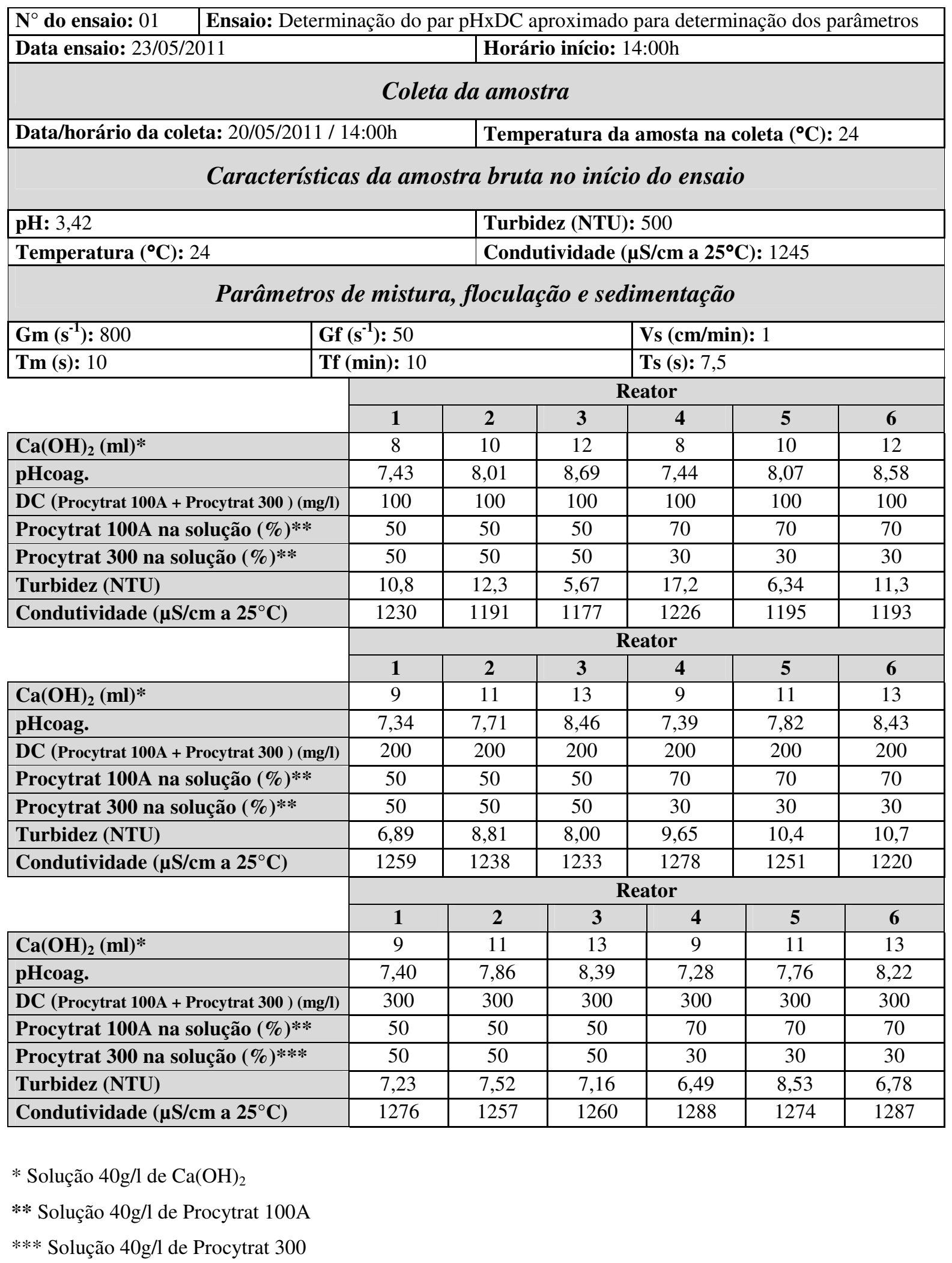




\section{Ensaios de Coagulação-Floculação-Sedimentação Coagulante: Procytrat 100A + Procytrat 300}

\begin{tabular}{|c|c|c|c|c|c|c|}
\hline \multicolumn{7}{|c|}{ Ensaio: Determinação dos parâmetros de mistura rápida } \\
\hline \multicolumn{2}{|l|}{ Data ensaio: $24 / 05 / 11$} & \multicolumn{5}{|c|}{ Horário início: $14: 00 \mathrm{~h}$} \\
\hline \multicolumn{7}{|c|}{ Coleta da amostra } \\
\hline \multicolumn{2}{|c|}{ Data/horário da coleta: $20 / 05 / 2011 / 14: 00 \mathrm{~h}$} & \multicolumn{5}{|c|}{ Temperatura da amosta na coleta $\left({ }^{\circ} \mathbf{C}\right): 24$} \\
\hline \multicolumn{7}{|c|}{ Características da amostra bruta no início do ensaio } \\
\hline \multicolumn{2}{|l|}{ pH: 3,33} & \multicolumn{5}{|c|}{ Turbidez (NTU): 500} \\
\hline \multicolumn{2}{|l|}{ Temperatura $\left({ }^{\circ} \mathrm{C}\right): 25$} & \multicolumn{5}{|c|}{ 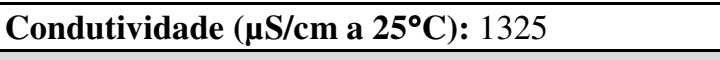 } \\
\hline \multicolumn{7}{|c|}{ Parâmetros de mistura, floculação e sedimentação } \\
\hline Gm $\left(\mathbf{s}^{-1}\right): 500$ & \multicolumn{3}{|c|}{ Gf $\left(\mathbf{s}^{-1}\right): 50$} & \multicolumn{3}{|c|}{ Vs (cm/min): 1} \\
\hline \multirow[t]{3}{*}{ Tm (s): variável } & \multicolumn{6}{|c|}{ Ts (s): 7,5 } \\
\hline & \multicolumn{6}{|c|}{ Reator } \\
\hline & 1 & 2 & 3 & 4 & 5 & 6 \\
\hline $\mathrm{Ca}(\mathrm{OH})_{2}(\mathrm{ml})^{*}$ & 14 & 14 & 14 & 14 & 14 & 14 \\
\hline Tm (s) & 5 & 10 & 15 & 30 & 60 & 90 \\
\hline pHcoag. & 8,08 & 6,38 & 7,20 & 7,79 & 9,34 & 13,6 \\
\hline DC (Proc. 100A-70\%+Proc. 300-30\% (mg/) $)^{* *}$ & 300 & 300 & 300 & 300 & 300 & 300 \\
\hline Turbidez (NTU) & 7,12 & 6,38 & 7,20 & 7,79 & 9,34 & 13,6 \\
\hline Condutividade $\left(\mu \mathrm{S} / \mathrm{cm}\right.$ a $\left.25^{\circ} \mathrm{C}\right)$ & 1289 & 1293 & 1293 & 1294 & 1294 & 1294 \\
\hline
\end{tabular}

\begin{tabular}{|c|c|c|c|c|c|c|}
\hline \multicolumn{7}{|c|}{ Ensaio: Determinação dos parâmetros de mistura rápida } \\
\hline \multicolumn{2}{|c|}{ Data ensaio: $24 / 05 / 11$} & \multicolumn{5}{|c|}{ Horário início: $15: 00 \mathrm{~h}$} \\
\hline \multicolumn{7}{|c|}{ Coleta da amostra } \\
\hline \multicolumn{2}{|l|}{ Data/horário da coleta: $20 / 05 / 2011 / 14: 00 \mathrm{~h}$} & \multicolumn{5}{|c|}{ Temperatura da amosta na coleta $\left({ }^{\circ} \mathbf{C}\right): 24$} \\
\hline \multicolumn{7}{|c|}{ Características da amostra bruta no início do ensaio } \\
\hline \multicolumn{2}{|l|}{ pH: 3,33} & \multicolumn{5}{|c|}{ Turbidez (NTU): 500} \\
\hline Temperatura $\left({ }^{\circ} \mathrm{C}\right): 25$ & & \multicolumn{5}{|c|}{ 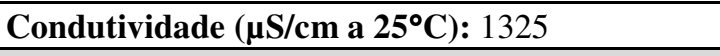 } \\
\hline \multicolumn{7}{|c|}{ Parâmetros de mistura, floculação e sedimentação } \\
\hline Gm $\left(\mathbf{s}^{-1}\right): 800$ & \multicolumn{3}{|c|}{ Gf $\left(\mathbf{s}^{-1}\right): 50$} & \multicolumn{3}{|c|}{ Vs (cm/min): 1} \\
\hline \multirow[t]{3}{*}{ Tm (s): variável } & \multicolumn{6}{|c|}{ Ts $(\mathbf{s}): 7,5$} \\
\hline & \multicolumn{6}{|c|}{ Reator } \\
\hline & 1 & 2 & 3 & 4 & 5 & 6 \\
\hline $\mathrm{Ca}(\mathrm{OH})_{2}(\mathrm{ml})^{*}$ & 14 & 14 & 14 & 14 & 14 & 14 \\
\hline $\operatorname{Tm}(\mathbf{s})$ & 5 & 10 & 15 & 30 & 60 & 90 \\
\hline pHcoag. & 6,92 & 6,69 & 5,45 & 7,32 & 8,31 & 11,6 \\
\hline DC (Proc. 100A-70\%+Proc. 300-30\% (mg/l)*** & 300 & 300 & 300 & 300 & 300 & 300 \\
\hline \multirow{2}{*}{$\begin{array}{l}\text { Turbidez }(\mathrm{NTU}) \\
\text { Condutividade }\left(\mu \mathrm{S} / \mathrm{cm} \text { a } 25^{\circ} \mathrm{C}\right)\end{array}$} & 6,92 & 6,69 & 5,45 & 7,32 & 8,31 & 11,6 \\
\hline & 1288 & 1292 & 1290 & 1285 & 1291 & 1292 \\
\hline
\end{tabular}

* Solução 40g/l de $\mathrm{Ca}(\mathrm{OH})_{2}$

** Soluções: 40g/l de Procytrat 100A e 40g/l de Procytrat 300 


\section{Ensaios de Coagulação-Floculação-Sedimentação \\ Coagulante: Procytrat 100A + Procytrat 300}

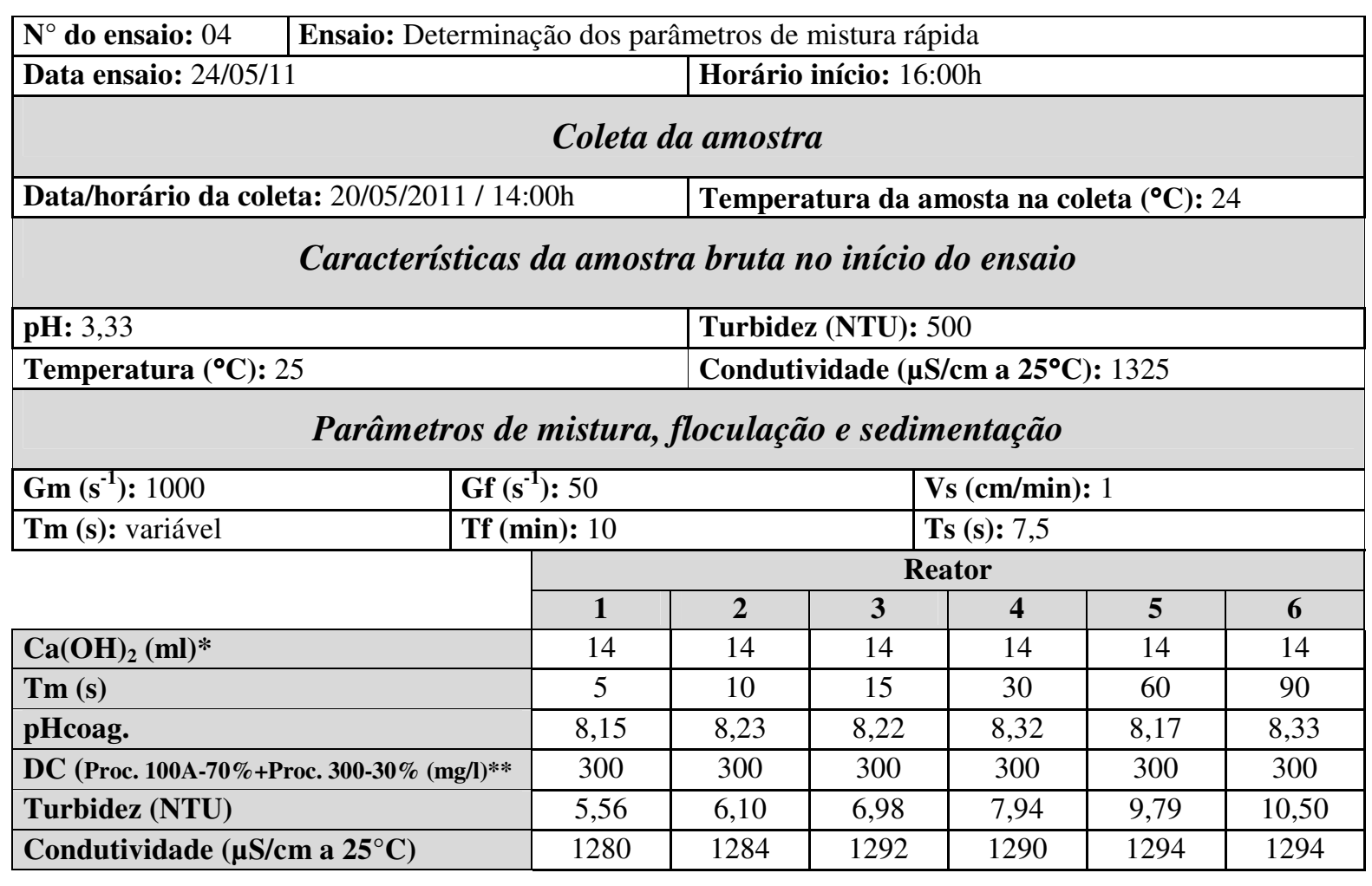

* Solução 40g/l de $\mathrm{Ca}(\mathrm{OH})_{2}$

** Soluções: 40g/l de Procytrat 100A e 40g/l de Procytrat 300 


\section{Ensaios de Coagulação-Floculação-Sedimentação Coagulante: Procytrat 100A + Procytrat 300}

\begin{tabular}{|c|c|c|c|c|c|c|}
\hline \multicolumn{7}{|c|}{ Ensaio: Determinação dos parâmetros de floculação } \\
\hline \multicolumn{2}{|l|}{ Data ensaio: $24 / 05 / 11$} & \multicolumn{5}{|c|}{ Horário início: 17:00h } \\
\hline \multicolumn{7}{|c|}{ Coleta da amostra } \\
\hline \multicolumn{2}{|l|}{ Data/horário da coleta: $20 / 05 / 2011 / 14: 00 \mathrm{~h}$} & \multicolumn{5}{|c|}{ Temperatura da amosta na coleta $\left({ }^{\circ} \mathbf{C}\right): 24$} \\
\hline \multicolumn{7}{|c|}{ Características da amostra bruta no início do ensaio } \\
\hline & \multicolumn{5}{|c|}{ Turbidez (NTU): 509} \\
\hline \multicolumn{2}{|l|}{ Temperatura $\left({ }^{\circ} \mathrm{C}\right): 25$} & \multicolumn{5}{|c|}{ 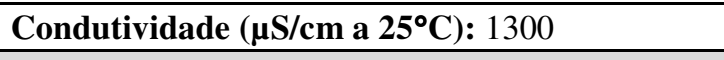 } \\
\hline \multicolumn{7}{|c|}{ Parâmetros de mistura, floculação e sedimentação } \\
\hline Gm $\left(\mathbf{s}^{-1}\right): 800$ & \multicolumn{3}{|c|}{ Gf $\left(\mathbf{s}^{-1}\right): 25$} & \multicolumn{3}{|c|}{ Vs (cm/min): 1} \\
\hline \multirow[t]{3}{*}{ Tm (s): 5} & ): vari & & & s): 7,5 & & \\
\hline & \multicolumn{6}{|c|}{ Reator } \\
\hline & 1 & 2 & 3 & 4 & 5 & 6 \\
\hline $\mathrm{Ca}(\mathrm{OH})_{2}(\mathrm{ml})^{*}$ & 14 & 14 & 14 & 14 & 14 & 14 \\
\hline Tf (min) & 5 & 10 & 20 & 30 & 40 & 60 \\
\hline pHcoag. & 8,04 & 8,16 & 8,09 & 8,13 & 8,11 & - \\
\hline DC (Proc. 100A-70\%+Proc. 300-30\% (mg/l)** & 300 & 300 & 300 & 300 & 300 & 300 \\
\hline Turbidez (NTU) & 4,23 & 4,28 & 5,89 & 8,68 & 9,87 & - \\
\hline Condutividade $\left(\mu \mathrm{S} / \mathrm{cm}\right.$ a $\left.25^{\circ} \mathrm{C}\right)$ & 1278 & 1278 & 1275 & 1279 & 1282 & - \\
\hline
\end{tabular}

\begin{tabular}{|c|c|c|c|c|c|c|}
\hline \multicolumn{7}{|c|}{ Ensaio: Determinação dos parâmetros de floculação } \\
\hline \multicolumn{2}{|c|}{ Data ensaio: $24 / 09 / 10$} & \multicolumn{5}{|c|}{ Horário início: $19: 00 \mathrm{~h}$} \\
\hline \multicolumn{7}{|c|}{ Coleta da amostra } \\
\hline \multicolumn{2}{|c|}{ Data/horário da coleta: $20 / 05 / 2011 / 14: 00 \mathrm{~h}$} & \multicolumn{5}{|c|}{ Temperatura da amosta na coleta $\left({ }^{\circ} \mathbf{C}\right): 24$} \\
\hline \multicolumn{7}{|c|}{ Características da amostra bruta no início do ensaio } \\
\hline \multicolumn{2}{|l|}{ pH: 3,32} & \multicolumn{5}{|c|}{ Turbidez (NTU): 509} \\
\hline \multicolumn{2}{|l|}{ Temperatura $\left({ }^{\circ} \mathrm{C}\right): 25$} & \multicolumn{5}{|c|}{ 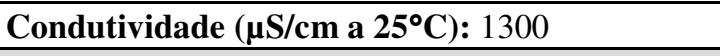 } \\
\hline \multicolumn{7}{|c|}{ Parâmetros de mistura, floculação e sedimentação } \\
\hline Gm $\left(\mathbf{s}^{-1}\right): 800$ & \multicolumn{3}{|c|}{ Gf $\left(\mathbf{s}^{-1}\right): 50$} & \multicolumn{3}{|c|}{ Vs $(\mathbf{c m} / \mathbf{m i n}): 1$} \\
\hline \multirow[t]{3}{*}{ Tm (s): 5} & : vari & & & s): 7,5 & & \\
\hline & \multicolumn{6}{|c|}{ Reator } \\
\hline & 1 & 2 & 3 & 4 & 5 & 6 \\
\hline $\mathrm{Ca}(\mathrm{OH})_{2}(\mathrm{ml})^{*}$ & 14 & 14 & 14 & 14 & 14 & 14 \\
\hline Tf $(\min )$ & 5 & 10 & 20 & 30 & 40 & 60 \\
\hline pHcoag. & 8,08 & 8,06 & 8,04 & 8,08 & 8,05 & 8,12 \\
\hline DC (Proc. 100A-70\%+Proc. 300-30\% (mg/l)*** & 300 & 300 & 300 & 300 & 300 & 300 \\
\hline \multirow{2}{*}{$\begin{array}{l}\text { Turbidez (NTU) } \\
\text { Condutividade }\left(\mu \mathrm{S} / \mathrm{cm} \text { a } 25^{\circ} \mathrm{C}\right)\end{array}$} & 2,83 & 6,06 & 8,20 & 5,61 & 12,7 & 14,6 \\
\hline & 1261 & 1267 & 1257 & 1265 & 1257 & 1267 \\
\hline
\end{tabular}

* Solução 40g/l de $\mathrm{Ca}(\mathrm{OH})_{2}$

** Soluções: 40g/l de Procytrat 100A + Procytrat 300 


\section{Ensaios de Coagulação-Floculação-Sedimentação \\ Coagulante: Procytrat 100A + Procytrat 300}

\begin{tabular}{|c|c|c|c|c|c|c|}
\hline Ensaio: Determin & \multicolumn{6}{|c|}{ Ensaio: Determinação dos parâmetros de floculação } \\
\hline Data ensaio: $24 / 05 / 11$ & & \multicolumn{5}{|c|}{ Horário início: $21: 00 \mathrm{~h}$} \\
\hline \multicolumn{7}{|c|}{ Coleta da amostra } \\
\hline \multicolumn{2}{|c|}{ Data/horário da coleta: $20 / 05 / 2011 / 14: 00 \mathrm{~h}$} & \multicolumn{5}{|c|}{ Temperatura da amosta na coleta $\left({ }^{\circ} \mathbf{C}\right): 24$} \\
\hline \multicolumn{7}{|c|}{ Características da amostra bruta no início do ensaio } \\
\hline \multirow{2}{*}{\multicolumn{2}{|c|}{$\begin{array}{l}\text { pH: } 3,32 \\
\text { Temperatura }\left({ }^{\circ} \mathrm{C}\right): 25 \\
\end{array}$}} & \multicolumn{5}{|c|}{ Turbidez (NTU): 509} \\
\hline & & \multicolumn{5}{|c|}{ Condutividade $\left(\mu \mathrm{S} / \mathrm{cm}\right.$ a $\left.25^{\circ} \mathrm{C}\right): 1300$} \\
\hline \multicolumn{7}{|c|}{ Parâmetros de mistura, floculação e sedimentação } \\
\hline Gm $\left(\mathbf{s}^{-1}\right): 800$ & \multicolumn{3}{|c|}{ Gf $\left(\mathbf{s}^{-1}\right): 75$} & \multicolumn{3}{|c|}{ Vs (cm/min): 1} \\
\hline \multirow[t]{3}{*}{$\operatorname{Tm}(\mathbf{s}): 5$} & ): varic & & & s): 7,5 & & \\
\hline & \multicolumn{6}{|c|}{ Reator } \\
\hline & 1 & 2 & 3 & 4 & 5 & 6 \\
\hline $\mathrm{Ca}(\mathrm{OH})_{2}(\mathrm{ml})^{*}$ & 14 & 14 & 14 & 14 & 14 & 14 \\
\hline Tf (min) & 5 & 10 & 20 & 30 & 40 & 60 \\
\hline pHcoag. & 8,09 & 8,18 & 8,21 & 8,21 & 8,22 & 8,24 \\
\hline DC (Proc. 100A-70\%+Proc. 300-30\% (mg/) ${ }^{* * *}$ & 300 & 300 & 300 & 300 & 300 & 300 \\
\hline Turbidez (NTU) & 4,17 & 7,74 & 7,96 & 9,33 & 13,7 & 14,9 \\
\hline Condutividade $\left(\mu \mathrm{S} / \mathrm{cm}\right.$ a $\left.25^{\circ} \mathrm{C}\right)$ & 1255 & 1251 & 1252 & 1243 & 1249 & 1248 \\
\hline
\end{tabular}

* Solução 40g/l de $\mathrm{Ca}(\mathrm{OH})_{2}$

** Soluções: 40g/l de Procytrat 100A e 40g/l de Procytrat 300 


\section{Ensaios de Coagulação-Floculação-Sedimentação Coagulante: Procytrat 100A + Procytrat 300}

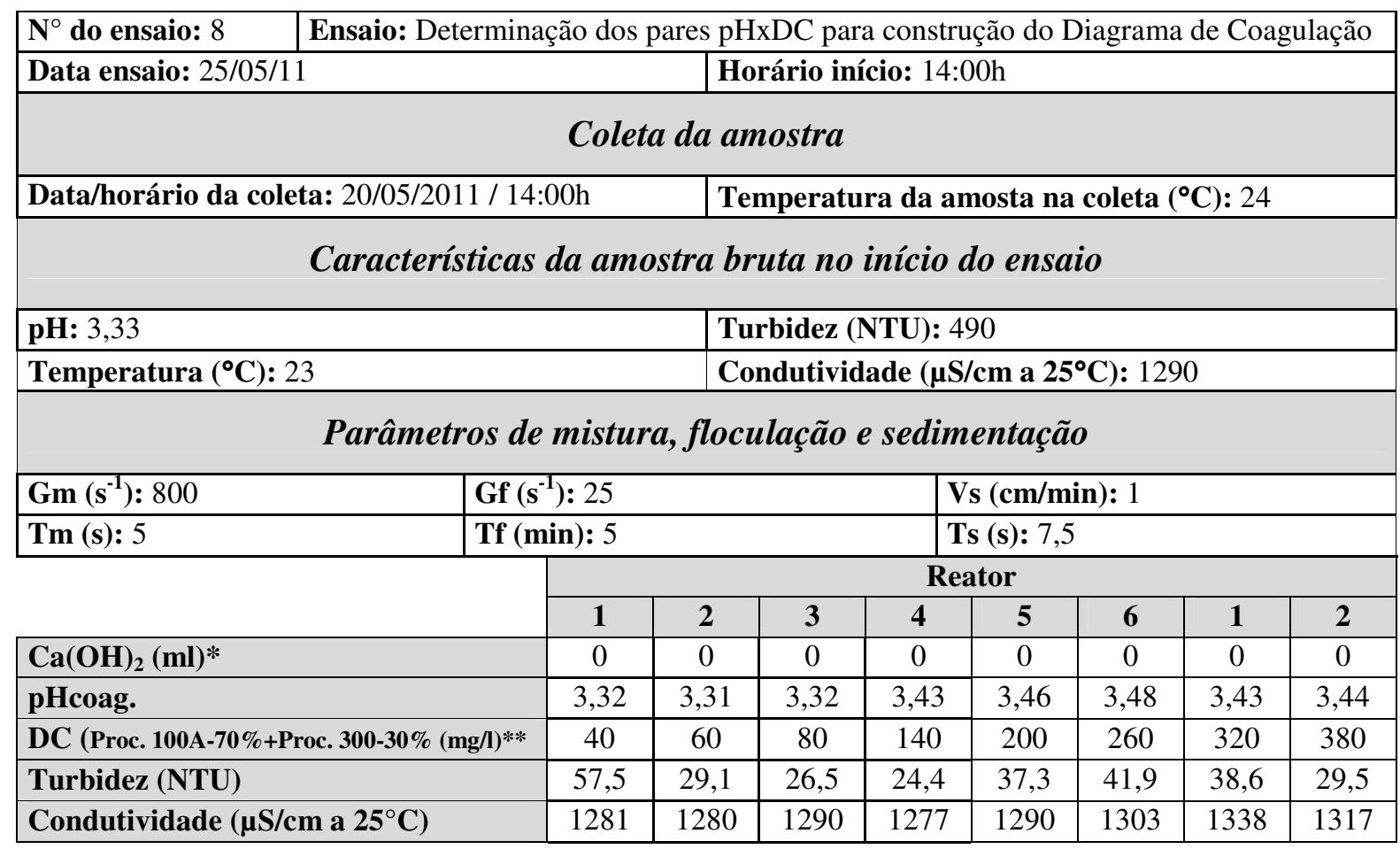

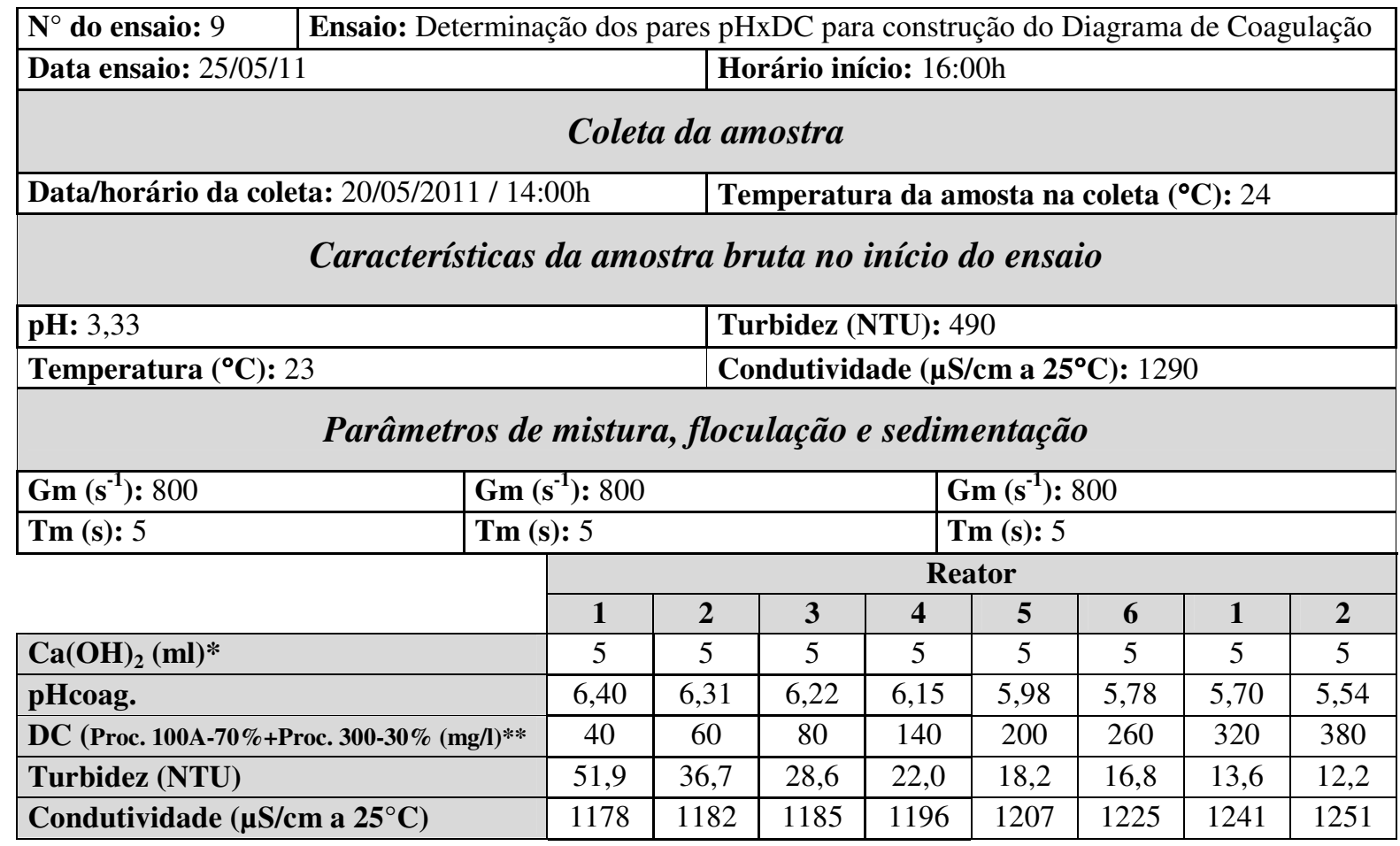

\footnotetext{
* Solução 40g/l de $\mathrm{Ca}(\mathrm{OH})_{2}$

** Soluções: 40g/l de Procytrat 100A e 40g/l de Procytrat 300
} 


\section{Ensaios de Coagulação-Floculação-Sedimentação Coagulante: Procytrat 100A + Procytrat 300}

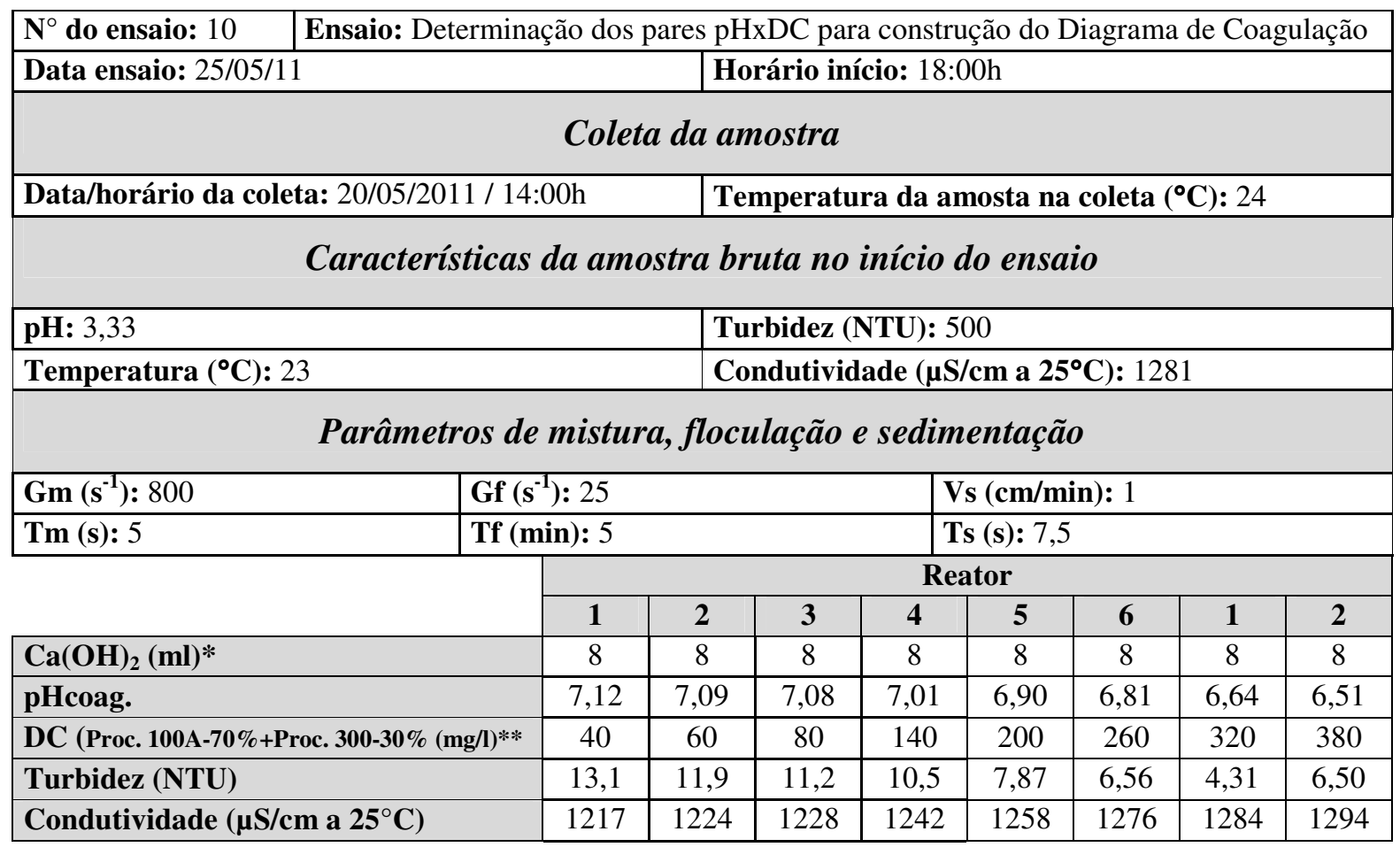

\begin{tabular}{|l|l|}
\hline $\mathbf{N}^{\circ}$ do ensaio: 11 & Ensaio: Determinação dos pares pHxDC para construção do Diagrama de Coagulação \\
\hline
\end{tabular} Data ensaio: $25 / 05 / 11$ Horário início: 20:00h

\section{Coleta da amostra}

\begin{tabular}{|l|l|}
\hline Data/horário da coleta: $20 / 05 / 2011 / 14: 00 \mathrm{~h}$ & Temperatura da amosta na coleta $\left({ }^{\circ} \mathbf{C}\right): 24$ \\
\hline
\end{tabular}

Características da amostra bruta no início do ensaio

\begin{tabular}{|l|l|}
\hline pH: 3,33 & Turbidez $(\mathbf{N T U}): 500$ \\
\hline Temperatura $\left({ }^{\circ} \mathbf{C}\right): 23$ & Condutividade $\left(\boldsymbol{\mu S} / \mathbf{c m ~ a ~} 25^{\circ} \mathbf{C}\right): 1281$ \\
\hline
\end{tabular}

Parâmetros de mistura, floculação e sedimentação

\begin{tabular}{|c|c|c|c|c|c|c|c|c|c|}
\hline Gm $\left(s^{-1}\right): 800$ & \multicolumn{5}{|c|}{ Gf $\left(s^{-1}\right): 25$} & \multicolumn{4}{|c|}{ Vs $(\mathbf{c m} / \mathbf{m i n}): 1$} \\
\hline \multirow{3}{*}{\multicolumn{2}{|c|}{$\operatorname{Tm}(s): 5$}} & & & & & \multicolumn{4}{|c|}{ Ts (s): 7,5} \\
\hline & & \multicolumn{8}{|c|}{ Reator } \\
\hline & & 1 & 2 & 3 & 4 & 5 & 6 & 1 & 2 \\
\hline $\mathrm{Ca}(\mathrm{OH})_{2}(\mathrm{ml})^{*}$ & & 10 & 10 & 10 & 10 & 10 & 10 & 10 & 10 \\
\hline pHcoag. & & 7,64 & 7,65 & 7,57 & 7,53 & 7,45 & 7,34 & 7,30 & 7,17 \\
\hline DC (Proc. 100A-70\%+Proc. 300-30\% & $g / \mathrm{l} /)^{* *}$ & 40 & 60 & 80 & 140 & 200 & 260 & 320 & 380 \\
\hline Turbidez (NTU) & & 9,37 & 9,63 & 9,42 & 9,11 & 6,71 & 7,37 & 4,67 & 3,62 \\
\hline Condutividade $\left(\mu \mathrm{S} / \mathrm{cm}\right.$ a $\left.25^{\circ} \mathrm{C}\right)$ & & 1160 & 1166 & 1178 & 1199 & 1221 & 1245 & 1257 & 1273 \\
\hline
\end{tabular}

\footnotetext{
* Solução 40g/l de $\mathrm{Ca}(\mathrm{OH})_{2}$

** Soluções: 40g/l de Procytrat 100A e 40g/l de Procytrat 300
} 


\section{Ensaios de Coagulação-Floculação-Sedimentação \\ Coagulante: Procytrat 100A + Procytrat 300}

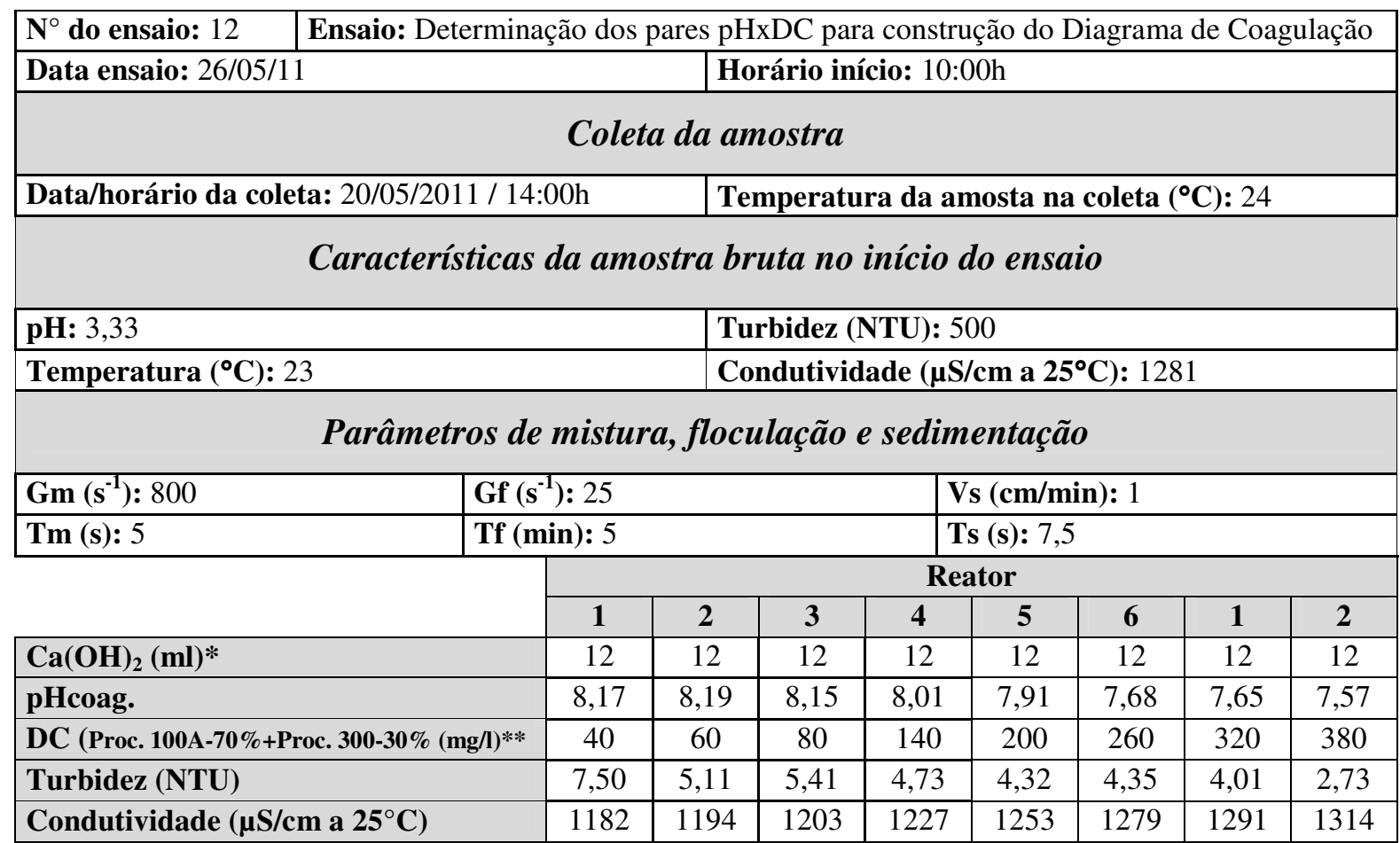

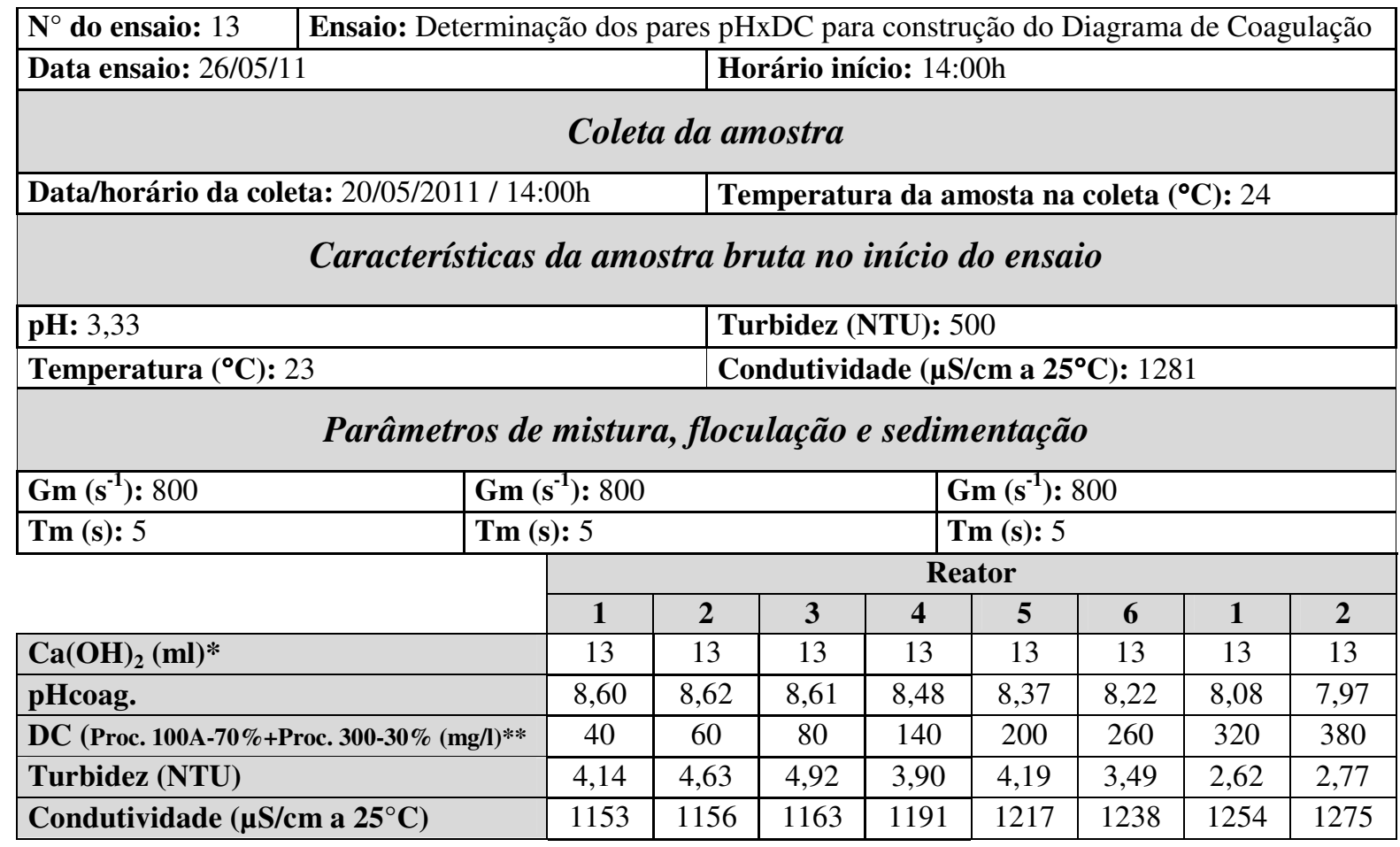

* Solução 40g/l de $\mathrm{Ca}(\mathrm{OH})_{2}$

** Soluções: 40g/l de Procytrat 100A e 40g/l de Procytrat 300 


\section{Ensaios de Coagulação-Floculação-Sedimentação Coagulante: Procytrat 100A + Procytrat 300}

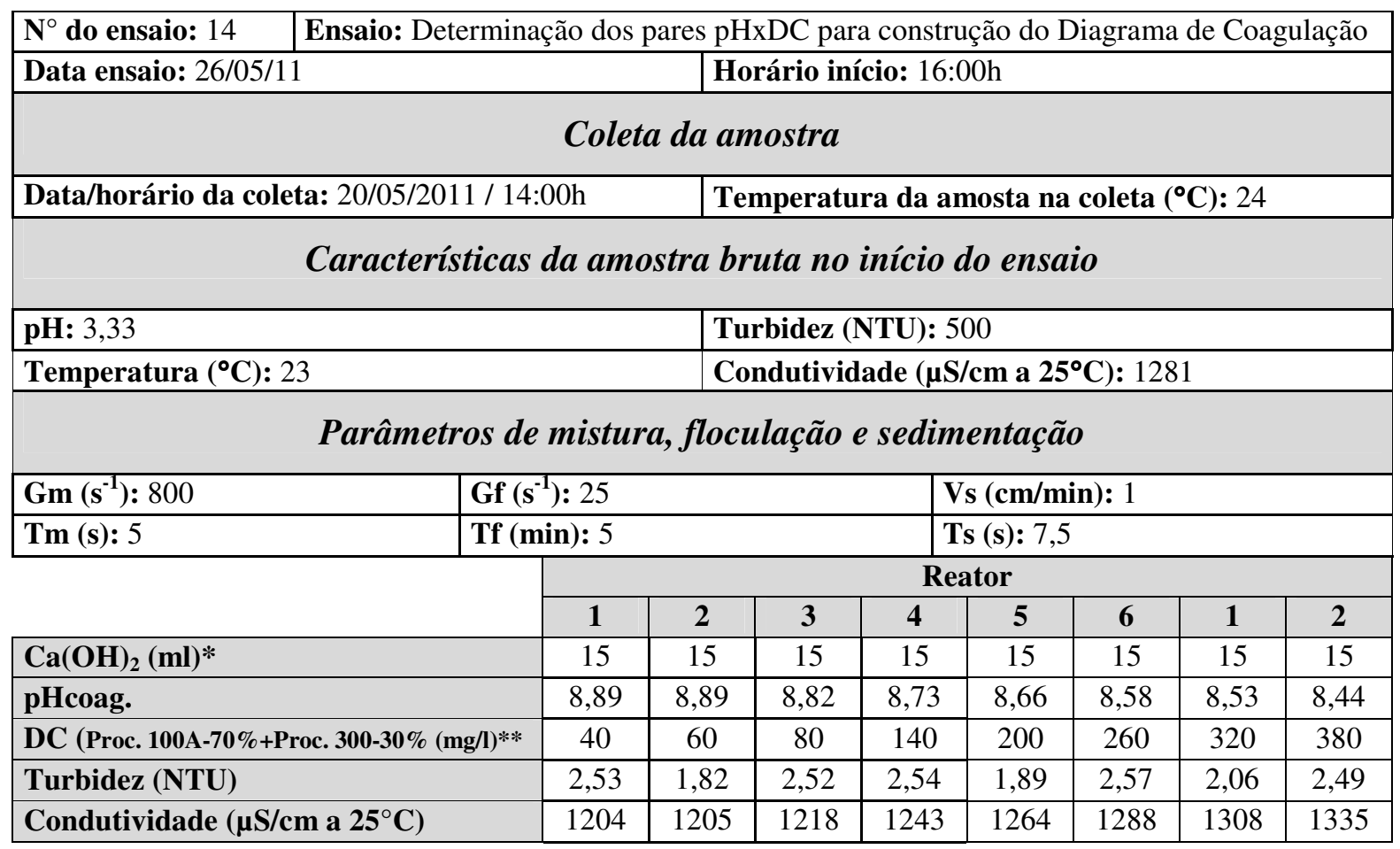

\begin{tabular}{|l|l|l|}
\hline $\mathbf{N}^{\circ}$ do ensaio: 15 & Ensaio: Determinação dos pares pHxDC para construção do Diagrama de Coagulação \\
\hline Data ensaio: $26 / 05 / 11$ & Horário início: $18: 00 \mathrm{~h}$ \\
\hline \multicolumn{2}{|c|}{ Coleta da amostra } \\
\hline Data/horário da coleta: $20 / 05 / 2011 / 14: 00 \mathrm{~h}$ & Temperatura da amosta na coleta $\left({ }^{\circ} \mathbf{C}\right): 24$ \\
\hline \multicolumn{2}{|c|}{ Características da amostra bruta no início do ensaio } \\
\hline pH: 3,35 & Turbidez (NTU): 508 \\
\hline Temperatura $\left({ }^{\circ} \mathbf{C}\right): 23$ & Condutividade $\left(\boldsymbol{\mu S} / \mathbf{c m}^{2} \mathbf{2 5 ^ { \circ }} \mathbf{C}\right): 1300$ \\
\hline
\end{tabular}

Temperatura $\left({ }^{\circ} \mathbf{C}\right): 23$

Parâmetros de mistura, floculação e sedimentação

\begin{tabular}{|c|c|c|c|c|c|c|c|c|}
\hline Gm $\left(\mathbf{s}^{-1}\right): 800$ & \multirow{2}{*}{\multicolumn{3}{|c|}{$\frac{G I(s): 25}{T f(\min ): 5}$}} & \multicolumn{5}{|c|}{ Vs $(\mathbf{c m} / \mathbf{m i n}): 1$} \\
\hline \multirow[t]{3}{*}{ Tm (s): 5} & & & & & s): & & & \\
\hline & \multicolumn{8}{|c|}{ Reator } \\
\hline & 1 & 2 & 3 & 4 & $\mathbf{5}$ & 6 & 1 & 2 \\
\hline $\mathrm{Ca}(\mathrm{OH})_{2}(\mathrm{ml})^{*}$ & 17 & 17 & 17 & & & & & \\
\hline pHcoag. & 8,79 & 8,71 & 8,62 & & & & & \\
\hline DC (Proc. 100A-70\%+Proc. 300-30\% (mg/ & 260 & 320 & 380 & & & & & \\
\hline Turbidez (NTU) & 1,95 & 1,22 & 1,77 & & & & & \\
\hline Condutividade $\left(\mu \mathrm{S} / \mathrm{cm}\right.$ a $\left.25^{\circ} \mathrm{C}\right)$ & 1265 & 1289 & 1321 & & & & & \\
\hline
\end{tabular}

* Solução 40g/l de $\mathrm{Ca}(\mathrm{OH})_{2}$

** Soluções: 40g/l de Procytrat 100A e 40g/l de Procytrat 300 


\section{Apêndice E}

Resultados dos ensaios de coagulação-floculação-flotação para o coagulante aluminato de sódio 


\section{Ensaios de Coagulação-Floculação-Flotação Coagulante: Aluminato de Sódio}

\begin{tabular}{|c|c|c|c|c|c|c|c|c|}
\hline \multirow{2}{*}{\multicolumn{3}{|c|}{$\mathbf{N}^{\circ}$ do ensaio: 01 a 12}} & $\mathrm{pHxDC}$ & proxima & para & ermin & ação dos & \\
\hline & & & \multicolumn{6}{|c|}{ Horário início: 8:00h } \\
\hline \multicolumn{9}{|c|}{ Coleta da amostra } \\
\hline \multicolumn{3}{|c|}{ Data/horário da coleta: $29 / 10 / 2010 / 16: 00 \mathrm{~h}$} & \multicolumn{6}{|c|}{ Temperatura da amosta na coleta $\left({ }^{\circ} \mathrm{C}\right): 27$} \\
\hline \multicolumn{9}{|c|}{ Características da amostra bruta no início do ensaio } \\
\hline \multirow{2}{*}{\multicolumn{3}{|c|}{$\begin{array}{l}\text { pH: } 3,4 \\
\text { Temperatura }\left({ }^{\circ} \mathbf{C}\right): 23 \\
\end{array}$}} & \multicolumn{6}{|c|}{ Turbidez (NTU): 640} \\
\hline & & & \multicolumn{6}{|c|}{ 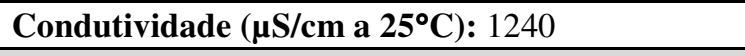 } \\
\hline \multicolumn{9}{|c|}{ Parâmetros de mistura, floculação e flotação } \\
\hline Gm $\left(\mathbf{s}^{-1}\right): 800$ & \multicolumn{2}{|c|}{ Vf1 (cm/min): 10} & \multicolumn{2}{|c|}{ Vf2 (cm/min): } & $\mathbf{R}(\%$ & & \multicolumn{2}{|c|}{ Psat (bar): 5} \\
\hline \multirow[t]{3}{*}{ Tf (min): 10} & \multicolumn{2}{|c|}{ Tflot1 (min): 3,5} & \multicolumn{2}{|c|}{ Tflot2 (min): 7} & & & \multicolumn{2}{|c|}{ Tsat (min): 10} \\
\hline & \multicolumn{8}{|c|}{ Reator } \\
\hline & 1 & 2 & 1 & 2 & 1 & 2 & 1 & 2 \\
\hline $\mathrm{Ca}(\mathrm{OH})_{2}(\mathrm{ml})^{*}$ & 0 & 0 & & 0 & 0 & 0 & 0 & 0 \\
\hline pHcoag & 3,50 & 3,91 & & 4,75 & 5,07 & 5,19 & 6,03 & 6,83 \\
\hline $\mathrm{DC}(\mathrm{mg} / \mathrm{l})^{* * *}$ & 0 & 20 & & 60 & 80 & 100 & 200 & 300 \\
\hline Turbidez (NTU) - Vf1 & 429 & 461 & & 248 & 260 & 203 & 640 & 592 \\
\hline \multirow[t]{3}{*}{ Turbidez (NTU) - Vf2 } & 339 & 330 & & 97 & 94 & 92 & 288 & 156 \\
\hline & \multicolumn{8}{|c|}{ Reator } \\
\hline & 1 & 2 & 1 & 2 & 1 & 2 & 1 & 2 \\
\hline $\mathrm{Ca}(\mathrm{OH})_{2}(\mathrm{ml})^{*}$ & 1 & 1 & & & & & & \\
\hline pHcoag & 4,96 & 5,71 & & & & & & \\
\hline $\mathrm{DC}(\mathrm{mg} / \mathrm{l})^{* *}$ & 20 & 100 & & & & & & \\
\hline Turbidez (NTU) - Vf1 & 174 & 461 & & & & & & \\
\hline Turbidez (NTU) - Vf2 & 90 & 147 & & & & & & \\
\hline & & & & $\mathbf{R e}$ & & & & \\
\hline & 1 & 2 & 1 & 2 & 1 & 2 & 1 & 2 \\
\hline $\mathrm{Ca}(\mathrm{OH})_{2}(\mathrm{ml})^{*}$ & 2 & 2 & 2 & 2 & & 2 & 2 & 2 \\
\hline pHcoag & 5,05 & 5,47 & 5,68 & 5,85 & & 6,18 & 6,85 & 7,62 \\
\hline $\mathrm{DC}(\mathrm{mg} / \mathrm{l})^{* *}$ & 0 & 20 & 40 & 60 & & 100 & 200 & 300 \\
\hline Turbidez (NTU) - Vf1 & 477 & 124 & 261 & 496 & & 515 & 650 & 762 \\
\hline Turbidez (NTU) - Vf2 & 394 & 90 & 107 & 204 & & 126 & 410 & 368 \\
\hline & & & & & & & & \\
\hline & 1 & 2 & 1 & 2 & 1 & 2 & 1 & 2 \\
\hline $\mathrm{Ca}(\mathrm{OH})_{2}(\mathrm{ml})^{*}$ & 5 & 5 & & 5 & & 5 & 5 & 5 \\
\hline pHcoag & 6,62 & 6,77 & & 7,02 & & 7,29 & 8,07 & 8,89 \\
\hline $\mathrm{DC}(\mathrm{mg} / \mathrm{l}) * *$ & 0 & 20 & & 60 & & 100 & 200 & 300 \\
\hline Turbidez (NTU) - Vf1 & 256 & 169 & & - & & 995 & 723 & 701 \\
\hline Turbidez (NTU) - Vf2 & 169 & 129 & & 265 & & 277 & 217 & 266 \\
\hline
\end{tabular}

* Solução 40g/l de $\mathrm{Ca}(\mathrm{OH})_{2}$

** Solução 40g/l de aluminato de sódio 


\section{Ensaios de Coagulação-Floculação-Flotação Coagulante: Aluminato de Sódio}

\begin{tabular}{|c|c|c|c|c|c|c|c|c|c|c|}
\hline \multicolumn{2}{|c|}{$\mathbf{N}^{\circ}$ do ensaio: 13 a 16} & \multicolumn{9}{|c|}{$\begin{array}{l}\text { Ensaio: Determinação do par pHxDC aproximado para determinação dos } \\
\text { parâmetros }\end{array}$} \\
\hline \multicolumn{5}{|c|}{ Data ensaio: $30 / 10 / 2010$} & \multicolumn{6}{|c|}{ Horário início: $14: 00 \mathrm{~h}$} \\
\hline \multicolumn{11}{|c|}{ Coleta da amostra } \\
\hline \multicolumn{5}{|c|}{ Data/horário da coleta: 29/10/2010 / 16:00h } & \multicolumn{6}{|c|}{ Temperatura da amosta na coleta $\left({ }^{\circ} \mathrm{C}\right): 27$} \\
\hline \multicolumn{11}{|c|}{ Características da amostra bruta no início do ensaio } \\
\hline \multicolumn{5}{|c|}{ pH: 3,4} & \multicolumn{6}{|c|}{ Turbidez (NTU): 640} \\
\hline \multicolumn{5}{|c|}{ Temperatura $\left({ }^{\circ} \mathrm{C}\right): 23$} & \multicolumn{6}{|c|}{ 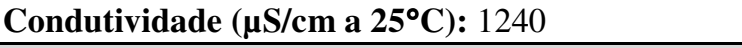 } \\
\hline \multicolumn{11}{|c|}{ Parâmetros de mistura, floculação e flotação } \\
\hline Gm $\left(\mathbf{s}^{-1}\right): 800$ & Gf ( & $-1): 80$ & \multicolumn{2}{|c|}{ Vf1 (cm/min): 10} & \multicolumn{2}{|c|}{ Vf2 $(\mathrm{cm} / \mathrm{min}): 5$} & \multicolumn{2}{|c|}{$\mathbf{R}(\%): 50$} & \multicolumn{2}{|c|}{ Psat (bar): 5} \\
\hline \multirow[t]{3}{*}{ Tm (s): 5} & Tf $(1$ & nin): 10 & Tflot1 & in): 3,5 & Tflot & $\min ): 7$ & & & Tsat (min & \\
\hline & & & \multicolumn{8}{|c|}{ Reator } \\
\hline & & & 1 & 2 & 1 & 2 & 1 & 2 & 1 & 2 \\
\hline \multicolumn{3}{|l|}{$\mathrm{Ca}(\mathrm{OH})_{2}(\mathrm{ml})^{*}$} & 10 & 10 & 10 & 10 & 10 & 15 & 15 & 15 \\
\hline \multicolumn{3}{|l|}{ PHcoag } & 8,15 & 8,47 & 8,67 & 8,87 & 9,08 & 9,48 & 9,56 & 9,69 \\
\hline \multicolumn{3}{|c|}{$\mathrm{DC}(\mathrm{mg} / \mathrm{l}) * *$} & 0 & 60 & 100 & 200 & 300 & 20 & 60 & 100 \\
\hline \multicolumn{3}{|c|}{ Turbidez (NTU) - Vf1 } & 938 & 778 & 1411 & 1194 & 1366 & 1366 & 1491 & 1382 \\
\hline \multicolumn{3}{|c|}{ Turbidez (NTU) - Vf2 } & 220 & 118 & 143 & 691 & 381 & 147 & 272 & 150 \\
\hline
\end{tabular}

* Solução 40g/l de $\mathrm{Ca}(\mathrm{OH})_{2}$

** Solução 40g/l de aluminato de sódio 


\section{Ensaios de Coagulação-Floculação-Flotação Coagulante: Aluminato de Sódio}

\begin{tabular}{|c|c|c|c|c|c|c|c|}
\hline \multirow{2}{*}{\multicolumn{3}{|c|}{ 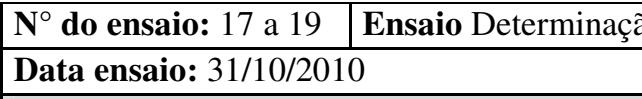 }} & parân & metros de floculaç & & & \\
\hline & & & & Horário início: 9 & & & \\
\hline \multicolumn{8}{|c|}{ Coleta da amostra } \\
\hline \multicolumn{4}{|c|}{ Data/horário da coleta: $29 / 10 / 2010 / 16: 00 \mathrm{~h}$} & \multicolumn{4}{|c|}{ Temperatura da amosta na coleta $\left({ }^{\circ} \mathrm{C}\right): 27$} \\
\hline \multicolumn{8}{|c|}{ Características da amostra bruta no início do ensaio } \\
\hline \multicolumn{4}{|c|}{ pH: 3,52} & \multicolumn{4}{|c|}{ Turbidez (NTU): 615} \\
\hline \multicolumn{4}{|c|}{ Temperatura $\left({ }^{\circ} \mathrm{C}\right): 26$} & \multicolumn{4}{|c|}{ 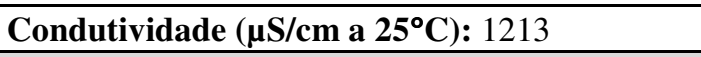 } \\
\hline \multicolumn{8}{|c|}{ Parâmetros de mistura, floculação e flotação } \\
\hline Gm $\left(s^{-1}\right): 800$ & Gf $\left(\mathbf{s}^{-1}\right): 40$ & \multicolumn{2}{|c|}{ Vf1 (cm/min): 10} & Vf2 $(\mathrm{cm} / \mathrm{min}): 5$ & $\mathbf{R}(\%): 50$ & \multicolumn{2}{|c|}{ Psat (bar): 5} \\
\hline \multirow{3}{*}{\multicolumn{2}{|c|}{ Tf (min): variável }} & \multicolumn{2}{|c|}{ Tflot1 (min): 3,5} & Tflot2 (min): 7 & & \multicolumn{2}{|c|}{ Tsat (min): 10} \\
\hline & & \multicolumn{6}{|c|}{ Reator } \\
\hline & & 1 & 2 & 1 & 2 & 1 & 2 \\
\hline \multicolumn{2}{|l|}{$\mathrm{Ca}(\mathrm{OH})_{2}(\mathrm{ml})^{*}$} & 2 & 2 & 2 & 2 & 2 & \\
\hline \multicolumn{2}{|l|}{ Tf $(\min )$} & 5 & 10 & 15 & 20 & 30 & \\
\hline \multicolumn{2}{|l|}{ pHcoag } & 5,63 & 5,59 & 5,59 & 5,60 & 5,60 & \\
\hline \multicolumn{2}{|c|}{$\mathrm{DC}(\mathrm{mg} / \mathrm{l})^{* *}$} & 20 & 20 & 20 & 20 & 20 & \\
\hline \multicolumn{2}{|c|}{ Turbidez (NTU) - Vf1 } & 142 & 151 & 136 & 149 & 127 & \\
\hline \multicolumn{2}{|c|}{ Turbidez (NTU) - Vf2 } & 93 & 86 & 88 & 104 & 87 & \\
\hline \multicolumn{2}{|c|}{ Condutiv. $\left(\mu \mathrm{S} / \mathrm{cm}\right.$ a $\left.25^{\circ} \mathrm{C}\right)-\mathrm{Vf1}$} & 1437 & 1452 & 1421 & 1450 & 1454 & \\
\hline \multicolumn{2}{|c|}{ Condutiv. $\left(\mu \mathrm{S} / \mathrm{cm}\right.$ a $\left.25^{\circ} \mathrm{C}\right)-\mathrm{Vf} 2$} & 1411 & 1406 & 1394 & 1386 & 1411 & \\
\hline
\end{tabular}

\begin{tabular}{|c|c|c|c|c|c|c|c|}
\hline \multirow{2}{*}{\multicolumn{4}{|c|}{ 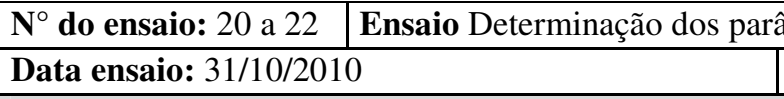 }} & metros de floculaç & & & \\
\hline & & & & \multicolumn{4}{|c|}{ Horário início: $10: 00 \mathrm{~h}$} \\
\hline \multicolumn{8}{|c|}{ Coleta da amostra } \\
\hline \multicolumn{4}{|c|}{ Data/horário da coleta: 29/10/2010 / 16:00h } & \multicolumn{4}{|c|}{ Temperatura da amosta na coleta $\left({ }^{\circ} \mathbf{C}\right): 27$} \\
\hline \multicolumn{8}{|c|}{ Características da amostra bruta no início do ensaio } \\
\hline \multicolumn{4}{|c|}{ pH: 3,52} & \multicolumn{4}{|c|}{ Turbidez (NTU): 615} \\
\hline \multicolumn{4}{|c|}{ Temperatura $\left({ }^{\circ} \mathrm{C}\right): 26$} & \multicolumn{4}{|c|}{ Condutividade $\left(\boldsymbol{\mu S} / \mathrm{cm}\right.$ a $\left.25^{\circ} \mathrm{C}\right): 1213$} \\
\hline \multicolumn{8}{|c|}{ Parâmetros de mistura, floculação e flotação } \\
\hline $\mathbf{G m}\left(\mathbf{s}^{-1}\right): 800$ & Gf $\left(\mathbf{s}^{-1}\right): 60$ & \multicolumn{2}{|c|}{ Vf1 (cm/min): 10} & Vf2 (cm/min): 5 & $\mathbf{R}(\%): 50$ & \multicolumn{2}{|c|}{ Psat (bar): 5} \\
\hline \multirow{3}{*}{\multicolumn{2}{|c|}{ Tf (min): variável }} & \multicolumn{2}{|c|}{ Tflot1 (min): 3,5} & Tflot2 (min): 7 & & \multicolumn{2}{|c|}{ Tsat (min): 10} \\
\hline & & \multicolumn{6}{|c|}{ Reator } \\
\hline & & 1 & 2 & 1 & 2 & 1 & 2 \\
\hline \multicolumn{2}{|l|}{$\mathrm{Ca}(\mathrm{OH})_{2}(\mathrm{ml})^{*}$} & 2 & 2 & 2 & 2 & 2 & \\
\hline \multicolumn{2}{|l|}{ Tf (min) } & 5 & 10 & 15 & 20 & 30 & \\
\hline \multicolumn{2}{|l|}{ pHcoag } & 5,60 & 5,60 & 5,65 & 5,60 & 5,63 & \\
\hline \multicolumn{2}{|l|}{$\mathrm{DC}(\mathrm{mg} / \mathrm{l}) * *$} & 20 & 20 & 20 & 20 & 20 & \\
\hline \multicolumn{2}{|c|}{ Turbidez (NTU) - Vf1 } & 128 & 138 & 121 & 171 & 127 & \\
\hline \multicolumn{2}{|c|}{ Turbidez (NTU) - Vf2 } & 83 & 80 & 88 & 85 & 91 & \\
\hline \multicolumn{2}{|c|}{ Condutiv. $\left(\mu \mathrm{S} / \mathrm{cm}\right.$ a $\left.25^{\circ} \mathrm{C}\right)-\mathrm{Vf1}$} & 1425 & 1429 & 1454 & 1448 & 1506 & \\
\hline \multicolumn{2}{|c|}{ Condutiv. $\left(\mu \mathrm{S} / \mathrm{cm}\right.$ a $\left.25^{\circ} \mathrm{C}\right)-\mathrm{Vf} 2$} & 1398 & 1396 & 1423 & 1398 & 1408 & \\
\hline
\end{tabular}

* Solução 40g/l de $\mathrm{Ca}(\mathrm{OH})_{2}$

** Solução 40g/l de aluminato de sódio 


\section{Ensaios de Coagulação-Floculação-Flotação Coagulante: Aluminato de Sódio}

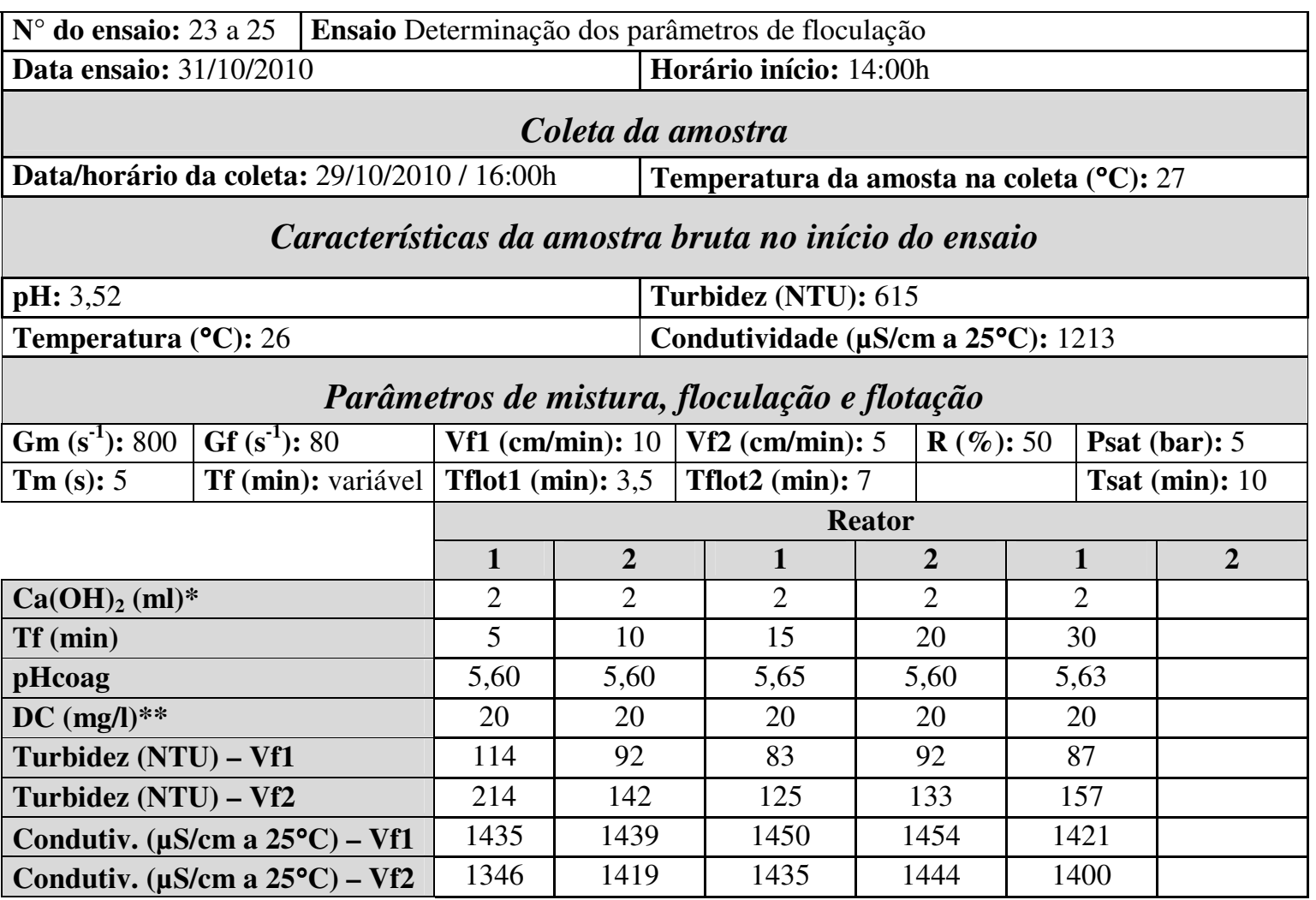

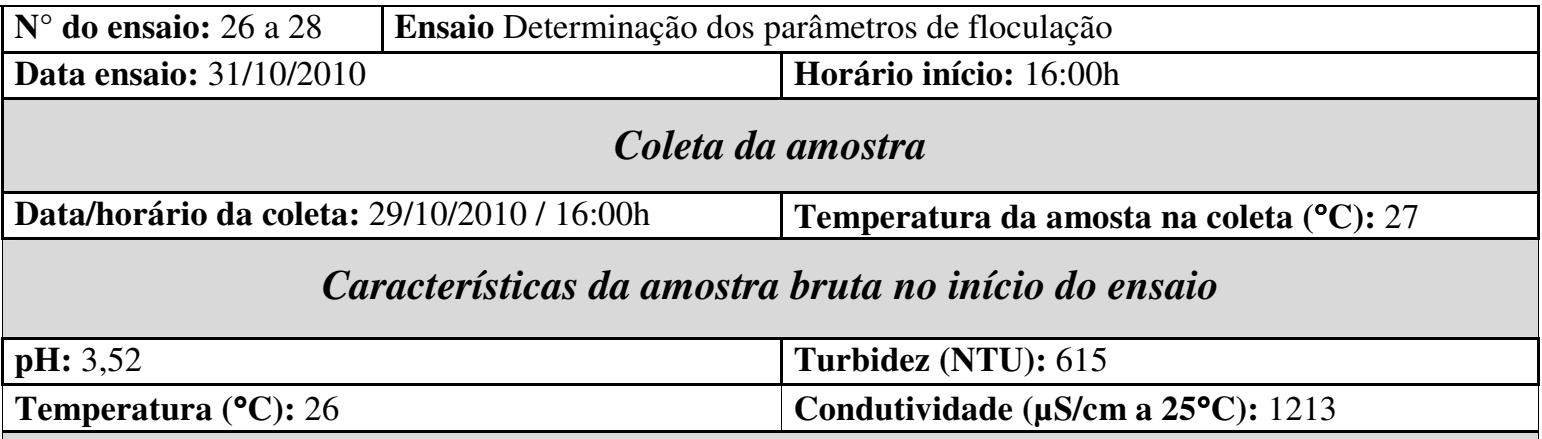

\section{Parâmetros de mistura, floculação e flotação}

\begin{tabular}{|l|l|l|l|l|l|}
\hline Gm $\left(\mathbf{s}^{-1}\right): 800$ & Gf $\left(\mathbf{s}^{-1}\right): 100$ & Vf1 $(\mathbf{c m} / \mathbf{m i n}): 10$ & Vf2 $(\mathbf{c m} / \mathbf{m i n}): 5$ & R (\%): 50 & Psat (bar): 5 \\
\hline Tm $(\mathbf{s}): 5$ & Tf $(\mathbf{m i n}):$ variável & Tflot1 $(\mathbf{m i n}): 3,5$ & Tflot2 $(\mathbf{m i n}): 7$ & & Tsat (min): 10 \\
\hline
\end{tabular}

\begin{tabular}{|c|c|c|c|c|c|}
\hline $\mathrm{Ca}(\mathrm{OH})_{2}(\mathrm{ml}) *$ & 2 & 2 & 2 & 2 & 2 \\
\hline Tf (min) & 5 & 10 & 15 & 20 & 30 \\
\hline pHcoag & 5,62 & 5,55 & 5,50 & 5,60 & 5,61 \\
\hline $\mathrm{DC}(\mathrm{mg} / \mathrm{l})^{* *}$ & 20 & 20 & 20 & 20 & 20 \\
\hline Turbidez (NTU) - Vf1 & 123 & 169 & 150 & 158 & 133 \\
\hline Turbidez (NTU) - Vf2 & 100 & 92 & 79 & 72 & 86 \\
\hline Condutiv. $\left(\mu \mathrm{S} / \mathrm{cm}\right.$ a $\left.25^{\circ} \mathrm{C}\right)-\mathrm{Vf1}$ & 1458 & 1429 & 1427 & 1433 & 1460 \\
\hline Condutiv. $\left(\mu \mathrm{S} / \mathrm{cm}\right.$ a $\left.25^{\circ} \mathrm{C}\right)-\mathrm{Vf} 2$ & 1419 & 1398 & 1396 & 1384 & 1435 \\
\hline
\end{tabular}

* Solução $40 \mathrm{~g} / \mathrm{l}$ de $\mathrm{Ca}(\mathrm{OH})_{2}$

** Solução 40g/l de aluminato de sódio 


\section{Ensaios de Coagulação-Floculação-Flotação \\ Coagulante: Aluminato de Sódio}

\begin{tabular}{|c|c|c|c|c|c|c|c|}
\hline $\mathbf{N}^{\circ}$ do ensaio: 29 a 31 & Ensaio: & eterminaça & $\operatorname{taxa}$ & de recirculação & & & \\
\hline \multicolumn{4}{|c|}{ Data ensaio: $31 / 10 / 2010$} & \multicolumn{4}{|c|}{ Horário início: $18: 00 \mathrm{~h}$} \\
\hline \multicolumn{8}{|c|}{ Coleta da amostra } \\
\hline \multicolumn{4}{|c|}{ Data/horário da coleta: 29/10/2010 / 16:00h } & \multicolumn{4}{|c|}{ Temperatura da amosta na coleta $\left({ }^{\circ} \mathbf{C}\right): 27$} \\
\hline \multicolumn{8}{|c|}{ Características da amostra bruta no início do ensaio } \\
\hline \multicolumn{4}{|c|}{ pH: 3,52} & \multicolumn{4}{|c|}{ Turbidez (NTU): 615} \\
\hline \multicolumn{4}{|c|}{ Temperatura $\left({ }^{\circ} \mathrm{C}\right): 26$} & \multicolumn{4}{|c|}{ Condutividade $\left(\boldsymbol{\mu S} / \mathrm{cm}\right.$ a $\left.25^{\circ} \mathrm{C}\right): 1213$} \\
\hline \multicolumn{8}{|c|}{ Parâmetros de mistura, floculação e flotação } \\
\hline $\mathbf{G m}\left(\mathbf{s}^{-1}\right): 800$ & Gf $\left(s^{-1}\right): 60$ & \multicolumn{2}{|c|}{ Vf1 (cm/min): 10} & Vf2 $(\mathrm{cm} / \mathrm{min}): 5$ & \multicolumn{2}{|c|}{$\mathbf{R}(\%)$ : variável } & Psat (bar): 5 \\
\hline \multirow[t]{3}{*}{ Tm (s): 5} & Tf (min): 10 & Tflot1 (n & 3,5 & Tflot2 (min): 7 & & & Tsat (min): 10 \\
\hline & & \multicolumn{6}{|c|}{ Reator } \\
\hline & & 1 & 2 & 1 & 2 & \multirow{2}{*}{$\frac{1}{2}$} & 2 \\
\hline \multicolumn{2}{|l|}{$\mathrm{Ca}(\mathrm{OH})_{2}(\mathrm{ml})^{*}$} & 2 & 2 & 2 & 2 & & \\
\hline \multicolumn{2}{|l|}{$\mathbf{R}(\%)$} & 20 & 30 & 40 & 50 & 70 & \\
\hline \multicolumn{2}{|l|}{ pHcoag } & 5,23 & 5,24 & 5,25 & 5,25 & 2,24 & \\
\hline \multicolumn{2}{|l|}{$\mathrm{DC}(\mathrm{mg} / \mathrm{l}) * *$} & 20 & 20 & 20 & 20 & 20 & \\
\hline \multicolumn{2}{|c|}{ Turbidez (NTU) - Vf1 } & 209 & 115 & 140 & 100 & 144 & \\
\hline \multicolumn{2}{|c|}{ Turbidez (NTU) - Vf2 } & 106 & 72 & 83 & 75 & 106 & \\
\hline \multicolumn{2}{|c|}{ Condutiv. $\left(\mu \mathrm{S} / \mathrm{cm}\right.$ a $\left.25^{\circ} \mathrm{C}\right)$ - Vf1 } & 1148 & 1216 & 1282 & 1342 & 1653 & \\
\hline Condutiv. $(\mu \mathrm{S} /$ & n a $\left.25^{\circ} \mathrm{C}\right)-\mathrm{Vf} 2$ & 1125 & 1203 & 1258 & 1328 & 1623 & \\
\hline
\end{tabular}

* Solução 40g/l de $\mathrm{Ca}(\mathrm{OH})_{2}$

** Solução 40g/l de aluminato de sódio 


\section{Ensaios de Coagulação-Floculação-Flotação Coagulante: Aluminato de Sódio}

\begin{tabular}{|c|c|c|c|c|c|c|c|c|c|}
\hline \multicolumn{10}{|c|}{ Ensaio: Determinação dos pares pHxDC para construção do Diagrama de Coagulação } \\
\hline \multicolumn{4}{|c|}{ Data ensaio: $02 / 11 / 2010$} & \multicolumn{6}{|c|}{ Horário início: 8:00h } \\
\hline \multicolumn{10}{|c|}{ Coleta da amostra } \\
\hline \multicolumn{4}{|c|}{ Data/horário da coleta: $29 / 10 / 2010 / 16: 00 \mathrm{~h}$} & \multicolumn{6}{|c|}{ Temperatura da amosta na coleta $\left({ }^{\circ} \mathrm{C}\right): 27$} \\
\hline \multicolumn{10}{|c|}{ Características da amostra bruta no início do ensaio } \\
\hline \multicolumn{4}{|l|}{ pH: 3,33} & \multicolumn{6}{|c|}{ Turbidez (NTU): 640} \\
\hline \multicolumn{4}{|c|}{ Temperatura $\left({ }^{\circ} \mathrm{C}\right): 22$} & \multicolumn{6}{|c|}{ Condutividade $\left(\boldsymbol{\mu S} / \mathrm{cm}^{2} \mathbf{2 5}^{\circ} \mathrm{C}\right): 1201$} \\
\hline \multicolumn{10}{|c|}{ Parâmetros de mistura, floculação e flotação } \\
\hline Gm $\left(s^{-1}\right): 800$ & Gf $\left(\mathbf{s}^{-1}\right): 60$ & \multicolumn{2}{|c|}{ Vf1 (cm/min): 10} & \multicolumn{2}{|c|}{ Vf2 (cm/min): 5} & \multicolumn{2}{|c|}{ R (\%): 50} & \multicolumn{2}{|c|}{ Psat (bar): 5} \\
\hline \multirow[t]{3}{*}{ Tm (s): 5} & Tf $(\min ): 10$ & Tflot1 ( & in): 3,5 & Tflot 2 & $\min ): 7$ & & & Tsat (min) & \\
\hline & & \multicolumn{8}{|c|}{ Reator } \\
\hline & & 1 & 2 & 1 & \begin{tabular}{l|l|l}
2 & -1 \\
\end{tabular} & 1 & 2 & 1 & 2 \\
\hline \multicolumn{2}{|l|}{$\mathrm{Ca}(\mathrm{OH})_{2}(\mathrm{ml})^{*}$} & 0 & 0 & 0 & 0 & 0 & 0 & 0 & 0 \\
\hline \multicolumn{2}{|l|}{ pHcoag } & 3,48 & 3,69 & 4,08 & 4,45 & 5,00 & 5,85 & 6,32 & 7,01 \\
\hline \multicolumn{2}{|c|}{$\mathrm{DC}(\mathrm{mg} / \mathrm{l}) * *$} & 0 & 20 & 40 & 60 & 100 & 200 & 260 & 360 \\
\hline \multicolumn{2}{|c|}{ Turbidez (NTU) - Vf1 } & - & - & 99 & 58 & 500 & 632 & 510 & 504 \\
\hline \multicolumn{2}{|c|}{ Turbidez (NTU) - Vf2 } & 300 & 274 & 71 & 30 & 119 & 150 & 192 & 206 \\
\hline \multicolumn{2}{|c|}{ Condutiv. $\left(\mu \mathrm{S} / \mathrm{cm}\right.$ a $\left.25^{\circ} \mathrm{C}\right)-\mathrm{Vf} 1$} & - & - & 1272 & 1296 & 1308 & 1314 & 1324 & 1328 \\
\hline \multicolumn{2}{|c|}{ Condutiv. $\left(\mu \mathrm{S} / \mathrm{cm}\right.$ a $\left.25^{\circ} \mathrm{C}\right)-\mathrm{Vf} 2$} & 1266 & 1270 & 1266 & 1262 & 1290 & 1308 & 1312 & 1322 \\
\hline
\end{tabular}

\begin{tabular}{|l|l|}
\hline $\mathbf{N}^{\circ}$ do ensaio: 36 a 39 & Ensaio: Determinação dos pares pHxDC para construção do Diagrama de Coagulação \\
\hline Data ensaio: $02 / 11 / 2010$ & Horário início: $10: 00 \mathrm{~h}$ \\
\hline \multicolumn{2}{|c|}{ Coleta da amostra } \\
\hline Data/horário da coleta: $29 / 10 / 2010 / 16: 00 \mathrm{~h}$ & Temperatura da amosta na coleta $\left({ }^{\circ} \mathbf{C}\right): 27$ \\
\hline
\end{tabular}

\section{Características da amostra bruta no início do ensaio}

\begin{tabular}{|l|l|}
\hline pH: 3,33 & Turbidez $(\mathbf{N T U}): 640$ \\
\hline Temperatura $\left({ }^{\circ} \mathbf{C}\right): 22$ & Condutividade $\left(\boldsymbol{\mu} \mathrm{S} / \mathbf{c m}\right.$ a $\left.25^{\circ} \mathbf{C}\right): 1201$ \\
\hline
\end{tabular}

\begin{tabular}{|c|c|c|c|c|c|c|c|c|c|}
\hline \multicolumn{4}{|c|}{ Temperatura $\left({ }^{\circ} \mathbf{C}\right): 22$} & \multicolumn{6}{|c|}{ Condutividade $\left(\mu \mathrm{S} / \mathrm{cm} \mathrm{a} 25^{\circ} \mathrm{C}\right): 1201$} \\
\hline \multicolumn{10}{|c|}{ Parâmetros de mistura, floculação e flotação } \\
\hline Gm $\left(\mathbf{s}^{-1}\right): 800$ & Gf $\left(\mathbf{s}^{-1}\right): 60$ & \multicolumn{2}{|c|}{ Vf1 (cm/min): 10} & \multicolumn{2}{|c|}{ Vf2 (cm/min): 5} & \multicolumn{2}{|c|}{ R (\%): 50} & \multicolumn{2}{|c|}{ Psat (bar): 5} \\
\hline \multirow[t]{3}{*}{$\operatorname{Tm}(\mathbf{s}): 5$} & Tf (min): 10 & Tflot1 & iin): 3,5 & Tflot2 & $\min ): 7$ & & & Tsat (min & \\
\hline & & \multicolumn{8}{|c|}{ Reator } \\
\hline & & 1 & 2 & 1 & 2 & 1 & 2 & 1 & 2 \\
\hline \multicolumn{2}{|l|}{$\mathrm{Ca}(\mathrm{OH})_{2}(\mathrm{ml})^{*}$} & 1 & 1 & 1 & 1 & 1 & 1 & 1 & 1 \\
\hline \multicolumn{2}{|l|}{ pHcoag } & 3,80 & 4,43 & 4,91 & 5,15 & 5,45 & 6,27 & 6,71 & 7,39 \\
\hline \multicolumn{2}{|c|}{$\mathrm{DC}(\mathrm{mg} / \mathrm{l})^{* *}$} & 0 & 20 & 40 & 60 & 100 & 200 & 260 & 360 \\
\hline \multicolumn{2}{|c|}{ Turbidez (NTU) - Vf1 } & 306 & 242 & 137 & 140 & 214 & 328 & 516 & 578 \\
\hline \multicolumn{2}{|c|}{ Turbidez (NTU) - Vf2 } & 332 & 234 & 76 & 63 & 97 & 133 & 218 & 244 \\
\hline \multicolumn{2}{|c|}{ Condutiv. $\left(\mu \mathrm{S} / \mathrm{cm}\right.$ a $\left.25^{\circ} \mathrm{C}\right)-\mathrm{Vf} 1$} & 1304 & 1310 & 1320 & 1336 & 1338 & 1376 & 1320 & 1328 \\
\hline \multicolumn{2}{|c|}{ Condutiv. $\left(\mu \mathrm{S} / \mathrm{cm}\right.$ a $\left.25^{\circ} \mathrm{C}\right)-\mathrm{Vf} 2$} & 1306 & 1306 & 1312 & 1326 & 1320 & 1350 & 1316 & 1328 \\
\hline
\end{tabular}

* Solução $40 \mathrm{~g} / \mathrm{l}$ de $\mathrm{Ca}(\mathrm{OH})_{2}$

** Solução 40g/l de aluminato de sódio 


\section{Ensaios de Coagulação-Floculação-Flotação Coagulante: Aluminato de Sódio}

\begin{tabular}{|c|c|c|c|c|c|c|c|c|c|}
\hline \multirow{2}{*}{\multicolumn{4}{|c|}{$\begin{array}{l}\mathbf{N}^{\circ} \text { do ensaio: } 40 \text { a } 43 \\
\text { Data ensaio: } 02 / 11 / 2010\end{array}$}} & res $\mathrm{pHx}$ & para co & rução & do Diagrama & e Coagu & \\
\hline & & & & \multicolumn{6}{|c|}{ Horário início: $14: 00 \mathrm{~h}$} \\
\hline \multicolumn{10}{|c|}{ Coleta da amostra } \\
\hline \multicolumn{4}{|c|}{ Data/horário da coleta: $29 / 10 / 2010 / 16: 00 \mathrm{~h}$} & \multicolumn{6}{|c|}{ Temperatura da amosta na coleta $\left({ }^{\circ} \mathbf{C}\right): 27$} \\
\hline \multicolumn{10}{|c|}{ Características da amostra bruta no início do ensaio } \\
\hline \multicolumn{4}{|l|}{ pH: 3,33} & \multicolumn{6}{|c|}{ Turbidez (NTU): 640} \\
\hline \multicolumn{4}{|c|}{ Temperatura $\left({ }^{\circ} \mathrm{C}\right): 22$} & \multicolumn{6}{|c|}{ Condutividade $\left(\boldsymbol{\mu S} / \mathrm{cm}^{2} \mathbf{2 5}^{\circ} \mathrm{C}\right): 1201$} \\
\hline \multicolumn{10}{|c|}{ Parâmetros de mistura, floculação e flotação } \\
\hline Gm $\left(\mathbf{s}^{-1}\right): 800$ & Gf $\left(\mathbf{s}^{-1}\right): 60$ & \multicolumn{3}{|c|}{ Vf1 (cm/min): 10} & \multicolumn{2}{|c|}{ f2 $(\mathbf{c m} / \mathbf{m i n}): 5$} & $\mathbf{R}(\%): 50$ & \multicolumn{2}{|c|}{ Psat (bar): 5} \\
\hline \multirow[t]{3}{*}{ Tm (s): 5} & Tf (min): 10 & Tflot1 ( & in): 3,5 & & t2 (mil & & & Tsat $(1$ & in): 10 \\
\hline & & \multicolumn{8}{|c|}{ Reator } \\
\hline & & 1 & 2 & 1 & 2 & 1 & 2 & 1 & 2 \\
\hline \multicolumn{2}{|l|}{$\mathrm{Ca}(\mathrm{OH})_{2}(\mathrm{ml})^{*}$} & 2 & 2 & 2 & 2 & 2 & 2 & 2 & 2 \\
\hline \multicolumn{2}{|l|}{ pHcoag } & 4,80 & 5,24 & 5,45 & 5,63 & 5,92 & 6,62 & 6,98 & 7,76 \\
\hline \multicolumn{2}{|c|}{$\mathrm{DC}(\mathrm{mg} / \mathrm{l}) * *$} & 0 & 20 & 40 & 60 & 100 & 200 & 260 & 360 \\
\hline \multicolumn{2}{|c|}{ Turbidez (NTU) - Vf1 } & 324 & 115 & 136 & 119 & 362 & 468 & 510 & 632 \\
\hline \multicolumn{2}{|c|}{ Turbidez (NTU) - Vf2 } & 288 & 72 & 72 & 67 & 125 & 118 & 166 & 352 \\
\hline \multicolumn{2}{|c|}{ Condutiv. $\left(\mu \mathrm{S} / \mathrm{cm}\right.$ a $\left.25^{\circ} \mathrm{C}\right)-\mathrm{Vf1}$} & 1352 & 1388 & 1376 & 1360 & 1344 & 1340 & 1328 & 1326 \\
\hline \multicolumn{2}{|c|}{ Condutiv. $\left(\mu \mathrm{S} / \mathrm{cm}\right.$ a $\left.25^{\circ} \mathrm{C}\right)-\mathrm{Vf} 2$} & 1344 & 1362 & 1350 & 1344 & 1342 & 1336 & 1322 & 1322 \\
\hline
\end{tabular}

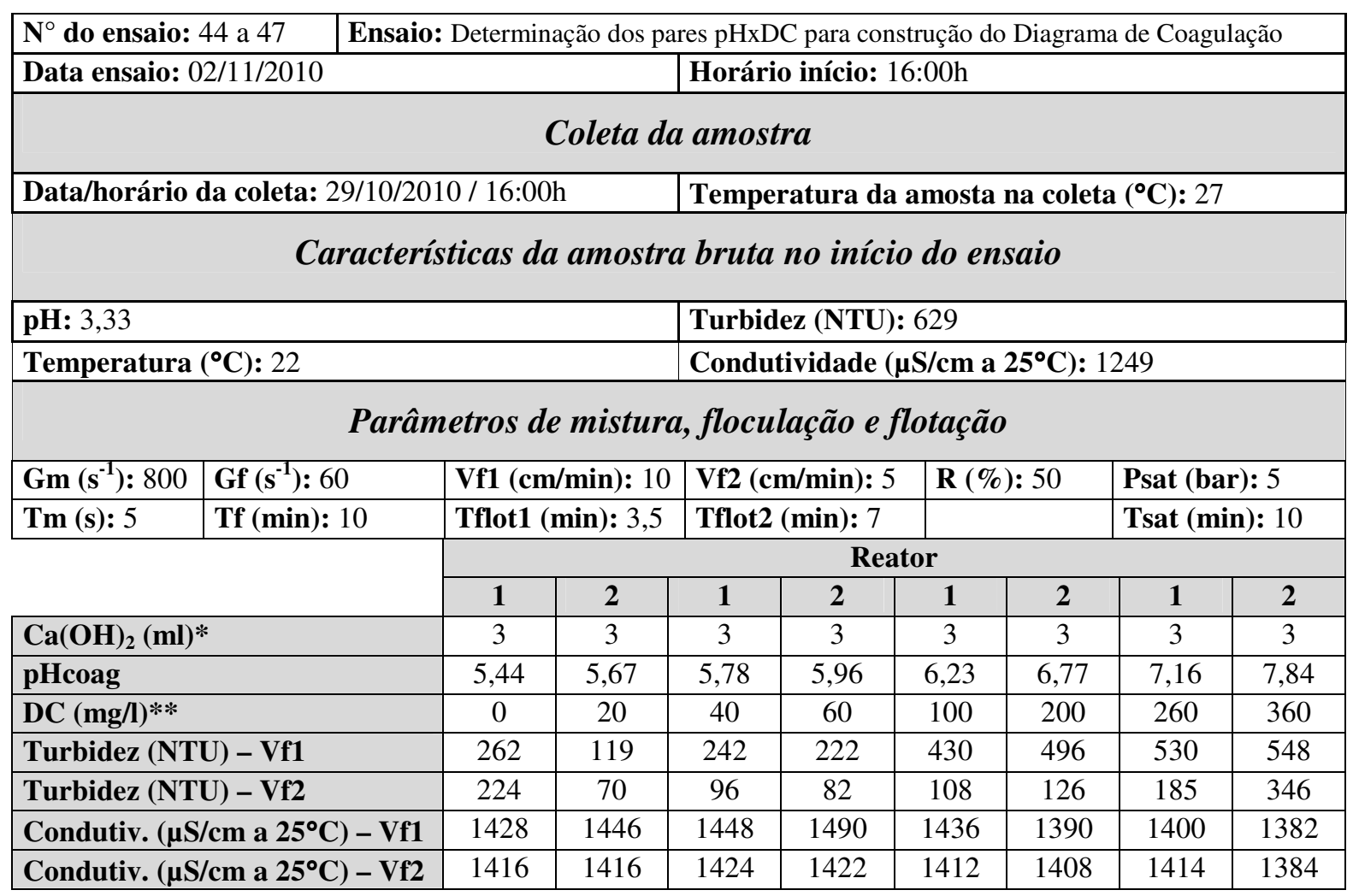

* Solução $40 \mathrm{~g} / \mathrm{l} \mathrm{de} \mathrm{Ca}(\mathrm{OH})_{2}$

** Solução 40g/l de aluminato de sódio 


\section{Ensaios de Coagulação-Floculação-Flotação Coagulante: Aluminato de Sódio}

\begin{tabular}{|c|c|c|c|c|c|c|c|c|c|}
\hline \multicolumn{10}{|c|}{$\mathbf{N}^{\circ}$ do ensaio: 48 a 51} \\
\hline \multicolumn{4}{|c|}{ Data ensaio: $02 / 11 / 2010$} & \multicolumn{6}{|c|}{ Horário início: $18: 00 \mathrm{~h}$} \\
\hline \multicolumn{10}{|c|}{ Coleta da amostra } \\
\hline \multicolumn{4}{|c|}{ Data/horário da coleta: $29 / 10 / 2010 / 16: 00 \mathrm{~h}$} & \multicolumn{6}{|c|}{ Temperatura da amosta na coleta $\left({ }^{\circ} \mathbf{C}\right): 27$} \\
\hline \multicolumn{10}{|c|}{ Características da amostra bruta no início do ensaio } \\
\hline \multirow{2}{*}{\multicolumn{4}{|c|}{$\begin{array}{l}\text { pH: } 3,33 \\
\text { Temperatura }\left({ }^{\circ} \mathbf{C}\right): 22\end{array}$}} & \multicolumn{6}{|c|}{ Turbidez (NTU): 629} \\
\hline & & & & \multicolumn{6}{|c|}{ Condutividade $\left(\boldsymbol{\mu S} / \mathrm{cm}^{2} \mathbf{2 5}^{\circ} \mathrm{C}\right): 1249$} \\
\hline \multicolumn{10}{|c|}{ Parâmetros de mistura, floculação e flotação } \\
\hline Gm $\left(\mathbf{s}^{-1}\right): 800$ & Gf $\left(s^{-1}\right): 60$ & \multicolumn{2}{|c|}{ Vf1 (cm/min): 10} & \multicolumn{3}{|c|}{ Vf2 $(\mathbf{c m} / \mathbf{m i n}): 5$} & $\mathbf{R}(\%): 50$ & \multicolumn{2}{|c|}{ Psat (bar): 5} \\
\hline \multirow{3}{*}{\multicolumn{2}{|c|}{ Tf (min): 10}} & \multicolumn{2}{|c|}{ Tflot1 (min): 3,5} & \multicolumn{3}{|c|}{ Tflot2 (min): 7} & & \multicolumn{2}{|c|}{ Tsat (min): 10} \\
\hline & & \multicolumn{8}{|c|}{ Reator } \\
\hline & & 1 & 2 & 1 & 2 & 1 & 2 & 1 & 2 \\
\hline \multicolumn{2}{|l|}{$\mathrm{Ca}(\mathrm{OH})_{2}(\mathrm{ml})^{*}$} & 5 & 5 & 5 & 5 & 5 & 5 & 5 & 5 \\
\hline \multicolumn{2}{|l|}{ pHcoag } & 6,34 & 6,50 & 6,59 & 6,68 & 6,89 & 7,53 & 7,95 & 8,37 \\
\hline \multicolumn{2}{|c|}{$\mathrm{DC}(\mathrm{mg} / \mathrm{l}) * *$} & 0 & 20 & 40 & 60 & 100 & 200 & 260 & 360 \\
\hline \multicolumn{2}{|c|}{ Turbidez (NTU) - Vf1 } & 128 & 320 & 772 & 774 & 432 & 472 & 772 & 758 \\
\hline \multicolumn{2}{|c|}{ Turbidez (NTU) - Vf2 } & 78 & 79 & 200 & 258 & 111 & 97 & 622 & 502 \\
\hline \multicolumn{2}{|c|}{ Condutiv. $\left(\mu \mathrm{S} / \mathrm{cm}\right.$ a $\left.25^{\circ} \mathrm{C}\right)-\mathrm{Vf1}$} & 1496 & 1486 & 1436 & 1404 & 1488 & 1472 & 1400 & 1404 \\
\hline \multicolumn{2}{|c|}{ Condutiv. $\left(\mu \mathrm{S} / \mathrm{cm}\right.$ a $\left.25^{\circ} \mathrm{C}\right)-\mathrm{Vf} 2$} & 1450 & 1450 & 1428 & 1396 & 1458 & 1460 & 1394 & 1392 \\
\hline
\end{tabular}

\begin{tabular}{|l|l|l|}
\hline $\mathbf{N}^{\circ}$ do ensaio: 52 a 55 & Ensaio: Determinação dos pares pHxDC para construção do Diagrama de Coagulação \\
\hline Data ensaio: $02 / 11 / 2010$ & Horário início: $20: 00 \mathrm{~h}$ \\
\hline \multicolumn{3}{|c|}{ Coleta da amostra } \\
\hline Data/horário da coleta: $29 / 10 / 2010 / 16: 00 \mathrm{~h}$ & Temperatura da amosta na coleta $\left({ }^{\circ} \mathbf{C}\right): 27$ \\
\hline
\end{tabular}

\section{Características da amostra bruta no início do ensaio}

\begin{tabular}{|l|l|}
\hline pH: 3,40 & Turbidez $(\mathbf{N T U}): 635$ \\
\hline Temperatura $\left({ }^{\circ} \mathbf{C}\right): 22$ & Condutividade $\left(\boldsymbol{\mu S} / \mathbf{c m}\right.$ a $\left.25^{\circ} \mathbf{C}\right): 1248$ \\
\hline
\end{tabular}

\section{Parâmetros de mistura, floculação e flotação}

\begin{tabular}{|l|l|l|l|l|l|}
\hline Gm $\left(\mathbf{s}^{-1}\right): 800$ & Gf $\left(\mathbf{s}^{-1}\right): 60$ & Vf1 $(\mathbf{c m} / \mathbf{m i n}): 10$ & Vf2 $(\mathbf{c m} / \mathbf{m i n}): 5$ & R $(\%): 50$ & Psat (bar): 5 \\
\hline Tm $(\mathbf{s}): 5$ & Tf $(\mathbf{m i n}): 10$ & Tflot1 $(\mathbf{m i n}): 3,5$ & Tflot2 $(\mathbf{m i n}): 7$ & & Tsat $(\mathbf{m i n}): 10$ \\
\hline
\end{tabular}

\begin{tabular}{|l|c|c|c|c|c|c|c|c|}
\multicolumn{1}{c|}{} & \multicolumn{9}{c|}{ Reator } \\
\cline { 2 - 10 } \multicolumn{1}{c|}{} & $\mathbf{1}$ & $\mathbf{2}$ & $\mathbf{1}$ & $\mathbf{2}$ & $\mathbf{1}$ & $\mathbf{2}$ & $\mathbf{1}$ & $\mathbf{2}$ \\
\hline $\mathbf{C a}(\mathbf{O H})_{\mathbf{2}}(\mathbf{m l})^{*}$ & 12 & 12 & 12 & 12 & 12 & 12 & 12 & 12 \\
\hline pHcoag & 8,57 & 8,60 & 8,62 & 8,65 & 8,66 & 8,86 & 8,90 & 9,06 \\
\hline $\mathbf{D C}(\mathbf{m g} / \mathbf{l}) * *$ & 0 & 20 & 40 & 60 & 100 & 200 & 260 & 360 \\
\hline Turbidez $(\mathbf{N T U})-\mathbf{V f 1}$ & 522 & 1236 & 1038 & 1226 & 1304 & 1516 & 1300 & 1606 \\
\hline Turbidez $(\mathbf{N T U})-\mathbf{V f 2}$ & 65 & 208 & 428 & 136 & 45 & 24 & 61 & 27 \\
\hline Condutiv. $\left(\boldsymbol{\mu S} / \mathbf{c m ~ a ~ 2 5}^{\circ} \mathbf{C}\right)-\mathbf{V f 1}$ & 1402 & 1412 & 1398 & 1394 & 1376 & 1392 & 1384 & 1412 \\
\hline Condutiv. $\left(\boldsymbol{\mu S} / \mathbf{c m ~ a ~ 2 5}^{\circ} \mathbf{C}\right)-\mathbf{V f} \mathbf{2}$ & 1386 & 1400 & 1388 & 1366 & 1370 & 1384 & 1386 & 1412 \\
\hline
\end{tabular}

* Solução 40g/l de $\mathrm{Ca}(\mathrm{OH})_{2}$

** Solução 40g/l de aluminato de sódio 


\section{Ensaios de Coagulação-Floculação-Flotação \\ Coagulante: Aluminato de Sódio}

\begin{tabular}{|c|c|c|c|c|c|c|c|c|c|}
\hline \multirow{2}{*}{\multicolumn{4}{|c|}{$\begin{array}{l}N^{\circ} \text { do ensaio: } 56 \text { a } 59 \\
\text { Data ensaio: } 02 / 11 / 2010\end{array}$}} & \multirow{2}{*}{\multicolumn{6}{|c|}{$\begin{array}{l}\text { res pHxDC para construção do Diagrama de Coagulação } \\
\text { Horário início: } 22: 00 \mathrm{~h}\end{array}$}} \\
\hline & & & & & & & & & \\
\hline \multicolumn{10}{|c|}{ Coleta da amostra } \\
\hline \multicolumn{4}{|c|}{ Data/horário da coleta: $29 / 10 / 2010 / 16: 00 \mathrm{~h}$} & \multicolumn{6}{|c|}{ Temperatura da amosta na coleta $\left({ }^{\circ} \mathrm{C}\right): 27$} \\
\hline \multicolumn{10}{|c|}{ Características da amostra bruta no início do ensaio } \\
\hline \multirow{2}{*}{\multicolumn{4}{|c|}{$\begin{array}{l}\text { pH: } 3,33 \\
\text { Temperatura }\left({ }^{\circ} \mathrm{C}\right): 22 \\
\end{array}$}} & \multicolumn{6}{|c|}{ Turbidez (NTU): 629} \\
\hline & & & & \multicolumn{6}{|c|}{ Condutividade $\left(\boldsymbol{\mu S} / \mathrm{cm}\right.$ a $\left.25^{\circ} \mathrm{C}\right): 1249$} \\
\hline \multicolumn{10}{|c|}{ Parâmetros de mistura, floculação e flotação } \\
\hline Gm $\left(\mathbf{s}^{-1}\right): 800$ & Gf $\left(\mathbf{s}^{-1}\right): 60$ & \multicolumn{2}{|c|}{ Vf1 (cm/min): 10} & \multirow{2}{*}{\multicolumn{2}{|c|}{\begin{tabular}{|l|} 
Vf2 $(\mathrm{cm} / \mathrm{min}): 5$ \\
Tflot2 (min): 7
\end{tabular}}} & \multicolumn{2}{|c|}{$\mathrm{R}(\%): 50$} & \multicolumn{2}{|c|}{ Psat (bar): 5} \\
\hline \multirow{3}{*}{\multicolumn{2}{|c|}{ Tf (min): 10}} & \multicolumn{2}{|c|}{ Tflot1 (min): 3,5} & & & & & Tsat $(\mathrm{m}$ & ): 10 \\
\hline & & \multicolumn{8}{|c|}{ Reator } \\
\hline & & 1 & 2 & 1 & 2 & 1 & 2 & 1 & 2 \\
\hline \multicolumn{2}{|l|}{$\mathrm{Ca}(\mathrm{OH})_{2}(\mathrm{ml})^{*}$} & 10 & 10 & 10 & 10 & 10 & 10 & 10 & 10 \\
\hline \multicolumn{2}{|l|}{ pHcoag } & 7,86 & 7,96 & 8,06 & 8,11 & 8,30 & 8,58 & 8,71 & 8,87 \\
\hline \multicolumn{2}{|c|}{$\mathrm{DC}(\mathrm{mg} / \mathrm{l})^{* *}$} & 0 & 20 & 40 & 60 & 100 & 200 & 260 & 360 \\
\hline \multicolumn{2}{|c|}{ Turbidez (NTU) - Vf1 } & 854 & 1056 & 896 & 818 & 906 & 1192 & 1070 & 1118 \\
\hline \multicolumn{2}{|c|}{ Turbidez (NTU) - Vf2 } & 107 & 472 & 886 & 908 & 792 & 746 & 696 & 702 \\
\hline \multicolumn{2}{|c|}{ Condutiv. $\left(\mu \mathrm{S} / \mathrm{cm}\right.$ a $\left.25^{\circ} \mathrm{C}\right)-\mathrm{Vf1}$} & 1442 & 1462 & 1406 & 1400 & 1386 & 1380 & 1378 & 1390 \\
\hline \multicolumn{2}{|c|}{ Condutiv. $\left(\mu \mathrm{S} / \mathrm{cm}\right.$ a $\left.25^{\circ} \mathrm{C}\right)-\mathrm{Vf} 2$} & 1438 & 1432 & 1400 & 1394 & 1386 & 1370 & 1368 & 1382 \\
\hline
\end{tabular}

* Solução $40 \mathrm{~g} / \mathrm{l}$ de $\mathrm{Ca}(\mathrm{OH})_{2}$

** Solução $40 \mathrm{~g} / \mathrm{l}$ de aluminato de sódio 


\section{Apêndice F}

Resultados dos ensaios de coagulação-floculação-flotação para o coagulante cloreto férrico 


\section{Ensaios de Coagulação-Floculação-Flotação Coagulante: Cloreto Férrico}

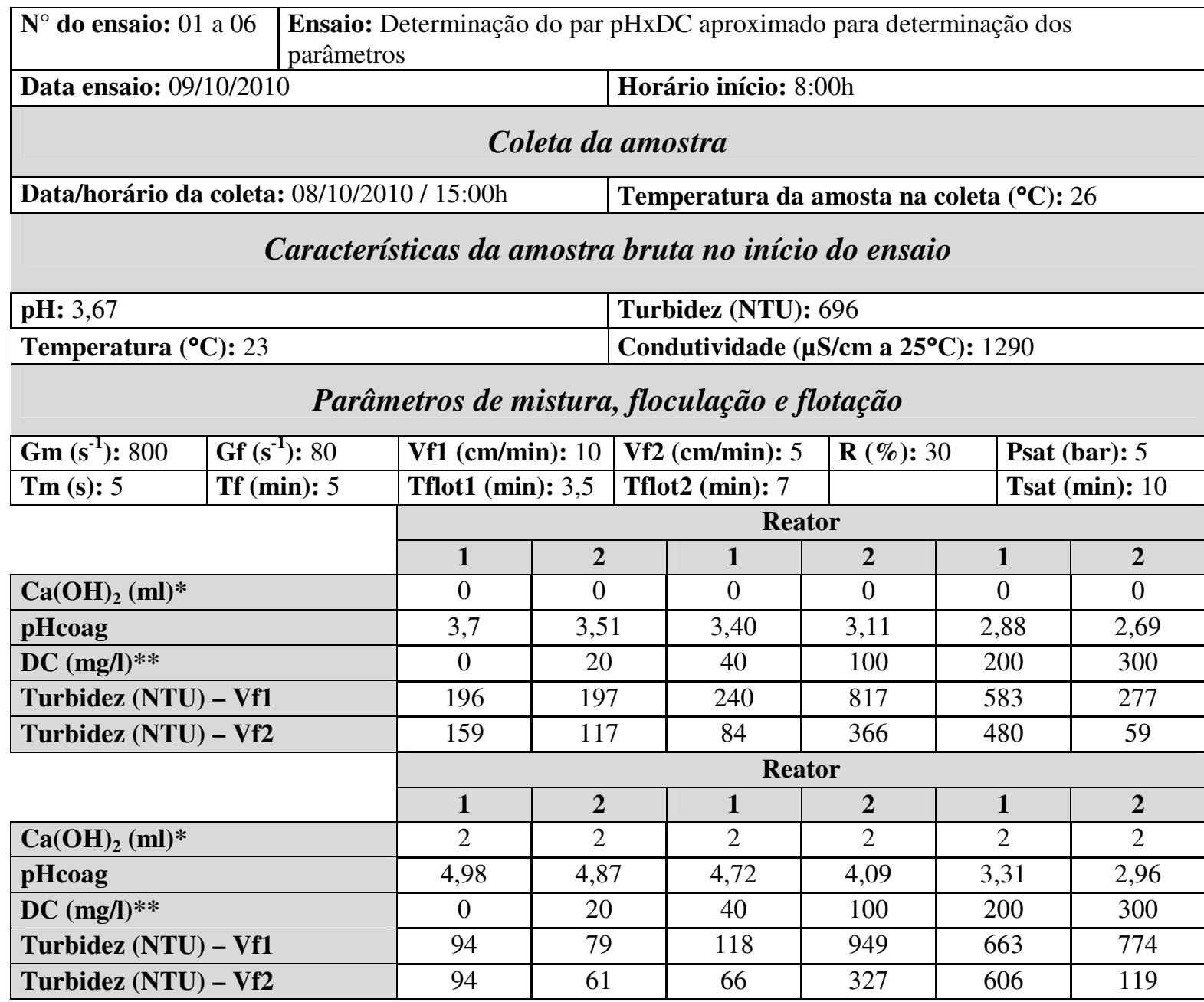

* Solução 40g/l de $\mathrm{Ca}(\mathrm{OH})_{2}$

** Solução 40g/l de cloreto férrico 


\section{Ensaios de Coagulação-Floculação-Flotação Coagulante: Cloreto Férrico}

\begin{tabular}{|c|c|c|c|c|c|c|c|c|}
\hline \multicolumn{2}{|c|}{$\mathbf{N}^{\circ}$ do ensaio: 07 a 11} & \multicolumn{7}{|c|}{ xDC aproxir } \\
\hline \multicolumn{5}{|c|}{ Data ensaio: 09/10/2010 } & \multicolumn{4}{|c|}{ Horário início: $11: 00 \mathrm{~h}$} \\
\hline \multicolumn{9}{|c|}{ Coleta da amostra } \\
\hline \multicolumn{5}{|c|}{ Data/horário da coleta: $08 / 10 / 2010 / 15: 00 \mathrm{~h}$} & \multicolumn{4}{|c|}{ Temperatura da amosta na coleta $\left({ }^{\circ} \mathrm{C}\right): 26$} \\
\hline \multicolumn{9}{|c|}{ Características da amostra bruta no início do ensaio } \\
\hline \multicolumn{5}{|c|}{ pH: 3,65} & \multicolumn{4}{|c|}{ Turbidez (NTU): 734} \\
\hline \multicolumn{5}{|c|}{ Temperatura $\left({ }^{\circ} \mathrm{C}\right): 23$} & \multicolumn{4}{|c|}{ Condutividade $\left(\mu \mathrm{S} / \mathrm{cm}\right.$ a $\left.25^{\circ} \mathrm{C}\right): 1295$} \\
\hline \multicolumn{9}{|c|}{ Parâmetros de mistura, floculação e flotação } \\
\hline Gm $\left(\mathbf{s}^{-1}\right): 800$ & \multicolumn{2}{|c|}{ Gf $\left(\mathbf{s}^{-1}\right): 80$} & \multicolumn{2}{|c|}{ Vf1 $(\mathbf{c m} / \mathbf{m i n}): 10$} & Vf2 (cm/min): 5 & $\mathbf{R}($ & \multicolumn{2}{|c|}{ Psat (bar): 5} \\
\hline \multirow[t]{3}{*}{ Tm (s): 5} & \multirow{3}{*}{\multicolumn{2}{|c|}{ Tf (min): 5}} & \multicolumn{2}{|c|}{ Tflot1 (min): 3,5} & \multicolumn{2}{|c|}{ Tflot2 (min): 7} & \multicolumn{2}{|c|}{ Tsat (min): 10} \\
\hline & & & \multicolumn{6}{|c|}{ Reator } \\
\hline & & & 1 & 2 & 1 & 2 & 1 & 2 \\
\hline \multicolumn{3}{|l|}{$\mathrm{Ca}(\mathrm{OH})_{2}(\mathrm{ml})^{*}$} & 5 & 5 & 5 & 5 & 5 & 5 \\
\hline \multicolumn{3}{|l|}{ pHcoag } & 6,07 & 5,97 & 5,79 & 5,46 & 4,98 & 4,05 \\
\hline \multicolumn{3}{|l|}{ DC $(\mathrm{mg} / \mathrm{l}) * *$} & 0 & 20 & 40 & 100 & 200 & 300 \\
\hline \multicolumn{3}{|c|}{ Turbidez (NTU) - Vf1 } & 450 & 619 & 596 & 787 & 843 & 729 \\
\hline \multirow{3}{*}{\multicolumn{3}{|c|}{ Turbidez (NTU) - Vf2 }} & 276 & 304 & 271 & 207 & 677 & 594 \\
\hline & & & \multicolumn{6}{|c|}{ Reator } \\
\hline & & & 1 & 2 & 1 & 2 & 1 & 2 \\
\hline \multicolumn{3}{|l|}{$\mathrm{Ca}(\mathrm{OH})_{2}(\mathrm{ml})^{*}$} & 3 & 3 & & & & \\
\hline \multicolumn{3}{|l|}{ pHcoag } & 5,25 & 5,17 & & & & \\
\hline \multicolumn{3}{|c|}{ DC $(\mathrm{mg} / \mathrm{l})^{* *}$} & 20 & 40 & & & & \\
\hline \multicolumn{3}{|c|}{ Turbidez (NTU) - Vf1 } & 133 & 136 & & & & \\
\hline Turbidez (NTL & $-V f 2$ & & 78 & 67 & & & & \\
\hline
\end{tabular}

\begin{tabular}{|l|l|}
\hline $\mathbf{N}^{\circ}$ do ensaio: 12 & Ensaio: Determinação do par pHxDC aproximado para determinação dos parâmetros \\
\hline
\end{tabular} Data ensaio: 09/10/2010

Horário início: 13:00h

\begin{tabular}{|c|c|c|c|c|c|c|c|}
\hline \multicolumn{8}{|c|}{ Coleta da amostra } \\
\hline \multicolumn{4}{|c|}{ Data/horário da coleta: $08 / 10 / 2010 / 15: 00 \mathrm{~h}$} & \multicolumn{4}{|c|}{ Temperatura da amosta na coleta $\left({ }^{\circ} \mathrm{C}\right): 26$} \\
\hline \multicolumn{8}{|c|}{ Características da amostra bruta no início do ensaio } \\
\hline \multicolumn{4}{|l|}{ pH: 3,65} & \multicolumn{4}{|c|}{ Turbidez (NTU): 739} \\
\hline \multicolumn{4}{|c|}{ Temperatura $\left({ }^{\circ} \mathrm{C}\right): 23$} & \multicolumn{4}{|c|}{ Condutividade $\left(\boldsymbol{\mu S} / \mathrm{cm}\right.$ a $\left.25^{\circ} \mathrm{C}\right): 1292$} \\
\hline \multicolumn{8}{|c|}{ Parâmetros de mistura, floculação e flotação } \\
\hline Gm $\left(\mathbf{s}^{-1}\right): 800$ & Gf $\left(\mathbf{s}^{-1}\right): 80$ & \multicolumn{2}{|c|}{ Vf1 (cm/min): 10} & Vf2 $(\mathrm{cm} / \mathrm{min}): 5$ & $\mathbf{R}(\%$ & \multicolumn{2}{|c|}{ Psat (bar): 5} \\
\hline \multirow[t]{3}{*}{ Tm (s): 5} & Tf (min): 5 & Tflot1 (n & 3,5 & Tflot2 (min): 7 & & \multicolumn{2}{|c|}{ Tsat (min): 10} \\
\hline & & \multicolumn{6}{|c|}{ Reator } \\
\hline & & 1 & 2 & 1 & 2 & 1 & 2 \\
\hline \multicolumn{2}{|c|}{$\mathrm{Ca}(\mathrm{OH})_{2}(\mathrm{ml})^{*}$} & 2 & $\frac{2}{2}$ & & & & \\
\hline \multicolumn{2}{|c|}{ pHcoag } & 4,85 &, 72 & & & & \\
\hline \multicolumn{2}{|c|}{$\mathrm{DC}(\mathrm{mg} / \mathrm{l}) * *$} & 20 & 40 & & & & \\
\hline \multicolumn{2}{|c|}{ Turbidez (NTU) - Vf1 } & 46 & 41 & & & & \\
\hline \multicolumn{2}{|c|}{ Turbidez (NTU) - Vf2 } & 44 & 38 & & & & \\
\hline
\end{tabular}

* Solução 40g/l de $\mathrm{Ca}(\mathrm{OH})_{2}$

** Solução $40 \mathrm{~g} / 1$ de cloreto férrico 


\section{Ensaios de Coagulação-Floculação-Flotação Coagulante: Cloreto Férrico}

\begin{tabular}{|c|c|c|c|c|c|c|c|}
\hline \multirow{2}{*}{\multicolumn{4}{|c|}{\begin{tabular}{l|l|}
$\mathbf{N}^{\circ}$ do ensaio: 13 & Ensaio Determinação dos parâm \\
Data ensaio: $10 / 10 / 2010$
\end{tabular}}} & etros de floculaçãc & & & \\
\hline & & & & \multicolumn{4}{|c|}{ Horário início: 9:00h } \\
\hline \multicolumn{8}{|c|}{ Coleta da amostra } \\
\hline \multicolumn{4}{|c|}{ Data/horário da coleta: 08/10/2010 / 15:00h } & \multicolumn{4}{|c|}{ Temperatura da amosta na coleta $\left({ }^{\circ} \mathrm{C}\right): 26$} \\
\hline \multicolumn{8}{|c|}{ Características da amostra bruta no início do ensaio } \\
\hline \multicolumn{4}{|l|}{ pH: 3,78} & \multicolumn{4}{|c|}{ Turbidez (NTU): 686} \\
\hline \multicolumn{4}{|c|}{ Temperatura $\left({ }^{\circ} \mathbf{C}\right): 23$} & \multicolumn{4}{|c|}{ Condutividade $\left(\mu \mathrm{S} / \mathrm{cm}\right.$ a $\left.25^{\circ} \mathrm{C}\right): 1250$} \\
\hline \multicolumn{8}{|c|}{ Parâmetros de mistura, floculação e flotação } \\
\hline $\mathbf{G m}\left(\mathbf{s}^{-1}\right): 800$ & Gf $\left(s^{-1}\right): 25$ & \multicolumn{2}{|c|}{ Vf1 (cm/min): 10} & Vf2 $(\mathrm{cm} / \mathrm{min}): 5$ & $\mathbf{R}(\%): 50$ & \multicolumn{2}{|c|}{ Psat (bar): 5} \\
\hline \multirow{3}{*}{\multicolumn{2}{|c|}{ Tf (min): variável }} & Tflot1 (m & 3,5 & Tflot2 (min): 7 & & \multicolumn{2}{|c|}{ Tsat (min): 10} \\
\hline & & \multicolumn{6}{|c|}{ Reator } \\
\hline & & 1 & 2 & \multirow[t]{2}{*}{1} & 2 & 1 & 2 \\
\hline \multicolumn{2}{|l|}{$\mathrm{Ca}(\mathrm{OH})_{2}(\mathrm{ml})^{*}$} & 2 & 2 & & & & \\
\hline \multicolumn{2}{|l|}{ Tf (min) } & 10 & 20 & 0 & & & \\
\hline \multicolumn{2}{|l|}{ pHcoag } & 4,90 & \multicolumn{2}{|c|}{89} & & & \\
\hline \multicolumn{2}{|c|}{$\mathrm{DC}(\mathrm{mg} / \mathrm{l}) * *$} & 40 & 40 & 0 & & & \\
\hline \multicolumn{2}{|c|}{ Turbidez (NTU) - Vf1 } & 41 & 52 & 2 & & & \\
\hline \multicolumn{2}{|c|}{ Turbidez (NTU) - Vf2 } & 35 & 43 & 3 & & & \\
\hline \multicolumn{2}{|c|}{ Condutiv. $\left(\mu \mathrm{S} / \mathrm{cm}\right.$ a $\left.25^{\circ} \mathrm{C}\right)-\mathrm{Vf1}$} & 1482 & \multicolumn{2}{|c|}{482} & & & \\
\hline \multicolumn{2}{|c|}{ Condutiv. $\left(\mu \mathrm{S} / \mathrm{cm}\right.$ a $\left.25^{\circ} \mathrm{C}\right)$ - Vf2 } & 1462 & \multicolumn{2}{|c|}{472} & & & \\
\hline
\end{tabular}

\begin{tabular}{|l|l|}
\hline $\mathbf{N}^{\circ}$ do ensaio: 14 a 16 & Ensaio Determinação dos parâmetros de floculação \\
\hline
\end{tabular}

\begin{tabular}{|l|l|}
\hline Data ensaio: $10 / 10 / 2010$ & Horário início: $11: 00 \mathrm{~h}$
\end{tabular}

\section{Coleta da amostra}

\begin{tabular}{|l|l|}
\hline Data/horário da coleta: $08 / 10 / 2010 / 15: 00 \mathrm{~h}$ & Temperatura da amosta na coleta $\left({ }^{\circ} \mathbf{C}\right): 26$ \\
\hline
\end{tabular}

\section{Características da amostra bruta no início do ensaio}

\begin{tabular}{|c|c|c|c|c|c|c|c|}
\hline \multirow{2}{*}{\multicolumn{2}{|c|}{$\begin{array}{l}\text { pH: } 3,78 \\
\text { Temperatura }\left({ }^{\circ} \mathrm{C}\right): 23\end{array}$}} & & & \multicolumn{4}{|c|}{ Turbidez (NTU): 686} \\
\hline & & & & \multicolumn{4}{|c|}{ Condutividade $\left(\boldsymbol{\mu S} / \mathrm{cm}\right.$ a $\left.25^{\circ} \mathrm{C}\right): 1250$} \\
\hline \multicolumn{8}{|c|}{ Parâmetros de mistura, floculação e flotação } \\
\hline Gm $\left(s^{-1}\right): 800$ & Gf $\left(\mathbf{s}^{-1}\right): 40$ & \multicolumn{2}{|c|}{ Vf1 (cm/min): 10} & Vf2 $(\mathbf{c m} / \mathbf{m i n}): 5$ & R (\%): 50 & \multicolumn{2}{|c|}{ Psat (bar): 5} \\
\hline \multirow[t]{3}{*}{$\operatorname{Tm}(\mathbf{s}): 5$} & Tf (min): variável & Tflot1 (n & 3,5 & Tflot2 (min): 7 & & Tsat & \\
\hline & & \multicolumn{6}{|c|}{ Reator } \\
\hline & & 1 & 2 & 1 & 2 & 1 & 2 \\
\hline \multicolumn{2}{|l|}{$\mathrm{Ca}(\mathrm{OH})_{2}(\mathrm{ml})^{*}$} & 2 & 2 & 2 & 2 & 2 & \\
\hline \multicolumn{2}{|l|}{ Tf (min) } & 5 & 10 & 15 & 20 & 30 & \\
\hline \multicolumn{2}{|l|}{ pHcoag } & 4,75 & 4,71 & 4,73 & 4,75 & 4,76 & \\
\hline \multicolumn{2}{|c|}{$\mathrm{DC}(\mathrm{mg} / \mathrm{l}) * *$} & 40 & 40 & 40 & 40 & 40 & \\
\hline \multicolumn{2}{|c|}{ Turbidez (NTU) - Vf1 } & 49 & 39 & 42 & 39 & 38 & \\
\hline \multicolumn{2}{|c|}{ Turbidez (NTU) - Vf2 } & 40 & 34 & 35 & 34 & 33 & \\
\hline \multicolumn{2}{|c|}{ Condutiv. $\left(\mu \mathrm{S} / \mathrm{cm}\right.$ a $\left.25^{\circ} \mathrm{C}\right)-\mathrm{Vf1}$} & 1484 & 1486 & 1482 & 1496 & 1504 & \\
\hline \multicolumn{2}{|c|}{ Condutiv. $\left(\mu \mathrm{S} / \mathrm{cm}\right.$ a $\left.25^{\circ} \mathrm{C}\right)-\mathrm{Vf} 2$} & 1480 & 1480 & 1478 & 1476 & 1480 & \\
\hline
\end{tabular}

* Solução 40g/l de $\mathrm{Ca}(\mathrm{OH})_{2}$

** Solução $40 \mathrm{~g} / \mathrm{l}$ de cloreto férrico 


\section{Ensaios de Coagulação-Floculação-Flotação Coagulante: Cloreto Férrico}

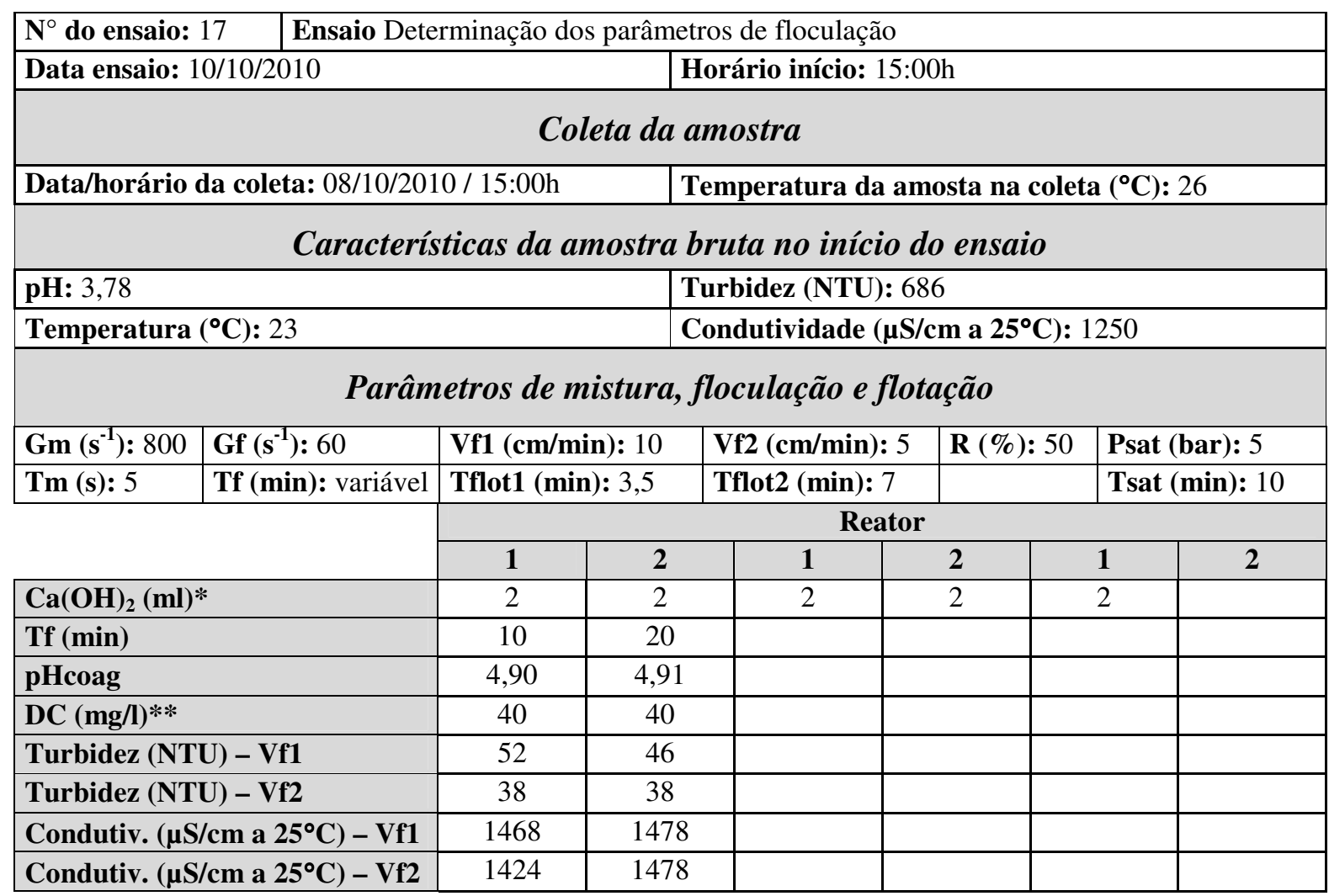

\begin{tabular}{|l|l|l|}
\hline $\mathbf{N}^{\circ}$ do ensaio: 18 a 20 & Ensaio Determinação dos parâmetros de floculação \\
\hline Data ensaio: $10 / 10 / 2010$ & Horário início: $16: 00 \mathrm{~h}$ \\
\hline \multicolumn{2}{|c|}{ Coleta da amostra } \\
\hline Data/horário da coleta: $08 / 10 / 2010 / 15: 00 \mathrm{~h}$ & Temperatura da amosta na coleta $\left({ }^{\circ} \mathbf{C}\right): 26$ \\
\hline
\end{tabular}

\section{Características da amostra bruta no início do ensaio}

\begin{tabular}{|l|l|}
\hline pH: 3,78 & Turbidez $(\mathbf{N T U}): 686$ \\
\hline Temperatura $\left({ }^{\circ} \mathbf{C}\right): 23$ & Condutividade $\left(\boldsymbol{\mu S} / \mathbf{c m}\right.$ a $\left.25^{\circ} \mathbf{C}\right): 1250$ \\
\hline
\end{tabular}

Parâmetros de mistura, floculação e flotação

\begin{tabular}{|c|c|c|c|c|c|c|c|}
\hline Gm $\left(s^{-1}\right): 800$ & Gf $\left(\mathbf{s}^{-1}\right): 80$ & Vf1 $(\mathrm{cm} / \mathrm{n}$ & 10 & Vf2 $(\mathrm{cm} / \mathrm{min}): 5$ & R (\%): 50 & Psat & \\
\hline $\operatorname{Tm}(\mathbf{s}): 5$ & Tf (min): variável & Tflot1 (m & & Tflot2 (min): 7 & & Tsat & \\
\hline & & & & Rea & & & \\
\hline & & 1 & 2 & 1 & 2 & 1 & 2 \\
\hline $\mathrm{Ca}(\mathrm{OH})_{2}(\mathrm{ml})$ & & 2 & 2 & 2 & 2 & 2 & \\
\hline Tf (min) & & 5 & 10 & 15 & 20 & 30 & \\
\hline pHcoag & & 4,77 & 4,87 & 4,88 & 4,80 & 4,88 & \\
\hline DC $(\mathrm{mg} / \mathrm{l}) * *$ & & 40 & 40 & 40 & 40 & 40 & \\
\hline Turbidez (NT & U) - Vf1 & 39 & 53 & 45 & 40 & 49 & \\
\hline Turbidez (NT & $U)-V f 2$ & 36 & 38 & 36 & 37 & 35 & \\
\hline Condutiv. $(\mu$ s & cm a $\left.25^{\circ} \mathrm{C}\right)$ - Vf1 & 1596 & 1598 & 1590 & 1572 & 1564 & \\
\hline Condutiv. $(\mu$ & $\left(\mathrm{cm}\right.$ a $\left.25^{\circ} \mathrm{C}\right)-\mathrm{Vf} 2$ & 1576 & 1574 & 1566 & 1562 & 1562 & \\
\hline
\end{tabular}

* Solução 40g/l de $\mathrm{Ca}(\mathrm{OH})_{2}$

** Solução 40g/l de cloreto férrico 


\section{Ensaios de Coagulação-Floculação-Flotação Coagulante: Cloreto Férrico}

\begin{tabular}{|c|c|c|c|c|c|c|c|}
\hline \multirow{2}{*}{\multicolumn{4}{|c|}{\begin{tabular}{l|l|l}
$N^{\circ}$ do ensaio: 21 a 23 & Ensaio Determinação dos parâ \\
Data ensaio: $10 / 10 / 2010$
\end{tabular}}} & tros de flocu & & & \\
\hline & & & & orário início & 7:00h & & \\
\hline \multicolumn{8}{|c|}{ Coleta da amostra } \\
\hline \multicolumn{4}{|c|}{ Data/horário da coleta: $08 / 10 / 2010 / 15: 00 \mathrm{~h}$} & \multicolumn{4}{|c|}{ Temperatura da amosta na coleta $\left({ }^{\circ} \mathbf{C}\right): 26$} \\
\hline \multicolumn{8}{|c|}{ Características da amostra bruta no início do ensaio } \\
\hline \multirow{2}{*}{\multicolumn{4}{|c|}{\begin{tabular}{|l|l} 
pH: 3,78 & ' \\
Temperatura $\left({ }^{\circ} \mathbf{C}\right): 23$ \\
\end{tabular}}} & \multicolumn{4}{|c|}{ Turbidez (NTU): 686} \\
\hline & & & & \multicolumn{4}{|c|}{ 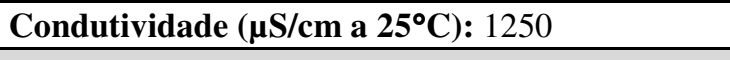 } \\
\hline \multicolumn{8}{|c|}{ Parâmetros de mistura, floculação e flotação } \\
\hline Gm $\left(\mathbf{s}^{-1}\right): 800$ & Gf $\left(\mathbf{s}^{-1}\right): 100$ & \multicolumn{2}{|c|}{ Vf1 (cm/min): 10} & \multicolumn{2}{|c|}{ Vf2 (cm/min): 5} & R (\%): 50 & Psat (bar): 5 \\
\hline \multirow{3}{*}{\multicolumn{2}{|c|}{ Tf (min): variável }} & \multicolumn{2}{|c|}{ Tflot1 (min): 3,5} & \multicolumn{2}{|c|}{ Tflot2 (min): 7} & \multicolumn{2}{|c|}{ Tsat (min): 10} \\
\hline & & \multicolumn{6}{|c|}{ Reator } \\
\hline & & 1 & 2 & 1 & 2 & 1 & 2 \\
\hline \multicolumn{2}{|c|}{$\mathrm{Ca}(\mathrm{OH})_{2}(\mathrm{ml})^{*}$} & 2 & 2 & 2 & 2 & 2 & \\
\hline \multicolumn{2}{|l|}{ Tf $(\min )$} & 5 & 10 & 15 & 20 & 30 & \\
\hline \multicolumn{2}{|l|}{ pHcoag } & 4,87 & 4,87 & 4,80 & 4,88 & 4,87 & \\
\hline \multicolumn{2}{|c|}{$\mathrm{DC}(\mathrm{mg} / \mathrm{l})^{* *}$} & 40 & 40 & 40 & 40 & 40 & \\
\hline \multicolumn{2}{|c|}{ Turbidez (NTU) - Vf1 } & 32 & 39 & 47 & 41 & 44 & \\
\hline \multicolumn{2}{|c|}{ Turbidez (NTU) - Vf2 } & 29 & 31 & 34 & 32 & 34 & \\
\hline \multicolumn{2}{|c|}{ Condutiv. $\left(\mu \mathrm{S} / \mathrm{cm}\right.$ a $\left.25^{\circ} \mathrm{C}\right)-\mathrm{Vf} 1$} & 1514 & 1534 & 1546 & 1520 & 1544 & \\
\hline \multicolumn{2}{|c|}{ Condutiv. $\left(\mu \mathrm{S} / \mathrm{cm}\right.$ a $\left.25^{\circ} \mathrm{C}\right)-\mathrm{Vf} 2$} & 1510 & 1526 & 1538 & 1520 & 1536 & \\
\hline
\end{tabular}

\begin{tabular}{|l|l|l|}
\hline$N^{\circ}$ do ensaio: 24 a 27 & Ensaio Determinação dos parâmetros de floculação \\
\hline Data ensaio: $10 / 10 / 2010$ & Horário início: $18: 00 \mathrm{~h}$ \\
\hline \multicolumn{2}{|c|}{ Coleta da amostra } \\
\hline Data/horário da coleta: $08 / 10 / 2010 / 15: 00 \mathrm{~h}$ & Temperatura da amosta na coleta $\left({ }^{\circ} \mathbf{C}\right): 26$ \\
\hline
\end{tabular}

\section{Características da amostra bruta no início do ensaio}

\begin{tabular}{|c|c|c|c|c|c|c|c|c|}
\hline \multirow{2}{*}{\multicolumn{2}{|c|}{$\begin{array}{l}\text { pH: } 3,78 \\
\text { Temperatura }\left({ }^{\circ} \mathrm{C}\right): 23\end{array}$}} & & \multicolumn{6}{|c|}{ Turbidez (NTU): 686} \\
\hline & & & \multicolumn{6}{|c|}{ Condutividade $\left(\mu \mathrm{S} / \mathrm{cm}\right.$ a $\left.25^{\circ} \mathrm{C}\right): 1250$} \\
\hline \multicolumn{9}{|c|}{ Parâmetros de mistura, floculação e flotação } \\
\hline $\mathbf{G m}\left(\mathbf{s}^{-1}\right): 800$ & Gf $\left(\mathbf{s}^{-1}\right): 120$ & \multicolumn{2}{|c|}{ Vf1 (cm/min): 10} & Vf2 $(\mathrm{cm} / \mathrm{min}): 5$ & \multicolumn{2}{|c|}{$\mathbf{R}(\%): 50$} & \multicolumn{2}{|c|}{ Psat (bar): 5} \\
\hline \multirow[t]{3}{*}{ Tm (s): 5} & Tf (min): variável & Tflot1 (r & & Tflot2 (min) & & & Tsa & ): 10 \\
\hline & & \multicolumn{7}{|c|}{ Reator } \\
\hline & & 1 & 2 & 1 & 2 & & 1 & 2 \\
\hline \multicolumn{2}{|c|}{$\mathrm{Ca}(\mathrm{OH})_{2}(\mathrm{ml})^{*}$} & 2 & 2 & 2 & 2 & & 2 & \\
\hline \multicolumn{2}{|c|}{ Tf (min) } & 5 & 10 & 15 & 20 & & 30 & \\
\hline \multicolumn{2}{|l|}{ pHcoag } & 4,89 & 4,88 & 4,88 & 4,88 & & 88 & \\
\hline \multicolumn{2}{|l|}{$\mathrm{DC}(\mathrm{mg} / \mathrm{l}) * *$} & 40 & 40 & 40 & 40 & & 40 & \\
\hline \multicolumn{2}{|c|}{ Turbidez (NTU) - Vf1 } & 78 & 41 & 69 & 46 & & 43 & \\
\hline \multicolumn{2}{|c|}{ Turbidez (NTU) - Vf2 } & 36 & 34 & 38 & 36 & & 34 & \\
\hline \multicolumn{2}{|c|}{ Condutiv. $\left(\mu \mathrm{S} / \mathrm{cm}\right.$ a $\left.25^{\circ} \mathrm{C}\right)$ - Vf1 } & 1518 & 1494 & 1500 & 1522 & & 490 & \\
\hline \multicolumn{2}{|c|}{ Condutiv. $\left(\mu \mathrm{S} / \mathrm{cm}\right.$ a $\left.25^{\circ} \mathrm{C}\right)-\mathrm{Vf} 2$} & 1500 & 1492 & 1496 & 1490 & & 486 & \\
\hline
\end{tabular}

* Solução $40 \mathrm{~g} / \mathrm{l}$ de $\mathrm{Ca}(\mathrm{OH})_{2}$

** Solução 40g/l de cloreto férrico 


\section{Ensaios de Coagulação-Floculação-Flotação Coagulante: Cloreto Férrico}

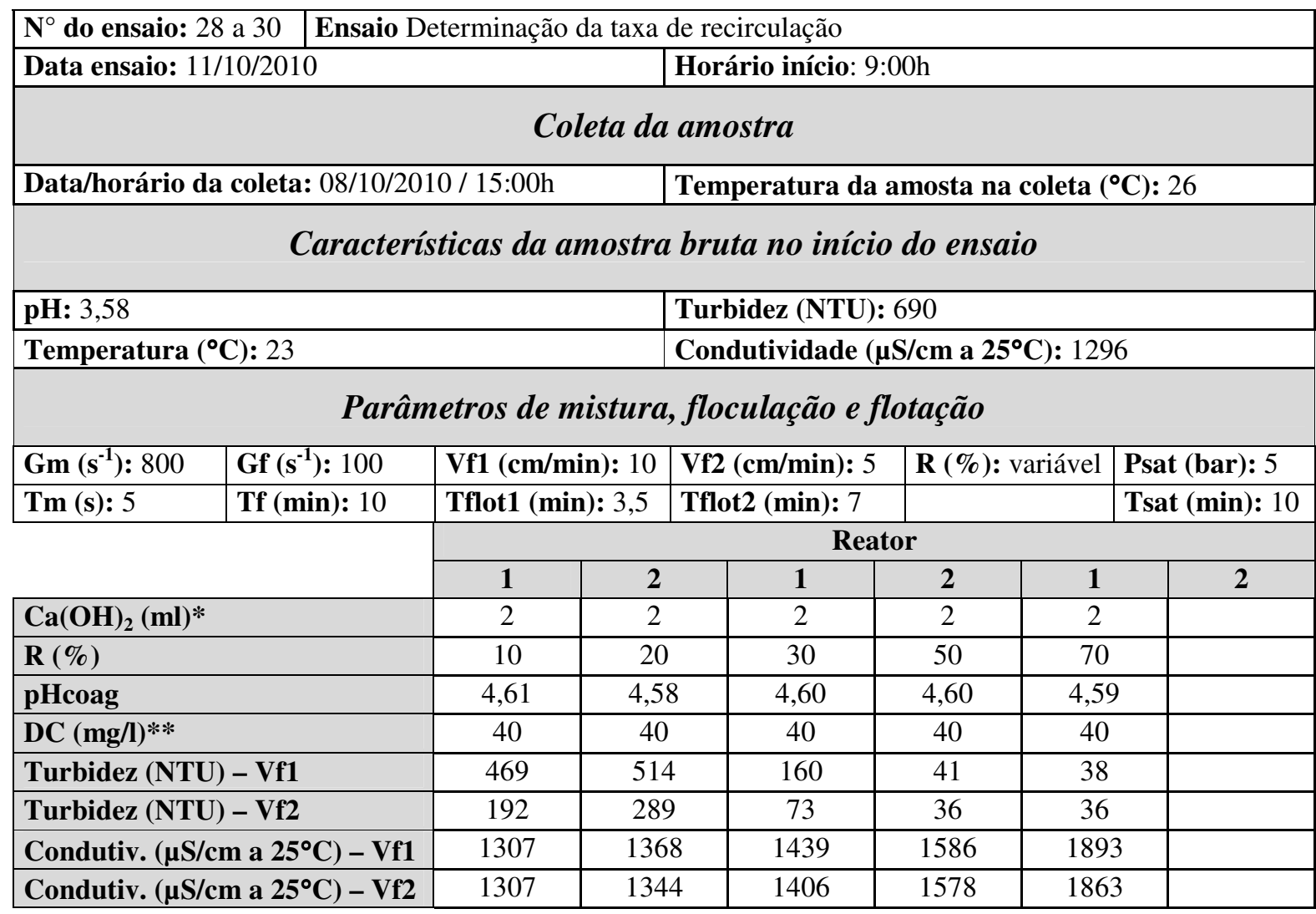

* Solução 40g/l de $\mathrm{Ca}(\mathrm{OH})_{2}$

** Solução 40g/l de cloreto férrico 


\section{Ensaios de Coagulação-Floculação-Flotação Coagulante: Cloreto Férrico}

\begin{tabular}{|c|c|c|c|c|c|c|c|c|c|}
\hline \multicolumn{10}{|c|}{\begin{tabular}{|l|l|}
$\mathbf{N}^{\circ}$ do ensaio: 30 a 34 & Ensaio: Determinação dos pares pHxDC para construção do Diagrama de Coagulação \\
\end{tabular}} \\
\hline \multicolumn{4}{|c|}{ Data ensaio: $12 / 10 / 2010$} & \multicolumn{6}{|c|}{ Horário início: 8:00h } \\
\hline \multicolumn{10}{|c|}{ Coleta da amostra } \\
\hline \multicolumn{4}{|c|}{ Data/horário da coleta: 08/10/2010 / 15:00h } & \multicolumn{6}{|c|}{ Temperatura da amosta na coleta $\left({ }^{\circ} \mathbf{C}\right): 26$} \\
\hline \multicolumn{10}{|c|}{ Características da amostra bruta no início do ensaio } \\
\hline \multicolumn{4}{|l|}{ pH: 3,57} & \multicolumn{6}{|c|}{ Turbidez (NTU): 645} \\
\hline \multicolumn{4}{|c|}{ Temperatura $\left({ }^{\circ} \mathbf{C}\right): 23$} & \multicolumn{6}{|c|}{ 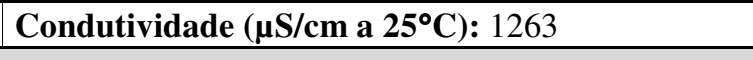 } \\
\hline \multicolumn{10}{|c|}{ Parâmetros de mistura, floculação e flotação } \\
\hline Gm $\left(\mathbf{s}^{-1}\right): 800$ & Gf $\left(\mathbf{s}^{-1}\right): 100$ & \multicolumn{2}{|c|}{ Vf1 (cm/min): 10} & \multirow{2}{*}{\multicolumn{2}{|c|}{ Vf2 $(\mathbf{c m} / \mathrm{min}): 5$}} & \multicolumn{2}{|c|}{$\mathbf{R}(\%): 50$} & \multicolumn{2}{|c|}{ Psat (bar): 5} \\
\hline \multirow{3}{*}{\multicolumn{2}{|c|}{ Tm (s): 5}} & Tflot1 & in): 3,5 & Tflot2 & & & & Tsat (min & \\
\hline & & \multicolumn{8}{|c|}{ Reator } \\
\hline & & 1 & 2 & 1 & 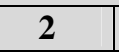 & 1 & 2 & 1 & 2 \\
\hline \multicolumn{2}{|l|}{$\mathrm{Ca}(\mathrm{OH})_{2}(\mathrm{ml})^{*}$} & 0 & 0 & 0 & 0 & 0 & 0 & 0 & 0 \\
\hline \multicolumn{2}{|l|}{ pHcoag } & 3,53 & 3,43 & 3,33 & 3,20 & 3,13 & 2,89 & 2,78 & 2,63 \\
\hline \multicolumn{2}{|c|}{$\mathrm{DC}(\mathrm{mg} / \mathrm{l}) * *$} & 0 & 20 & 40 & 60 & 100 & 200 & 260 & 360 \\
\hline \multicolumn{2}{|c|}{ Turbidez (NTU) - Vf1 } & 140 & 106 & 47 & 76 & 716 & 658 & 43 & 127 \\
\hline \multicolumn{2}{|c|}{ Turbidez (NTU) - Vf2 } & 121 & 83 & 29 & 23 & 464 & 129 & 28 & 41 \\
\hline \multicolumn{2}{|c|}{ Condutiv. $\left(\mu \mathrm{S} / \mathrm{cm}\right.$ a $\left.25^{\circ} \mathrm{C}\right)-\mathrm{Vf1}$} & 1504 & 1498 & 1478 & 1522 & 1596 & 1836 & 1918 & 2264 \\
\hline \multicolumn{2}{|c|}{ Condutiv. $\left(\mu \mathrm{S} / \mathrm{cm}\right.$ a $\left.25^{\circ} \mathrm{C}\right)-\mathrm{Vf} 2$} & 1378 & 1452 & 1440 & 1494 & 1558 & 1742 & 1860 & 2178 \\
\hline
\end{tabular}

\begin{tabular}{|c|c|c|c|c|c|c|c|c|c|}
\hline \multirow{2}{*}{\multicolumn{4}{|c|}{$\begin{array}{l}\mathbf{N}^{\circ} \text { do ensaio: } 35 \text { a } 38 \\
\text { Data ensaio: } 12 / 10 / 2010\end{array}$}} & \multirow{2}{*}{\multicolumn{6}{|c|}{$\begin{array}{l}\text { pHxDC para construção do Diagrama de Coagulação } \\
\text { Horário início: } 10: 00 \mathrm{~h}\end{array}$}} \\
\hline & & & & & & & & & \\
\hline \multicolumn{10}{|c|}{ Coleta da amostra } \\
\hline \multicolumn{4}{|c|}{ Data/horário da coleta: $08 / 10 / 2010 / 15: 00 \mathrm{~h}$} & \multicolumn{6}{|c|}{ Temperatura da amosta na coleta $\left({ }^{\circ} \mathbf{C}\right): 26$} \\
\hline \multicolumn{10}{|c|}{ Características da amostra bruta no início do ensaio } \\
\hline \multirow{2}{*}{\multicolumn{4}{|c|}{$\begin{array}{l}\text { pH: } 3,53 \\
\text { Temperatura }\left({ }^{\circ} \mathrm{C}\right): 23 \\
\end{array}$}} & \multicolumn{6}{|c|}{ Turbidez (NTU): 682} \\
\hline & & & & \multicolumn{6}{|c|}{ Condutividade $\left(\boldsymbol{\mu S} / \mathrm{cm}^{2} \mathbf{2 5}^{\circ} \mathrm{C}\right): 1299$} \\
\hline \multicolumn{10}{|c|}{ Parâmetros de mistura, floculação e flotação } \\
\hline Gm $\left(\mathbf{s}^{-1}\right): 800$ & Gf $\left(\mathbf{s}^{-1}\right): 100$ & \multicolumn{2}{|c|}{ Vf1 (cm/min): 10} & \multicolumn{3}{|c|}{\begin{tabular}{l|l} 
Vf2 $(\mathbf{c m} / \mathbf{m i n}): 5$ \\
\end{tabular}} & $\mathbf{R}(\%): 50$ & \multicolumn{2}{|c|}{ Psat (bar): 5} \\
\hline \multirow{3}{*}{\multicolumn{2}{|c|}{ Tf (min): 10}} & \multicolumn{2}{|c|}{ Tflot1 (min): 3,5} & \multicolumn{3}{|c|}{ Tflot2 (min): 7} & & \multicolumn{2}{|c|}{ Tsat (min): 10} \\
\hline & & \multicolumn{8}{|c|}{ Reator } \\
\hline & & 1 & 2 & 1 & 2 & 1 & 2 & 1 & 2 \\
\hline \multicolumn{2}{|l|}{$\mathrm{Ca}(\mathrm{OH})_{2}(\mathrm{ml})^{*}$} & 1 & 1 & 1 & 1 & 1 & 1 & 1 & 1 \\
\hline \multicolumn{2}{|l|}{ pHcoag } & 4,32 & 4,01 & 3,82 & 3,60 & 3,35 & 2,96 & 2,80 & 2,65 \\
\hline \multicolumn{2}{|l|}{ DC $(\mathrm{mg} / \mathrm{l}) * *$} & 0 & 20 & 40 & 60 & 100 & 200 & 260 & 360 \\
\hline \multicolumn{2}{|c|}{ Turbidez (NTU) - Vf1 } & 110 & 87 & 74 & 70 & 780 & 932 & 564 & 538 \\
\hline \multicolumn{2}{|c|}{ Turbidez (NTU) - Vf2 } & 111 & 82 & 55 & 32 & 426 & 364 & 432 & 85 \\
\hline \multicolumn{2}{|c|}{ Condutiv. $\left(\mu \mathrm{S} / \mathrm{cm}\right.$ a $\left.25^{\circ} \mathrm{C}\right)-\mathrm{Vf1}$} & 1598 & 1616 & 1620 & 1628 & 1632 & 1846 & 1938 & 2314 \\
\hline \multicolumn{2}{|c|}{ Condutiv. $\left(\mu \mathrm{S} / \mathrm{cm}\right.$ a $\left.25^{\circ} \mathrm{C}\right)-\mathrm{Vf} 2$} & 1562 & 1616 & 1574 & 1628 & 1582 & 1750 & 1870 & 2172 \\
\hline
\end{tabular}

* Solução $40 \mathrm{~g} / \mathrm{l} \mathrm{de} \mathrm{Ca}(\mathrm{OH})_{2}$

** Solução 40g/l de cloreto férrico 


\section{Ensaios de Coagulação-Floculação-Flotação Coagulante: Cloreto Férrico}

\begin{tabular}{|c|c|c|c|c|c|c|c|c|c|}
\hline \multicolumn{10}{|c|}{ Ensaio: Determinação dos pares pHxDC para construção do Diagrama de Coagulação } \\
\hline \multicolumn{4}{|c|}{ Data ensaio: $12 / 10 / 2010$} & \multicolumn{6}{|c|}{ Horário início: 14:00h } \\
\hline \multicolumn{10}{|c|}{ Coleta da amostra } \\
\hline \multicolumn{4}{|c|}{ Data/horário da coleta: $08 / 10 / 2010 / 15: 00 \mathrm{~h}$} & \multicolumn{6}{|c|}{ Temperatura da amosta na coleta $\left({ }^{\circ} \mathrm{C}\right): 26$} \\
\hline \multicolumn{10}{|c|}{ Características da amostra bruta no início do ensaio } \\
\hline \multicolumn{4}{|l|}{ pH: 3,53} & \multicolumn{6}{|c|}{ Turbidez (NTU): 682} \\
\hline \multicolumn{4}{|c|}{ Temperatura $\left({ }^{\circ} \mathrm{C}\right): 23$} & \multicolumn{6}{|c|}{ Condutividade $\left(\boldsymbol{\mu S} / \mathrm{cm}\right.$ a $\left.25^{\circ} \mathrm{C}\right): 1299$} \\
\hline \multicolumn{10}{|c|}{ Parâmetros de mistura, floculação e flotação } \\
\hline Gm $\left(s^{-1}\right): 800$ & Gf $\left(\mathbf{s}^{-1}\right): 100$ & \multicolumn{2}{|c|}{ Vf1 (cm/min): 10} & \multicolumn{2}{|c|}{ Vf2 (cm/min): 5} & \multicolumn{2}{|c|}{$\mathbf{R}(\%): 50$} & \multicolumn{2}{|c|}{ Psat (bar): 5} \\
\hline \multirow[t]{3}{*}{ Tm (s): 5} & Tf $(\min ): 10$ & Tflot1 ( & in): 3,5 & Tflot 2 & $\min ): 7$ & & & Tsat (mi & ): 10 \\
\hline & & \multicolumn{8}{|c|}{ Reator } \\
\hline & & 1 & 2 & 1 & \begin{tabular}{l|l|l}
2 & -1 \\
\end{tabular} & 1 & 2 & 1 & 2 \\
\hline \multicolumn{2}{|l|}{$\mathrm{Ca}(\mathrm{OH})_{2}(\mathrm{ml})^{*}$} & 2 & 2 & 2 & 2 & 2 & 2 & 2 & 2 \\
\hline \multicolumn{2}{|l|}{ pHcoag } & 4,90 & 4,75 & 4,61 & 4,41 & 3,89 & 3,21 & 2,99 & 2,74 \\
\hline \multicolumn{2}{|c|}{$\mathrm{DC}(\mathrm{mg} / \mathrm{l}) * *$} & 0 & 20 & 40 & 60 & 100 & 200 & 260 & 360 \\
\hline \multicolumn{2}{|c|}{ Turbidez (NTU) - Vf1 } & 63 & 41 & 37 & 40 & 143 & 700 & 702 & 46 \\
\hline \multicolumn{2}{|c|}{ Turbidez (NTU) - Vf2 } & 62 & 37 & 30 & 29 & 37 & 424 & 536 & 34 \\
\hline \multicolumn{2}{|c|}{ Condutiv. $\left(\mu \mathrm{S} / \mathrm{cm}\right.$ a $\left.25^{\circ} \mathrm{C}\right)$ - Vf1 } & 1610 & 1618 & 1604 & 1598 & 1628 & 1722 & 1842 & 2116 \\
\hline \multicolumn{2}{|c|}{ Condutiv. $\left(\mu \mathrm{S} / \mathrm{cm}\right.$ a $\left.25^{\circ} \mathrm{C}\right)-\mathrm{Vf} 2$} & 1572 & 1590 & 1592 & 1596 & 1600 & 1614 & 1786 & 2082 \\
\hline
\end{tabular}

\begin{tabular}{|c|c|c|c|c|c|c|c|c|c|}
\hline \multirow{2}{*}{\multicolumn{4}{|c|}{\begin{tabular}{l|l}
$N^{\circ}$ do ensaio: 42 a 45 & Ensaio: Determinação dos pares \\
Data ensaio: $12 / 10 / 2010$
\end{tabular}}} & $\mathrm{pHxDC}$ & Ira constru & ẫ do & grama & i de Coa & \\
\hline & & & & \multicolumn{6}{|c|}{ Horário início: $16: 00 \mathrm{~h}$} \\
\hline \multicolumn{10}{|c|}{ Coleta da amostra } \\
\hline \multicolumn{4}{|c|}{ Data/horário da coleta: 08/10/2010/ 15:00h } & \multicolumn{6}{|c|}{ Temperatura da amosta na coleta $\left({ }^{\circ} \mathrm{C}\right): 26$} \\
\hline \multicolumn{10}{|c|}{ Características da amostra bruta no início do ensaio } \\
\hline \multicolumn{4}{|l|}{ pH: 3,64} & \multicolumn{6}{|c|}{ Turbidez (NTU): 686} \\
\hline \multicolumn{4}{|c|}{ Temperatura $\left({ }^{\circ} \mathrm{C}\right): 23$} & \multicolumn{6}{|c|}{ 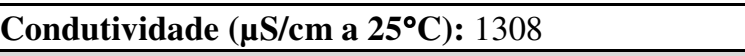 } \\
\hline \multicolumn{10}{|c|}{ Parâmetros de mistura, floculação e flotação } \\
\hline Gm $\left(\mathbf{s}^{-1}\right): 800$ & Gf $\left(\mathbf{s}^{-1}\right): 100$ & \multicolumn{2}{|c|}{ Vf1 (cm/min): 10} & \multicolumn{2}{|c|}{ Vf2 (cm/min): 5} & \multicolumn{2}{|c|}{ R (\%): 50} & \multicolumn{2}{|c|}{ Psat (bar): 5} \\
\hline \multirow[t]{3}{*}{ Tm (s): 5} & Tf (min): 10 & Tflot1 ( & nin): 3,5 & Tflot2 & nin): 7 & & & Tsat (mi & \\
\hline & & \multicolumn{8}{|c|}{ Reator } \\
\hline & & 1 & 2 & 1 & 2 & 1 & 2 & 1 & 2 \\
\hline \multicolumn{2}{|l|}{$\mathrm{Ca}(\mathrm{OH})_{2}(\mathrm{ml})^{*}$} & 3 & 3 & 3 & 3 & 3 & 3 & & 2 \\
\hline \multicolumn{2}{|l|}{ pHcoag } & 5,38 & 5,30 & 5,16 & 5,01 & 4,80 & 3,70 & & 3,00 \\
\hline \multicolumn{2}{|c|}{$\mathrm{DC}(\mathrm{mg} / \mathrm{l}) * *$} & 0 & 20 & 40 & 60 & 100 & 200 & & 360 \\
\hline \multicolumn{2}{|c|}{ Turbidez (NTU) - Vf1 } & 37 & 39 & 65 & 108 & 590 & 854 & & 630 \\
\hline \multicolumn{2}{|c|}{ Turbidez (NTU) - Vf2 } & 37 & 31 & 32 & 38 & 87 & 658 & & 69 \\
\hline \multicolumn{2}{|c|}{ Condutiv. $\left(\mu \mathrm{S} / \mathrm{cm}\right.$ a $\left.25^{\circ} \mathrm{C}\right)-\mathrm{Vf1}$} & 1574 & 1604 & 1596 & 1604 & 1608 & 1712 & & 1890 \\
\hline \multicolumn{2}{|c|}{ Condutiv. $\left(\mu \mathrm{S} / \mathrm{cm}\right.$ a $\left.25^{\circ} \mathrm{C}\right)-\mathrm{Vf} 2$} & 1560 & 1594 & 1590 & 1594 & 1600 & 1710 & & 1846 \\
\hline
\end{tabular}

* Solução $40 \mathrm{~g} / \mathrm{l}$ de $\mathrm{Ca}(\mathrm{OH})_{2}$

** Solução 40g/l de cloreto férrico 


\section{Ensaios de Coagulação-Floculação-Flotação Coagulante: Cloreto Férrico}

\begin{tabular}{|c|c|c|c|c|c|c|c|c|c|}
\hline \multirow{2}{*}{\multicolumn{4}{|c|}{$\begin{array}{l}\mathbf{N}^{\circ} \text { do ensaio: } 46 \text { a } 49 \\
\text { Data ensaio: } 12 / 10 / 2010\end{array}$}} & $\mathrm{pHxDC}$ & ara cons & Ição do & agrama & e Coagu & \\
\hline & & & & \multicolumn{6}{|c|}{ Horário início: $20: 00 \mathrm{~h}$} \\
\hline \multicolumn{10}{|c|}{ Coleta da amostra } \\
\hline \multicolumn{4}{|c|}{ Data/horário da coleta: $08 / 10 / 2010 / 15: 00 \mathrm{~h}$} & \multicolumn{6}{|c|}{ Temperatura da amosta na coleta $\left({ }^{\circ} \mathbf{C}\right): 26$} \\
\hline \multicolumn{10}{|c|}{ Características da amostra bruta no início do ensaio } \\
\hline \multicolumn{4}{|l|}{ pH: 3,64} & \multicolumn{6}{|c|}{ Turbidez (NTU): 686} \\
\hline \multicolumn{4}{|c|}{ Temperatura $\left({ }^{\circ} \mathrm{C}\right): 23$} & \multicolumn{6}{|c|}{ 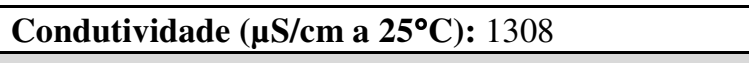 } \\
\hline \multicolumn{10}{|c|}{ Parâmetros de mistura, floculação e flotação } \\
\hline Gm $\left(\mathbf{s}^{-1}\right): 800$ & Gf $\left(\mathbf{s}^{-1}\right): 100$ & \multicolumn{2}{|c|}{ Vf1 (cm/min): 10} & \multicolumn{3}{|c|}{ Vf2 (cm/min): 5} & 7): 50 & \multicolumn{2}{|c|}{ Psat (bar): 5} \\
\hline \multirow[t]{3}{*}{ Tm (s): 5} & Tf (min): 10 & Tflot1 ( & in): 3,5 & Tflo & $(\min )$ & & & Tsat $(1$ & ): 10 \\
\hline & & \multicolumn{8}{|c|}{ Reator } \\
\hline & & 1 & 2 & 1 & 2 & 1 & 2 & 1 & 2 \\
\hline \multicolumn{2}{|l|}{$\mathrm{Ca}(\mathrm{OH})_{2}(\mathrm{ml})^{*}$} & 5 & 5 & 5 & 5 & 5 & 5 & & 5 \\
\hline \multicolumn{2}{|l|}{ pHcoag } & 6,06 & 5,93 & 5,75 & 5,66 & 5,43 & 4,96 & & 3,59 \\
\hline \multicolumn{2}{|c|}{$\mathrm{DC}(\mathrm{mg} / \mathrm{l}) * *$} & 0 & 20 & 40 & 60 & 100 & 200 & & 360 \\
\hline \multicolumn{2}{|c|}{ Turbidez (NTU) - Vf1 } & 198 & 760 & 800 & 646 & 746 & 886 & & 736 \\
\hline \multicolumn{2}{|c|}{ Turbidez (NTU) - Vf2 } & 55 & 162 & 89 & 75 & 122 & 131 & & 620 \\
\hline \multicolumn{2}{|c|}{ Condutiv. $\left(\mu \mathrm{S} / \mathrm{cm}\right.$ a $\left.25^{\circ} \mathrm{C}\right)-\mathrm{Vf1}$} & 1622 & 1636 & 1620 & 1636 & 1652 & 1708 & & 1804 \\
\hline \multicolumn{2}{|c|}{ Condutiv. $\left(\mu \mathrm{S} / \mathrm{cm}\right.$ a $\left.25^{\circ} \mathrm{C}\right)-\mathrm{Vf} 2$} & 1608 & 1630 & 1614 & 1636 & 1640 & 1698 & & 1790 \\
\hline
\end{tabular}

\begin{tabular}{|c|c|c|c|c|c|c|c|c|c|}
\hline \multirow{2}{*}{\multicolumn{4}{|c|}{$\begin{array}{l}\mathbf{N}^{\circ} \text { do ensaio: } 50 \text { a } 53 \\
\text { Data ensaio: } 12 / 10 / 2010\end{array}$}} & $\mathrm{pHxDC}$ & ara constru & ho do & ram & a de Coagulaç & \\
\hline & & & & \multicolumn{6}{|c|}{ Horário início: 22:00h } \\
\hline \multicolumn{10}{|c|}{ Coleta da amostra } \\
\hline \multicolumn{4}{|c|}{ Data/horário da coleta: $08 / 10 / 2010 / 15: 00 \mathrm{~h}$} & \multicolumn{6}{|c|}{ Temperatura da amosta na coleta $\left({ }^{\circ} \mathbf{C}\right): 26$} \\
\hline \multicolumn{10}{|c|}{ Características da amostra bruta no início do ensaio } \\
\hline \multirow{2}{*}{\multicolumn{4}{|c|}{$\begin{array}{l}\text { pH: } 3,64 \\
\text { Temperatura }\left({ }^{\circ} \mathbf{C}\right): 23 \\
\end{array}$}} & \multicolumn{6}{|c|}{ Turbidez (NTU): 686} \\
\hline & & & & \multicolumn{6}{|c|}{ 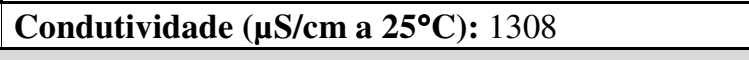 } \\
\hline \multicolumn{10}{|c|}{ Parâmetros de mistura, floculação e flotação } \\
\hline Gm $\left(\mathbf{s}^{-1}\right): 800$ & Gf $\left(\mathbf{s}^{-1}\right): 100$ & \multicolumn{2}{|c|}{ Vf1 (cm/min): 10} & \multicolumn{2}{|c|}{ Vf2 (cm/min): 5} & \multicolumn{2}{|c|}{$\mathbf{R}(\%): 50$} & \multicolumn{2}{|c|}{ Psat (bar): 5} \\
\hline \multirow{3}{*}{\multicolumn{2}{|c|}{ Tf (min): 10}} & Tflot1 & in): 3,5 & Tflot2 & $\min ): 7$ & & & Tsat (min) & \\
\hline & & \multicolumn{8}{|c|}{ Reator } \\
\hline & & 1 & 2 & 1 & 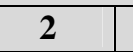 & 1 & 2 & 1 & 2 \\
\hline \multicolumn{2}{|l|}{$\mathrm{Ca}(\mathrm{OH})_{2}(\mathrm{ml})^{*}$} & 10 & 10 & 10 & 10 & & & 15 & 15 \\
\hline \multicolumn{2}{|l|}{ pHcoag } & 7,44 & 7,33 & 7,26 & 7,18 & & & 8,48 & 8,44 \\
\hline \multicolumn{2}{|c|}{ DC $(\mathrm{mg} / \mathrm{l}) * *$} & 0 & 20 & 40 & 60 & & & 0 & 40 \\
\hline \multicolumn{2}{|c|}{ Turbidez (NTU) - Vf1 } & 264 & 804 & 1034 & 1012 & & & 583 & 354 \\
\hline \multicolumn{2}{|c|}{ Turbidez (NTU) - Vf2 } & 57 & 154 & 58 & 52 & & & 152 & 842 \\
\hline \multicolumn{2}{|c|}{ Condutiv. $\left(\mu \mathrm{S} / \mathrm{cm} \mathrm{a} 25^{\circ} \mathrm{C}\right)-\mathrm{Vf} 1$} & 1668 & 1702 & 1696 & 1706 & & & 813 & 840 \\
\hline \multicolumn{2}{|c|}{ Condutiv. $\left(\mu \mathrm{S} / \mathrm{cm}\right.$ a $\left.25^{\circ} \mathrm{C}\right)-\mathrm{Vf} 2$} & 1644 & 1690 & 1676 & 1686 & & & 1580 & 1670 \\
\hline
\end{tabular}

* Solução $40 \mathrm{~g} / \mathrm{l} \mathrm{de} \mathrm{Ca}(\mathrm{OH})_{2}$

** Solução 40g/l de cloreto férrico 


\section{Apêndice G}

Resultados dos ensaios de coagulação-floculação-flotação para o coagulante Procytrat $100 \mathrm{~A}+$ Procytrat 300 


\section{Ensaios de Coagulação-Floculação-Flotação Coagulante: Procytrat 100A + Procytrat 300}

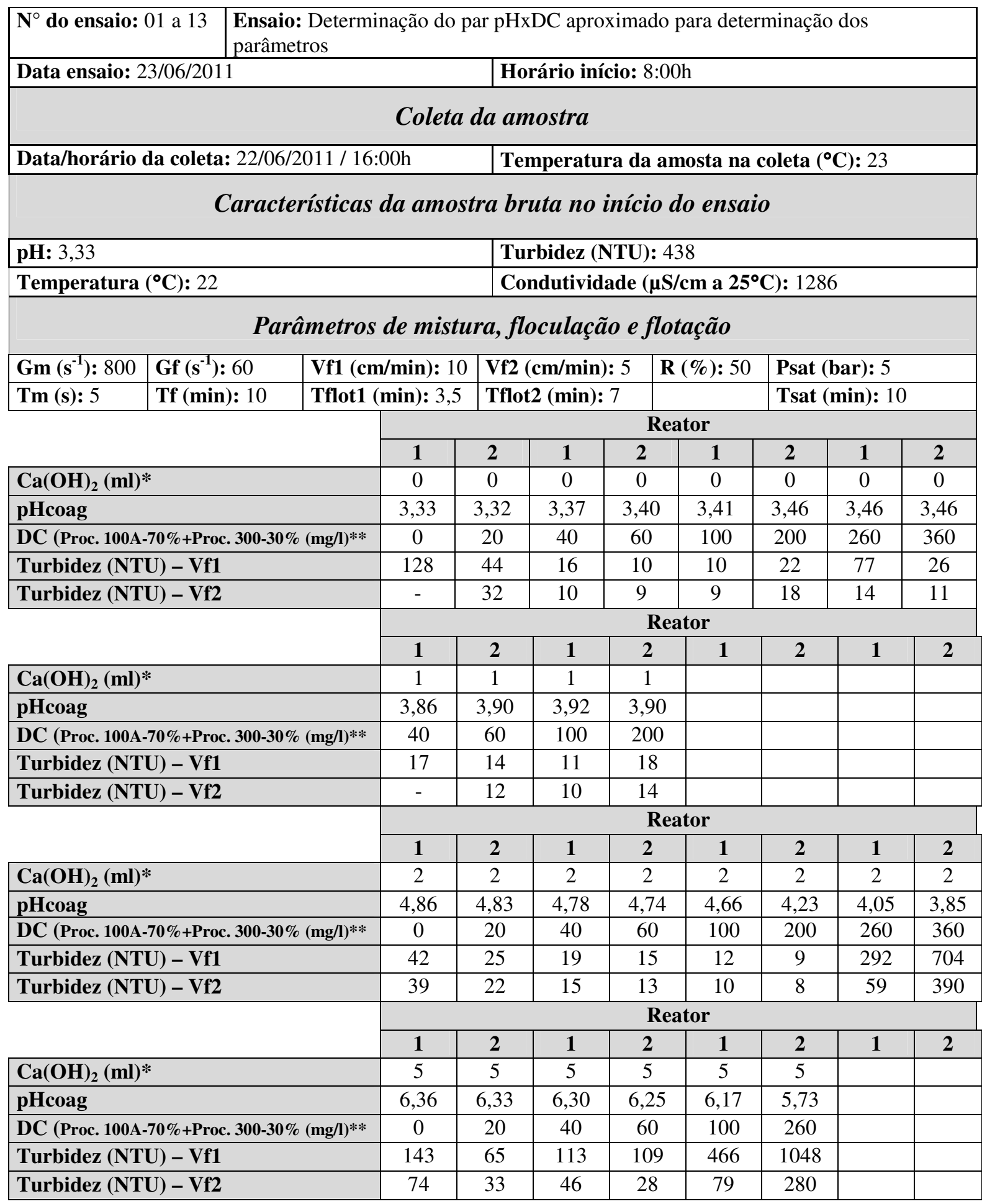

* Solução $40 \mathrm{~g} / 1 \mathrm{de} \mathrm{Ca}(\mathrm{OH})_{2}$

** Soluções: 40g/l de Procytrat 100A e 40g/l de Procytrat 300 


\section{Ensaios de Coagulação-Floculação-Flotação Coagulante: Procytrat 100A + Procytrat 300}

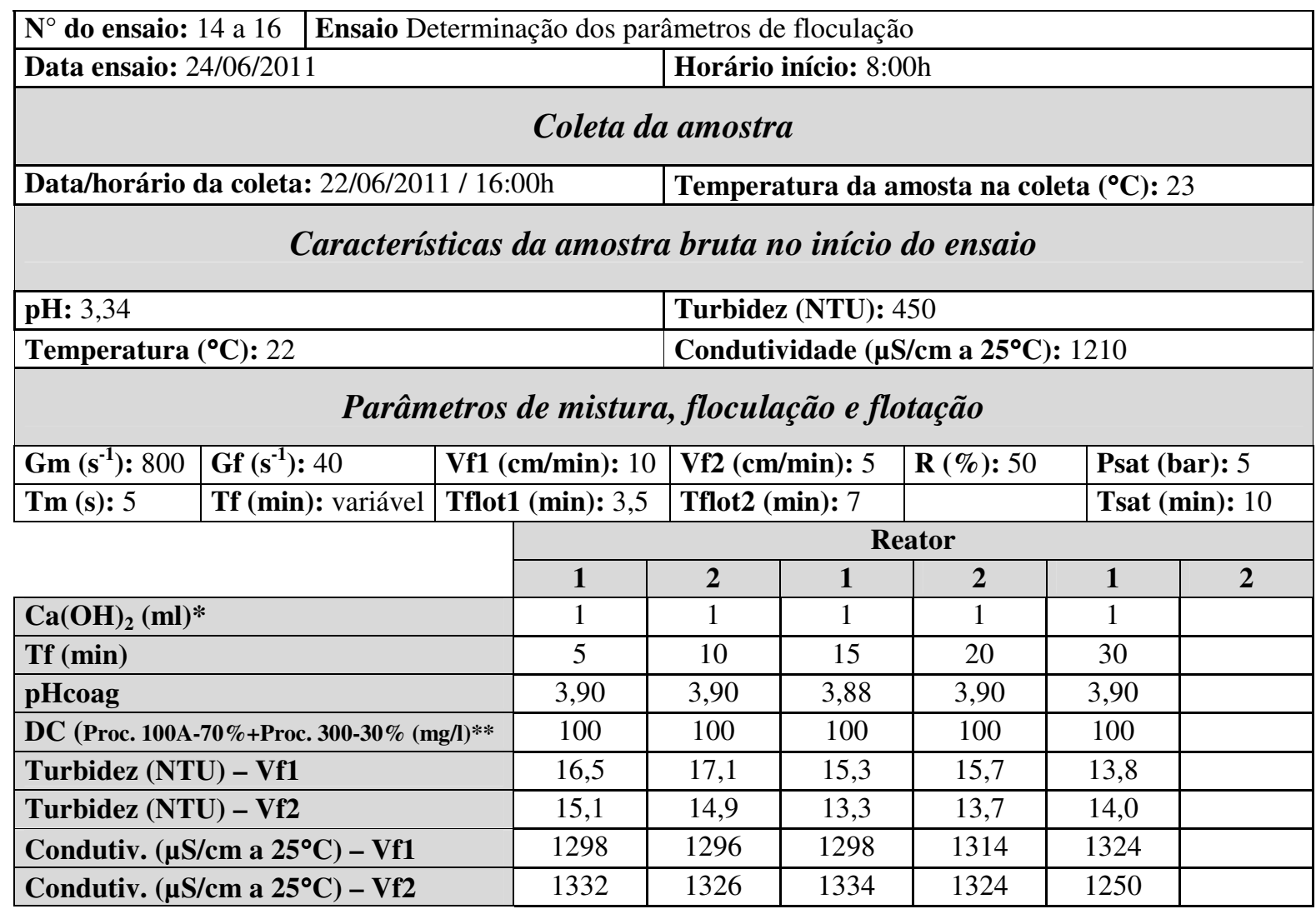

* Solução 40g/l de $\mathrm{Ca}(\mathrm{OH})_{2}$

** Soluções: 40g/l de Procytrat 100A e 40g/l de Procytrat 300 


\section{Ensaios de Coagulação-Floculação-Flotação \\ Coagulante: Procytrat 100A + Procytrat 300}

\begin{tabular}{|c|c|c|c|c|c|c|c|c|}
\hline \multirow{2}{*}{\multicolumn{4}{|c|}{ 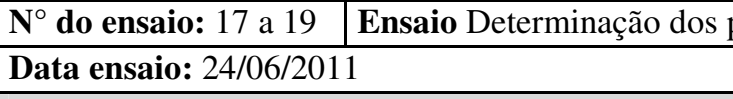 }} & âmetros & loculação & & & \\
\hline & & & & Horár & lício: $10: 0$ & & & \\
\hline \multicolumn{9}{|c|}{ Coleta da amostra } \\
\hline \multicolumn{4}{|c|}{ Data/horário da coleta: $22 / 06 / 2011 / 16: 00 \mathrm{~h}$} & \multicolumn{5}{|c|}{ Temperatura da amosta na coleta $\left({ }^{\circ} \mathrm{C}\right): 23$} \\
\hline \multicolumn{9}{|c|}{ Características da amostra bruta no início do ensaio } \\
\hline \multicolumn{4}{|l|}{ pH: 3,34} & \multicolumn{5}{|c|}{ Turbidez (NTU): 450} \\
\hline \multicolumn{4}{|c|}{ Temperatura $\left({ }^{\circ} \mathbf{C}\right): 22$} & \multicolumn{5}{|c|}{ Condutividade $\left(\boldsymbol{\mu S} / \mathrm{cm}\right.$ a $\left.25^{\circ} \mathrm{C}\right): 1210$} \\
\hline \multicolumn{9}{|c|}{ Parâmetros de mistura, floculação e flotação } \\
\hline $\mathbf{G m}\left(\mathbf{s}^{-1}\right): 800$ & Gf $\left(\mathbf{s}^{-1}\right): 60$ & \multicolumn{2}{|c|}{ Vf1 (cm/min): 10} & \multicolumn{2}{|c|}{ Vf2 $(\mathrm{cm} / \mathrm{min}): 5$} & $\mathbf{R}(\%)$ & \multicolumn{2}{|c|}{ Psat (bar): 5} \\
\hline \multirow[t]{3}{*}{$\operatorname{Tm}(\mathbf{s}): 5$} & Tf (min): variável & \multicolumn{2}{|c|}{ Tflot1 (min): 3,5} & \multicolumn{2}{|c|}{ Tflot2 (min): 7} & & \multicolumn{2}{|c|}{ Tsat (min): 10} \\
\hline & & & \multicolumn{6}{|c|}{ Reator } \\
\hline & & & 1 & 2 & 1 & 2 & 1 & 2 \\
\hline \multicolumn{3}{|l|}{$\mathrm{Ca}(\mathrm{OH})_{2}(\mathrm{ml})^{*}$} & 1 & 1 & 1 & 1 & 1 & \\
\hline \multicolumn{3}{|l|}{ Tf $(\min )$} & 5 & 10 & 15 & 20 & 30 & \\
\hline \multicolumn{3}{|l|}{ pHcoag } & 3,91 & 3,90 & 3,90 & 3,92 & 3,91 & \\
\hline \multicolumn{3}{|c|}{ DC (Proc. 100A-70\%+Proc. 300-30\% (mg/l)** } & 100 & 100 & 100 & 100 & 100 & \\
\hline \multicolumn{3}{|c|}{ Turbidez (NTU) - Vf1 } & 14,3 & 15,3 & 13,8 & 13,4 & 12,2 & \\
\hline \multicolumn{3}{|c|}{ Turbidez (NTU) - Vf2 } & 13,2 & 14,2 & 12,6 & 12,6 & 11,0 & \\
\hline \multicolumn{3}{|c|}{ Condutiv. $\left(\mu \mathrm{S} / \mathrm{cm}\right.$ a $\left.25^{\circ} \mathrm{C}\right)-\mathrm{Vf1}$} & 1282 & 1262 & 1260 & 1266 & 1272 & \\
\hline \multicolumn{3}{|c|}{ Condutiv. $\left(\mu \mathrm{S} / \mathrm{cm}\right.$ a $\left.25^{\circ} \mathrm{C}\right)-\mathrm{Vf} 2$} & 1274 & 1236 & 1258 & 1262 & 1274 & \\
\hline
\end{tabular}

\begin{tabular}{|l|l|l|}
\hline $\mathbf{N}^{\circ}$ do ensaio: 20 a 22 & Ensaio Determinação dos parâmetros de floculação \\
\hline Data ensaio: $24 / 06 / 2011$ & Horário início: $14: 00 \mathrm{~h}$ \\
\hline \multicolumn{2}{|c|}{ Coleta da amostra } \\
\hline Data/horário da coleta: $22 / 06 / 2011 / 16: 00 \mathrm{~h}$ & Temperatura da amosta na coleta $\left({ }^{\circ} \mathrm{C}\right): 23$ \\
\hline \multicolumn{2}{|c|}{ Características da amostra bruta no início do ensaio } \\
\hline pH: 3,34 & Turbidez $(\mathbf{N T U}): 450$ \\
\hline Temperatura $\left({ }^{\circ} \mathrm{C}\right): 22$ & Condutividade $\left(\boldsymbol{\mu S} / \mathbf{c m}\right.$ a $\left.25^{\circ} \mathbf{C}\right): 1210$ \\
\hline
\end{tabular}

\section{Parâmetros de mistura, floculação e flotação}

\begin{tabular}{|l|l|l|l|l|l|}
\hline Gm $\left(\mathbf{s}^{-1}\right): 800$ & Gf $\left(\mathbf{s}^{-1}\right): 80$ & Vf1 $(\mathbf{c m} / \mathbf{m i n}): 10$ & Vf2 $(\mathbf{c m} / \mathbf{m i n}): 5$ & R $(\%): 50$ & Psat $(\mathbf{b a r}): 5$ \\
\hline Tm $(\mathbf{s}): 5$ & Tf $(\mathbf{m i n}):$ variável & Tflot1 $(\mathbf{m i n}): 3,5$ & Tflot2 $(\mathbf{m i n}): 7$ & & Tsat $(\mathbf{m i n}): 10$ \\
\hline
\end{tabular}

\begin{tabular}{|l|l|l|l|l|} 
Tm (s): 5 & Tf (min): variável & Tflot1 (min): 3,5 & Tflot2 (min): 7 & Tsat (min): 10
\end{tabular}

\begin{tabular}{|c|c|c|c|c|c|}
\hline $\mathrm{Ca}(\mathrm{OH})_{2}(\mathrm{ml})^{*}$ & 1 & 1 & 1 & 1 & 1 \\
\hline Tf (min) & 5 & 10 & 15 & 20 & 30 \\
\hline pHcoag & 3,92 & 3,91 & 3,94 & 3,94 & 3,93 \\
\hline DC (Proc. 100A-70\%+Proc. 300-30\% (mg/l)** & 100 & 100 & 100 & 100 & 100 \\
\hline Turbidez (NTU) - Vf1 & 14,4 & 13,9 & 15,4 & 16,1 & 11,4 \\
\hline Turbidez (NTU) - Vf2 & 12,6 & 12,3 & 14,0 & 13,9 & 10,0 \\
\hline Condutiv. $\left(\mu \mathrm{S} / \mathrm{cm}\right.$ a $\left.25^{\circ} \mathrm{C}\right)-\mathrm{Vf1}$ & 1268 & 1260 & 1276 & 1312 & 1282 \\
\hline Condutiv. $\left(\mu \mathrm{S} / \mathrm{cm}\right.$ a $\left.25^{\circ} \mathrm{C}\right)-\mathrm{Vf} 2$ & 1324 & 1316 & 1310 & 1340 & 1340 \\
\hline
\end{tabular}

* Solução $40 \mathrm{~g} / \mathrm{l}$ de $\mathrm{Ca}(\mathrm{OH})_{2}$

** Soluções: 40g/l de Procytrat 100A e 40g/l de Procytrat 300 


\section{Ensaios de Coagulação-Floculação-Flotação Coagulante: Procytrat 100A + Procytrat 300}

\begin{tabular}{|c|c|c|c|c|c|c|c|c|}
\hline \multirow{2}{*}{\multicolumn{4}{|c|}{ 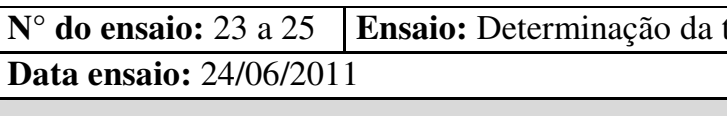 }} & xa de reci & ação & & & \\
\hline & & & & \multicolumn{5}{|c|}{ Horário início: 18:00h } \\
\hline \multicolumn{9}{|c|}{ Coleta da amostra } \\
\hline \multicolumn{4}{|c|}{ Data/horário da coleta: 22/06/2011 / 16:00h } & \multicolumn{5}{|c|}{ Temperatura da amosta na coleta $\left({ }^{\circ} \mathrm{C}\right): 23$} \\
\hline \multicolumn{9}{|c|}{ Características da amostra bruta no início do ensaio } \\
\hline \multicolumn{4}{|c|}{ pH: 3,34} & \multicolumn{5}{|c|}{ Turbidez (NTU): 450} \\
\hline \multicolumn{4}{|c|}{ Temperatura $\left({ }^{\circ} \mathrm{C}\right): 22$} & \multicolumn{5}{|c|}{ Condutividade $\left(\mu \mathrm{S} / \mathrm{cm}\right.$ a $\left.25^{\circ} \mathrm{C}\right): 1210$} \\
\hline \multicolumn{9}{|c|}{ Parâmetros de mistura, floculação e flotação } \\
\hline Gm $\left(s^{-1}\right): 800$ & Gf $\left(s^{-1}\right): 60$ & \multicolumn{2}{|c|}{ Vf1 (cm/min): 10} & \multirow{2}{*}{\multicolumn{2}{|c|}{$\begin{array}{l}\text { Vf2 }(\mathbf{c m} / \mathbf{m i n}): 5 \\
\text { Tflot2 (min): } 7\end{array}$}} & $\mathbf{R}(\%)$ : var & \multicolumn{2}{|c|}{ Psat (bar): 5} \\
\hline \multirow[t]{3}{*}{$\operatorname{Tm}(\mathbf{s}): 5$} & Tf (min): 15 & \multicolumn{2}{|c|}{ Tflot1 (min): 3,5} & & & & \multicolumn{2}{|c|}{ Tsat (min): 10} \\
\hline & & & \multicolumn{6}{|c|}{ Reator } \\
\hline & & & 1 & 2 & 1 & 2 & 1 & 2 \\
\hline \multicolumn{3}{|c|}{$\mathrm{Ca}(\mathrm{OH})_{2}(\mathrm{ml})^{*}$} & 1 & 1 & 1 & 1 & 1 & \\
\hline \multicolumn{3}{|c|}{$\mathbf{R}(\%)$} & 20 & 30 & 40 & 50 & 70 & \\
\hline \multicolumn{3}{|c|}{ pHcoag } & 3,94 & 3,93 & 3,93 & 3,94 & 3,95 & \\
\hline \multicolumn{3}{|c|}{ DC (Proc. 100A-70\%+Proc. 300-30\% (mg/l)** } & 100 & 100 & 100 & 100 & 100 & \\
\hline \multicolumn{3}{|c|}{ Turbidez (NTU) - Vf1 } & 56,9 & 79,3 & 13,4 & 14,7 & 22,9 & \\
\hline \multicolumn{3}{|c|}{ Turbidez (NTU) - Vf2 } & 13,5 & 10,8 & 10,1 & 12,6 & 20,0 & \\
\hline \multicolumn{3}{|c|}{ Condutiv. $\left(\mu \mathrm{S} / \mathrm{cm}\right.$ a $\left.25^{\circ} \mathrm{C}\right)-\mathrm{Vf1}$} & 1138 & 1171 & 1195 & 1270 & 1463 & \\
\hline \multicolumn{3}{|c|}{ Condutiv. $\left(\mu \mathrm{S} / \mathrm{cm}\right.$ a $\left.25^{\circ} \mathrm{C}\right)-\mathrm{Vf} 2$} & 1145 & 1174 & 1193 & 1282 & 1457 & \\
\hline
\end{tabular}

* Solução 40g/l de $\mathrm{Ca}(\mathrm{OH})_{2}$

** Soluções: 40g/l de Procytrat 100A e 40g/l de Procytrat 300 


\section{Ensaios de Coagulação-Floculação-Flotação Coagulante: Procytrat 100A + Procytrat 300}

\begin{tabular}{|c|c|c|c|c|c|c|c|c|c|c|}
\hline \multicolumn{11}{|c|}{ Ensaio: Determinação dos pares pHxDC para construção do Diagrama de Coagulação } \\
\hline \multicolumn{5}{|c|}{ Data ensaio: $25 / 06 / 2011$} & \multicolumn{6}{|c|}{ Horário início: 8:00h } \\
\hline \multicolumn{11}{|c|}{ Coleta da amostra } \\
\hline \multicolumn{5}{|c|}{ Data/horário da coleta: $22 / 06 / 2011 / 16: 00 \mathrm{~h}$} & \multicolumn{6}{|c|}{ Temperatura da amosta na coleta $\left({ }^{\circ} \mathbf{C}\right): 23$} \\
\hline \multicolumn{11}{|c|}{ Características da amostra bruta no início do ensaio } \\
\hline \multicolumn{5}{|l|}{ pH: 3,33} & \multicolumn{6}{|c|}{ Turbidez (NTU): 469} \\
\hline \multicolumn{4}{|c|}{ Temperatura $\left({ }^{\circ} \mathbf{C}\right): 22$} & \multicolumn{7}{|c|}{ 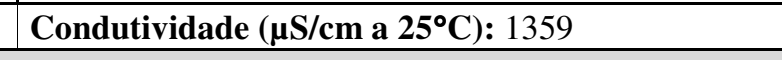 } \\
\hline \multicolumn{11}{|c|}{ Parâmetros de mistura, floculação e flotação } \\
\hline Gm $\left(\mathbf{s}^{-1}\right): 800$ & Gf $\left(\mathbf{s}^{-1}\right): 60$ & \multicolumn{3}{|c|}{ Vf1 (cm/min): 10} & \multicolumn{2}{|c|}{ Vf2 (cm/min): 5} & \multicolumn{2}{|c|}{$\mathbf{R}(\%): 40$} & \multicolumn{2}{|c|}{ Psat (bar): 5} \\
\hline Tm (s): 5 & Tf (min): 15 & \multicolumn{3}{|c|}{ Tflot1 (min): 3,5} & \multicolumn{2}{|c|}{ Tflot2 (min): 7} & & & \multicolumn{2}{|c|}{ Tsat (min): 10} \\
\hline & & & \multicolumn{8}{|c|}{ Reator } \\
\hline & & & 1 & 2 & 1 & 2 & 1 & 2 & 1 & 2 \\
\hline \multicolumn{3}{|l|}{$\mathrm{Ca}(\mathrm{OH})_{2}(\mathrm{ml})^{*}$} & 0 & 0 & 0 & 0 & 0 & 0 & 0 & 0 \\
\hline \multicolumn{3}{|l|}{ pHcoag } & 3,34 & 3,31 & 3,31 & 3,32 & 3,35 & 3,42 & 3,45 & 3,45 \\
\hline \multicolumn{3}{|c|}{ DC (Proc. 100A-70\%+Proc. 300-30\% (mg//)** } & 0 & 20 & 40 & 60 & 100 & 200 & 260 & 360 \\
\hline \multicolumn{3}{|c|}{ Turbidez (NTU) - Vf1 } & 160 & 40 & 21 & 10 & 8 & 13 & 31 & 13 \\
\hline \multicolumn{3}{|c|}{ Turbidez (NTU) - Vf2 } & 89 & 18 & 10 & 7 & 7 & 14 & 14 & 10 \\
\hline \multicolumn{3}{|c|}{ Condutiv. $\left(\mu \mathrm{S} / \mathrm{cm}\right.$ a $\left.25^{\circ} \mathrm{C}\right)$ - Vf1 } & 1405 & 1390 & 1402 & 1388 & 1398 & 1488 & 1493 & 1522 \\
\hline \multicolumn{3}{|c|}{ Condutiv. $\left(\mu \mathrm{S} / \mathrm{cm}\right.$ a $\left.25^{\circ} \mathrm{C}\right)$ - Vf2 } & 1413 & 1377 & 1383 & 1377 & 1403 & 1425 & 1483 & 1495 \\
\hline
\end{tabular}

\begin{tabular}{|c|c|c|c|c|c|c|c|c|c|c|}
\hline \multirow{2}{*}{\multicolumn{5}{|c|}{\begin{tabular}{l|l|l}
$\mathbf{N}^{\circ}$ do ensaio: 30 a 33 & Ensaio: Determinação dos pares \\
Data ensaio: $25 / 06 / 2011$ \\
\end{tabular}}} & \multirow{2}{*}{\multicolumn{6}{|c|}{$\begin{array}{l}\text { s pHxDC para construção do Diagrama de Coagulação } \\
\text { Horário início: } 10: 00 \mathrm{~h}\end{array}$}} \\
\hline & & & & & & & & & & \\
\hline \multicolumn{11}{|c|}{ Coleta da amostra } \\
\hline \multicolumn{5}{|c|}{ Data/horário da coleta: $22 / 06 / 2011 / 16: 00 \mathrm{~h}$} & \multicolumn{6}{|c|}{ Temperatura da amosta na coleta $\left({ }^{\circ} \mathbf{C}\right): 23$} \\
\hline \multicolumn{11}{|c|}{ Características da amostra bruta no início do ensaio } \\
\hline \multirow{2}{*}{\multicolumn{5}{|c|}{$\begin{array}{l}\text { pH: } 3,33 \\
\text { Temperatura }\left({ }^{\circ} \mathbf{C}\right): 22 \\
\end{array}$}} & \multicolumn{6}{|c|}{ Turbidez (NTU): 469} \\
\hline & & & & & \multicolumn{6}{|c|}{ Condutividade $\left(\boldsymbol{\mu S} / \mathrm{cm}\right.$ a $\left.25^{\circ} \mathrm{C}\right): 1359$} \\
\hline \multicolumn{11}{|c|}{ Parâmetros de mistura, floculação e flotação } \\
\hline Gm $\left(\mathbf{s}^{-1}\right): 800$ & Gf $\left(\mathbf{s}^{-1}\right): 60$ & \multicolumn{3}{|c|}{ Vf1 (cm/min): 10} & \multicolumn{2}{|c|}{ Vf2 (cm/min): 5} & \multicolumn{2}{|c|}{$\mathbf{R}(\%): 40$} & \multicolumn{2}{|c|}{ Psat (bar): 5} \\
\hline Tm (s): 5 & Tf (min): 15 & \multicolumn{2}{|c|}{ Tflot1 (min): 3,5} & \multicolumn{3}{|c|}{ Tflot2 (min): 7} & & \multicolumn{3}{|c|}{ Tsat (min): 10} \\
\hline & & & \multicolumn{8}{|c|}{ Reator } \\
\hline & & & 1 & 2 & $\mathbf{1}$ & 2 & 1 & 2 & $\mathbf{1}$ & 2 \\
\hline \multicolumn{3}{|c|}{$\mathrm{Ca}(\mathrm{OH})_{2}(\mathrm{ml})^{*}$} & 1 & 1 & 1 & 1 & 1 & 1 & 1 & 1 \\
\hline \multicolumn{3}{|c|}{ pHcoag } & 3,80 & 3,80 & 3,85 & 3,85 & 3,85 & 3,76 & 3,70 & 3,63 \\
\hline \multicolumn{3}{|c|}{ DC (Proc. 100A-70\%+Proc. 300-30\% (mg/) ${ }^{* *}$} & 0 & 20 & 40 & 60 & 100 & 200 & 260 & 360 \\
\hline \multicolumn{3}{|c|}{ Turbidez (NTU) - Vf1 } & 52 & 52 & 24 & 15 & 14 & 14 & 468 & 463 \\
\hline \multicolumn{3}{|c|}{ Turbidez (NTU) - Vf2 } & 49 & 21 & 15 & 11 & 11 & 12 & 130 & 122 \\
\hline \multicolumn{3}{|c|}{ Condutiv. $\left(\mu \mathrm{S} / \mathrm{cm}\right.$ a $\left.25^{\circ} \mathrm{C}\right)-\mathrm{Vf1}$} & 1330 & 1335 & 1320 & 1337 & 1327 & 1395 & 1433 & 1477 \\
\hline \multicolumn{3}{|c|}{ Condutiv. $\left(\mu \mathrm{S} / \mathrm{cm}\right.$ a $\left.25^{\circ} \mathrm{C}\right)-\mathrm{Vf} 2$} & 1328 & 1325 & 1323 & 1322 & 1328 & 1400 & 1400 & 1465 \\
\hline
\end{tabular}

* Solução 40g/l de $\mathrm{Ca}(\mathrm{OH})_{2}$

** Soluções: 40g/l de Procytrat 100A e 40g/l de Procytrat 300 


\section{Ensaios de Coagulação-Floculação-Flotação Coagulante: Procytrat 100A + Procytrat 300}

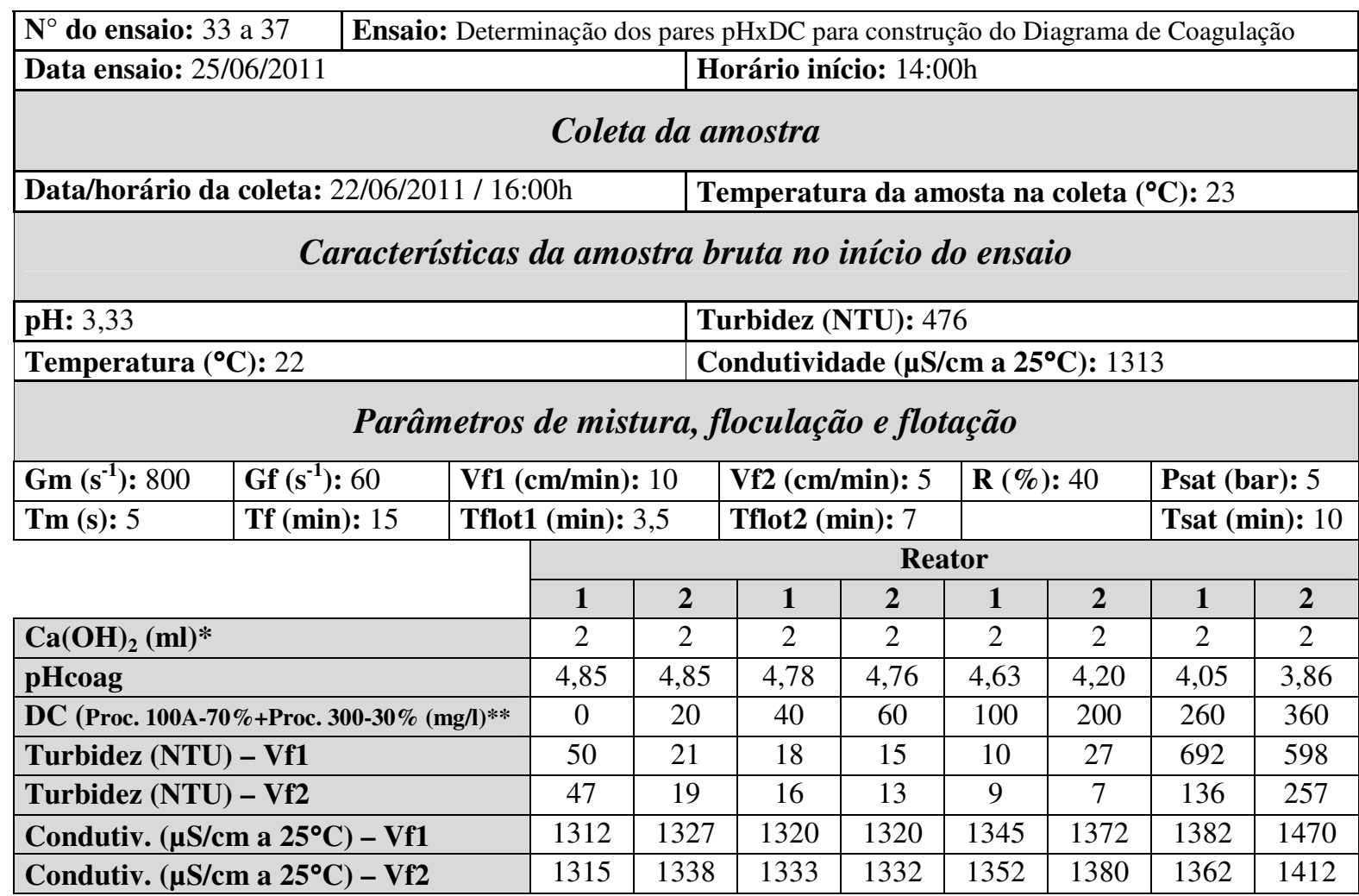

\begin{tabular}{|l|l|l|}
\hline $\mathbf{N}^{\circ}$ do ensaio: 33 a 37 & Ensaio: Determinação dos pares pHxDC para construção do Diagrama de Coagulação \\
\hline Data ensaio: $25 / 06 / 2011$ & Horário início: $16: 00 \mathrm{~h}$ \\
\hline \multicolumn{2}{|c|}{ Coleta da amostra } \\
\hline Data/horário da coleta: $22 / 06 / 2011 / 16: 00 \mathrm{~h}$ & Temperatura da amosta na coleta $\left({ }^{\circ} \mathrm{C}\right): 23$ \\
\hline
\end{tabular}

\section{Características da amostra bruta no início do ensaio}

\begin{tabular}{|c|c|c|c|c|c|}
\hline \multicolumn{3}{|l|}{ pH: 3,33} & \multicolumn{3}{|c|}{ Turbidez (NTU): 476} \\
\hline \multicolumn{3}{|c|}{ Temperatura $\left({ }^{\circ} \mathrm{C}\right): 22$} & \multicolumn{3}{|c|}{ Condutividade $\left(\boldsymbol{\mu S} / \mathbf{c m}\right.$ a $\left.25^{\circ} \mathrm{C}\right): 1313$} \\
\hline \multicolumn{6}{|c|}{ Parâmetros de mistura, floculação e flotação } \\
\hline Gm $\left(\mathbf{s}^{-1}\right): 800$ & Gf $\left(\mathbf{s}^{-1}\right): 60$ & Vf1 (cm/min): 10 & Vf2 $(\mathrm{cm} / \mathrm{min}): 5$ & R (\%): 40 & Psat (bar): 5 \\
\hline $\operatorname{Tm}(\mathbf{s}): 5$ & Tf (min): 15 & Tflot1 (min): 3,5 & Tflot2 (min): 7 & & Tsat (min): 10 \\
\hline
\end{tabular}

\begin{tabular}{|c|c|c|c|c|c|c|c|c|}
\hline & \multicolumn{8}{|c|}{ Reator } \\
\hline & 1 & 2 & 1 & 2 & 1 & 2 & 1 & 2 \\
\hline $\mathrm{Ca}(\mathrm{OH})_{2}(\mathrm{ml})^{*}$ & 3 & 3 & 3 & 3 & 3 & 3 & 3 & 3 \\
\hline pHcoag & 5,60 & 5,55 & 5,48 & 5,42 & 5,26 & 4,85 & 4,62 & 4,21 \\
\hline DC (Proc. 100A-70\%+Proc. 300-30\% (mg/l)** & 0 & 20 & 40 & 60 & 100 & 200 & 260 & 360 \\
\hline Turbidez (NTU) - Vf1 & 49 & 21 & - & - & 8 & 178 & 90 & 907 \\
\hline Turbidez (NTU) - Vf2 & 39 & 19 & 18 & 14 & 6 & 17 & 627 & 503 \\
\hline Condutiv. $\left(\mu \mathrm{S} / \mathrm{cm}\right.$ a $\left.25^{\circ} \mathrm{C}\right)-\mathrm{Vf1}$ & 1335 & 1338 & - & - & 1350 & 1375 & 1487 & 1528 \\
\hline Condutiv. $\left(\mu \mathrm{S} / \mathrm{cm}\right.$ a $\left.25^{\circ} \mathrm{C}\right)-\mathrm{Vf} 2$ & 1343 & 1352 & 1347 & 1355 & 1350 & 1372 & 1500 & 1533 \\
\hline
\end{tabular}

* Solução 40g/l de $\mathrm{Ca}(\mathrm{OH})_{2}$

** Soluções: 40g/l de Procytrat 100A e 40g/l de Procytrat 300 


\section{Ensaios de Coagulação-Floculação-Flotação Coagulante: Procytrat 100A + Procytrat 300}

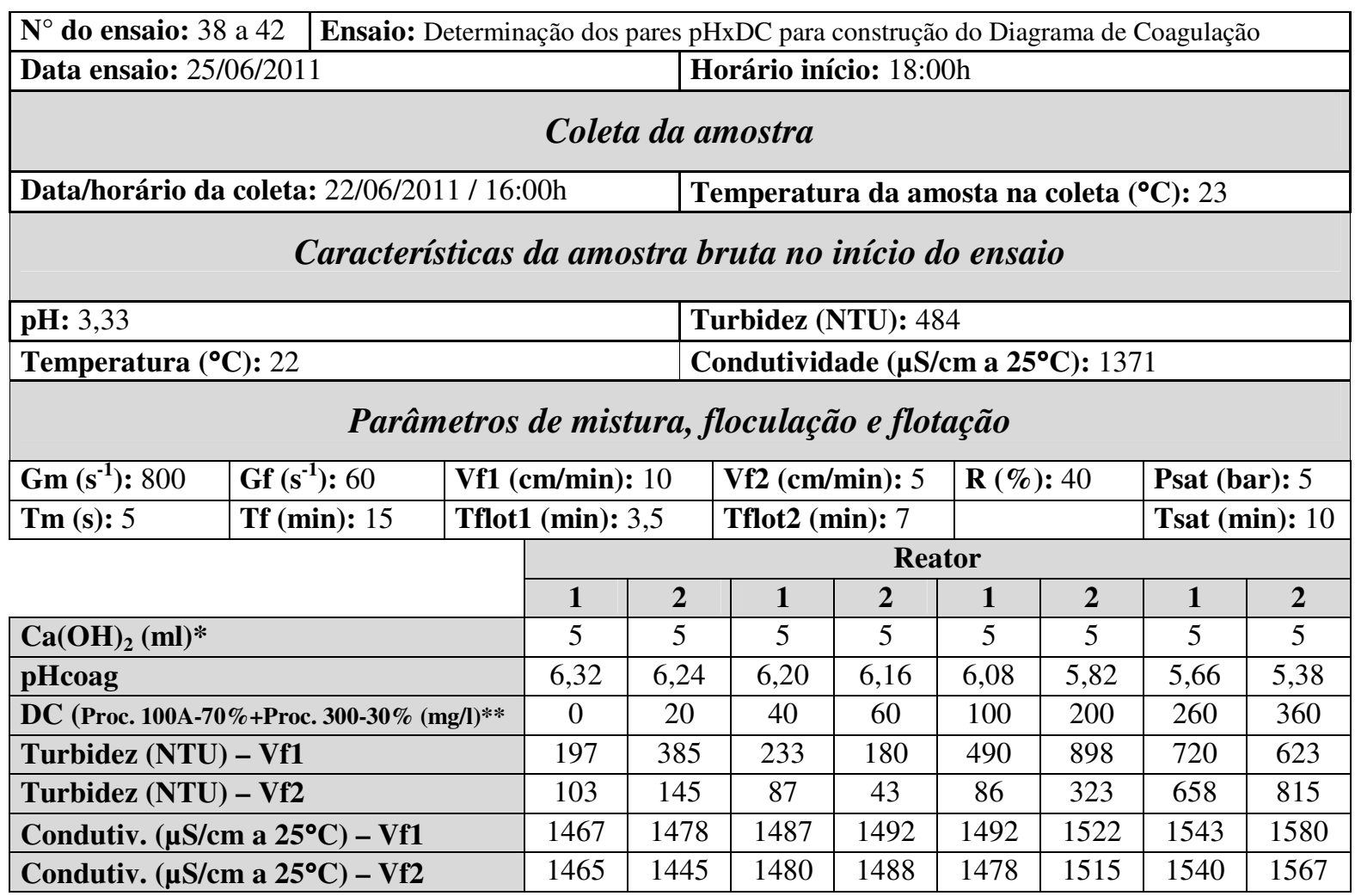

\begin{tabular}{|c|c|c|c|c|c|c|c|c|c|c|}
\hline \multirow{2}{*}{\multicolumn{5}{|c|}{\begin{tabular}{l|l|}
$\mathbf{N}^{\circ}$ do ensaio: 42 a 45 & Ensaio: Determinação dos pares \\
Data ensaio: $26 / 06 / 2011$
\end{tabular}}} & \multirow{2}{*}{\multicolumn{6}{|c|}{$\begin{array}{l}\text { pHxDC para construção do Diagrama de Coagulação } \\
\text { Horário início: } 8: 00 \mathrm{~h}\end{array}$}} \\
\hline & & & & & & & & & & \\
\hline \multicolumn{11}{|c|}{ Coleta da amostra } \\
\hline \multicolumn{5}{|c|}{ Data/horário da coleta: $22 / 06 / 2011 / 16: 00 \mathrm{~h}$} & \multicolumn{6}{|c|}{ Temperatura da amosta na coleta $\left({ }^{\circ} \mathbf{C}\right): 23$} \\
\hline \multicolumn{11}{|c|}{ Características da amostra bruta no início do ensaio } \\
\hline \multirow{2}{*}{\multicolumn{5}{|c|}{$\begin{array}{l}\text { pH: } 3,33 \\
\text { Temperatura }\left({ }^{\circ} \mathbf{C}\right): 22 \\
\end{array}$}} & \multicolumn{6}{|c|}{ Turbidez (NTU): 484} \\
\hline & & & & & \multicolumn{6}{|c|}{ Condutividade $\left(\boldsymbol{\mu S} / \mathrm{cm}^{2} 25^{\circ} \mathrm{C}\right): 1371$} \\
\hline \multicolumn{11}{|c|}{ Parâmetros de mistura, floculação e flotação } \\
\hline Gm $\left(\mathbf{s}^{-1}\right): 800$ & Gf $\left(\mathbf{s}^{-1}\right): 60$ & \multicolumn{3}{|c|}{ Vf1 (cm/min): 10} & \multicolumn{2}{|c|}{ Vf2 (cm/min): 5} & \multicolumn{2}{|c|}{ R (\%): 40} & \multicolumn{2}{|c|}{ Psat (bar): 5} \\
\hline \multirow{3}{*}{\multicolumn{2}{|c|}{ Tm (s): 5}} & \multicolumn{3}{|c|}{ Tflot1 (min): 3,5} & \multicolumn{2}{|c|}{ Tflot2 (min): 7} & & & \multicolumn{2}{|c|}{ Tsat (min): 10} \\
\hline & & & \multicolumn{8}{|c|}{ Reator } \\
\hline & & & 1 & 2 & 1 & 2 & $\mathbf{1}$ & 2 & 1 & 2 \\
\hline \multicolumn{3}{|l|}{$\mathrm{Ca}(\mathrm{OH})_{2}(\mathrm{ml})^{*}$} & 10 & 10 & 10 & 10 & 10 & 10 & 10 & 10 \\
\hline \multicolumn{3}{|l|}{ pHcoag } & 7,97 & 7,95 & 7,89 & 7,84 & 7,74 & 7,55 & 7,45 & 7,20 \\
\hline \multicolumn{3}{|c|}{ DC (Proc. 100A-70\%+Proc. 300-30\% (mg/) ${ }^{* *}$} & 0 & 20 & 40 & 60 & 100 & 200 & 260 & 360 \\
\hline \multicolumn{3}{|c|}{ Turbidez (NTU) - Vf1 } & 687 & 805 & 882 & 923 & 775 & 733 & 663 & 633 \\
\hline \multicolumn{3}{|c|}{ Turbidez (NTU) - Vf2 } & 94 & 428 & 502 & 463 & 663 & 732 & 710 & 717 \\
\hline \multicolumn{3}{|c|}{ Condutiv. $\left(\mu \mathrm{S} / \mathrm{cm}\right.$ a $\left.25^{\circ} \mathrm{C}\right)-\mathrm{Vf1}$} & 1438 & 1455 & 1468 & 1467 & 1487 & 1520 & 1557 & 1580 \\
\hline \multicolumn{3}{|c|}{ Condutiv. $\left(\mu \mathrm{S} / \mathrm{cm}\right.$ a $\left.25^{\circ} \mathrm{C}\right)-\mathrm{Vf} 2$} & 1438 & 1458 & 1472 & 1468 & 1487 & 1523 & 1555 & 1583 \\
\hline
\end{tabular}

* Solução 40g/l de $\mathrm{Ca}(\mathrm{OH})_{2}$

** Soluções: 40g/l de Procytrat 100A e 40g/l de Procytrat 300 


\section{Ensaios de Coagulação-Floculação-Flotação}

Coagulante: Procytrat 100A + Procytrat 300

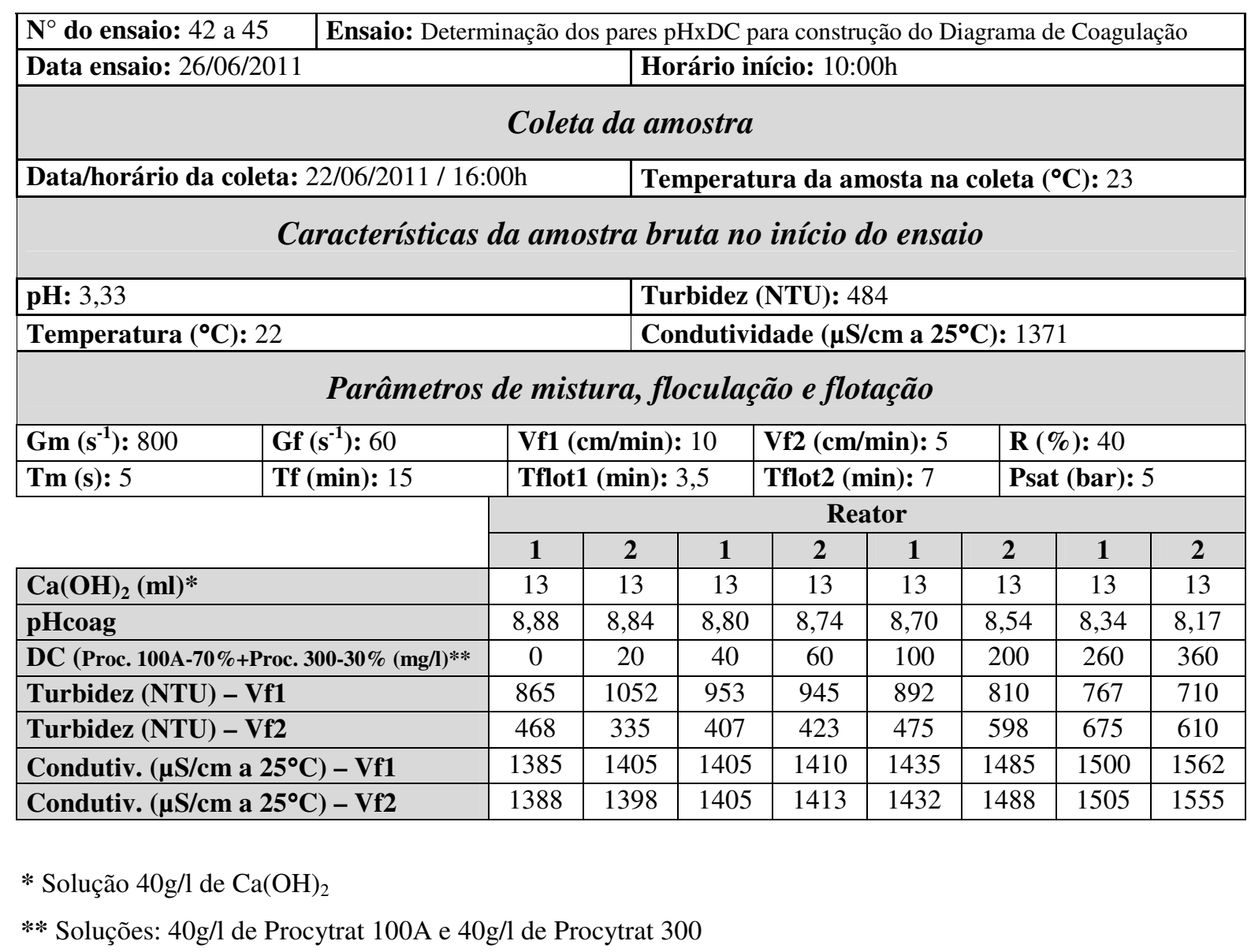




\section{Apêndice H}

Memória de cálculo do custo com energia elétrica para a flotação por ar dissolvido 


\section{Memória de cálculo do custo com energia elétrica para a flotacão por ar dissolvido.}

A energia elétrica consumida no processo de flotação por ar dissolvido se deve principalmente ao sistema de pressurização de ar, ou seja, ao conjunto moto-bomba para bombeamento da água até a pressão de saturação e ao compressor de ar. Porém, o consumo de energia para pressurização do ar pode ser desprezado, pois, por metro cúbico de água saturada, este geralmente representa menos de $1 \%$ do consumo de energia para bombeamento da água. Logo, a seguir considera-se apenas o custo com energia elétrica para bombeamento da água.

\section{Custo com energia elétrica no conjunto moto-bomba}

Segundo Azevedo Netto e Alvarez (1991), considerando-se a eficiência do conjunto moto-bomba de aproximadamente $67 \%$, tem-se:

$P(c v)=\frac{Q(l / s) x H \operatorname{man}(\text { m.c.a. })}{50}$, em que

$\mathrm{P}(\mathrm{cv})$ : potência do motor, em cv;

$\mathrm{Q}(\mathrm{L} / \mathrm{s})$ : vazão, em L/s:

Hman: altura monométrica, em m.c.a.

Para pressurização da água até a pressão de saturação considerada em todos os ensaios neste trabalho (500 $\mathrm{kPa}$ ou 50 m.c.a.) e considerando-se a perda de carga total de 5 m.c.a. (5 m.c.a.), tem-se:

$P(c v)=Q(l / s) \times 1,1$

Sabe-se ainda que:

$P(c v)=\frac{P(k W)}{0,7457}$ e que $Q(l / s)=\frac{Q\left(m^{3} / h\right)}{3,6}$, em que:

$\mathrm{P}(\mathrm{kW})$ : potência do motor, em $\mathrm{kW}$;

$\mathrm{Q}\left(\mathrm{m}^{3} / \mathrm{h}\right)$ : vazão, em $\mathrm{m}^{3} / \mathrm{h}$ 
Logo:

$P(k W)=0,22785 x Q\left(m^{3} / h\right)$ ou $P(k W)=0,22785 x \frac{V\left(m^{3}\right)}{t(h)}$, em que:

$\mathrm{V}\left(\mathrm{m}^{3}\right)$ : volume de água bombeado, $\mathrm{em}^{3}$

$\mathrm{t}(\mathrm{h})$ : tempo de bombeamento, em $\mathrm{h}$

O consumo de energia elétrica pelo conjunto moto-bomba pode ser calculado pela fórmula a seguir:

$C(k W . h)=P(k W) x t(h)$, em que:

$\mathrm{C}(\mathrm{kW} . \mathrm{h})$ : consumo de energia elétrica pelo conjunto moto-bomba, em kW.h

Portanto:

$C(k W . h)=0,22785 \times V\left(m^{3}\right)$

Assim, o consumo de energia para cada metro cúbico de água pressurizada será:

$$
\frac{C(k W \cdot h}{V\left(m^{3}\right)}=0,22785 \frac{k W \cdot h}{m^{3}}
$$

Considerando-se o custo de cada kW.h igual R $\$ 0,50$, o custo por metro cúbico de água saturada será:

$\operatorname{Custo}\left(\frac{R \$}{m^{3}}\right)=0,22785 \frac{k W \cdot h}{m^{3}} x \frac{R \$ 0,50}{k W \cdot h}=R \$ 0,114 / m^{3}$

OBS.: para calcular o custo com energia elétrica por metro cúbico tratado, em um ensaio de flotação em particular, multiplica-se o valor obtido acima pela razão de recirculação. 